\title{
Untersuchung, Entwicklung und Anwendung reversibel schaltbarer fluoreszierender Proteine
}

\author{
Dissertation \\ zur Erlangung des mathematisch-naturwissenschaftlichen Doktorgrades \\ "Doctor rerum naturalium" \\ der Georg-August-Universität Göttingen
}

vorgelegt von

Martin Andresen

aus Göttingen

Göttingen 2008 
Referent: Prof. Dr. Gerhard Braus Korreferent: Prof. Dr. Ralf Ficner

Tag der mündlichen Prüfung: 22.01.2009 


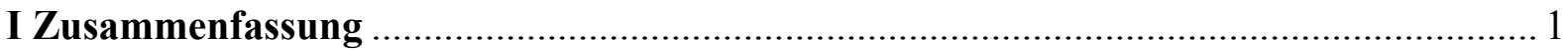

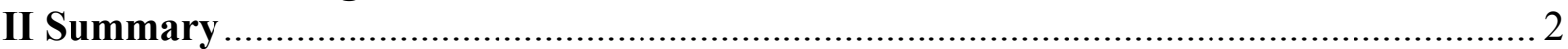

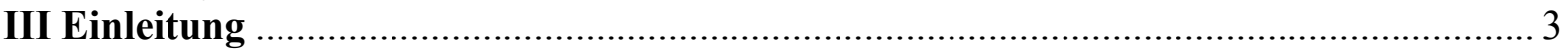

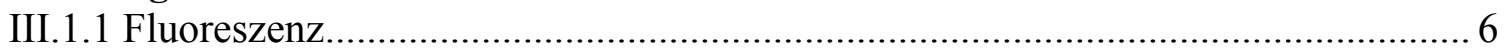

III.1.2 Aufbau von Fluoreszenzmikroskopen............................................................. 8

III.1.3 Die Auflösungsgrenze .................................................................................. 9

III.1.4 Hochauflösende Mikroskopie durch schaltbare Fluorophore .............................. 10

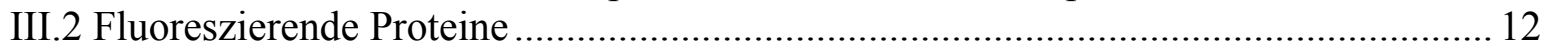

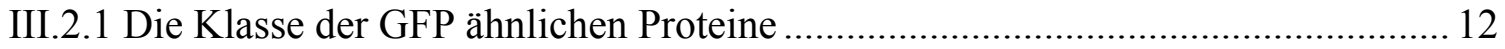

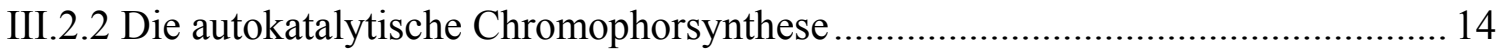

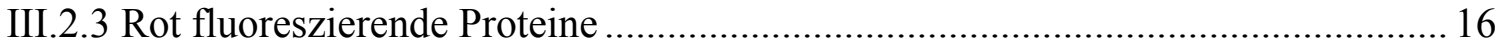

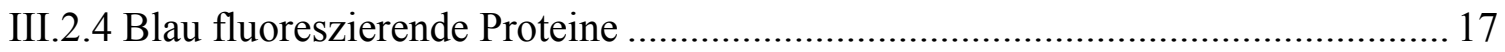

III.2.5 Die spektrale Vielfalt der fluoreszierenden Proteine ........................................... 19

III.2.6 Einfluss der Chromophorumgebung auf die Fluoreszenzeigenschaften ............... 20

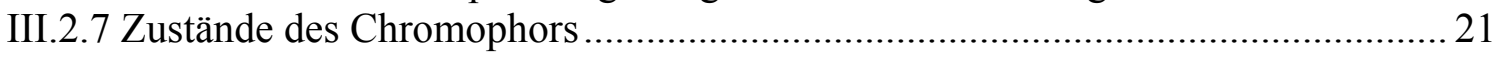

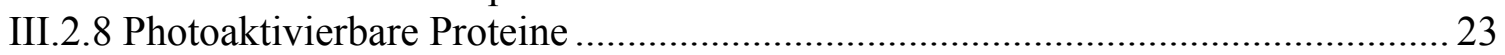

III.2.9 Reversibles Schalten in fluoreszierenden Proteinen ......................................... 24

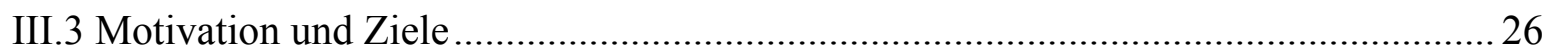

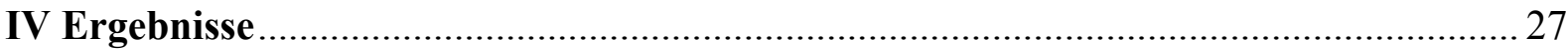

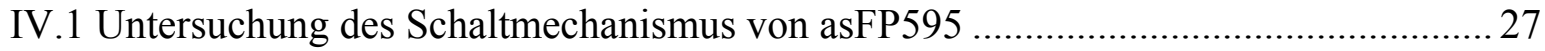

IV.1.1 Das Protein asFP595, ein reversibel schaltbares fluoreszierendes Protein:.......... 27

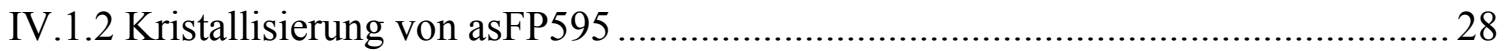

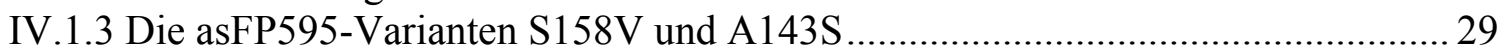

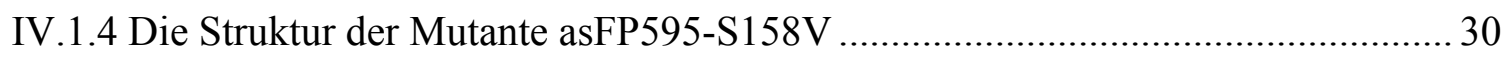

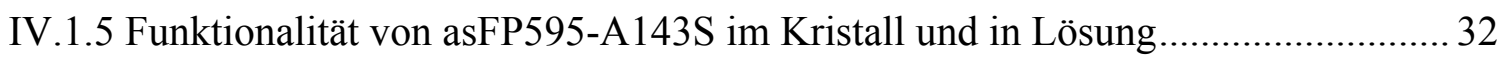

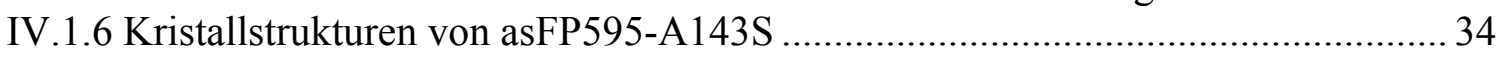

IV.1.7 Cis-trans-Isomerie des Chromophors ermöglicht An- und Ausschalten von

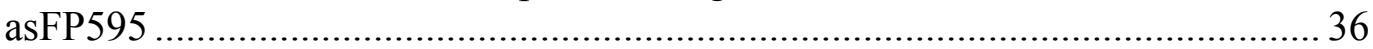

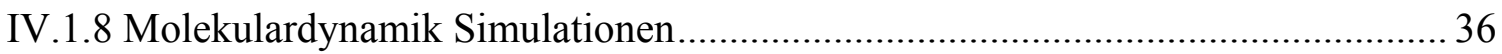

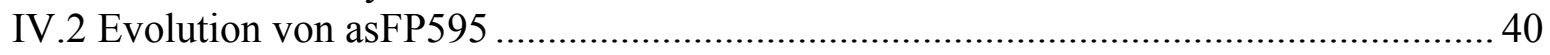

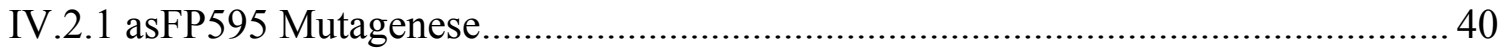

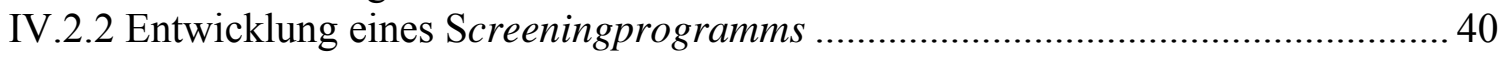

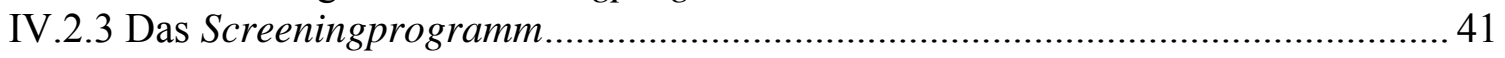

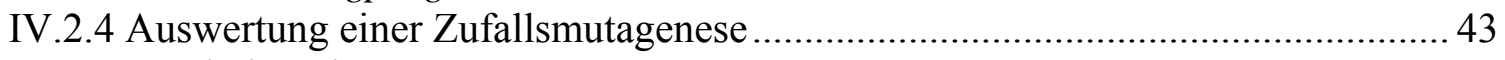

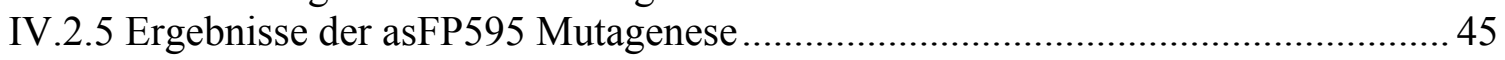

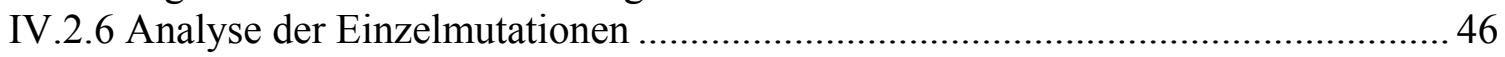

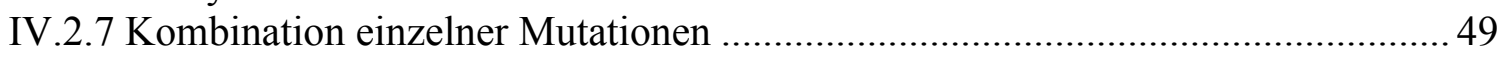

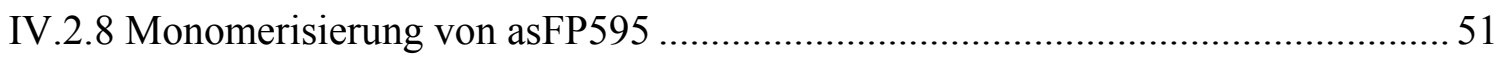

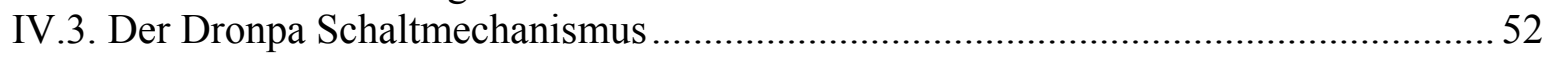

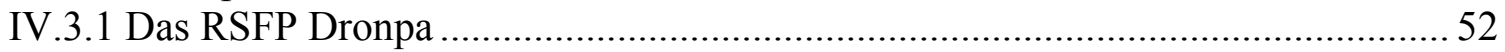

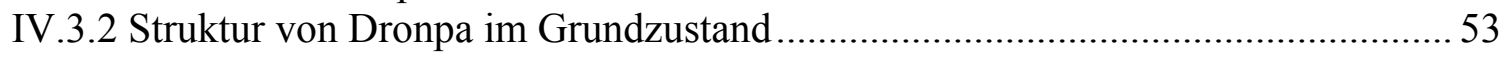

IV.3.3 Struktur von Dronpa im nicht fluoreszierenden Zustand ...................................54

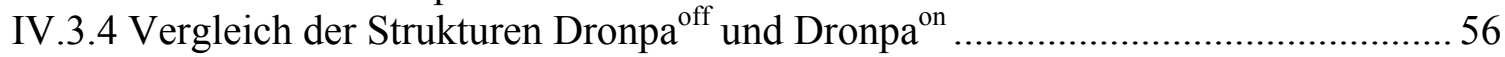

IV.3.5 Unterschiede in der Stabilisierung und der elektrostatischen Umgebung des

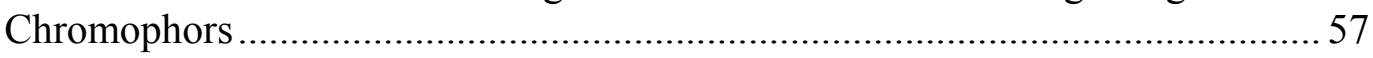

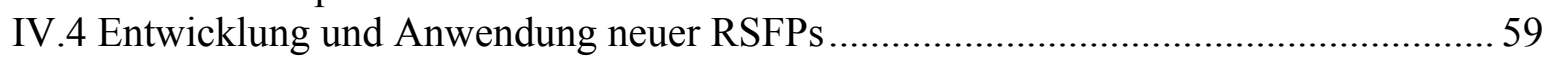

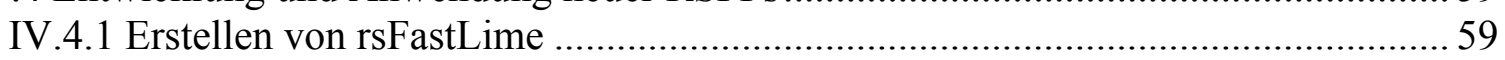

IV.4.2 rsFastLime ermöglicht die Umsetzung neuer Mikroskopietechniken ...................6 60

IV.4.3 Padron und bsDronpa zwei RSFPs mit einzigartigen Eigenschaften .................... 61

IV.4.4 Monochromatische Dreifarben-Fluoreszenzmikroskopie .................................. 64 
IV.4.5 Crosstalk bei monochromatischer Dreifarben-Fluoreszenzmikroskopie.............. 65

IV.4.6 Lineares Entmischen und optimierte Detektionsfenster reduzieren den Crosstalk auf ein Minimum

IV.4.7 Konfokale 3D Zeitraffer Aufnahmen mit monochromatischer ZweifarbenMikroskopie in lebenden Hefezellen. .67

IV.4.8 Aberrationsfreie monochromatische Mehrfarben Fluoreszenzmikroskopie .......... 70

IV.4.9 Zwei Farben Hochauflösung mit bsDronpa und Dronpa ....................................... 71

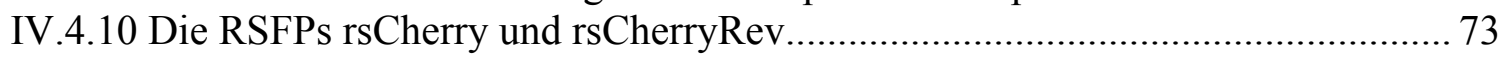

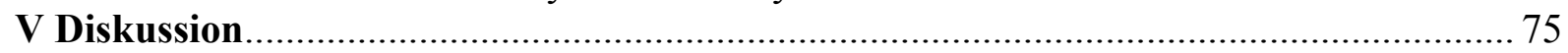

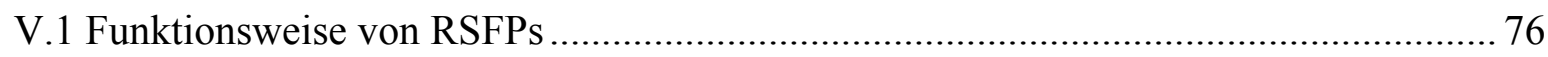

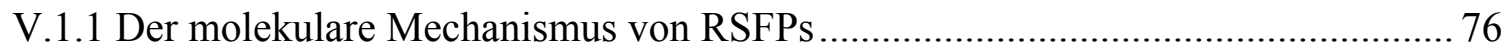

V.1.2 Die cis-trans-Isomerie als genereller Mechanismus des Schaltens ........................ 78

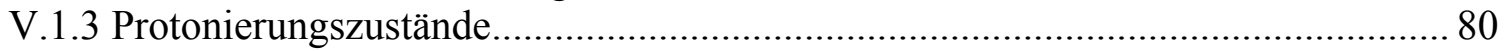

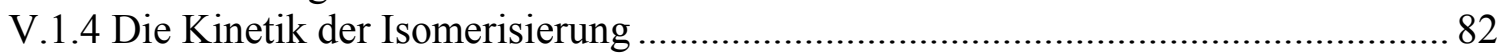

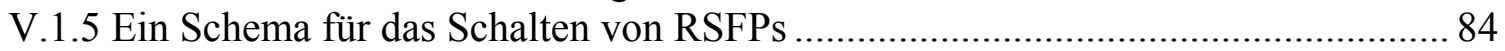

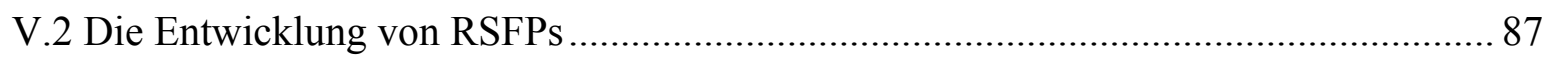

V.2.1 Einfluss des Test- und Auswahlverfahrens auf die gemessenen Eigenschaften

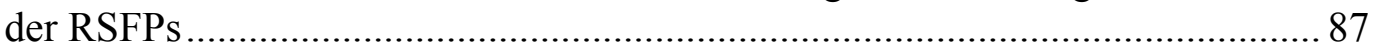

V.2.3 Die Restfluoreszenz in Abhängigkeit der Lichtintensität...................................... 88

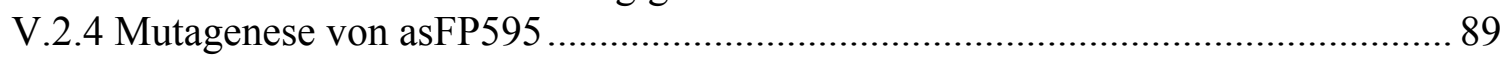

V.2.5 Die Hypothese funktional und örtlich begrenzter Clustern.................................90

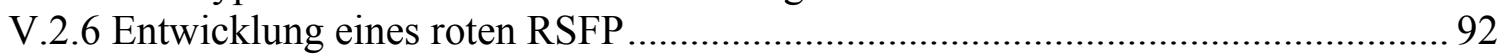

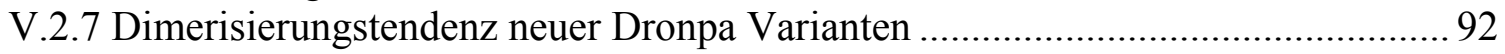

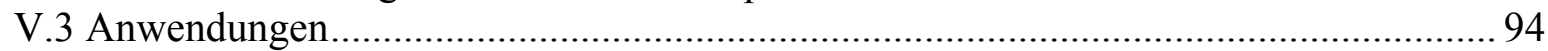

V.3.1 RSFPs in der RESOLFT-Mikroskopietechnik ................................................. 94

V.3.2 Negativ schaltbare RSFPs in dem Einzelmolekül-Lokalisationsverfahren............ 95

V.3.3 RSFPs als Katalysatoren für neue Techniken in der Mikroskopie........................ 96

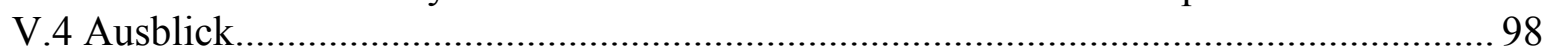

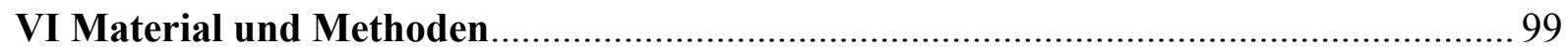

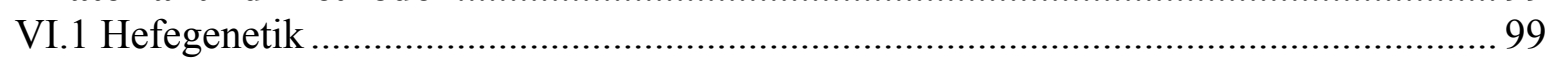

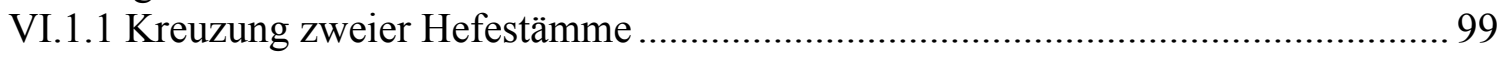

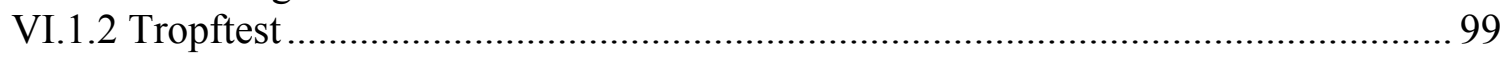

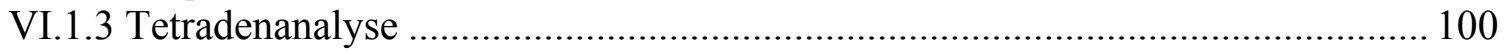

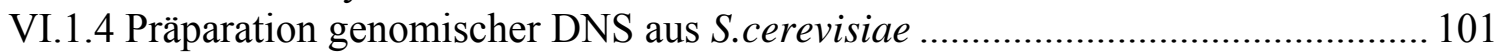

VI.1.5 Transformation von Plasmid DNS in S.cerevisiae .............................................. 102

VI.1.6 Verwendung von Auxotrophiemarkern in S.cerevisiae ..................................... 103

VI.1.7 Integration von DNS ins Genom von S.cerevisiae über homologe

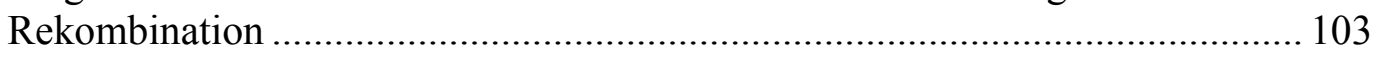

VI.1.8 Deletion einer KanMX4-Kassette aus dem Genom von S. cerevisiae mit der Cre-Rekombinase ................................................................................. 104

VI.1.9 Selektion auf Verlust von URA3 Plasmiden mit 5'Fluoroorotic acid ................. 105

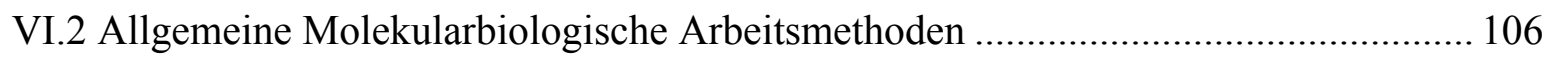

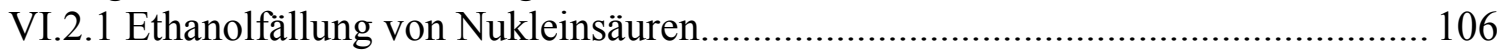

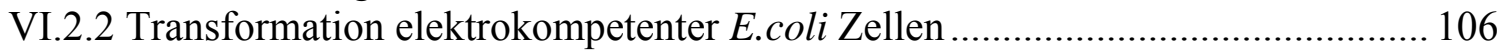

VI.2.3 Verwendung von Resistenzmarkern in E.coli ................................................... 107

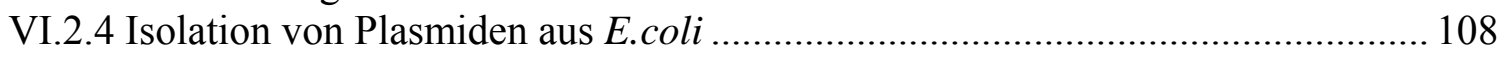

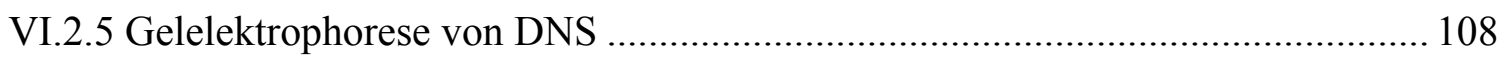

VI.2.6 Aufreinigung von DNS-Fragmenten aus Agarosegelen ................................... 109

VI.2.7 Konzentrationsbestimmung einer DNS- bzw. RNS-Lösung ............................. 110

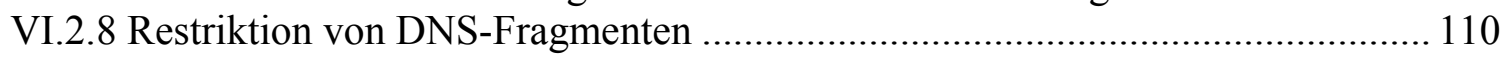

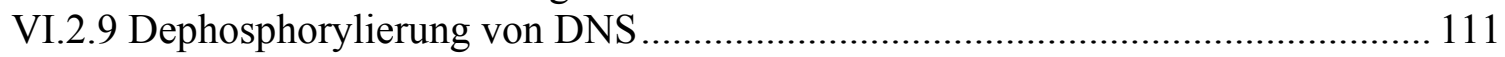




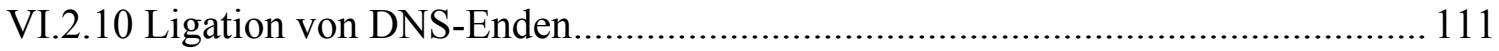

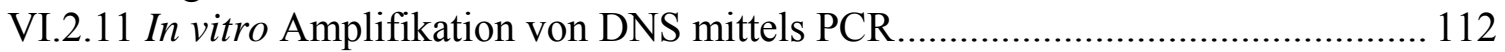

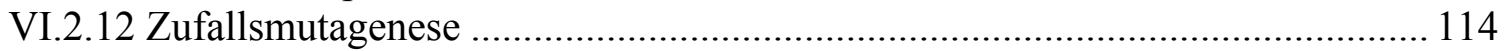

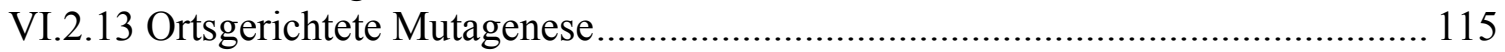

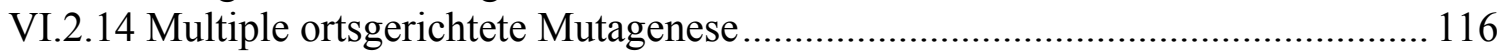

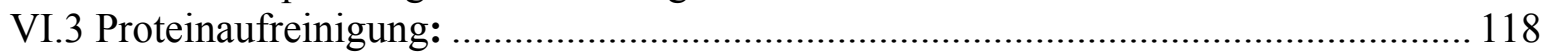

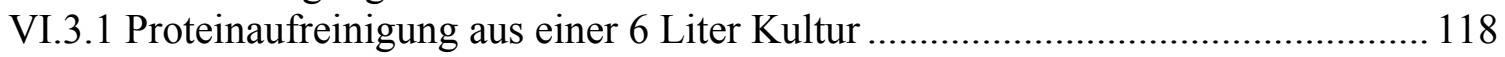

VI.3.2 Parallelisierte Proteinaufreinigung in kleinerem Maßstab ................................ 120

VI.3.3 Bestimmung von Proteinkonzentrationen .......................................................... 120

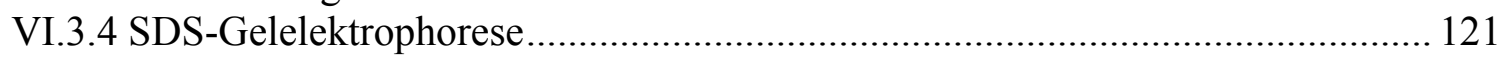

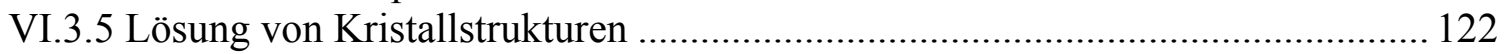

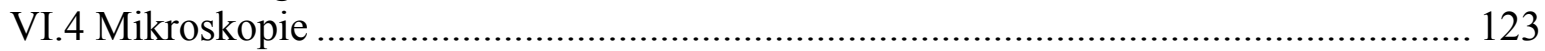

VI.4.1 Fixierung von Zellen auf einem Objektträger mit Poly-L Lysin ....................... 123

VI.4.2 Präparation lebender Zellen für die Mikroksopie ................................................ 123

VI.4.3 Mikroskopie an einem konfokalen Mikroskop ................................................ 124

VI.4.4 Separates Auslesen der Fluoreszenz von rsFastLime und Padron in lebenden

Zellen mit einem konfokalen Laser-Raster-Mikroskop ................................. 124

VI.4.5 Separates Auslesen der Fluoreszenz von rsFastLime, Padron und bsDronpa mit einem konfokalen Laser-Raster-Mikroskop ............................................... 125

VI.4.6 Zwei Farben hochauflösende Mikroskopie nach dem EinzelmolekülLokalisationsverfahren mit negativ schaltbaren RSFPs .................................. 125

VI.4.7 Messung der Abberation an einem konfokalen Mikroskop .............................. 126

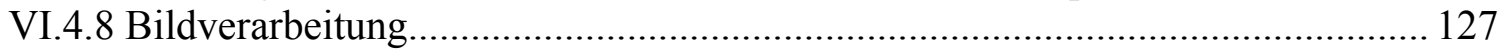

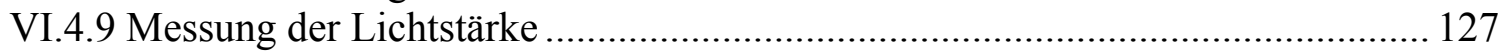

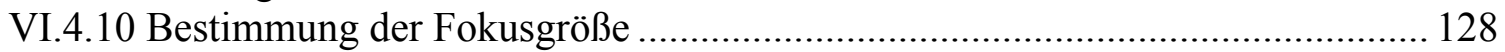

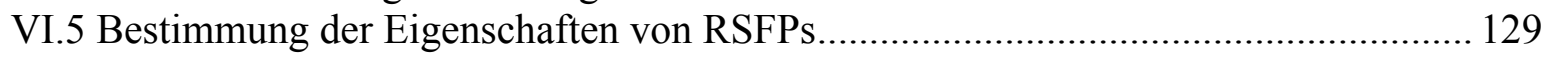

VI.5.1 Schalten von RSFPs auf ganzen E.coli-Kolonien ........................................... 129

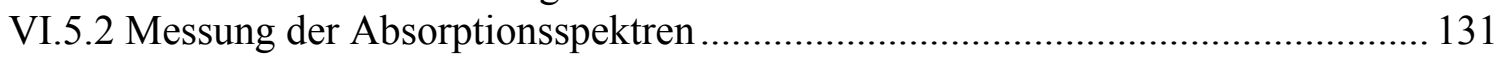

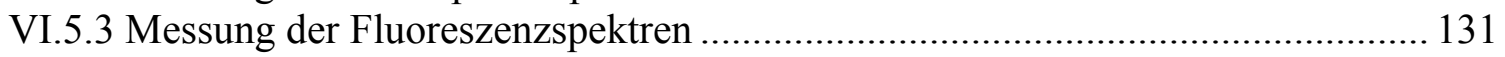

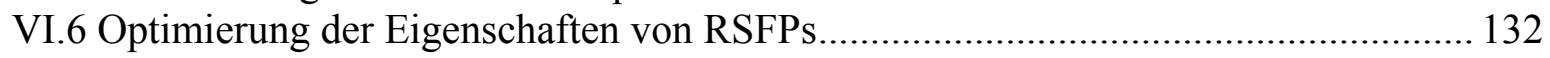

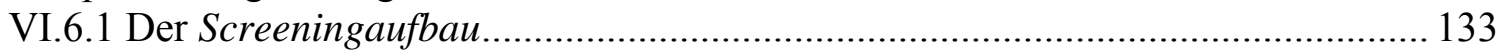

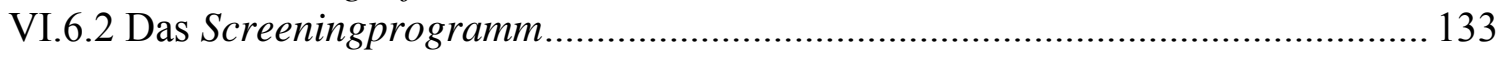

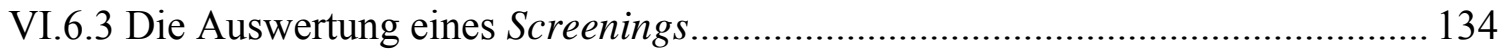

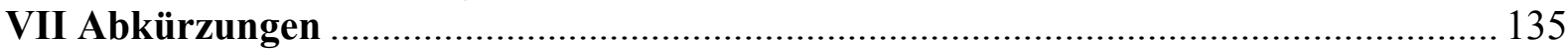

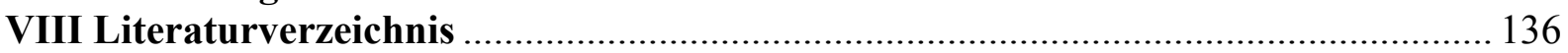

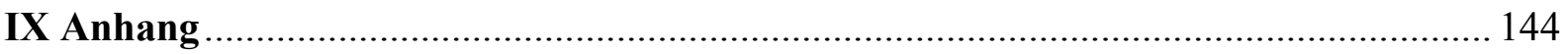

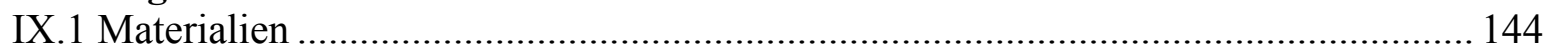

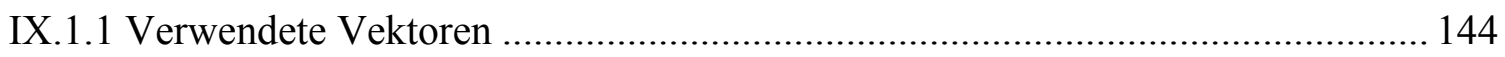

IX.1.2 Auswahl der verwendeten Oligonucleotide ................................................... 148

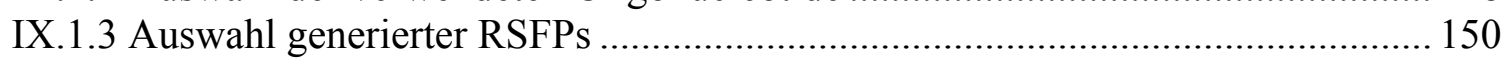

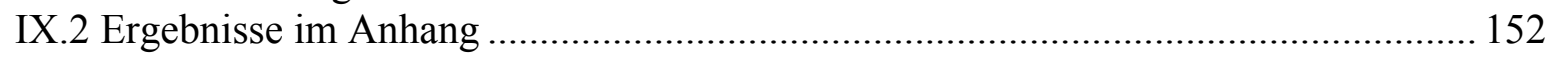

IX.2.1 Darstellung der Interaktionen des Chromophors von Dronpa im ein- und

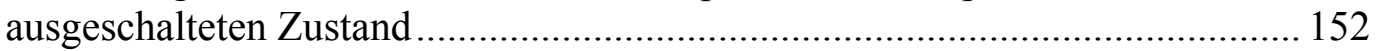

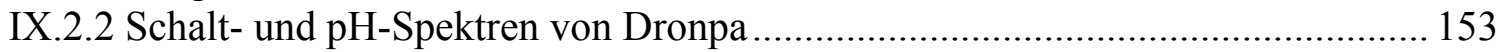

IX.2.3 Bleichverhalten in der monochromatischen Mehrfarben-Mikroskopie in

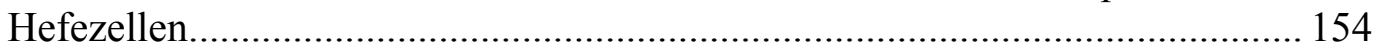

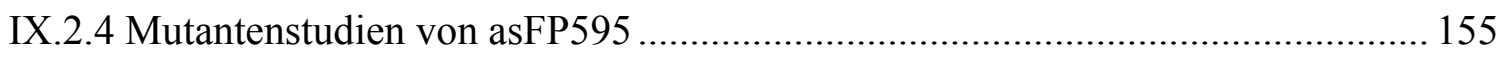

IX.2.5 Größenchromatographien der Dronpa-Varianten .......................................... 158

IX.2.6 Crosstalk bei der monochromatischen Mehrfarben-Mikroskopie ...................... 158

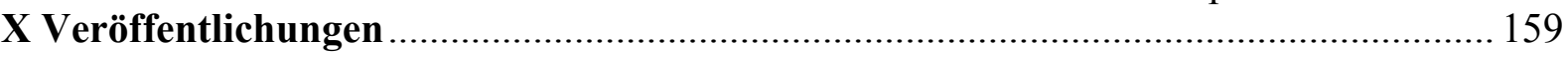

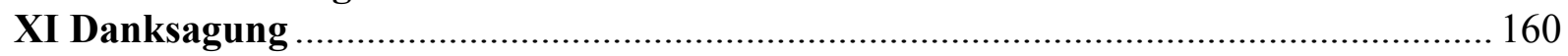




\section{Zusammenfassung}

Fluoreszierende Proteine sind innerhalb des letzten Jahrzehnts zu einem essentiellen Bestandteil der biologischen Forschung geworden. Seit ihrer Entdeckung als Marker für Proteine in lebenden Zellen wurden FPs mit unterschiedlichen Eigenschaften in nahezu allen Farben des sichtbaren Spektrums entwickelt.

Eine neue Unterklasse der fluoreszierenden Proteine kann reversibel mit Licht von einem fluoreszierenden in einen nicht fluoreszierenden Zustand geschaltet werden. Diese reversibel schaltbaren fluoreszierenden Proteine (RSFPs) haben aufgrund dieser einzigartigen Eigenschaft großes Potential in der Anwendung und Entwicklung neuer lichtmikroskopischer Methoden.

In dieser Doktorarbeit wurde der molekulare Mechanismus der reversibel schaltbaren fluoreszierenden Proteine in den Grundlagen aufgeklärt, neue RSFPs mit verbesserten Eigenschaften wurden generiert und in verschiedenen Mikroskopietechniken eingesetzt.

Für die Untersuchung des Schaltens auf molekularer Ebene wurden die Proteine kristallisiert und im Kristall vollständig in den fluoreszierenden und nicht fluoreszierenden Zustand geschaltet, um dessen strukturelle Unterschiede zu bestimmen. Durch die Analyse beider zu diesem Zeitpunkt bekannten RSFPs, asFP595 und Dronpa, konnte eine cis-trans-Isomerie des Chromophors als grundlegender Mechanismus für das reversible Schalten identifiziert werden.

Die Isomerisierung führt zu einer Änderung der Umgebung des Chromophors, so dass die beiden Zustände unterschiedliche Absorptions- und Fluoreszenzeigenschaften aufweisen. Diese haben ihre Ursache in der Protonierung und Stabilisierung des Chromophors, welche als entscheidende Eigenschaften für das reversible Schalten identifiziert wurden. Aufgrund dieser Ergebnisse war es möglich, ein vereinfachtes Modell des Schaltens aufzustellen, das für alle derzeit bekannten RSFPs gültig ist.

Der Aufbau eines Test- und Auswahlverfahrens ermöglichte die gezielte Modifikation der Eigenschaften von RSFPs. Durch gerichtete und zufällige Mutagenese wurden die verbesserten reversibel schaltbaren fluoreszierenden Proteine rsFastLime, bsDronpa, Padron und Padron* entwickelt.

Unter Verwendung der Proteine rsFastLime und bsDronpa konnte hochauflösende Mikroskopie in Zellen mit einer Auflösung jenseits der Beugungsgrenze gezeigt werden. Zusätzlich wurde mit den neu generierten Proteinen eine Methode entwickelt, die eine aberrationsfreie Aufnahme mehrerer fluoreszierender Proteine in einer Zelle erlaubt, die monochromatische Mehrfarben-Mikroskopie.

Das Verständnis des Schaltmechanismus, die in dieser Arbeit generierten RSFPs und deren Anwendung erweitern die Möglichkeiten zur Erforschung lebender Zellen. 


\section{Summary}

Over the course of the last decade fluorescent proteins became an essential part of biological research. Since their first use as a marker for proteins in living cells, numerous fluorescent proteins in almost all colours of the visible spectrum with miscellaneous properties have been developed.

A new subclass of these fluorescent proteins may be switched "on" and "off" between a fluorescent and a non-fluorescent state. These reversibly switchable fluorescent proteins (RSFPs) have great potential in the development and use of microscopic techniques because of their unique switching property.

In this thesis the molecular mechanism of the reversible switching in RSFPs was identified. Furthermore, novel RSFPs with improved properties were generated and applied in different microscopy schemes.

The molecular basis of switching was solved by x-ray analysis. Protein crystals were analysed after switching them completely into either the fluorescent or the non-fluorescent state to identify structural differences on the molecular level. The determination of these states for asFP595 and Dronpa, the only two known RSFPs at that moment, revealed a cis-transisomerisation of the chromophore as the key event of reversible switching.

The isomerisation from the cis- into the trans-conformation changes the environment of the chromophore, resulting in different absorption and fluorescence properties. These differences arise from modifications in protonation and stabilisation of the two states. On the basis of these results, it was possible to propose a reduced model for the reversible switching, which holds for all currently known RSFPs.

In order to customise the proteins, a screening setup was built, allowing for the directed evolution of RSFPs. By using random and directed mutagenesis the proteins rsFastLime, bsDronpa, Padron and Padron* were developed. These proteins exhibit improved switching properties and were especially designed for the use in high resolution microscopy schemes. For rsFastLime and bsDronpa, microscopy with a resolution beyond the diffraction limit was readily demonstrated. In addition to the use of RSFPs in high resolution microscopy, a new method allowing for multicolour imaging without aberrations, the monochromatic multilabel microscopy, was established.

By solving the basic molecular mechanism of reversible switching and the subsequent development of new improved RSFPs, this thesis should broaden the possibilities for research in living cells. 


\section{Einleitung}

Die Erforschung und das Verständnis der Natur finden durch Beobachtung und anschließende Interpretation statt. Dieses einfache Vorgehen ist möglich, sofern die Prozesse direkt betrachtet werden können. Entziehen sich die Prozesse jedoch dem menschlichen Auge, so müssen Hilfsmittel verwendet werden.

Die Naturwissenschaft der Biologie ist bestrebt, die Grundlagen des Lebens zu verstehen. Für dieses Verständnis ist es essentiell, die Vorgänge zwischen, sowie innerhalb einzelner Zellen $\mathrm{zu}$ erforschen. In der Zellbiologie finden nahezu alle Prozesse in so kleinen Dimensionen statt, dass sie nicht mit dem bloßen Auge betrachtet werden können. Aus diesem Grund werden Experimente durchgeführt, die Vorgänge, die für das Auge nicht mehr sichtbar sind, in ein für den Menschen sichtbares Ergebnis umwandeln.

Die Entwicklung von Mikroskopen ermöglichte es, Objekte direkt zu betrachten, die jenseits dessen liegen, was mit bloßem Auge erkannt werden kann. Bereits im 17. Jahrhundert erkannte Robert Hooke mit Hilfe eines Mikroskops, dass pflanzliches Gewebe aus einzelnen Zellen aufgebaut ist (Hooke 1665). Die Auflösung der Mikroskope wurde mit der Zeit besser, so dass 1830 von Robert Brown der Zellkern (sowie die Brownsche Molekularbewegung) entdeckt wurden (Brown 1828; Einstein 1905).

Die Lichtmikroskopie zur Untersuchung von Funktionen in Zellen ist jedoch aufgrund des Mangels an Kontrast begrenzt. So können Objekte nur unterschieden werden, wenn sie Licht unterschiedlich stark brechen, streuen oder absorbieren. Ein solcher Unterschied ist innerhalb der Zellen jedoch selten, die optische Dichte ist hauptsächlich in den räumlich getrennten Organellen und deren Membranen ausreichend verschieden. Daher können zwar die Membranen selbst und Organelle, die unterschiedliche optische Dichten aufweisen, mit der Durchlichtmikroskopie abgebildet werden, einzelne Proteine jedoch nicht.

Eine Möglichkeit, den Kontrast innerhalb von Zellen zu verstärken, ist die Verwendung von Farbstoffen, die spezifisch in Kompartimente einer Zelle eingelagert werden. Um einen ausreichend hohen Kontrast bei dieser Form der Mikroskopie zu erzeugen, muss der Farbstoff allerdings in relativ hoher Konzentration vorliegen. Das Problem mangelnden Kontrasts bei der Markierung wurde gelöst, indem Farbstoffe verwendet wurden, die nicht nur absorbieren, sondern auch fluoreszieren $(\rightarrow$ III.1.1).

Bei der Fluoreszenzmikroskopie ist der Kontrast nahezu absolut, da nur die Fluoreszenz detektiert wird, nicht aber das Licht mit dem die Probe bestrahlt wird ( $\rightarrow$ III.1.2). Man ist also in der Lage, auch sehr geringe Mengen Farbstoff, bis hin zu einzelnen Molekülen, 
nachzuweisen (Moerner et al. 1989; Moerner 2002). Die Fluoreszenzmikroskopie ermöglicht daher die Beobachtung einzelner Proteinmoleküle in Zellen, um anschließend Hypothesen über deren Funktion aufstellen zu können.

Die Mikroskopische Untersuchung einzelner Proteine war lange Zeit auf tote Zellen beschränkt, da die einzige praktikable Methode der Markierung von Proteinen eine Kopplung von Fluoreszenzfarbstoffen an proteinspezifische Antikörper war.

Eine Entdeckung, deren Bedeutung erst etwa 30 Jahre später begriffen wurde, sollte dieses Problem lösen. 1962 wurde das grün fluoreszierende Protein (GFP) in der Qualle Aequorea victoria entdeckt (Shimomura et al. 1962) ( $\rightarrow$ III.2.1). Die Funktion des Proteins wurde 1974 beschrieben (Morise et al. 1974). GFP absorbiert das blaue Licht der Chemolumineszenz und emittiert selbst grünes Licht, welches Wasser weiter durchdringt als blaues Licht. Die Bedeutung von GFP für die biologische Forschung wurde jedoch erst in den 90er Jahren deutlich. Die Sequenz des aus 232 Aminosäuren bestehenden Proteins wurde 1992 analysiert (Prasher et al. 1992) und der volle Umfang seiner Bedeutung für die Zellbiologie wurde klar als GFP im Jahr 1994 als Marker in lebenden Zellen eingesetzt wurde (Chalfie et al. 1994). Das Protein kann sowohl C- als auch N-terminal an Proteine geknüpft werden, ohne dabei die Eigenschaft der Fluoreszenz zu verlieren (Inouye et al. 1994; Wang et al. 1994).

Drei Eigenschaften machen GFP zu einem nahezu optimalen Marker für die Fluoreszenzmikroskopie, der in lebenden Organismen eingesetzt werden kann: Erstens bildet das Protein seinen Chromophor autokatalytisch und benötigt außer molekularem Sauerstoff keine weiteren Kofaktoren ( $\rightarrow$ III.2.2); zweitens ist GFP genetisch kodiert und kann in nahezu jedem Organismus eingesetzt werden; drittens verliert GFP als Fusionsprotein nicht die Eigenschaft der Fluoreszenz und kann somit als Markierung an andere Proteine gekoppelt werden.

Als Fluoreszenzmarker in lebenden Zellen hat GFP innerhalb kürzester Zeit Einzug in viele Bereiche der Zellbiologie gehalten (Tsien 1998). Das Spektrum der fluoreszierenden Proteine (FP) wurde 1999 durch die Entdeckung GFP homologer Proteine in der Klasse der Anthozoen in den roten Spektralbereich erweitert (Matz et al. 1999) ( $\rightarrow$ III.2.3). Die Entdeckung von GFP-Homologen ermöglicht Mehrfachmarkierungen, die eine gleichzeitige Lokalisation mehrerer Proteine in einer Zelle zulassen. Seitdem wurde das Spektrum fluoreszierender Proteine durch die Entdeckung neuer, sowie die Mutagenese vorhandener Proteine, auf den gesamten Bereich des sichtbaren Lichts ausgedehnt ( $\rightarrow$ III.2.3 bis III.2.5).

Die Farbvielfalt und die Möglichkeiten der Modifizierung fluoreszierender Proteine haben zu einer breiten Anwendbarkeit in nahezu allen Bereichen der biologischen Forschung geführt 
(Cole et al. 1996; Lippincott-Schwartz et al. 2003; Livet et al. 2007; Sieber et al. 2007). Die Bedeutung dieser Klasse von Proteinen wurde durch die Vergabe des Nobelpreises im Oktober 2008 an den Entdecker Osamu Shimomura, sowie Martin Chalfie und Roger Tsien, die deren Anwendung und Entwicklung entscheidend vorangetrieben haben, unterstrichen.

Die Verwendung und Entwicklung fluoreszierender Proteine beschränkt sich jedoch nicht allein auf das Markieren von Proteinen in lebenden Zellen. So wurden z.B. spezielle FPs als pH-Sensoren (Llopis et al. 1998), für FRET-Konstrukte (Förster Resonanz Energie Transfer) (Wouters et al. 1998) oder sogar für die lichtinduzierte Zerstörung von Fusionsproteinen (Bulina et al. 2006; Bulina et al. 2006) eingesetzt. Näher an der ursprünglichen Verwendung, dem Visualisieren von Proteinen in einer Zelle, sind die Anwendungen der photoaktivierbaren FPs $(\rightarrow$ III.2.8). Bei dieser Untergruppe der fluoreszierenden Proteine können die Fluoreszenzeigenschaften irreversibel verändert werden, indem man die Proteine mit Licht bestimmter Wellenlängen bestrahlt (Lukyanov et al. 2005). Dies ermöglicht die separate Verfolgung dieser aktivierten Fusionsproteine innerhalb einer Zelle.

Die Irreversibilität dieser Reaktion setzt der Anwendung photoaktivierbarer FPs in verschiedenen Mikroskopietechniken jedoch Grenzen. Mit der Entdeckung von asFP595 wurde der erste Vertreter der reversibel schaltbaren fluoreszierenden Proteine (RSFPs) gefunden (Lukyanov et al. 2000). Diese Proteine können durch Bestrahlung mit Licht bestimmter Wellenlängen mehrmals von einem fluoreszierenden in einen nicht fluoreszierenden Zustand und wieder zurück geschaltet werden ( $\rightarrow$ III.2.9). Die RSFPs sind aufgrund der Reversibilität des Schaltens, neben der Verfolgung aktivierter Subpopulationen von Fusionsproteinen in Zellen, viel versprechende Kandidaten für hochauflösende Bildgebungsverfahren wie RESOLFT (REversible Saturable OpticaL Fluorescence Transitions) und die erst im Verlauf dieser Doktorarbeit entwickelten EinzelmolekülLokalisationsverfahren (PALM, STORM, PALMIRA usw.) ( $\rightarrow$ III.1.4) (Hofmann et al. 2005; Betzig et al. 2006; Dedecker et al. 2006; Rust et al. 2006; Bock et al. 2007; Egner et al. 2007; Geisler et al. 2007; Schwentker et al. 2007). 


\section{III.1 Fluoreszenzmikroskopie}

Die Fluoreszenzmikroskopie ist ein bildgebendes Verfahren, welches durch einen hohen Kontrast auch den Nachweis einzelner Moleküle erlaubt. Um diesen Kontrast zu erzeugen, wird ausgenutzt, dass Fluorophore Licht absorbieren und dieses in Form von Fluoreszenz wieder abgeben. Das emittierte Fluoreszenzlicht hat eine geringere Energie als das absorbierte Licht und ist daher im Spektrum rotverschoben. Dieser spektrale Unterschied ermöglicht es, das Fluoreszenzlicht vom Streulicht der Anregung zu trennen. Praktisch wird diese Trennung durch Langpass- oder Bandpassfilter verwirklicht, die nur für Licht bestimmter Wellenlängen durchlässig sind. Der Kontrast bei der Fluoreszenzmikroskopie ist aufgrund der spezifischen Markierung und der Trennung von Anregung und Fluoreszenz nahezu absolut.

\section{III.1.1 Fluoreszenz}

Absorbiert ein Molekül Licht einer bestimmten Wellenlänge, werden Elektronen in einen energetisch höheren Zustand gehoben. Die aufgenommene Energie kann anschließend entweder in Form von Fluoreszenz bei Fluorophoren, oder in Form von Bewegungsenergie, z.B. durch Schwingungsrelaxation bei Chromophoren wieder abgegeben werden.

Bei der Absorption eines Photons wird ein Molekül normalerweise aus seinem elektronischen Grundzustand $\mathrm{S}_{0}$ in den ersten angeregten elektronischen Zustand $\mathrm{S}_{1}$ gehoben. Die Energie des Photons muss dabei ungefähr derjenigen zwischen den beiden Zuständen $\mathrm{S}_{0}$ und $\mathrm{S}_{1}$ entsprechen. Das Molekül fällt nach wenigen Nanosekunden unter Abgabe eines Photons oder thermisch zurück in den Grundzustand $\mathrm{S}_{0}$. Das emittierte Photon besitzt dabei weniger Energie als das absorbierte (Stokessche Regel). Dies lässt sich durch eine genauere Betrachtung der Zustände erklären (Abbildung 1). Bei der Absorption wird das Molekül nicht exakt auf das Energieniveau $\mathrm{S}_{1}$ angehoben, sondern in so genannte Vibrationsunterzustände die geringfügig energiereicher sind. Die vibronische Relaxation in den Zustand $S_{1}$ erfolgt jedoch nahezu sofort. Ebenso geht Energie beim Übergang von dem Zustand $\mathrm{S}_{1}$ in den Grundzustand $\mathrm{S}_{0}$ verloren. Die bei diesen Prozessen durch vibronische Relaxation abgegebene Energie definiert den Unterschied zwischen der Anregungs- und der Emissionswellenlänge (Jablonski 1933; Jablonski et al. 1935), der als Stokesverschiebung (Stokesshift) bezeichnet wird. 

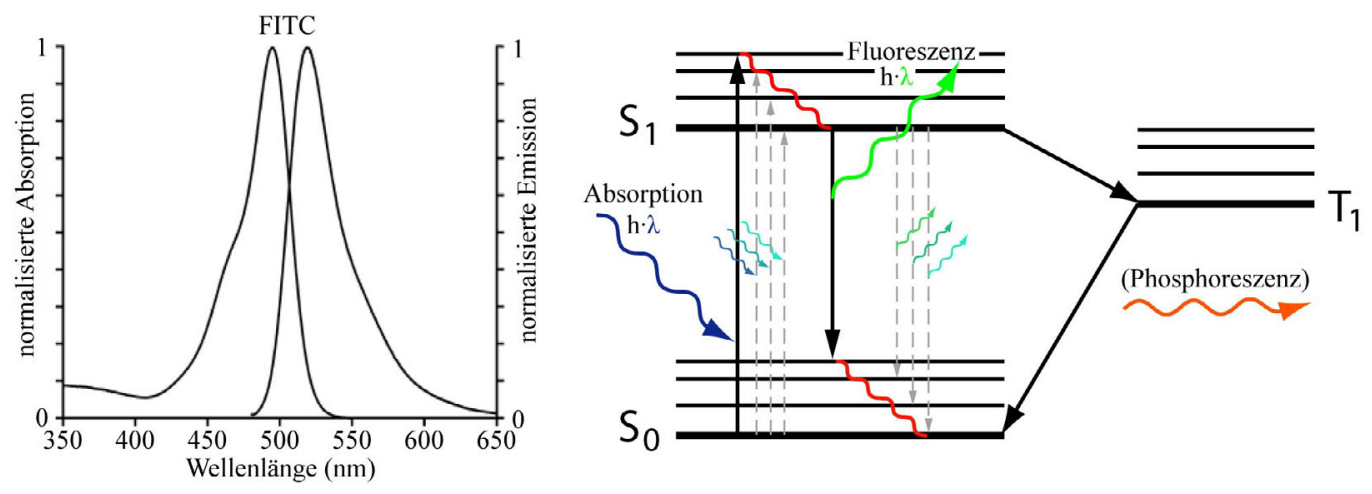

Abbildung 1: Spektren und elektronische Übergänge von Fluoreszenzfarbstoffen. In (a) sind Absorptions- und Emissionsspektrum des Fluoreszenzfarbstoffs FITC (Fluoreszeinisothiocyanat) abgebildet. (b) zeigt ein Jablonski Diagramm, welches schematisch die elektronischen und vibronischen Zustände und deren Übergänge eines Farbstoffmoleküls bei Absorption eines Photons wiedergibt. Details siehe Text.

Ob ein Molekül, welches ein Photon absorbiert hat, fluoresziert oder nicht fluoresziert, liegt einzig daran, welche Prozesse schneller sind, die Abgabe der Energie über ein Photon, oder die strahlungsfreie Abgabe der Energie über Stöße oder Schwingungen. Dabei hat die Umgebung des Moleküls einen entscheidenden Einfluss, denn je besser ein Chromophor in seiner Umgebung stabilisiert ist, desto wahrscheinlicher ist die Abgabe der Energie in Form eines Photons. Diese Wahrscheinlichkeit, mit der ein Molekül nach Absorption eines Photons Fluoreszenz abgibt, ist durch die Quantenausbeute definiert (Anzahl der emittierten Photonen geteilt durch die Anzahl der absorbierten Photonen).

Obwohl ein Molekül aus dem $\mathrm{S}_{1}$ Zustand in wenigen Nanosekunden wieder in den Grundzustand zurückfällt, kann es aus diesem Zustand auch in andere Zustände übergehen. So ist zum Beispiel der Übergang in einen metastabilen Tripletzustand möglich. Das Rückfallen in den Zustand $\mathrm{S}_{0}$ erfolgt wie der aus dem $\mathrm{S}_{1}$ Zustand entweder durch thermische Relaxation oder unter Abgabe eines Photons, wobei diese Form der Strahlung als Phosphoreszenz bezeichnet wird, bei Raumtemperatur jedoch zu vernachlässigen ist.

Aus den Zuständen $\mathrm{S}_{1}$ oder $\mathrm{T}_{1}$ kann es außerdem vorkommen, dass ein Chromophor zerstört wird, da diese aufgrund ihrer höheren Energie reaktiver sind. Zusätzlich sind bei hohen Intensitäten Übergänge von $\mathrm{S}_{1}$ oder $\mathrm{T}_{1}$ in noch höhere Zustände möglich, in denen eine Zerstörung des Chromophors noch wahrscheinlicher ist. Dieses so genannte Bleichen führt zu irreversiblen Veränderungen der Chromophorstruktur, wodurch die Fluoreszenzeigenschaften verloren gehen. 


\section{III.1.2 Aufbau von Fluoreszenzmikroskopen}

Mit einem Fluoreszenzmikroskop wird die Verteilung fluoreszierender Moleküle in einer Probe gemessen und in ein Bild umgewandelt. Dabei wird ausschließlich die Fluoreszenz gemessen, so dass der Rest der Probe nicht sichtbar ist.

Das Anregungslicht wird entweder durch die Verwendung eines Lasers oder mit Hilfe eines Filters in seinem Spektrum auf wenige Nanometer beschränkt. Es wird von einem dichroitischen Spiegel im $90^{\circ}$ Winkel reflektiert und durch das Objektiv auf die Probe fokussiert. Dort wird es von Fluorophoren absorbiert, die wiederum Fluoreszenz emittieren. Da Fluoreszenz gleichmäßig in alle Raumrichtungen abgegeben wird, kann ein Teil durch das Objektiv wieder eingefangen werden. Der dichroitische Spiegel muss so beschaffen sein, dass er das Anregungslicht reflektiert und das Fluoreszenzlicht passieren lässt, damit die Fluoreszenz vom Streulicht getrennt werden kann. Hinter dem dichroitischen Spiegel wird das Fluoreszenzlicht auf einen Detektor gelenkt, der die Intensitäten an den verschiedenen Orten in der Probe misst. Dadurch kann dann ein Bild der Fluorophorverteilung in der Probe erzeugt werden.

Im Rahmen dieser Arbeit wurden zwei Arten der Fluoreszenzmikroskopie genutzt: die Weitfeldfluoreszenzmikroskopie und die konfokale Laser-Raster-Mikroskopie (Abbildung 2). Bei der Weitfeldfluoreszenzmikroskopie wird die Probe großflächig $(\sim 10-100 \mu \mathrm{m}$ Durchmesser) durch ein Objektiv beleuchtet. Bei der Verwendung eines Objektivs mit 100 facher Vergrößerung hat der Fokus üblicherweise einen Durchmesser von ca. $20 \mu \mathrm{m}$. Die Auflösung wird bei dieser Art der Fluoreszenzmikroskopie durch die Detektion bestimmt. Die Fluoreszenz wird auf eine CCD Kamera gelenkt, welche die Fluorophore, bei ausreichend hoher Pixelierung des Detektors, mit der beugungsbegrenzten Auflösung von ca. $300 \mathrm{~nm}$ in xy-Richtung abbildet.

Bei der konfokalen Laser-Raster-Mikroskopie wird die Auflösung durch die Art der Anregung, sowie durch die Detektion mit einer Lochblende bestimmt. Das Licht aus einem Laser wird mit dem Objektiv $\mathrm{zu}$ einem möglichst kleinen beugungsbegrenzten Fokus gebündelt. Die Detektion geschieht dann meist mit einem Photomultiplier, welcher die Fluoreszenz ausschließlich quantitativ erfasst. Auf diese Weise wird die Probe abgerastert und an jedem Punkt die Intensität der Fluoreszenz gemessen. Der Vorteil bei dieser Methode ist, dass die Detektion durch eine Lochblende geschehen kann, da die Fluoreszenz immer nur von einem beugungsbegrenzten Bereich abgestrahlt wird. Die Lochblende ist in einer Zwischenbildebene platziert, so dass sie Licht der Ebenen über und unter der eigentlichen Bildebene blockiert (Abbildung 2). Auf diese Weise wird im Vergleich zum 
Weitfeldfluoreszenzmikroskop eine verbesserte Auflösung in z-Richtung (entlang der optischen Achse) erreicht, die im besten Fall bei etwa $450 \mathrm{~nm}$ liegt.

Weitfeld

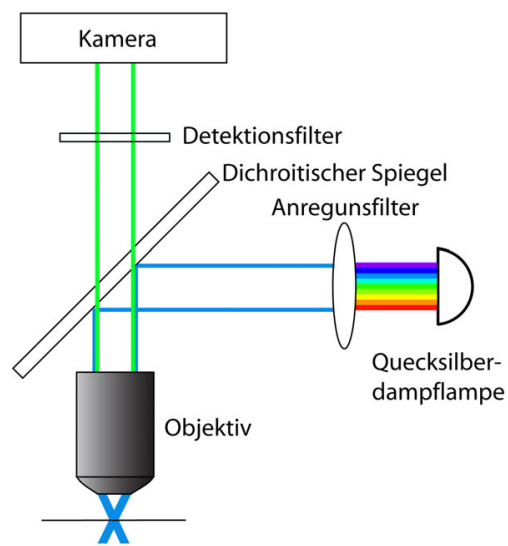

Konfokal

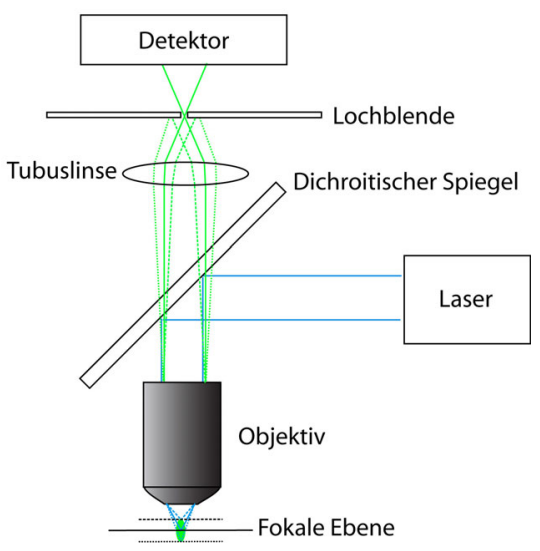

Abbildung 2: Aufbau von konfokalen- und Weitfeldmikroskopen. Details siehe Text.

\section{III.1.3 Die Auflösungsgrenze}

Als Auflösung bezeichnet man den minimalen Abstand zweier punktförmiger nebeneinander liegender Objekte, die noch getrennt abgebildet werden können. Lord Rayleigh (1842-1919) erkannte bereits, dass man zwei Objekte nur getrennt voneinander abbilden kann, wenn ihr Abstand größer ist als der Abstand des zentralen Maximums vom ersten Minimum der erzeugten Punktabbildung. Weiterhin beschrieb Ernst Abbe 1870, dass es nicht möglich ist, Licht mit Hilfe von Linsen auf einen Punkt zu fokussieren, dessen Durchmesser kleiner als etwa 1/3 der Wellenlänge des Lichts ist.

Aus diesen Bedingungen ergibt sich der minimale Abstand zweier Objekte, die sich getrennt darstellen lassen. Er wird mathematisch durch folgende Formel ausgedrückt (1):

$$
d=\frac{\lambda}{2 n \sin \alpha}
$$

Formel 1: $\mathrm{d}=$ Durchmesser des Fokus; $\lambda=$ Wellenlänge des Lichts; $\mathrm{n}=$ Brechzahl des Mediums zwischen Objektiv und Deckglas; $\alpha=$ halber Öffnungswinkel des Objektivs

Die Auflösungsgrenze ist also allein durch die Wellenlänge des Lichts und die numerische Apertur $(\mathrm{NA}=\mathrm{n} \cdot \sin \alpha)$ des Objektivs gegeben. Bei den gängigen Objektiven liegt die maximale NA bei etwa 1,4. Dadurch ergibt sich eine maximale Auflösung von $\sim 0,36 \cdot \lambda$. 


\section{III.1.4 Hochauflösende Mikroskopie durch schaltbare Fluorophore}

In der Fluoreszenzmikroskopie gibt es zwei Methoden, mit denen man die Position von Objekten über die Auflösungsgrenze hinaus lokalisieren kann, die beide auf dem Ein- bzw. Ausschalten der Fluoreszenz basieren. Bei der RESOLFT-Technik (Hell 2003; Hell et al. 2003) wird ausgenutzt, dass man angeregte Fluorophore durch einen zweiten Lichtimpuls ausschalten kann (Hell et al. 1994; Hell 2007). Im Falle der STED-Mikroskopie wird wenige Pikosekunden nach der Anregung der Fluorophore ein zweiter Lichtimpuls eingestrahlt, um die Fluorophore im angeregten Zustand zu treffen. Dieser zweite Lichtimpuls induziert die Emission eines Photons vom angeregten Chromophor. Gestaltet man den Fokus dieses zweiten Lichtimpulses so, dass in der Mitte durch Interferenz ein Intensitätsminimum entsteht (Abbildung 3a), bleiben effektiv nur die Fluorophore in diesem Intensitätsminimum im angeregten Zustand $\mathrm{S}_{1}$ (Abbildung 3b).
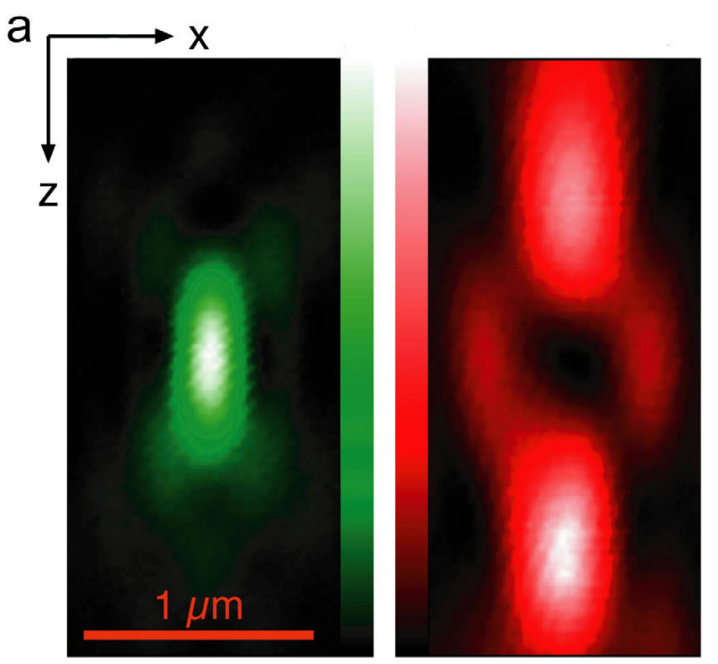

b
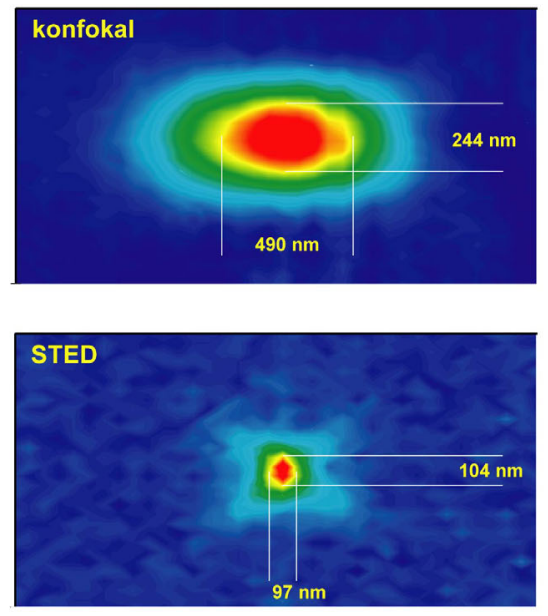

Abbildung 3: In (a) ist links die Form des Fokus bei Anregung der Fluorophore, rechts die Form des Fokus bei dem Lichtimpuls für die stimulierte Emission zu sehen (Klar et al. 2000). In (b) ist oben der normale Fokus eines konfokalen Mikroskops zu sehen, unten ist der Bereich zu sehen, der nach dem Impuls der stimulierten Emission immer noch Signal erzeugt hat.

Bei der zweiten Methode der hochauflösenden Mikroskopie wird ausgenutzt, dass die Photonen eines einzelnen ortsfesten Fluorophors auf einer CCD-Kamera in Form einer Gaussverteilung detektiert werden (Betzig et al. 2006). Bei Detektion mehrerer Photonen, die von einem Fluorophor ausgesendet werden, kann man den Mittelpunkt der Gaussverteilung berechnen. Je mehr Photonen detektiert werden, desto genauer kann der Ort eines Fluorophors über die Beugungsgrenze des Lichts hinaus bestimmt werden. Die bisher entwickelten 
Einzelmolekül-Lokalisationsverfahren (PALM, STORM, PALMIRA) funktionieren alle nach demselben Prinzip, dass bereits 1930 beschrieben wurde (Heisenberg 1930).

Bei dieser Art der hochauflösenden Mikroskopie ist es essentiell, dass die detektierten Photonen einem einzigen Molekül zugeordnet werden können. Dieses Problem kann durch die Verwendung irreversibel schaltbarer Fluorophore gelöst werden. Dabei wird möglichst immer nur ein Molekül in einem beugungsbegrenzten Bereich eingeschaltet und anschließend ausgelesen, bis es geblichen ist. Eine weitere Möglichkeit besteht darin, reversibel schaltbare Fluorophore zu benutzen und die aktive Fluorophorkonzentration stark zu reduzieren. In beiden Fällen kann es trotzdem notwendig sein, die Probe vorher zu bleichen, um die Konzentration der Fluorophore im Vorhinein zu reduzieren.

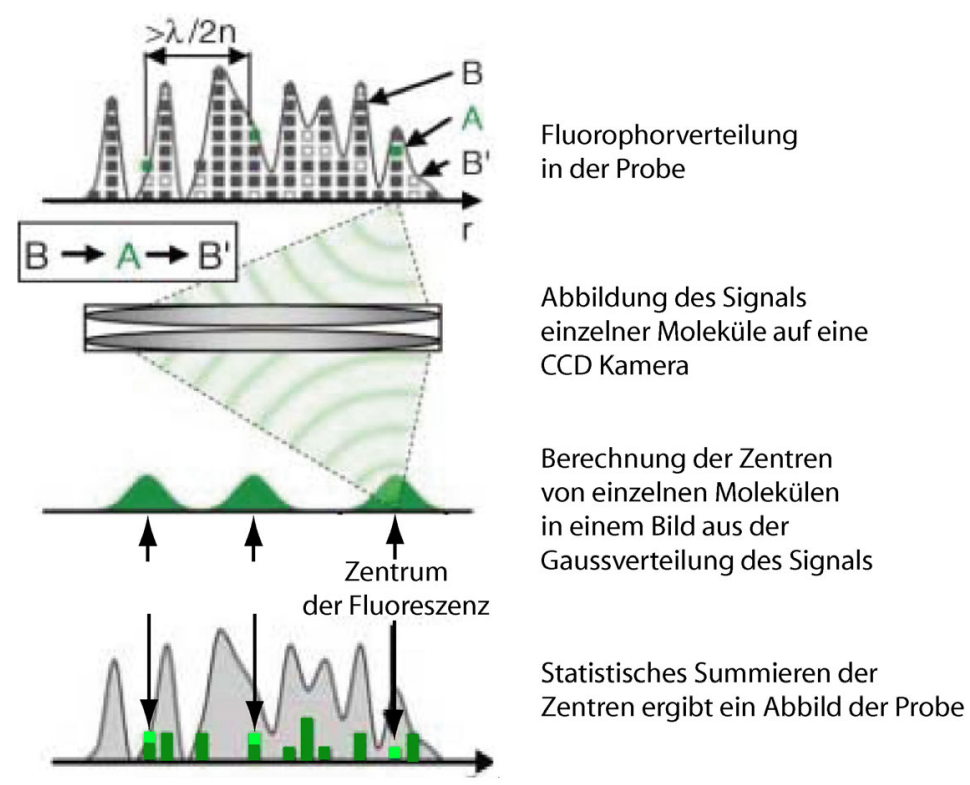

Abbildung 4: Die Entstehung eines Einzelmolekülspektroskopiebildes (Hell 2007). Oben ist die Fluorophorverteilung in einer Probe schematisch dargestellt. Befinden sich nur wenige Moleküle im fluoreszierenden Zustand, die einen Mindestabstand von $\lambda / 2 \mathrm{n}$ zueinander haben, ergibt die Fluoreszenz auf einer CCD-Kamera für jedes Molekül eine Gaussverteilung. Durch anschließende Berechnung des Zentrums der Gaussverteilung, können die Positionen der Moleküle über die Auflösungsgrenze hinaus zugeordnet werden. 


\section{III.2 Fluoreszierende Proteine}

\section{III.2.1 Die Klasse der GFP ähnlichen Proteine}

Das grün fluoreszierende Protein (GFP) wurde bereits in den sechziger Jahren zufällig bei der Aufreinigung von Aequorin aus der Qualle Aequorea victoria entdeckt (Shimomura et al. 1962). Die Funktion des Proteins in der Qualle wurde 1974 von Morise et al. beschrieben. GFP absorbiert chemolumineszentes UV-Licht, und verlängert so die Wellenlänge der Chemolumineszenz in den grünen Spektralbereich (Morise et al. 1974). Der Vorteil dabei ist, dass grünes Licht Wasser weiter durchdringt als blaues Licht. Erst 1992 wurde die Sequenz des Proteins, welches aus 232 Aminosäuren besteht, veröffentlicht (Prasher et al. 1992). Das Protein bildet eine fassförmige Struktur aus elf antiparallelen $\beta$-Faltblättern, in deren Mitte der Chromophor liegt (Ormo et al. 1996; Yang et al. 1996).
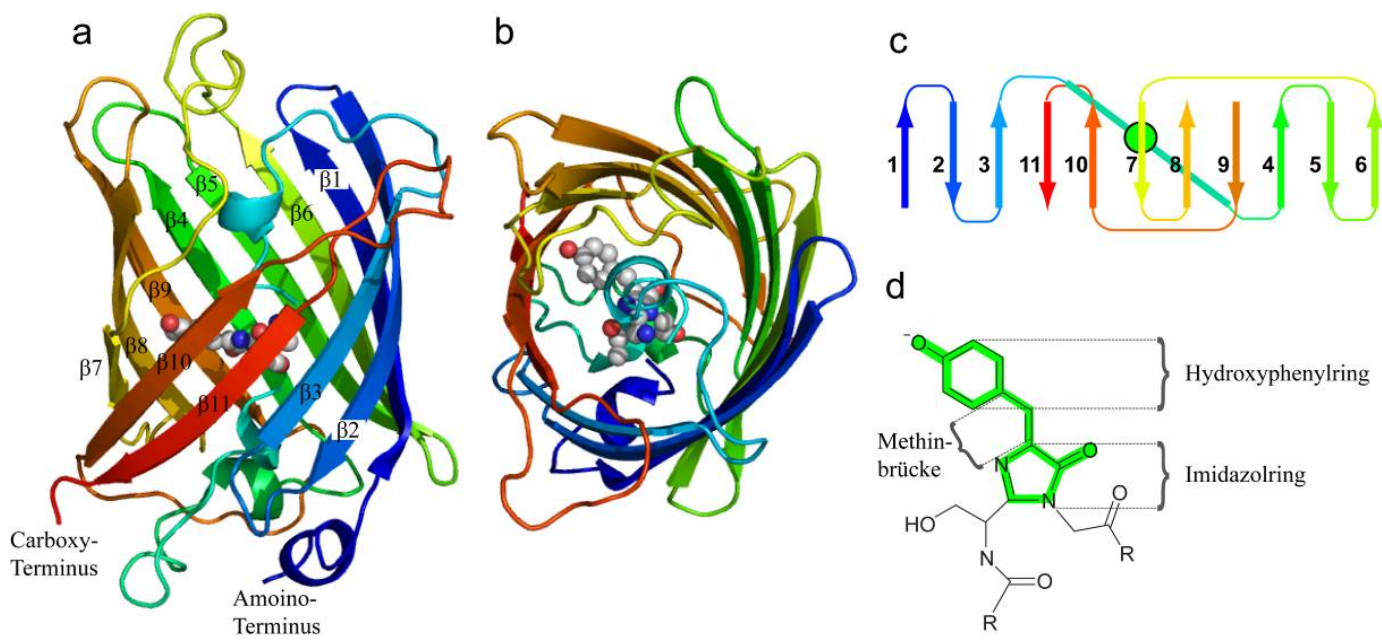

Abbildung 5: Aufbau von GFP homologen Proteinen. (a) und (b) zeigen die Röntgenkristallstruktur von GFP (PDB ID: 1EMA), wobei das Proteinrückgrat mit der „Chainbow“ Funktion des Programms pyMol in Regenbogenfarben dargestellt ist (vom Amino-Terminus in blau bis zum Carboxy-Terminus in rot). Die Atome des Chromophors sind durch eine Kugeldarstellung hervorgehoben, wobei Kohlenstoffatome weiß, Sauerstoffatome rot und Stickstoffatome blau sind. In (a) sind die einzelnen $\beta$-Stränge, sowie der Amino- und Carboxy-Terminus benannt. Abbildung (c) verdeutlicht den Verlauf der Aminosäurekette. Zwischen den $\beta$-Faltblatt-Strängen $\beta 3$ und $\beta 4$ befindet sich der Chromophor, welches als grüner Kreis dargestellt ist, und in einer Helix liegt, die einmal von oben nach unten durch das $\beta$-Fass verläuft. Struktur des GFP-Chromophors (d) mit dem konjugierten $\pi$-Elektronensystem in grün markiert. 
Die Bedeutung dieser Entdeckung für die Fluoreszenzmikroskopie wurde deutlich, als 1994 gezeigt wurde, dass GFP in Prokaryoten und Eukaryoten exprimiert werden und sowohl Nals auch C-terminal an Proteine fusioniert werden kann, ohne dass die Eigenschaft der Fluoreszenz verloren geht (Chalfie et al. 1994; Wang et al. 1994). Da der Chromophor außerdem autokatalytisch gebildet wird und GFP als Protein genetisch kodiert ist, kann es in nahezu jedem Organismus und in lebenden Zellen als Markierung verwendet werden.

Ebenfalls bereits 1995 wurden die ersten Verbesserungen an GFP publiziert, wie die Mutation S65T, welche zu einer stark erhöhten Fluoreszenz und einer verbesserten Faltungseffizienz führt (Heim et al. 1995). Weiterhin ist S65T die entscheidende Mutation in dem 1995 entwickelten EGFP (Thastrup et al. 1995).

Obwohl das enorme Potential der fluoreszierenden Proteine bereits 1994 allgemein anerkannt war, dauerte es weitere fünf Jahre bis GFP homologe Proteine entdeckt wurden, die das Farbspektrum erweiterten. Dies rührt daher, dass GFP in einer farblosen Qualle gefunden wurde, in der es durch FRET die Farbe der Biolumineszenz in den längerwelligen Bereich verschiebt (Morise et al. 1974). Die Jagd nach GFP ähnlichen Proteinen wurde deshalb auf biolumineszente Organismen beschränkt, während Organismen, die eine Färbung aber keine Biolumineszenz aufwiesen, nicht berücksichtigt wurden. Es wurden tatsächlich zwei weitere grün fluoreszierende FPs entdeckt, die aus den Organismen Ptylosarcus und Renilla stammen. Der Durchbruch gelang jedoch mit der Ausweitung der Suche auf die Klasse der nicht bioluminszenten Anthozoa (Matz et al. 1999), aus denen die Mehrheit der heute bekannten FPs stammt.

Neben GFP ist das 1999 beschriebene rot fluoreszierende Protein DsRed eines der wichtigsten Vertreter der fluoreszierenden Proteine (Matz et al. 2002). Als erstes Protein mit einer Fluoreszenz im roten Spektralbereich wurde das als Tetramer vorliegende DsRed zu dem monomeren Protein mRFP1 mutagenisiert (Campbell et al. 2002). Dieses Protein stellt die Basis vieler Proteine im roten Spektralbereich dar (mCherry, mOrange, mApple usw.). Ebenso ist EGFP der Vorgänger vieler Proteine im grünen Spektralbereich.

Mittlerweile ist durch Mutagenese vorhandener sowie die Entdeckung neuer fluoreszierender Proteine nahezu das komplette sichtbare Spektrum durch GFP-ähnliche Proteine abgedeckt (Abbildung 8).

Die große Bedeutung der FPs in der Molekularbiologie ist zum Großteil durch die genetische Kodierung gegeben. Ist die Information für ein FP einmal auf einem Plasmid oder direkt in das Genom einer Zelle eingebracht, wird es automatisch von der Zelle produziert und 
vollständig autokatalytisch gebildet. Daher können FPs in nahezu jedem Organismus eingesetzt werden. Diese autokatalytische Bildung des Chromophors wird im folgenden Abschnitt näher beschrieben.

\section{III.2.2 Die autokatalytische Chromophorsynthese}

Bis zur vollständigen Bildung des Chromophors katalysieren GFP ähnliche Proteine mehrere chemische Reaktionen, bei denen sie Substrat und Enzym gleichzeitig sind (Gross et al. 2000; Matz et al. 2002). Diese Eigenschaft ist unter allen bekannten Proteinen nahezu beispiellos, da keine weiteren Enzyme oder Kofaktoren, abgesehen von molekularem Sauerstoff, notwendig sind (Heim et al. 1994).

Obwohl die fluoreszierenden Proteine fast den kompletten spektralen Bereich abdecken, ist der Mechanismus, der zur Chromophorbildung führt, hoch konserviert. Bei allen bisher entdeckten GFP ähnlichen Proteinen wird der Chromophor aus drei Aminosäuren gebildet. Die erste der Aminosäuren ist variabel, während es sich bei den beiden folgenden im Falle natürlich vorkommender FPs immer um Tyrosin und Glycin handelt.

Der Chromophor von GFP wird aus den Aminosäuren Ser 65, Tyr 66 und Gly 67 gebildet, die $\mathrm{zu}$ einem Fünf- und einem Sechsring verbunden werden und ein großes delokalisiertes $\pi$ Elektronensystem bilden. Der Sechsring ist der Hydroxyphenylring des Tyrosins, während der kleinere Fünfring (Imidazolring) durch eine nukleophile Verknüpfung der Carbonylgruppe von Ser 65 mit dem Stickstoff des Gly 67 zustande kommt (Barondeau et al. 2005). 


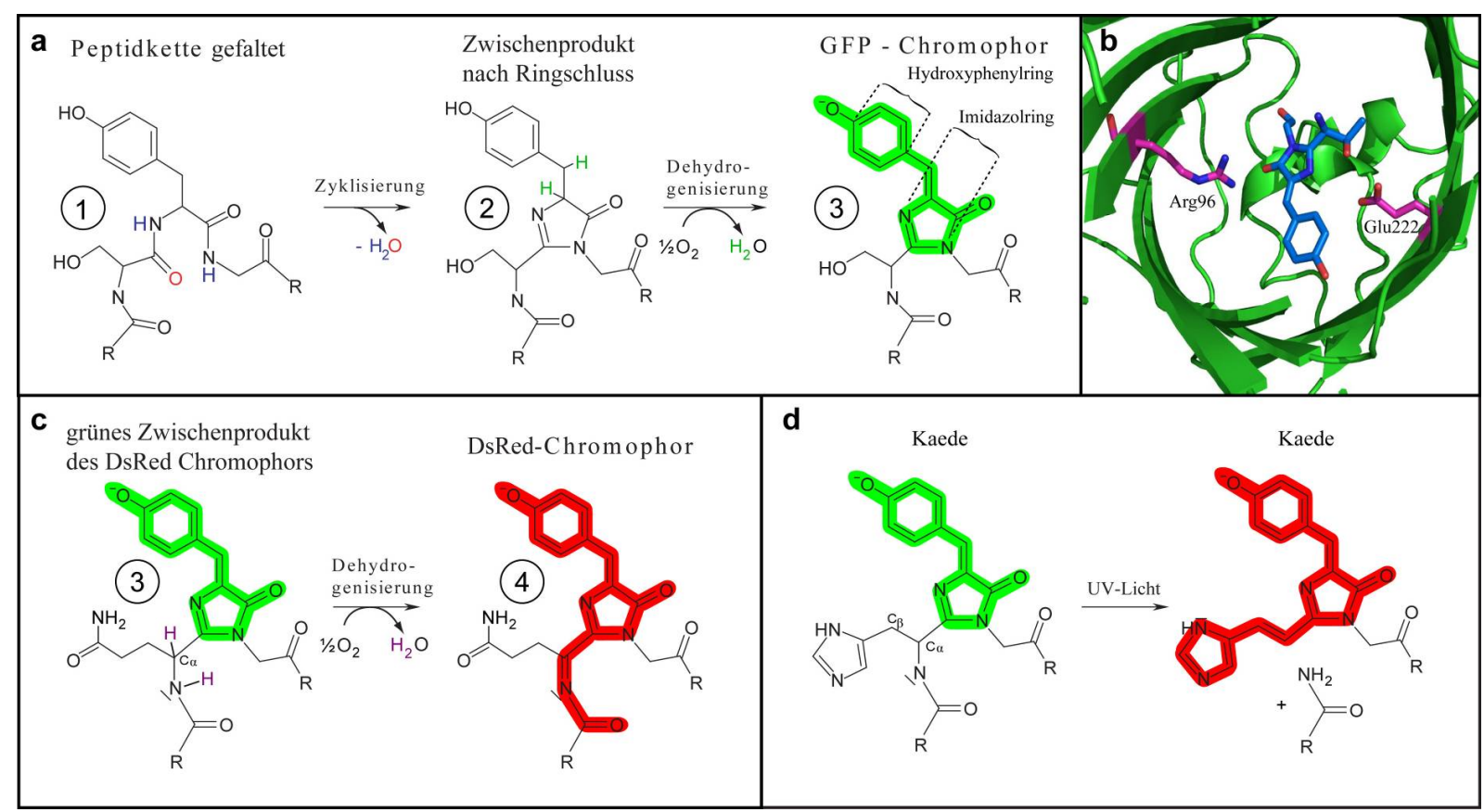

Abbildung 6: Chromophorbildung von GFP, DsRed und Kaede. Als Grundstruktur aller fluoreszierenden Proteine wird zunächst der GFP-Chromphor gebildet (a). Die Peptidkette faltet sich zunächst, so dass der Stickstoff des Gly 67 in die Nähe der Carbonylgruppe von Ser 65 kommt (Struktur 1). Die umgebenden Aminosäuren katalysieren die Zyklisierung unter Abspaltung von $\mathrm{H}_{2} \mathrm{O}$ woraus der Imidazolring entsteht (Struktur 2). Als zweiter Katalyseschritt wird mit molekularem Sauerstoff die Verbindung zwischen den beiden Ringsystemen durch eine Dehydrierung hergestellt. Daraus ergibt sich dann das verbundene $\pi$-Elektronensystem, der GFP-Chromophor (Struktur 3). In (b) ist der Chromophor und die Position der beiden für die Katalyse wichtigen Aminosäuren Arg 96 und Glu 222 dargestellt. Eine Erweiterung des chromophoren Systems ist in (c) an dem Beispiel von DsRed gezeigt. Eine weitere Dehydrierung, ausgehend vom GFP-Chromophor, zwischen dem $\mathrm{C}_{\alpha}$ und dem Stickstoff der ersten Aminosäure des Chromophors führt $\mathrm{zu}$ der Erweiterung des $\pi$ Elektronensystems. Der resultierende Chromophor (Struktur 4) fluoresziert im roten Spektralbereich. Eine andere Möglichkeit der Bildung eines roten Chromophors ist bei den photaktivierbaren FPs gegeben, bei denen durch Bestrahlung mit UV-Licht eine chemische Veränderung hervorgerufen wird. Als Beispiel ist hier Kaede angeführt, bei dem die Bestrahlung mit UV-Licht zu einer Spaltung des Proteinrückgrats führt. Bei dieser $\beta$-Eliminierung entsteht eine Doppelbindung zwischen dem $\mathrm{C}_{\alpha}$ und dem $\mathrm{C}_{\beta}$, sodass das Histidin, die erste Aminosäure des Chromophors, mit dem konjugierten $\pi$ Elektronensystem verbunden wird.

Das Stickstoff des Gly67 wird durch die dreidimensionale Struktur des Peptids in räumliche Nähe zur Carbonylgruppe von Ser65 gebracht (Barondeau et al. 2003). Der Ringschluss wird durch die umgebenden Aminosäuren katalysiert. Dabei wird angenommen, dass die zwei hoch 
konservierten Aminosäuren Arg96 und Glu222 eine entscheidende Rolle spielen (Wachter 2007).

Das Arg 96 erhöht wahrscheinlich zunächst die Nukleophilie des Stickstoffs von Gly 67 (Barondeau et al. 2005; Wood et al. 2005), sodass durch nukleophile Addition an das $\mathrm{C}_{\alpha}$ von Ser 65 der Imidazolring gebildet werden kann. Die beiden $\pi$-Elektronensysteme des Imidazolund Hydroxyphenylrings werden in der zweiten autokatalytischen Reaktion zu einem konjugierten Elektronensystem verbunden (Abbildung 6a). Dies geschieht durch eine $\beta$ Eliminierung die molekularen Sauerstoff benötigt und von Glu 222 katalysiert wird. Es wird angenommen, dass die Carboxylgruppe des Glu 222 die Abgabe eines Protons am $\mathrm{C}_{\alpha}$ von Tyr 66 ermöglicht (Sniegowski et al. 2005). Nach diesen zwei Reaktionsschritten ergibt sich die grundlegende Chromophorstruktur, die bei allen bekannten, natürlich vorkommenden fluoreszierenden Proteinen gleich ist. Ein solches Chromophor fluoresziert normalerweise im grünen Spektralbereich.

Bei FPs, die im roten Spektralbereich emittieren, findet nach der Bildung des GFPChromophors ein dritter autokatalytischer Reaktionsschritt statt, der verantwortlich für die Erweiterung des $\pi$-Elektronensystems ist.

\section{III.2.3 Rot fluoreszierende Proteine}

Mit DsRed wurde in den Anthozoen 1999 das erste Protein entdeckt, dass Licht im grünen Bereich absorbiert und rotes Licht emittiert (Matz et al. 1999). Die Rotverschiebung resultiert aus einer zusätzlichen Oxidierung zwischen dem $\mathrm{C}_{\alpha}$ und dem Stickstoff der ersten Aminosäure des Chromophors (Baird et al. 2000; Gross et al. 2000; Wall et al. 2000; Yarbrough et al. 2001). Bei dieser Reaktion entsteht ein Acylimin, dessen Doppelbindung zum $\pi$-Elektronensystem beiträgt und es über den Fünfring hinaus erweitert (Abbildung $6 \mathrm{c}$ ). Der Mechanismus dieser Reaktion ist derzeit noch nicht bekannt, ein grün fluoreszierendes Faltungsintermediat von DsRed zeigt jedoch, dass die Reaktion unabhängig und nach der Bildung des grün fluoreszierenden Chromophors stattfindet (Gross et al. 2000).

Durch die Entwicklung des in der Fluoreszenz noch weiter rotverschobenen Proteins mPlum ist das Spektrum der FPs mittlerweile auf etwa $650 \mathrm{~nm}$ bis in den nahen Infrarotbereich ausgedehnt (Wang et al. 2004). Das Fluoreszenzmaximum von mPlum liegt bei $649 \mathrm{~nm}$, obwohl es wie auch die anderen rot fluoreszierenden Proteine bei 590-600 nm angeregt wird. Die Ursache für diese sehr große Stokesverschiebung von mPlum wird der Flexibilität der Chromophorumgebung zugeschrieben (Abbyad et al. 2007). 
Das zurzeit wohl am häufigsten verwendete rot fluoreszierende FP ist mCherry, welches ebenfalls von der monomeren Variante mRFP1 abstammt. Es ist mit einer Quantenausbeute von 0,22 noch relativ hell und zeigt eine gute Photostabilität (Campbell et al. 2002). Ein kürzlich entwickeltes Protein, TagRFP-T, wurde bezüglich des Bleichverhaltens optimiert und ist bei einer Quantenausbeute von 0,41 zusätzlich um den Faktor 3 stabiler gegenüber Photobleichen (Merzlyak et al. 2007; Shaner et al. 2008).

\section{III.2.4 Blau fluoreszierende Proteine}

GFP ähnliche blau fluoreszierende Proteine wurden in der Natur bisher nicht gefunden. Dennoch wurden zwei Möglichkeiten entdeckt, wie die Fluoreszenz GFP homologer Proteine in den blauen Spektralbereich verschoben werden kann.

Obwohl das Tyrosin als zweite Chromophoraminosäure in allen natürlich vorkommenden FPs konserviert ist, ist es für die autokatalytischen Reaktionen nicht essentiell. Im Gegensatz zu Glycin, der dritten Aminosäure des Chromophors, kann das Tyrosin durch andere Aminosäuren wie Phenylalanin, Histidin oder Tryptophan ersetzt werden, ohne dass die Bildung des Chromophors beeinträchtigt wird. Die dadurch entstehenden Chromophore haben blauverschobene Absorptions- und Emissionsspektren (Heim et al. 1994; Wachter et al. 1997). Ein Austausch der Aminosäure Tyrosin im Chromophor führt zu einem kleineren $\pi$ Elektronensystem. Bei dem cyan fluorescent protein (CFP) befindet sich anstelle des Tyrosins ein Tryptophan, bei dem blue fluorescent protein (BFP) ein Histidin (Heim et al. 1994; Ormo et al. 1996). Die Aminosäuren Tryptophan und Histidin sind beide in der Lage das Chromophorsystem des Fünfrings zu erweitern, allerdings in geringerem Maße als dies durch die Phenolatgruppe des Tyrosins geschieht. Dadurch ist die Absorption der Chromophore in den UV-Bereich verschoben. Dies führt im Falle von BFP zu einer blauen (448 nm), im Falle von CFP zu einer blau-grünen (478 nm) Emission. 


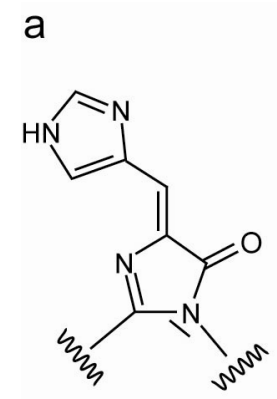

EBFP

Chromophor b

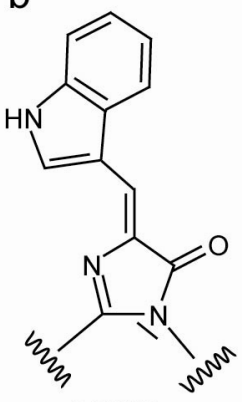

ECFP

Chromophor
C<smiles>CCC1=N/C(=C\c2ccc(O)cc2)C(=O)N1CC</smiles>

mKalama

Chromophor

Abbildung 7: Chromophore blau fluoreszierender Proteine. Die Strukturen in (a) und (b) zeigen die Chromophorsysteme von EBFP und ECFP. Bei EBFP wird das $\pi$-Elektronensystem durch ein Histidin, bei ECFP durch ein Tryptophan erweitert. Bei mKalama wird der Chromophor durch seine Umgebung in eine protonierte Form gezwungen, so dass eine Abgabe des Protons nicht mehr möglich ist.

Eine andere Möglichkeit blaue Fluoreszenz zu erzeugen wurde bei der Entwicklung des Proteins mKalama verwirklicht. Der Hydroxyphenylring liegt bei GFP in einem Gleichgewicht zwischen der protonierten und deprotonierten Form vor. Die Absorptionsmaxima liegen bei etwa $400 \mathrm{~nm}$ für eine protonierte und $485 \mathrm{~nm}$ für eine deprotonierte Hydroxylgruppe am Chromophor (Haupts et al. 1998). Es wäre zu erwarten, dass eine Anregung bei $400 \mathrm{~nm}$ zur Fluoreszenz im blauen Spektralbereich führt. Dies ist jedoch nicht der Fall, da ein angeregter protonierter Hydroxyphenylring ein Proton abgibt sofern dies möglich ist. Dadurch wird das $\pi$-Elektronensystem vergrößert und die Fluoreszenz erfolgt aus dem angeregten deprotonierten Zustand, also im grünen Spektralbereich (Brejc et al. 1997; Palm et al. 1997). Ein solcher Vorgang wird als excited state proton transfer (ESPT) bezeichnet. Im Fall von GFP ist ein Protonenakzeptor durch die Aminosäure Glu 222 gegeben. Der Austausch von Glutamat zu Glutamin (E222Q) führt dazu, dass kein ESPT mehr möglich ist (Stoner-Ma et al. 2008). Der ESPT kann jedoch durch den Austausch von Histidin an Position 148 gegen Glutamat wieder hergestellt werden. Das Histidin liegt ebenfalls nahe an der Hydroxylgruppe des Chromophors, so dass es in diesem Fall als Akzeptor für das Proton dienen kann (Shi et al. 2007; Stoner-Ma et al. 2008).

Mit einer EGFP Variante, welche die Mutationen T65S, H148G, T203V und S205V trägt, gelang es Ai et al. den ESPT zu unterbinden und das blau fluoreszierende Protein mKalama $\mathrm{zu}$ generieren. In mKalama ist kein Akzeptor für das Proton an der Hydroxyphenylgruppe mehr vorhanden, deshalb bleibt es auch nach der Anregung im protonierten Zustand und emittiert im blauen Spektralbereich (Ai et al. 2007). 
Wie an diesem Beispiel zu erkennen ist, kann die Wellenlänge der Fluoreszenz auch durch die Umgebung des Chromophors beeinflusst werden. Wie bei allen bisher angesprochenen farblichen Variationen in der Klasse fluoreszierender Proteine ist jedoch auch bei mKalama ein direkter Einfluss auf die chemische Beschaffenheit des Chromophors für die Änderung des Spektrums verantwortlich. Die exakte Farbe wird aber auch durch elektrostatische und hydrophobe Wechselwirkungen mit der Umgebung des Chromophors bestimmt. Obwohl der Chromophor seine chemischen Eigenschaften beibehält, führen diese Wechselwirkungen zu geringfügigen Veränderungen in den Absorptions- und Emissionsspektren, die eine enorme Vielfalt der Farbgebung ermöglicht.

\section{III.2.5 Die spektrale Vielfalt der fluoreszierenden Proteine}

Obwohl die Anzahl chemisch unterschiedlicher Chromophore auf einige wenige beschränkt ist, wird mittlerweile nahezu das komplette Spektrum im sichtbaren Bereich von ihnen abgedeckt (Abbildung 8). Die Vielfalt dieses Farbspektrums ist möglich, weil Wechselwirkungen des Chromophors mit seiner Umgebung das $\pi$-Elektronensystem beeinflussen und auf diese Weise die Absorption und Emission verändern.

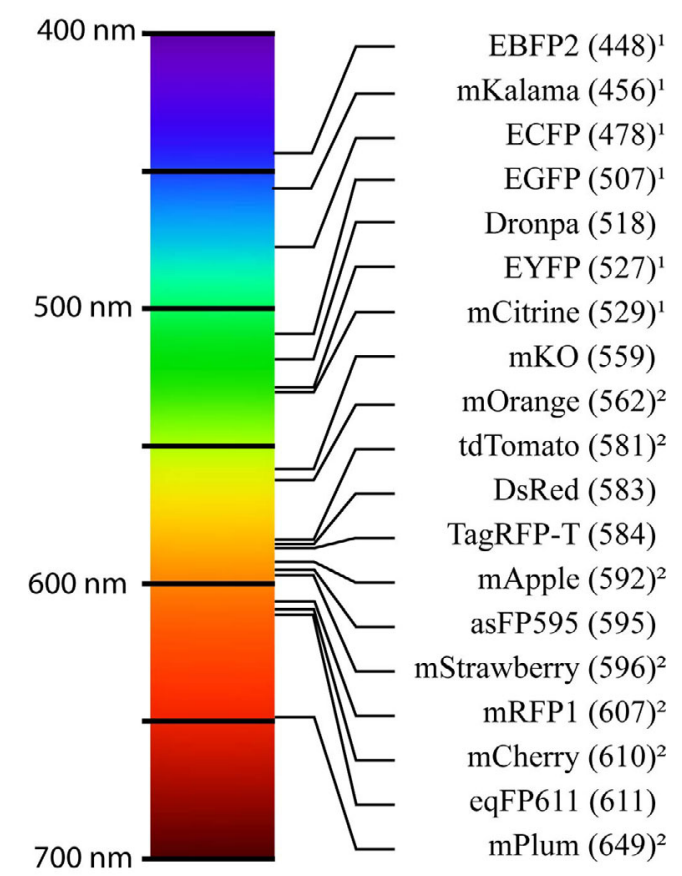

Abbildung 8: Sichtbares Farbspektrum mit fluoreszierenden Proteinen, die entsprechend ihrer Emissionswellenlänge zugeordnet sind. Eine 1 markiert die Proteine, die von GFP abgeleitet sind, eine 2 diejenigen, die von DsRed, bzw. mRFP1 abgeleitet sind. Abgesehen von den zwei reversibel schaltbaren Proteinen asFP595 und Dronpa, die weiter unten beschrieben werden ( $\rightarrow$ III.2.9), sind ausschließlich normale fluoreszierende Proteine aufgeführt. 
Der GFP-Chromophor zeigt allein durch Wechselwirkungen mit seiner Umgebung eine Variation in der Emissionswellenlänge zwischen $483 \mathrm{~nm}$ (dsFP483) und $529 \mathrm{~nm}$ (YFP) (Wachter et al. 1998; Matz et al. 1999; Malo et al. 2008). Bei YFP ist der Austausch von Threonin $203 \mathrm{zu}$ Tyrosin für die Rotverschiebung in der Emission verantwortlich. Die Mutation führt zu einer $\pi$-Stapelung des Tyrosins mit dem Chromophor. Auf diese Weise wird das $\pi$-Elektronensystem erweitert, so dass ein gelb fluoreszierendes Protein entsteht, welches chemisch jedoch den gleichen Chromophor wie GFP besitzt.

Bei der Verschiebung zu kürzeren Wellenlängen ist wahrscheinlich ebenfalls eine $\pi$ Stapelung verantwortlich, jedoch mit einem Histidin anstelle von Tyrosin. Allerdings ist in diesem Fall die Wirkungsweise nicht genau bekannt.

Veränderungen der Absorption und Emission werden ebenfalls bei organischen Chromophoren beobachtet, wenn sie sich in unterschiedlichen Lösungsmitteln befinden (Lakowicz 1999). Es ist also keine Überraschung, dass besonders geladene und polare Aminosäuren in der Nähe des Chromophors mit dem $\pi$-Elektronensystem interagieren und so einen starken Effekt auf die Absorptions- und Emissionsmaxima eines fluoreszierenden Proteins haben.

\section{III.2.6 Einfluss der Chromophorumgebung auf die Fluoreszenzeigenschaften}

Die Umgebung eines Chromophors beeinflusst jedoch nicht nur die Farbe der Fluoreszenz, sondern auch seine sonstigen Eigenschaften. Die Aminosäuren nahe des Chromophors sind für die Effizienz der Chromophorsynthese wichtig und bestimmen zusammen mit der Faltungseffizienz des gesamten Proteins, wie lange das Protein von dessen Synthese bis zur vollständigen Chromophorbildung benötigt (Maturierungszeit) (Bevis et al. 2002).

Weiterhin werden der Absorptionsquerschnitt, die Quantenausbeute und die Photostabilität des Chromophors durch die umgebenden Aminosäuren stark beeinflusst (Niwa et al. 1996). Die Photostabilität ist ein Maß dafür, wie häufig ein Chromophor angeregt werden kann, bevor es zerstört wird. Der Absorptionsquerschnitt bezeichnet die Häufigkeit, mit der ein Chromophor ein Photon absorbiert, während die Quantenausbeute bestimmt, wie häufig ein absorbiertes Photon in Form von Fluoreszenz wieder abgegeben wird.

Der Einfluss zeigt sich deutlich in einem Experiment, bei dem für einen synthetisierten GFPChromophor in wässriger Lösung eine wesentlich geringere Quantenausbeute als in der Proteinmatrix gemessen wurde (Niwa et al. 1996). Die Proteinmatrix stabilisiert das Chromophor, so dass das Fluoreszenzsignal stärker wird. 
Absorbiertes Licht kann entweder in Form eines Photons oder in Form von Wärme wieder an seine Umgebung abgegeben werden. Die strahlungsfreie Abgabe der Energie erfolgt über Bewegungen (Schwingungen und Drehungen), die an die Umgebung weitergeleitet werden. Ein gut stabilisiertes Chromophor ist somit ein besserer Emitter, als ein bewegliches Chromophor, welches die Energie wahrscheinlich häufiger in Form von Bewegungsenergie an seine Umgebung abgibt.

Bei einer Betrachtung der Strukturen verschiedener FPs sind bestimmte Eigenschaften des Chromophors für eine gute Quantenausbeute als wichtig identifiziert worden. So findet man in fast allen fluoreszierenden Proteinen die Chromophore in einer mehr oder weniger planaren cis-Konformation. Die bisher einzige Ausnahme stellt das Protein eqFP611 dar, bei dem der Chromophor zwar planar ist, allerdings in der trans-Konformation vorliegt. Im Gegenteil dazu zeigen alle bisher analysierten nicht fluoreszierenden Proteine eine nicht planare transKonformation des Chromophors. Der genaue Grund weshalb ein Chromophor in einem bestimmten Zustand fluoresziert oder nicht ist jedoch unbekannt.

\section{III.2.7 Zustände des Chromophors}

Der Chromophor kann je nach seiner Umgebung in unterschiedlichen Konformationen oder Protonierungszuständen vorliegen. Weiterhin sind durch die Absorption von Licht weitere höherenergetische Zustände zugänglich, die ebenfalls andere Eigenschaften aufweisen als dies im Grundzustand der Fall ist.

Sowohl der Imidazolring als auch der Hydroxyphenylring können protoniert oder deprotoniert vorliegen, wobei die Protonierung des Imidazolrings keinen bedeutenden Einfluss auf die Eigenschaften des Chromophors $\mathrm{zu}$ haben scheint. Die Protonierung der Hydroxyphenylgruppe dagegen führt zu einer Blauverschiebung der Absorption von etwa $100 \mathrm{~nm}$. Der Chromophor kann in einem anionischen (A), einem neutralen (N) oder in einem zwitterionischen (Z) Zustand vorliegen (Abbildung 9). 
cis-Konformation

(A)

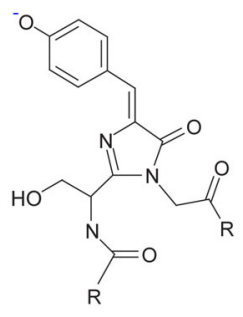

(N)

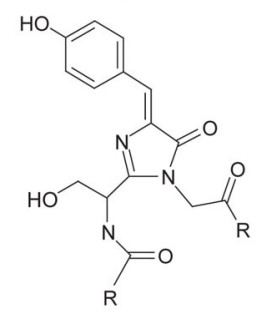

trans-Konformation

(A)

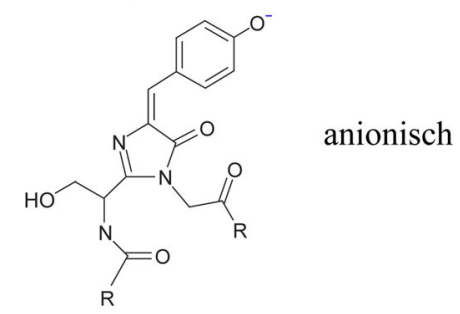

$(Z)$

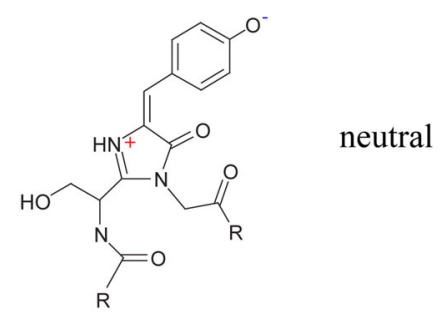

Abbildung 9: Die Grundzustände eines Chromophors. Die Ladung des Chromophors wird durch die Protonierung an zwei Positionen bestimmt. Erstens kann die Hydroxylgruppe protoniert oder deprotoniert vorliegen. Eine Protonierung an dieser Position führt zu einer Verschiebung des Absorptionsspektrums um etwa $100 \mathrm{~nm}$ zu kürzeren blauen Wellenlängen. Die Ladung wird von der Umgebung des Chromophors bestimmt und ist somit unabhängig von einer cis- oder transKonformation des Hydroxyphenylrings. Im Gegensatz dazu führt die Protonierung am Imidazolring nicht zu einer deutlichen Änderung des Spektrums und ist stark in der trans-Konformation bevorzugt.

Die Ladung des Chromophors scheint jedoch hauptsächlich für die Farbgebung verantwortlich zu sein, während die Konformation einen großen Einfluss auf die Quantenausbeute hat. Die Hydroxyphenylgruppe kann in cis- oder trans-Konformation vorliegen. Wie bereits in Abschnitt III.2.6 erwähnt, scheint eine cis-Konformation Fluoreszenz zu fördern, während eine trans-Konformation meist $\mathrm{zu}$ einem nicht fluoreszierenden Chromophor führt (die einzige bekannte Ausnahme ist der transChromophor des Proteins eqFP611).

Die cis-Konformation beeinflusst den Chromophor jedoch auch in seiner Protonierung, weil durch eine sterische Hinderung mit dem Imidazolring eine Protonierung des Stickstoffs am Imidazolring ungünstig ist.

Die höher energetischen Zustände sind aufgrund ihrer Kurzlebigkeit schwerer zu erfassen. Die Bindungen des Chromophors sind im ersten angeregten Zustand $\mathrm{S}_{1}$ labiler, so kann zum Beispiel um Doppelbindungen gedreht werden (Voityuk et al. 1998; Weber et al. 1999). Weiterhin scheint eine protonierte Hydroxyphenylgruppe im $\mathrm{S}_{1}$ Zustand energetisch ungünstig, da der Chromophor im angeregten protonierten Zustand, häufig über einen ESPT 
deprotoniert wird. Aufgrund der hohen Energie der Zustände $\mathrm{S}_{1}$ und $\mathrm{T}_{1}$ kann aus diesen ebenfalls das Photobleichen, die Zerstörung eines Chromophors stattfinden (Abbildung 1).

Neben dem Bleichen, einer irreversiblen Reaktion die zur Zerstörung des Chromophors führt, gibt es auch noch weitere durch Absorption hervorgerufene irreversible Reaktionen, die zu einer gezielten Veränderung der Absorptions- und Emissionseigenschaften in dem Protein führen. Diese Reaktionen finden jedoch nicht aus dem angeregten Zustand statt und werden im nächsten Abschnitt näher erläutert.

\section{III.2.8 Photoaktivierbare Proteine}

Ein photoaktivierbares Protein zeichnet sich dadurch aus, dass es durch Bestrahlung mit Licht einer bestimmten Wellenlänge irreversibel in einen Zustand geschaltet werden kann, der sich in der Absorption oder Emission vom Grundzustand unterscheidet. Für GFP wurde eine Aktivierung in sauerstofffreier Umgebung beschrieben, die dazu führt, dass GFP im roten Spektralbereich fluoresziert (Elowitz et al. 1997; Jakobs et al. 2003). Das erste speziell entwickelte photoaktivierbare fluoreszierende Protein ist eine Variante von GFP, das Protein pa-GFP. (Patterson et al. 2002) Bei diesem liegt der Chromophor vollständig im protonierten, neutralen Zustand vor, welcher Licht bei $400 \mathrm{~nm}$ absorbiert. Diese neutrale Form kann jedoch durch Bestrahlung mit Licht von etwa $400 \mathrm{~nm}$ irreversibel in einen anionischen Zustand konvertiert werden. Die ausschlaggebende chemische Modifikation ist eine Decarboxylierung der Aminosäure Glu222, welche dazu führt, dass der anionische Chromophor im Protein stärker stabilisiert wird als der neutrale. Das Gleichgewicht verschiebt sich daher zu Gunsten der deprotonierten Hydroxyphenylgruppe und die Absorptionsbande bei $490 \mathrm{~nm}$ steigt an. Ein Vergleich der grünen Fluoreszenz $(512 \mathrm{~nm})$ bei Anregung mit $488 \mathrm{~nm}$ vor und nach der Photoaktivierung zeigt eine Steigerung um den Faktor 100 (Patterson et al. 2002).

Eine ähnliche Art der Photoaktivierung mit UV-Licht wurde bei Kaede beobachtet und untersucht. Kaede ist ein grün fluoreszierendes Protein, welches nach Bestrahlung mit UVLicht eine Verschiebung der Absorption und Emission in den roten Spektralbereich zeigt (Ando et al. 2002). Die Aktivierung führt ebenfalls zu einer irreversiblen, chemischen Veränderung, einem Bruch des Proteinrückgrats durch eine $\beta$-Eliminierung (Abbildung 6d). Durch die Eliminierung entsteht eine Doppelbindung zwischen dem $C_{a}$ und dem $C_{B} \operatorname{der}$ ersten Aminosäure des Chromophors (Hayashi et al. 2007). Da bei Kaede diese Aminosäure ein Histidin ist, wird das $\pi$-Elektronensystem des Chromohpors durch den Bruch des Proteinrückgrats vergrößert (Abbildung 6d). 
Bei all diesen Proteinen wird eine irreversible Reaktion durch Bestrahlung mit UV-Licht hervorgerufen, die die Absorptions- und Emissionseigenschaften verändert. Im Gegensatz dazu gibt es jedoch auch die reversibel schaltbaren fluoreszierenden Proteine (RSFPs), die im Rahmen dieser Doktorarbeit untersucht und im nächsten Abschnitt vorgestellt werden.

\section{III.2.9 Reversibles Schalten in fluoreszierenden Proteinen}

Das irreversible Schalten fluoreszierender Proteine basiert immer auf einer chemischen Modifikation, die meist durch hochenergetisches Licht (UV-Licht) hervorgerufen wird. Im Gegensatz dazu wurde im Jahr 2000 von Konstantin Lukyanov das fluoreszierende Protein asFP595 beschrieben, welches mit grünem Licht aus einem nicht fluoreszierenden in einen fluoreszierenden Zustand überführt werden kann (Lukyanov et al. 2000). Das Protein ist in diesem Zustand für wenige Sekunden stabil, kann aber mit Licht der Wellenlänge $450 \mathrm{~nm}$ wieder in den nicht fluoreszierenden Grundzustand gebracht werden (Abbildung 10). Für ein solches reversibles Schalten mit Licht ist eine chemische Modifikation des Chromophors äußerst unwahrscheinlich.
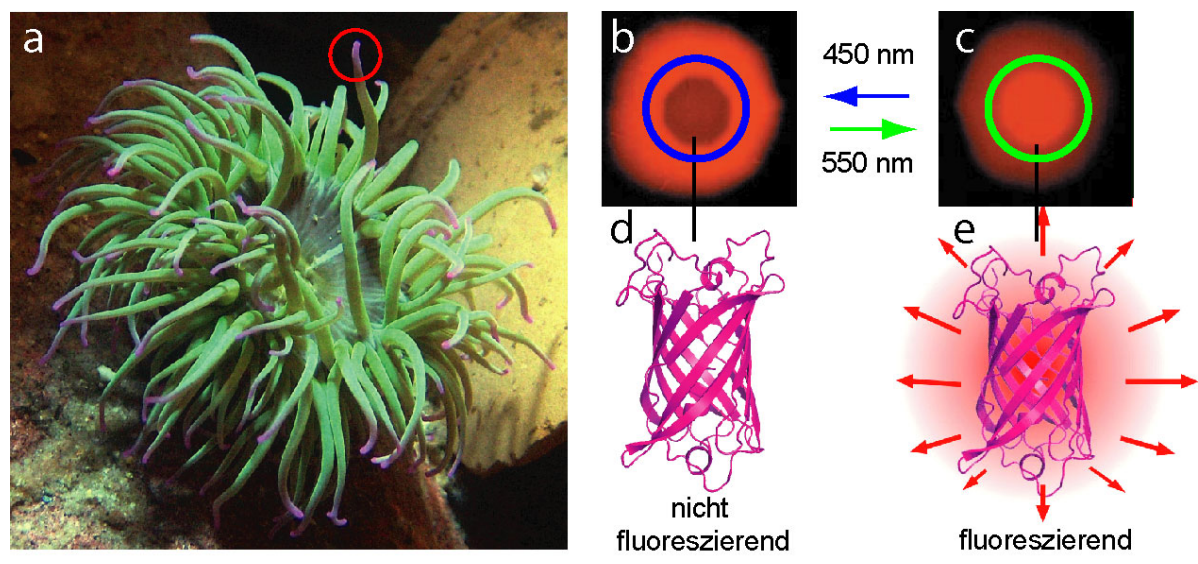

Abbildung 10: Bild (a) zeigt die Seeanemone Anemonia sulcata, in deren Tentakelspitzen das Protein asFP595 exprimiert wird. Die beiden Fluoreszenzaufnahmen von E.coli-Kolonien (b,c), wurden in dem markierten Bereich in der Koloniemitte mit Licht der Wellenlänge $450 \mathrm{~nm}$ und $550 \mathrm{~nm}$ belichtet (Lukyanov et al. 2000). Darunter (d,e) sind die jeweiligen Zustände des Proteins im fluoreszierenden bzw. nicht fluoreszierenden Zustand dargestellt.

Von GFP ist bekannt, dass es in einen kurzlebigen Dunkelzustand übergehen und anschließend wieder fluoreszieren kann (Dickson et al. 1997). Dieses so genannte „Blinken“ wird durch die Anregung hervorgerufen. Einzelmolekülstudien zeigten, dass es zwei Dunkelzustände gibt, einen kurzen mit einer Lebensdauer von etwa $50 \mathrm{~ms}$ und einen langlebigen mit einer Halbwertszeit von etwa $30 \mathrm{~s}$ (Peterman et al. 1999). Im Falle dieses 
Blinkens von GFP wurde vermutet, dass der Chromophor von der fluoreszierenden anionischen in eine nicht fluoreszierende zwitterionische Form wechselt (Weber et al. 1999) (Abbildung 9). Experimente bei verschiedenen $\mathrm{pH}-$ Werten zeigten allerdings, dass der $\mathrm{pH}$ Wert keinen Einfluss auf das Blinkens hat. Deshalb wurde angenommen, dass eine Photoisomerisierung des Chromophors den Ausschlag für den Übergang in den Dunkelzustand gibt (Peterman et al. 1999).

Bei GFP ist dieses Schalten jedoch ein nicht kontrollierbarer, zufälliger Prozess, während bei asFP595 ein quantitatives Schalten der Proteine möglich ist. Dadurch ist asFP595 das erste Protein, das als reversibel schaltbares fluoreszierendes Protein (RSFP) bezeichnet werden kann. Dieses Schalten soll im Rahmen dieser Doktorarbeit erforscht werden.

Im Verlauf dieser Doktorarbeit entdeckte die Arbeitsgruppe von A. Miyawaki das RSFP Dronpa (Ando et al. 2004). Dronpa stammt aus einem Protein in dem Organismus Echinophyllia spec., liegt als Monomer vor und weist eine starke grüne Fluoreszenz auf. Außerdem wurden die beiden Zwischenprodukte mTFP0.7 und mApple0.5, die bei der Entwicklung von mTFP1 und mApple auftraten, als eingeschränkt reversibel schaltbar identifiziert (Henderson et al. 2007; Shaner et al. 2008). mApple ist ein rot fluoreszierendes Protein, während mTFP0.7 ein cyan fluoreszierendes Protein ist.

Die reversibel schaltbaren FPs haben ein großes Potential in Bezug auf protein-tracking, im Bereich hochauflösender Mikroskopie, sowie dem Verständnis fluoreszierender Proteine im Allgemeinen. Besonders für die hochauflösende Mikroskopie sind die reversibel schaltbaren FPs von großer Bedeutung, da für diese Methoden das Ein- bzw. Ausschalten der Fluoreszenz essentiell ist. 


\section{III.3 Motivation und Ziele}

Seit GFP 1994 erstmals als Markierung für andere Proteine eingesetzt wurde, hat die Nutzung fluoreszierender Proteine auf nahezu alle Bereiche der biologischen und medizinischen Grundlagenforschung ausgedehnt. Die Erforschung und das Verständnis der fluoreszierenden Proteine in den folgenden Jahren hat eine Entwicklung verbesserter fluoreszierender Proteine ermöglicht, die ihrerseits neue Möglichkeiten zur Untersuchung lebender Zellen geschaffen haben.

Die kürzlich entdeckten reversibel schaltbaren fluoreszierenden Proteine (RSFPs) zeigen die einzigartige Eigenschaft des reversiblen Schaltens zwischen einem fluoreszierenden und einem nicht fluoreszierenden Zustand mit Licht. Aufgrund dieser Eigenschaft sollten sie neue Möglichkeiten für bestehende Methoden wie z.B. das protein-tracking erlauben. Die RSFPs sollten aufgrund ihrer Eigenschaften allerdings ebenfalls für die hochauflösende Fluoreszenzmikroskopie geeignet sein und könnten daher völlig neue Einblicke in die Vorgänge lebender Zellen auf einer Ebene jenseits der Beugungsgrenze des Lichts erlauben.

Das Ziel dieser Doktorarbeit war daher die Aufklärung des molekularen Mechanismus, welcher dem reversiblen Schalten dieser Proteine zugrunde liegt. Anschließend sollten verbesserte RSFPs entwickelt und in der Fluoreszenzmikroskopie angewandt werden. 


\section{Ergebnisse}

\section{IV.1 Untersuchung des Schaltmechanismus von asFP595}

\section{IV.1.1 Das Protein asFP595, ein reversibel schaltbares fluoreszierendes Protein:}

Eine neue Klasse von Fluoreszenzproteinen kann von einem fluoreszierenden in einen nicht fluoreszierenden Zustand und umgekehrt geschaltet werden. Dieses Ein- bzw. Ausschalten ist reversibel und wird mit Licht induziert. Das reversibel schaltbare fluoreszierende Protein (RSFP) asFP595 ist im Grundzustand nicht fluoreszierend. Es wird durch Beleuchtung mit grünem Licht $(\sim 550 \mathrm{~nm})$ in den fluoreszierenden Zustand gebracht und dort gleichzeitig auch angeregt. Eine konstante Bestrahlung mit grünem Licht bewirkt somit einen Anstieg des Fluoreszenzsignals (Abbildung 1). Das Ausschalten in den nicht fluoreszierenden Zustand wird durch blaues Licht $(\sim 450 \mathrm{~nm})$ induziert. Diese Kinetik ist wesentlich schneller, weshalb bei gleichzeitiger Bestrahlung mit grünem und blauem Licht effektiv ausgeschaltet werden kann (Abbildung 1).

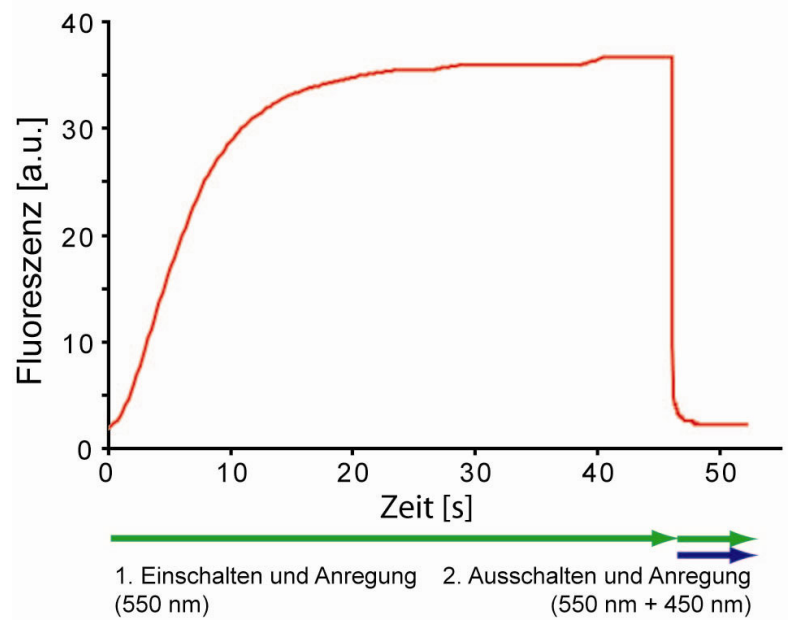

Abbildung 1: Reversibles Schalten einer asFP595 exprimierenden E.coli-Kolonie: Zuerst (Schritt 1) wurde die Kolonie für $46 \mathrm{~s}$ mit Licht der Wellenlänge $550 \mathrm{~nm}$ belichtet, wobei asFP595 komplett eingeschaltet und die Fluoreszenz angeregt wurde. Anschließend wurde für $6 \mathrm{~s}$ mit Licht der Wellenlängen 550 und $450 \mathrm{~nm}$ belichtet, so dass das Protein bei gleichzeitigem Auslesen der Fluoreszenz ausgeschaltet wurde. 


\section{IV.1.2 Kristallisierung von asFP595}

Im Rahmen dieser Doktorarbeit sollte der Schaltmechanismus von RSFPs untersucht werden, um anschließend RSFPs mit verbesserten Eigenschaften zu generieren und einzusetzen. Um etwas über den Mechanismus des Schaltens in asFP595 herauszufinden, sollte zunächst dessen Struktur aufgeklärt werden. Dazu wurde das Protein mit Hilfe des Plasmids pQE30 in dem E.coli Stamm HMS exprimiert ( $\rightarrow$ IX.1.1.1). Auf dem Plasmid befindet sich außerdem noch eine Sequenz, die für sechs Histidine kodiert und im 5'-Bereich von asFP595 liegt. Nach Expression und Zellaufschluss, konnte das Protein über die Affinität dieser Histidine zu Nickel durch eine Ni-NTA-Säule von dem Zelllysat getrennt werden. Anschließend wurde das Protein über eine Gelfiltrationssäule (HiLoad26/60 Superdex 200; Pharmacia, Upsala, Schweden) gegeben, um Verunreinigungen mit anderen Proteinen über eine Größentrennung zu entfernen. Das auf diese Weise gewonnene Protein wurde zur Kristallisierung eingesetzt. Die asFP595-Kristalle wuchsen mit einem Reservoir in dem 20 \% PEG 3350, 0,2 M Tris HCl pH 7,1 und 0,3 M NaCl vorhanden waren. Das Protein wurde 1:1 mit der Reservoir-Lösung gemischt und anschließend für die Kristallisierung versiegelt. Für die Röntgenstrukturanalyse, die in Zusammenarbeit mit der Gruppe von Markus Wahl durchgeführt wurde, wurden die Kristalle in das Öl Perfluoropolyether überführt, tiefgefroren und in einem Strom aus flüssigem Stickstoff (Cryostream 700 series, Oxford Cryosystems, Oxford) bei 100 Kelvin an dem Synchrotron in Hamburg gemessen (Deutsches Elektronen Synchrotron, Hamburg, Germany). Die Struktur wurde mit Hilfe von „molekularem Ersetzen“ (Molecular Replacement) der Struktur von eqFP611 gelöst (Petersen et al. 2003) (PDB ID: 1uis). Die Struktur des Proteins asFP595 wurde mit einer Auflösung von 1,3 $\AA$ bestimmt (PDB ID: 2a50). Das Chromophor des Proteins wurde als eventuell bewegliche Gruppe bei der Verfeinerung erst ganz am Ende in die Elektronendichte eingesetzt, um den Einfluss des Modells (EqFP611) möglichst gering zu halten.

Der Aufbau des Proteins entspricht dem aller GFP-ähnlichen fluoreszierenden Proteine. Die Struktur des Proteins asFP595 zeigt ein elfsträngiges Fass aus B-Faltblättern, durch dessen Mitte vertikal von oben nach unten eine Helix verläuft. Weiterhin ist zu erkennen, dass das Molekül als Tetramer vorliegt (Abbildung 2). Die vertikale Helix beinhaltet in der Mitte des gesamten Moleküls, gut geschützt, das Chromophor (Abbildung 2). Dieses wird autokatalytisch aus den drei Aminosäuren Methionin, Tyrosin und Glycin gebildet und liegt in einer nicht planaren trans-Konformation vor, welche typisch für nicht fluoreszierende Proteine ist. 

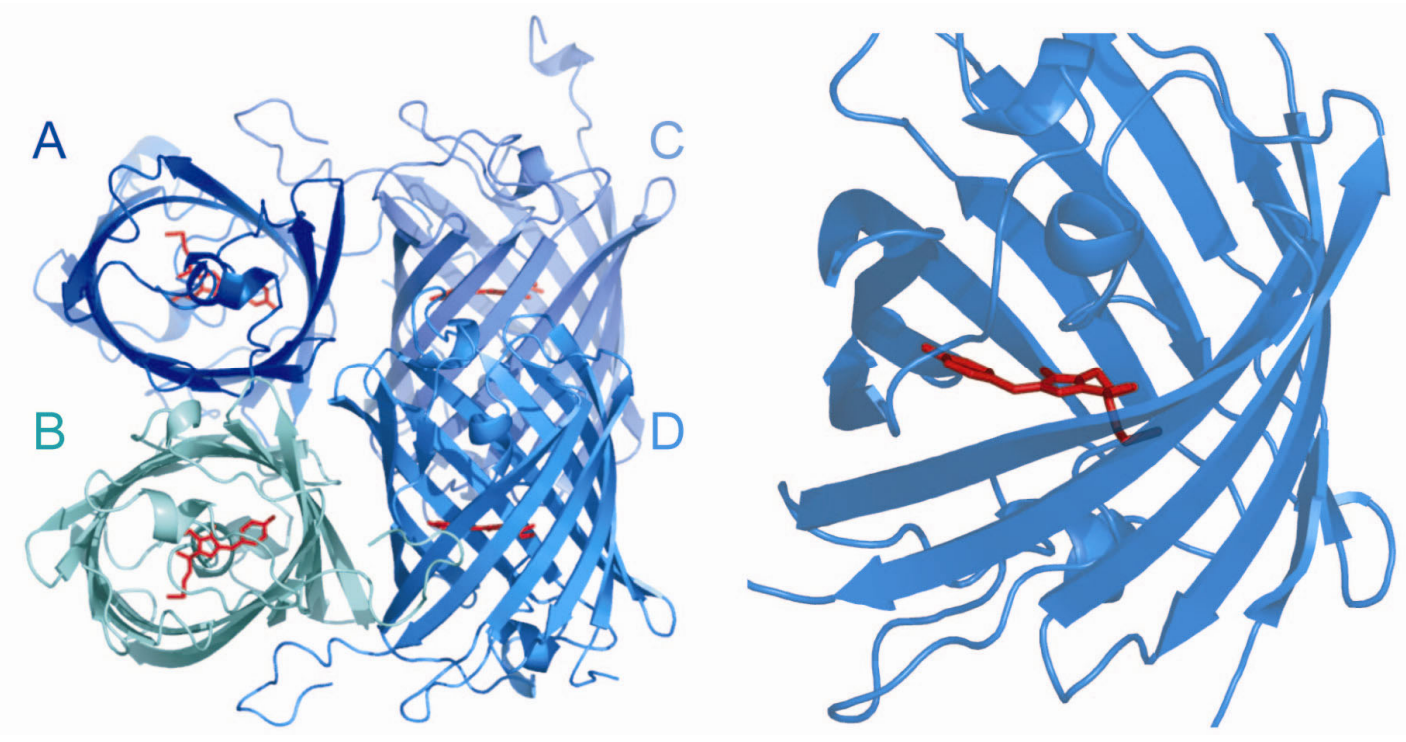

Abbildung 2: Übersicht der Struktur von asFP595 im Grundzustand. Links sind die vier Untereinheiten des Tetramers A bis D dargestellt, rechts die Lage des Chromophors. Das Chromophor nimmt deutlich sichtbar eine nicht planare Konformation ein.

Die asFP595 Struktur zeigt das Protein im Grundzustand, welcher der nicht fluoreszierende Zustand ist. Um eine Idee der Funktionsweise des Schaltens zu bekommen, ist es notwendig, die Strukturen des nicht fluoreszierenden und fluoreszierenden Zustands zu vergleichen. Aus diesem Grund sollte ebenfalls der fluoreszierende Zustand untersucht werden. Allerdings ist asFP595 dafür schlecht geeignet, da das Protein nach dem Einschalten sehr dunkel ist. Dies bedeutet, dass eventuell nicht alle Proteine gleichzeitig eingeschaltet werden können. Wichtiger ist jedoch, dass es bei $22^{\circ} \mathrm{C}$ mit einer Halbwertszeit von nur sechs Sekunden in seinen Grundzustand zurückfällt. Um die Struktur im fluoreszierenden Zustand zu bestimmen, wurde daher nach Mutanten gesucht, welche nach dem Einschalten in dem fluoreszierenden Zustand für längere Zeit stabil waren.

\section{IV.1.3 Die asFP595-Varianten S158V und A143S}

Bei einer Zufallsmutagenese auf dem Protein asFP595 wurden zwei Mutanten mit deutlich stabilisiertem fluoreszierenden Zustand identifiziert, die bereits als wesentlich hellere Varianten von asFP595 beschrieben wurden (Chudakov et al. 2003). Die Mutante S158V befindet sich im Grundzustand in der fluoreszierenden Form und lässt sich kaum ausschalten (Abbildung 3). Die Mutante A143S dagegen lässt sich nahezu vollständig in einen nicht fluoreszierenden Zustand schalten. Bei $22^{\circ} \mathrm{C}$ wurde die Halbwertszeit $\mathrm{t}_{1 / 2}{ }^{\text {relax }}$ für asFP595A143S auf $80 \mathrm{~s}$ und für asFP595 auf $6 \mathrm{~s}$ bestimmt. 


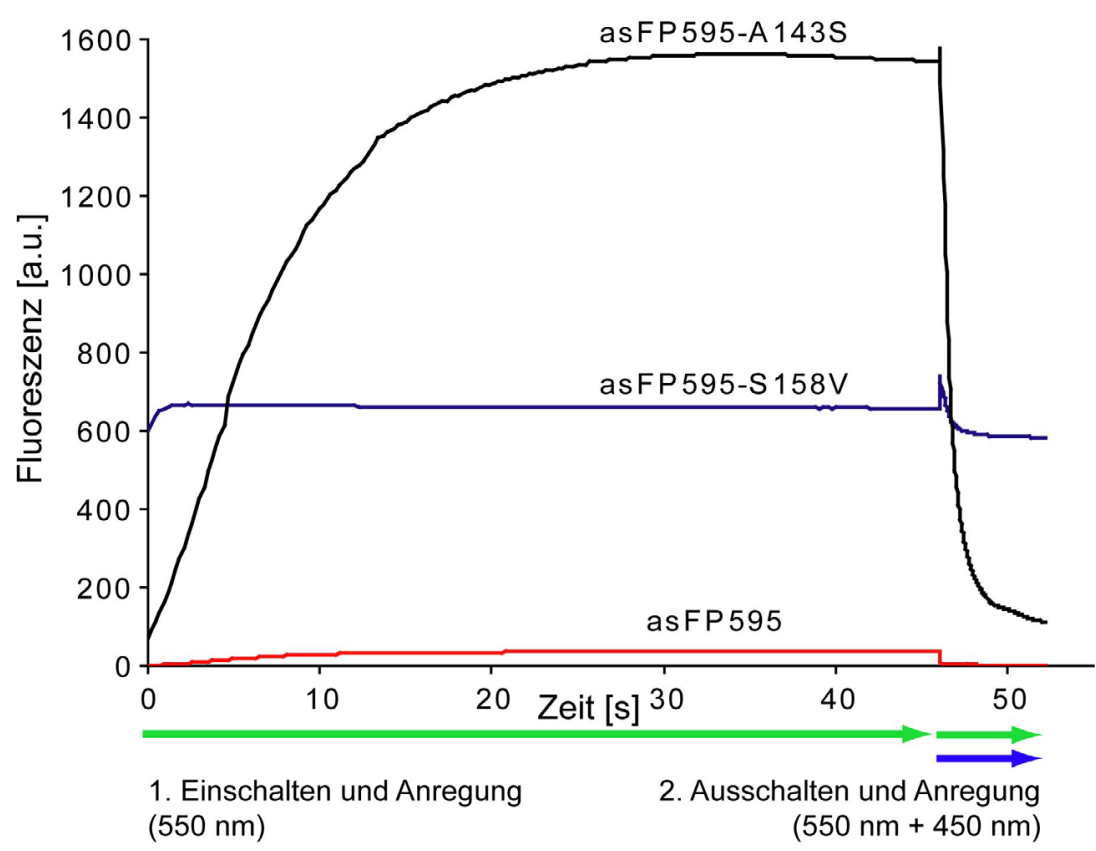

Abbildung 3: Schaltkurven von asFP595, asFP595-A143S und asFP595-S158V. Ganze E.coliKolonien wurden zuerst (Schritt 1) für $46 \mathrm{~s}$ mit Licht der Wellenlänge $550 \mathrm{~nm}$ belichtet, anschließend wurde für $6 \mathrm{~s}$ mit Licht der Wellenlängen 550 und $450 \mathrm{~nm}$ belichtet (46 s grün; $6 \mathrm{~s}$ grün und blau). Während asFP595 und asFP595-A143S gut schaltbar sind, kann asFP595-S158V kaum geschaltet werden, und befindet sich quasi immer im angeschalteten Zustand. Weiterhin sind die beiden Mutanten deutlich heller.

Eine Struktur der Mutante asFP595-S158V wird definitiv den fluoreszierenden Zustand des Proteins zeigen, während mit der Variante asFP595-A143S aufgrund der hohen Stabilität sogar beide Zustände dargestellt werden könnten. Eine Strukturanalyse beider Mutanten sollte Aufschluss über den Schaltmechanismus des reversibel schaltbaren fluoreszierenden Proteins asFP595 geben.

\section{IV.1.4 Die Struktur der Mutante asFP595-S158V}

Die Kristalle von asFP595-S158V waren, ebenso wie das Protein in Lösung fluoreszierend und wuchsen bei ähnlichen Bedingungen wie die von asFP595. Für die anschließende Strukturanalyse wurde die asFP595 Struktur für das „molekulare Ersetzen“ verwendet. Die Berechnung der asFP595-A158V Struktur erfolgte abgesehen davon homolog zu derjenigen von asFP595.

Die resultierende Struktur der fluoreszierenden Mutante asFP595-S158V (PDB ID: 2a52) zeigt außer der Mutation nur eine weitere deutliche Veränderung. Das Chromophor befindet sich im Gegensatz zu dem von asFP595 in der cis-Konformation. Bei einem $\mathrm{C}_{\alpha}$-Abgleich der 
Strukturen von asFP595-S158V und asFP595 wird deutlich, dass die nicht fluoreszierende trans-Konformation des Chromophors aufgrund der Größe und Lage von Val158 sterisch blockiert ist (Abbildung 4). Der Chromophor von asFP595-S158V nimmt daher die cisKonformation ein. Die fluoreszierende asFP595 Variante mit der Mutation S158V ist also durch ein Chromophor in der cis-Konformation ausgezeichnet.

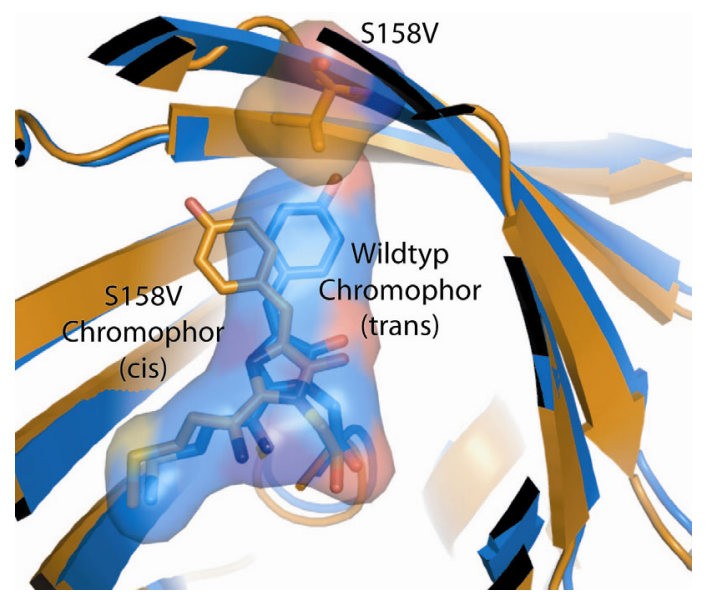

Abbildung 4: $C_{a}$ Abgleich der Strukturen asFP595 und asFP595-S158V. Die Oberflächen von Valin an Position 158, sowie der Chromophor des asFP595-Proteins sind transparent dargestellt. Die Aminosäure Valin an Position 158 liegt in dem Bereich, der vorher von dem trans-Chromophor beansprucht wurde. Die Mutation S158V zwingt den Chromophor in eine cis-Konformation.

Dies ist ein Hinweis darauf, dass der fluoreszierende Zustand von asFP595 Proteins ebenfalls einen cis-Chromophor aufweist. Da die Mutante asFP595-S158V jedoch nicht schaltbar ist, lässt sich nicht eindeutig auf einen Mechanismus für das Schalten von asFP595 schließen.

Um sowohl die Struktur des fluoreszierenden als auch des nicht fluoreszierenden Zustandes an dem gleichen Protein zu bestimmen, wird ein Protein benötigt, das in beiden Zuständen stabil vorliegt. Die Variante asFP595-A143S weist in ihrem Grundzustand ein Gleichgewicht zwischen dem fluoreszierenden und dem nicht fluoreszierenden Zustand auf. Das thermodynamische Gleichgewicht bei $22^{\circ} \mathrm{C}$ liegt dabei stark auf der nicht fluoreszierenden Seite, es sind mindestens 90\% aller asFP595-A143S Moleküle in einer E.coli-Kolonie im ausgeschalteten (nicht fluoreszierenden) Zustand. Die Mutante asFP595-A143S zeigt im angeschalteten Zustand eine stark erhöhte Fluoreszenz (Abbildung 3) und lässt sich bis zu einer Restfluoreszenz von 3,6 \% ausschalten. Dies deutet darauf hin, dass das Gleichgewicht zwischen dem fluoreszierenden und dem nicht fluoreszierenden Zustand nahezu vollständig $\mathrm{zu}$ jeder Seite verschoben werden kann. Weiterhin ist die Dauer, bis das Protein in seinen Grundzustand zurückgefallen ist, ca. 22-mal höher als bei asFP595: während asFP595 in etwa 
18 s vollständig in den Grundzustand zurück fällt, dauert dieser Vorgang bei asFP595-A143S etwa $400 \mathrm{~s}$.

Das Protein asFP595-A143S sollte aufgrund seiner Bistabilität ein optimaler Kandidat für die Bestimmung der Kristallstrukturen im fluoreszierenden und nicht fluoreszierenden Zustand sein. Um eine Aussage über den Mechanismus zu treffen, sollte jedoch sichergestellt werden, dass sich das Protein im Kristall genauso verhält wie in Lösung.

\section{IV.1.5 Funktionalität von asFP595-A143S im Kristall und in Lösung}

Zunächst wurde mit asFP595-A143S-Kristallen geprüft, ob das Protein in kristalliner Form noch reversibel schaltbar ist. Die Kristalle ließen sich bis zu einer Restfluoreszenz von etwa $5 \%$ ausschalten (Abbildung 5). Das Schalten war bis auf einen leichten Anstieg der Hintergrundfluoreszenz und ein Bleichen von etwa $1 \%$ pro Schaltzyklus vollständig reversibel. Der zeitliche Verlauf der Fluoreszenz, sowie die Abfolge der Kristallbilder belegen also, dass sich das Protein im Kristall genau so wie in Lösung reversibel schalten lässt. 
a

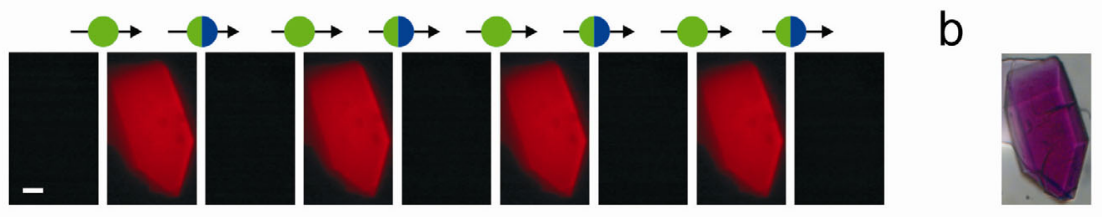

C

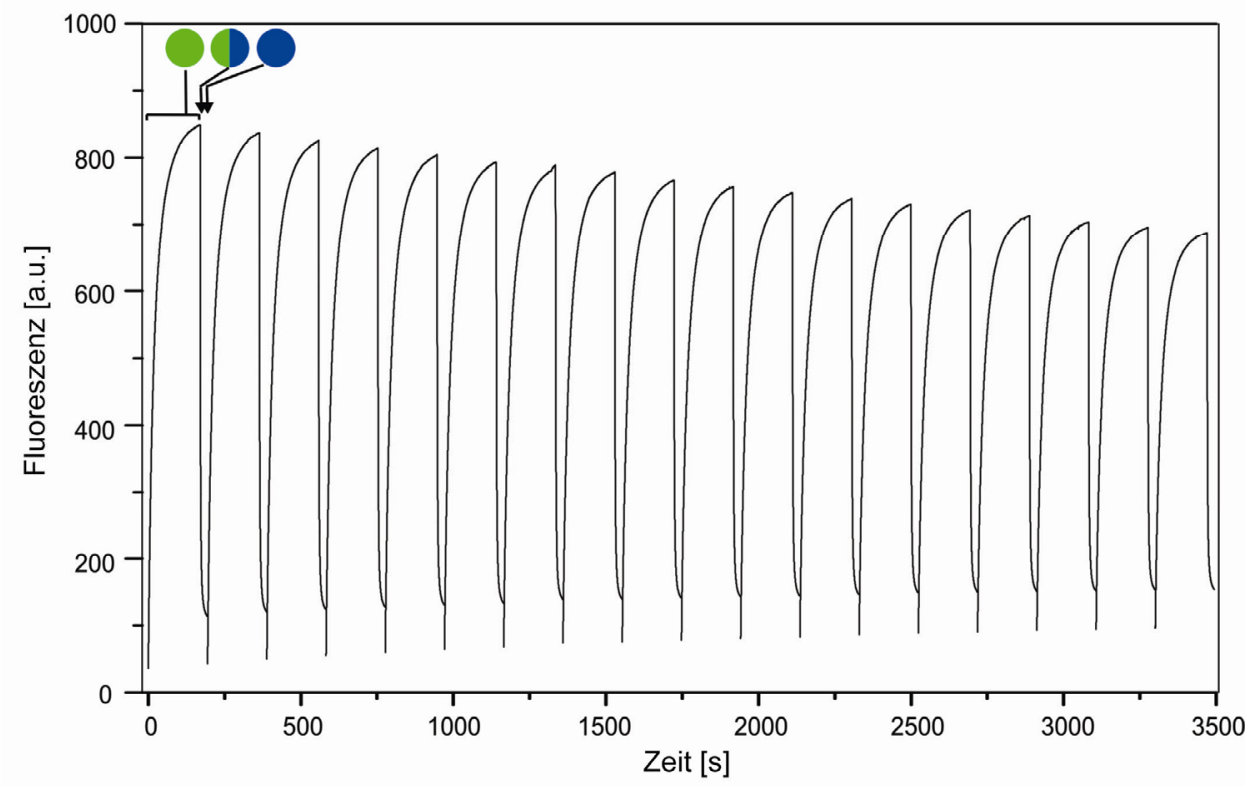

Abbildung 5: Reversibles Schalten eines asFP595-A143S Proteinkristalls. Der Kristall konnte mit grünem Licht $\left(550 \pm 20 \mathrm{~nm}, 50 \mathrm{~W} \cdot \mathrm{cm}^{-2}\right)$ eingeschaltet, und anschließend mit grünem und blauem (450 $\pm 20 \mathrm{~nm}, 3 \mathrm{~W} \cdot \mathrm{cm}^{-2}$ ) Licht wieder ausgeschaltet werden (a); Größenstandard $=20 \mu \mathrm{m}$. (b) Hellfeldbild des Kristalls im Grundzustand. In (c) sind 18 Schaltzyklen dargestellt, bei denen dieselben Intensitäten verwendet wurden, wie in (a). Die Belichtungssequenz für jeden der 18 Schaltzyklen begann mit grünem Licht für 170 Sekunden, gefolgt von grünem und blauem Licht für 24 Sekunden und abschließend blauem Licht für 1 Sekunde. Die Fluoreszenz wurde nur in den ersten beiden Schritten detektiert.

Um das natürliche Verhalten des Proteins asFP595-A143S noch genauer zu überprüfen, wurden die Halbwertszeiten der thermischen Relaxation in den Grundzustand $\left(t_{1} /{ }^{\text {relax }}\right)$ im Kristall und in Lösung verglichen. Dazu wurde das Protein so weit wie möglich eingeschaltet, um anschließend den Rückgang der Fluoreszenz in den Gleichgewichtszustand zu verfolgen. Dieses Gleichgewicht befindet sich bei etwa $10 \%$ des maximalen Fluoreszenzsignals. Die Abfrage der Fluoreszenz bei der thermodynamisch getriebenen Relaxation in den Grundzustand erfolgte jeweils für $0,02 \mathrm{~s}$ mit einem Drittel der Intensität, die für das Einschalten verwendet wurde. Als Ergebnis dieses Experiments wurde für das Protein in Lösung und im Kristall ein nahezu identischer Wert von $t_{1 / 2}{ }^{\text {relax }} \approx 60 \mathrm{~s}$ bestimmt. In einem zweiten Versuch wurden die Kinetiken des Proteins im Kristall und in Lösung aus dem 
vollständig ausgeschalteten Zustand in den Gleichgewichtszustand gemessen. Diese erwiesen sich ebenfalls als identisch (Abbildung 6).
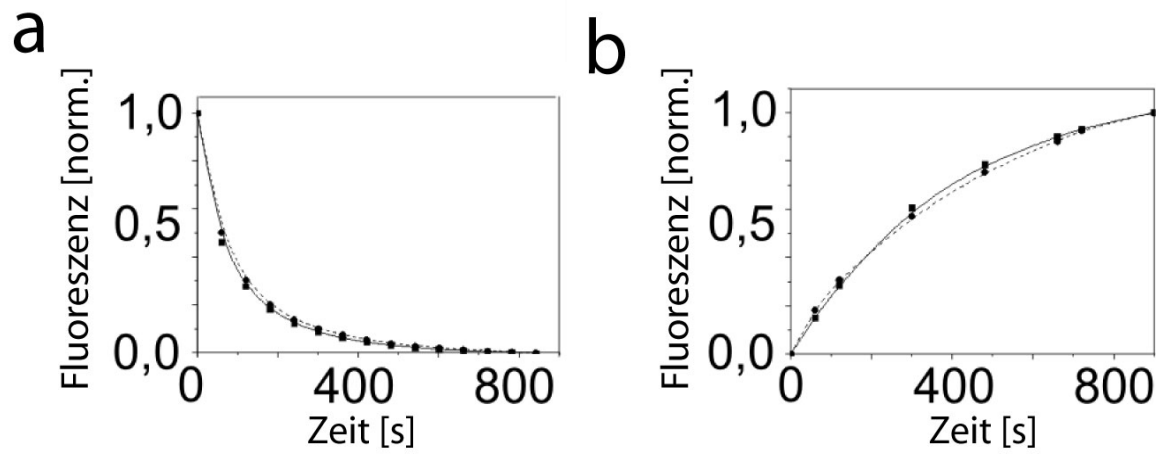

Abbildung 6: Vergleich der thermischen Relaxation in den Grundzustand von asFP595-A143S im Kristall und in Lösung. Die Kristalle und das Protein wurden in dem Reservoir des Kristalls geschaltet. Für die Relaxation aus dem angeschalteten Zustand (a) wurde das Protein mit grünem Licht $\left(550 \pm 20 \mathrm{~nm} ; 50 \mathrm{~W} \cdot \mathrm{cm}^{-2}\right)$ vollständig eingeschaltet, für die Relaxation aus dem ausgeschalteten Zustand (b) mit blauem Licht $\left(450 \pm \mathrm{nm} ; 20 \mathrm{~W} \cdot \mathrm{cm}^{-2}\right)$ vollständig ausgeschaltet. Das Zurückfallen in das thermodynamische Gleichgewicht wurde durch Belichtung für $0,02 \mathrm{~s}$ mit grünem Licht $\left(15 \mathrm{~W} \cdot \mathrm{cm}^{-2}\right)$ verfolgt.

Aufgrund dieser identischen Verhaltensweise liegt es nahe, dass dem Schalten des Proteins im Kristall und in Lösung derselbe Mechanismus zugrunde liegt. Die Schaltbarkeit des Kristalls, sowie die höhere Stabilität der Mutante asFP595-A143S im Vergleich zum Wildtyp ermöglichen eine Analyse der Struktur des Proteins im fluoreszierenden und im nicht fluoreszierenden Zustand.

\section{IV.1.6 Kristallstrukturen von asFP595-A143S}

Insgesamt wurden von dem Protein asFP595-A143S drei Kristallstrukturen aus Kristallen in unterschiedlichen Zuständen analysiert. Der erste Kristall wurde im Grundzustand (ohne vorherige Belichtung) gemessen (PDB ID: 2a53), der zweite wurde in einem Zwischenzustand etwa bei $50 \%$ der maximalen Fluoreszenz analysiert (1 min Belichtung; PDB ID: 2a54), und ein dritter Kristall wurde vollständig eingeschaltet, bevor er vermessen wurde (5 min Belichtung; 2a56). Die Kristalle wurden mit Licht der Wellenlänge $550 \pm 20 \mathrm{~nm}\left(50 \mathrm{~W} \cdot \mathrm{cm}^{-2}\right)$ eingeschaltet. Anschließend wurden sie so schnell wie möglich (10$15 \mathrm{~s}$ ) in Perfluoropolyether überführt und in flüssigem Stickstoff eingefroren. Die Strukturbestimmungen der drei Kristalle wurden analog zu derjenigen von asFP595-S158V durchgeführt. 
Der Kristall im Grundzustand zeigte bei einer Auflösung von 1,45 ̊ eine ähnliche Struktur wie der Grundzustand des Proteins asFP595 (durchschnittliche quadratische Abweichung der Position der $\mathrm{C}_{\alpha}$ atome $=$ root mean square deviation $=\mathrm{rmsd}=0,23 \AA$ ). Die $2 \mathrm{~F}_{\mathrm{o}}-\mathrm{F}_{\mathrm{c}}$ Elektronendichte zeigt das Chromophor hauptsächlich in der trans-Position (Abbildung 7a). Die genaue Auswertung der Elektronendichte des Chromophors ergab eine leichte Abweichung von der asFP595 Struktur, diese konnte jedoch einem Chromophor in cisKonformation zugewiesen werden und wurde auf etwa $10 \%$ bestimmt. Dieses Ergebnis stimmt mit dem gemessenen Gleichgewichtszustand von asFP595-A143S überein, in dem ebenfalls etwa $10 \%$ der Moleküle im angeschalteten Zustand vorliegen.

Die Auswertung der beiden belichteten Kristalle ergab nahezu identische Strukturen (rmsd = 0,22 Å). Der einzige Unterschied in der Elektronendichte (abgesehen von der Konformation einzelner Oberflächenaminosäuren) bestand in der Konformation der Chromophore. Während bei dem nur für $\sim 1$ min belichteten Kristall die cis- und die trans-Konformation zu etwa $50 \%$ in der Elektronendichte vertreten waren, befand sich bei dem für $\sim 5$ min belichteten Kristall die Elektronendichte nahezu vollständig in der cis-Position (Abbildung 7).

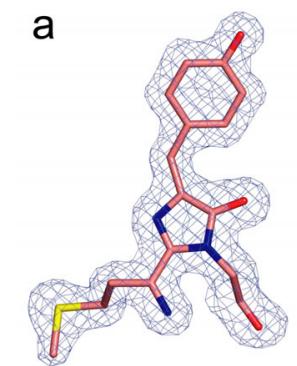

asFP595-A143S (Grundzustand)

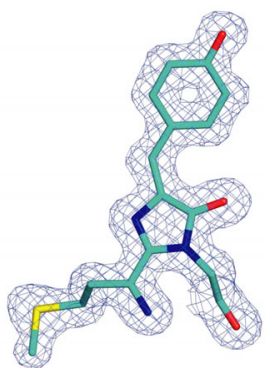

asFP595

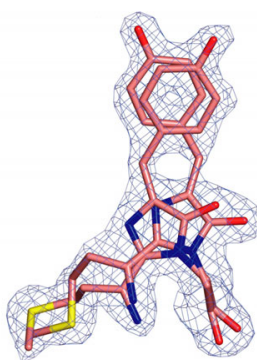

asFP595-A143S (1 min bestrahlt)

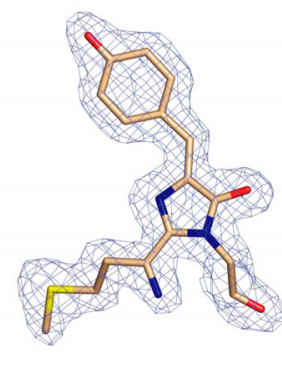

asFP595-S158V

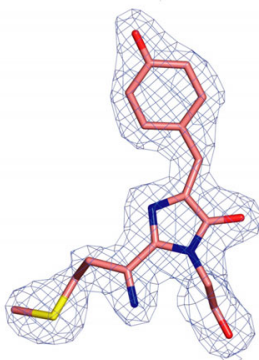

asFP595-A143S (5 min bestrahlt)

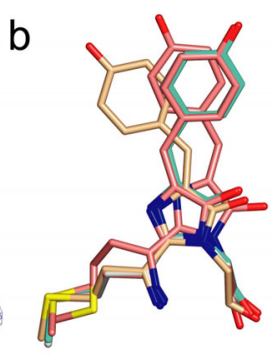

Abbildung7: Trans- und cis-Konformationen der Chromophore in den nicht fluoreszierenden und fluoreszierenden Zuständen. Die Chromophore sind jeweils mit ihrer $2 F_{o}-F_{c}$ Elektronendichte auf dem $1 \sigma$-Level dargestellt (a). Im Falle des für eine Minute bestrahlten Kristalls, wurden ein cisund ein trans-Chromophor in die Struktur eingebaut, da die Elektronendichte beider Konformationen zu etwa 50 \% vorhanden ist. Bei der Überlagerung der Chromophore nach einem $\mathrm{C}_{\alpha}$-Abgleich (b), zeigt sich, dass das cis-Chromophor von asFP595-S158V weiter verschoben ist als bei asFP595A143S; Farben wie in (a). 
Eine Überlagerung aller asFP595 Strukturen zeigt, dass die Positionen der Chromophore in der trans-Konformation bei asFP595 und asFP595-A143S identisch sind (Abbildung 7b). Das Chromophor der S158V-Variante ist im Gegensatz zu dem der A143S-Variante deutlich in cis-Richtung verschoben. Dies kann allerdings durch eine sterische Hinderung der an Position 158 eingebrachten Aminosäure Valin erklärt werden.

Die Strukturen fluoreszierender Kristalle von asFP595-A143S und asFP595-S158V, zeigen beide einen cis-Chromophor, während die Strukturen der nicht fluoreszierenden Kristalle asFP595 und asFP595-A143S beide einen trans-Chromophor zeigen. Anhand der Strukturen desselben Proteins im fluoreszierenden, sowie im nicht fluoreszierenden Zustand, wurde die strukturelle Grundlage des Schaltens, eine cis-trans-Isomerie des Chromophors eindeutig belegt.

IV.1.7 Cis-trans-Isomerie des Chromophors ermöglicht An- und Ausschalten von asFP595

Anhand der Strukturanalyse von asFP595, sowie zweier asFP595 Varianten (asFP595-A143S und asFP595-S158V) konnte gezeigt werden, dass der ausgeschaltete Zustand in asFP595 durch ein trans-Chromophor charakterisiert ist, während der eingeschaltete Zustand einen cisChromophor aufweist. Diese grundlegende Erkenntis wurde im Folgenden genutzt, um den molekularen Mechanismus der Isomerisierung genauer zu bestimmen.

\section{IV.1.8 Molekulardynamik Simulationen}

Im Prinzip gibt es zwei Möglichkeiten einer cis-trans-Isomerisierung des Chromophors. Entweder kann eine Rotation um den Winkel $\alpha$ stattfinden, wobei der Tyrosyl-Rest um die hintere Bindung der Methin-Brücke gedreht wird, oder es kommt zu einem so genannten Hula-Twist, bei dem eine gleichzeitige Drehung um die Winkel $\alpha$ und $\beta$ stattfindet (Abbildung 8a). Der Hula-Twist ermöglicht eine weniger raumgreifende Isomerisierung als die Rotation, da bei letzterer der gesamte Tyrosyl-Ring aus der Chromophor-Ebene heraustreten muss. Beim Hula-Twist schwingt die Methin-Brücke aus der Ebene heraus, während der Imidazolring und der para-Hydroxyphenylring diese Bewegung durch eine Verkippung ausgleichen. Allerdings muss bei dem Hula-Twist simultan um zwei Bindungen gedreht werden. Weiterhin sind eine Rotation bzw. ein Hula-Twist in beide Richtungen möglich, somit bleiben vier Möglichkeiten der Isomerisierung: der Hula-Twist nach unten $\left(\mathrm{HT}^{\mathrm{bot}}\right)$ und nach oben $\left(\mathrm{HT}^{\mathrm{top}}\right)$, so wie eine Rotation nach unten $\left(\mathrm{R}^{\mathrm{bot}}\right)$ und nach oben $\left(\mathrm{R}^{\mathrm{top}}\right)$. 

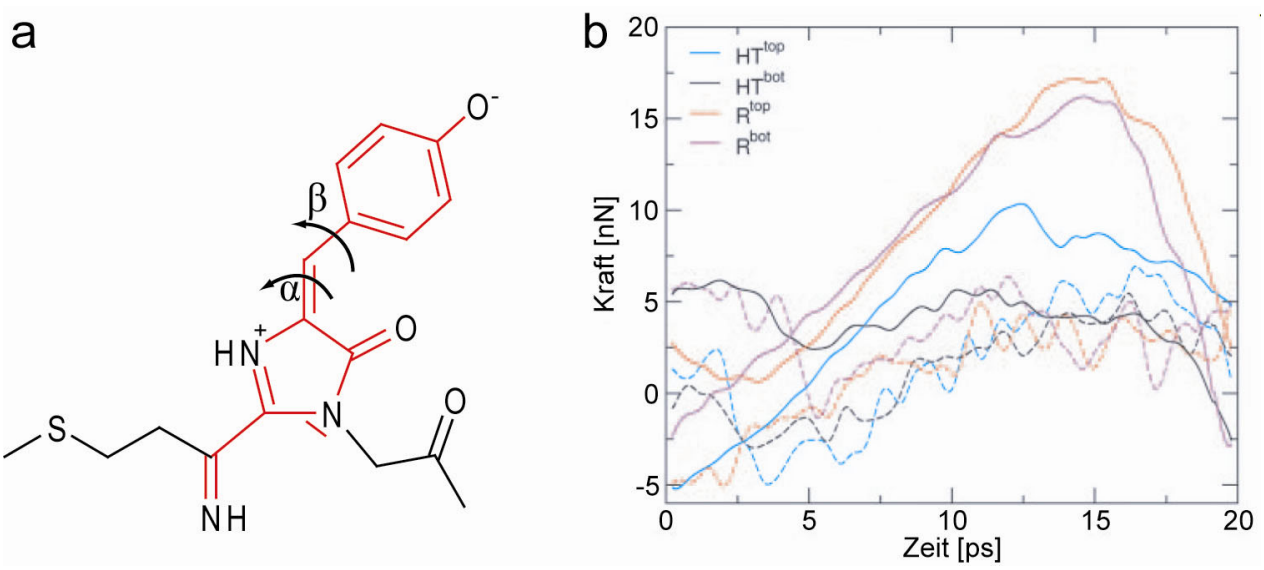

Abbildung 8: Berechnungen zur Chromophorisomerisierung von asFP595. Eine Isomerisierung ist möglich durch eine Drehung um den Winkel $\beta$ (Rotation) oder $\alpha$ und $\beta$ gleichzeitig (Hula-Twist) (a). In (b) sind die Berechnungen der einer Isomerisierung entgegenwirkenden Kräfte für die vier möglichen Mechanismen in einem Diagramm dargestellt (Kurven aus jeweils 10 Berechnungen gemittelt). Die gepunkteten Linien zeigen Simulationen des Chromophors in Wasser, die durchgezogenen Linien zeigen Simulationen des Chromophors in der Proteinmatrix. In Wasser wird keiner der vier Mechanismen bevorzugt (b), während in der Proteinmatrix für den bottom Hula-Twist die geringsten Kräfte berechnet wurden.

Zunächst wurden mit Hilfe intramolekularer Simulationen der einer Isomerisierung entgegenwirkenden Kräfte festgestellt, ob das Chromophor für den Hula-Twist oder die Rotation mehr Energie benötigt. In Zusammenarbeit mit der Abteilung von Prof. Helmut Grubmüller wurden Simulationen der Isomerisierung in wässriger Umgebung durchgeführt, bei denen die entgegenwirkenden Kräfte von Drehungen der Winkel $\alpha$ und $\beta$ des Chromophors berechnet wurden (Abbildung 8b). Bei diesen in silico Experimenten zeigte sich, dass keiner der vier möglichen Mechanismen energetisch vorteilhafter ist, wenn nur der Chromophor in wässriger Umgebung betrachtet wird. Anschließend wurden Force Probe Simulationen in der Proteinumgebung durchgeführt, bei denen sowohl für den Hula-Twist, als auch für die Rotation starke Kräfte berechnet wurden, welche der Isomerisierung entgegenwirken. Das Molekül zeigte jedoch eine schwache Präferenz für eine Isomerisierung nach dem bottom Hula-Twist (HT ${ }^{\text {bot }}$ ) Mechanismus, da für diesen die niedrigste Energiebarriere berechnet wurde.

Abschließend wurden dynamische Simulationen durchgeführt, die jegliche Bewegung des Chromophors und der Umgebung zulassen. Die Isomerisierung des Chromophors wird durch Absorption grüner Photonen $(\sim 550 \mathrm{~nm})$ induziert, wodurch das Chromophor in den $\mathrm{S}_{1}$ Zustand übergeht und schließlich eingeschaltet wird. Die Isomerisierung erfolgt also aus dem ersten angeregten Zustand $\mathrm{S}_{1}$. Um die Vorgänge bei der Isomerisierung möglichst genau 
nachzustellen, wurden die Simulationen in der Proteinmatrix mit einem Chromophor im $\mathrm{S}_{1}$ Zustand durchgeführt. Die beiden Raumwinkel $\alpha$ und $\beta$ wurden in der Ausgangsposition mit $180^{\circ}$ bzw. $-180^{\circ}$ definiert (trans-Chromophor). Da die Isomerisierung einer Drehung der beiden Winkel $\alpha$ und $\beta$ um jeweils $180^{\circ}$ entspricht, ist das cis-Chromophor durch die Winkel $0^{\circ}$ und $360^{\circ}$ bzw. $-360^{\circ}$ definiert.

Bei diesem in silico Experiment konnte ausschließlich die Isomerisierung nach dem $\mathrm{HT}^{\text {bot }}$ Mechanismus beobachtet werden (Abbildung 9 - oben). Dies zeigt sich daran, dass die Isomerisierung der Winkel $\alpha$ und $\beta$ immer gleichzeitig stattfindet und zwar ausschließlich in eine Richtung. Ein Kontrollexperiment des Chromophors in Wasser zeigte ebenfalls eine Präferenz für die Isomerisierung nach dem $\mathrm{HT}^{\text {bot }}$ Mechanismus, es wurde jedoch auch der $\mathrm{HT}^{\text {top }}$ beobachtet (Abbildung 9 - unten).

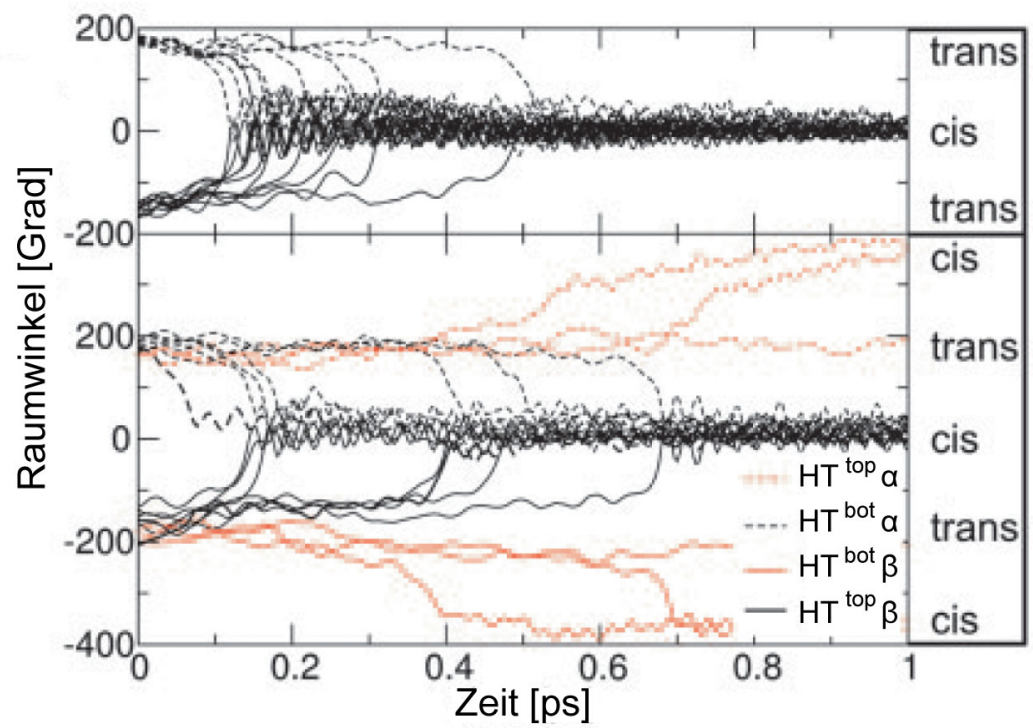

Abbildung 9: Dynamische Simulationen von asFP595 in der Proteinmatrix (oben) und in Wasser (unten). Die Änderung der beiden Drehwinkel ist auf der y-Achse dargestellt. Bei $0^{\circ}$ und $360^{\circ}$ befindet sich das Chromophor im fluoreszierenden cis-Zustand. Bei $180^{\circ}$ befindet sich das Chromophor im nicht fluoreszierenden trans-Zustand. Während die Simultaionen in der Proteinmatrix ausschließlich den $\mathrm{HT}^{\text {bot }}$ Mechanismus zeigen, wurde bei der Kontrolle in wässriger Umgebung ebenfalls der $\mathrm{HT}^{\text {top }}$ beobachtet.

Die Simulationen haben eindeutig eine Isomerisierung nach dem bottom Hula-Twist bevorzugt; die Bewegungen des Chromophors können dabei folgendermaßen beschrieben werden: Der para-Hydroxyphenylring und der Imidazolring des Chromophors bewegen sich im Zuge der Isomerisierung leicht nach unten, während die Methin-Brücke, welche die beiden Ringe verknüpft, ein wenig nach oben in Richtung des Histidin 197 ausweicht. Die resultierende Bewegung ist der bottom Hula-Twist. 
Dieses Wissen über den Mechanismus sollte helfen, die richtigen Aminosäuren auszuwählen, um die Schalteigenschaften des Proteins zu verbessern. 


\section{IV.2 Evolution von asFP595}

Das Protein asFP595 zeigt zwar einzigartige Schalteigenschaften, ist aber aufgrund seiner sonstigen Eigenschaften nicht gut für die Anwendung in der Zellbiologie geeignet. Einerseits ist zu erwarten, dass die tetramere Struktur zu Beschränkungen bei einer Verwendung als Fusionsprotein führt. Ein essentielles Problem stellt jedoch auf der anderen Seite die extrem geringe Quantenausbeute von weniger als 0,001 dar (Chudakov et al. 2003).

\section{IV.2.1 asFP595 Mutagenese}

Um das Protein asFP595 für die Fluoreszenzmikroskopie nutzbar zu machen, wurden gerichtete Mutagenesen anhand der Strukturen und des postulierten Mechanismus durchgeführt und durch Zufallsmutagenesen ergänzt. Die zufällige Mutagenese wurde mit den Primern asCP-mutpQE-f und asCP-mutpQE-r ( $\rightarrow$ IX.1.2) auf dem Plasmid pQE30-asFP595 durchgeführt. Die beiden Primer binden an das Plasmid, so dass ausschließlich der für asFP595 kodierende Bereich vervielfältigt wird. Die auf diese Weise erstellte mutagene DNA wurde mit den Enzymen BamHI und KpnI verdaut und in den ebenso geschnittenen leeren Vector pQE30 ligiert.

Bei der ortsgerichteten Mutagenese wurden meist solche Primer verwendet, welche den Austausch eines Codons gegen drei zufällige Basen zur Folge haben. Auf diese Weise kann eine Aminosäure im Protein gegen alle anderen getauscht werden ( $\rightarrow$ VI.2.13). Allerdings wurden in einigen Fällen auch Primer verwendet, die einen Austausch gegen eine spezifische Aminosäure, oder einen Austausch gegen mehrere, aber nicht alle anderen Aminosäuren ermöglichen. Weiterhin wurde eine Mutagenese durchgeführt, mit der mehrere Aminosäuren gleichzeitig an verschiedenen Positionen im Protein ausgetauscht werden konnten $(\rightarrow$ VI.2.14). Diese Methoden, ermöglichen ein effektives und schnelles Erstellen vieler unterschiedlicher Mutanten. Die Suche nach den verbesserten Eigenschaften ist daher der begrenzende Faktor beim Screening.

\section{IV.2.2 Entwicklung eines Screeningprogramms}

Eine Möglichkeit innerhalb kurzer Zeit in vielen Zellen nach fluoreszierenden Proteinen mit verbesserter Helligkeit $\mathrm{zu}$ suchen, bietet das Sortieren von Zellen mit einem FACS (Fluorescence Activated Cell Sorter). Dies ist jedoch bei einem Protein unmöglich, welches im Grundzustand nicht fluoresziert. Desweiteren ist die Analyse über ein FACS auf die Messung der Helligkeit fluoreszierender Proteine beschränkt. Bei einem RSFP sind jedoch 
der dynamische Bereich des Fluoreszenzsignals und die Schaltgeschwindigkeit ebenfalls essentielle Eigenschaften, die bei der Suche nach verbesserten Varianten berücksichtigt werden müssen.

Ein Screening, sollte daher zumindest die Analyse dieser drei Eigenschaften von RSFPs ermöglichen. Für die Bestimmung von Helligkeit, Schaltgeschwindigkeit und Restfluoreszenz muss das Protein allerdings einen kompletten Schaltzyklus durchlaufen ( $\rightarrow$ VI.5). Dies ist nur möglich, wenn die Proteine einzeln vorliegen und getrennt voneinander mit einer Belichtungsreihenfolge gemessen werden können. Das Screening wurde daher an E.coliKolonien auf Agarplatten durchgeführt, die mit Hilfe eines computergesteuerten Mikroskops über einen in xy-Richtung beweglichen Objekttisch angefahren werden konnten. Eine Agarplatte mit E.coli-Kolonien kann mit diesem Aufbau Punkt für Punkt abgerastert werden (Abbildung 10).

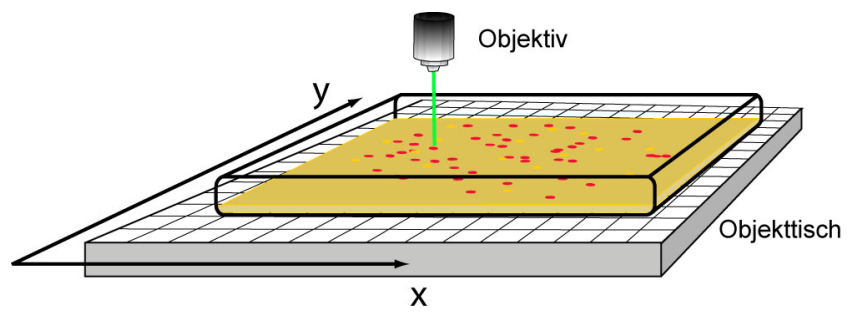

Abbildung 10: Schematische Darstellung des Abrasterns einer Agarplatte mit mutageniserten E.coli-Kolonien. Der Objekttisch, auf dem sich die E.coli Platte befindet, wird von einem Computer angesteuert. Die Platte wird auf diese Weise in 1-2 mm Schritten abgerastert, wobei an jeder Kolonie das vorher festgelegte Belichtungsprogramm durchlaufen wird.

Beim Abrastern wurde an jeder Position zunächst geprüft, ob sich dort eine Kolonie befand, welche asFP595 exprimierte ( $\rightarrow$ IV.2.3). Falls eine solche Kolonie vorhanden war, wurde eine vorher festgelegte Belichtungsreihenfolge gestartet, durch die das RSFP einen kompletten Schaltzyklus durchlief.

\section{IV.2.3 Das Screeningprogramm}

Jede Kolonie mit asFP595 Expression wurde zunächst durch kurze Bestrahlung mit blauem Licht $(450 \mathrm{~nm})$ vollständig in den nicht fluoreszierenden Zustand gebracht (Schritt 1). Dies erlaubt das Auslesen der minimalen Fluoreszenz (Fluo ${ }^{\mathrm{min}}$ ) bei dem ersten Messpunkt des nächsten Schrittes (Abbildung 11). Danach (Schritt 2) wurden die Proteine mit grünem Licht $(550 \mathrm{~nm})$ eingeschaltet und gleichzeitig die Fluoreszenz angeregt. In diesem Schritt können Informationen über die Halbwertszeit der Einschaltkinetik $\left(\mathrm{t}_{1 / 2}{ }^{\text {on }}\right)$ und die maximale Fluoreszenz (Fluo $\left.{ }_{\max }\right)$ gesammelt werden. Anschließende, gleichzeitige Bestrahlung mit 
grünem und blauem Licht (Schritt 3) induziert das Ausschalten, bei dem die Halbwertszeit der Ausschaltkinetik $\left(t_{1 / 2}{ }^{\text {off }}\right)$ und die minimale Fluoreszenz bei Belichtung mit beiden Wellenlängen gemessen werden können. Das Ausschalten mit beiden Wellenlängen ist möglich, da bei asFP595 und dessen Derivaten die lichtgetriebene Isomerisierung mit blauem Licht wesentlich effektiver, und somit um ein Vielfaches schneller abläuft als die Isomerisierung mit grünem Licht. Generell sollte hier noch erwähnt werden, dass die Zeit, in der die Isomerisierung abläuft, stark von der Intensität des eingestrahlten Lichts abhängig ist. Vergleichende Messungen von $t_{1 / 2}{ }^{\text {on }}$ wurden daher immer mit der gleichen Intensität durchgeführt.

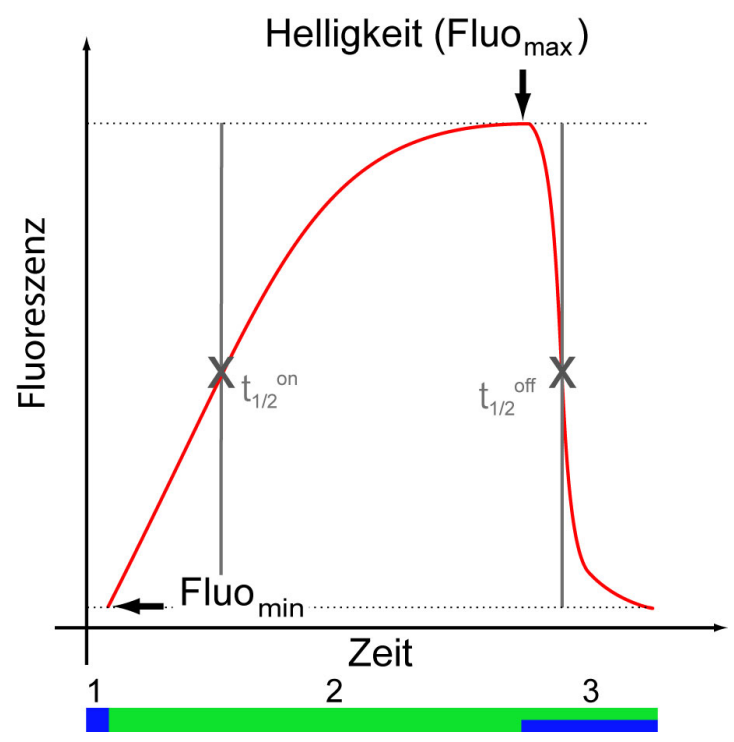

Abbildung 11: Schematische Darstellung eines Schaltzyklus im Screeningprogramm. Das Screening an jeder Kolonie einer Agarplatte besteht aus drei Belichtungsschritten. Zunächst werden die Proteine mit blauem Licht $(450 \mathrm{~nm})$ komplett in den nicht fluoreszierenden Zustand gebracht, um die minimale Fluoreszenz zu bestimmen. Die Fluoreszenz wird im zweiten Schritt durch Belichtung mit grünem Licht $(550 \mathrm{~nm})$ gemessen, wobei der erste Wert dieser Kurve Fluo ${ }^{\text {min }}$ entspricht. Die Belichtung muss ausreichend lang sein, damit das Fluoreszenzsignal ein Plateau erreicht, welches Fluo $_{\max }$ darstellt. Der Zeitpunkt, an dem der Wert $\left(0,5 \cdot\left(\right.\right.$ Fluo $^{\max }-$ Fluo $\left.^{\min }\right)+$ Fluo $\left.^{\mathrm{min}}\right)$ erreicht ist, entspricht der Halbwertszeit der Einschaltkinetik, $t_{1 / 2}{ }^{\text {on }}$. Abschließend wird durch gleichzeitige Belichtung mit grünem und blauem Licht die Halbwertszeit der Ausschaltkinetik $t_{1 / 2}$ off bestimmt.

Die Entscheidung, ob sich an einem Messpunkt eine asFP595 exprimierende Kolonie befand, wurde anhand der ersten beiden Messwerte von Schritt 2 (Einschalten) bestimmt. Es wurden zwei Kriterien festgelegt, von denen eine zutreffen musste, damit die Messung fortgesetzt wird. Das erste Kriterium ist die Höhe des Fluoreszenzsignals, und das zweite dessen Änderung in Schritt 2. 
Die Eigenfluoreszenz des Agars, sowie nicht exprimierender Kolonien wurden benutzt, um das minimale Fluoreszenzsignal zu ermitteln, bei dem an einer Position weiterhin gemessen werden sollte. Für das zweite Kriterium wurde das nötige Verhältnis der ersten zwei Messwerte im Bereich zwischen 1,1 und 1,2 gewählt, sodass ein Anstieg der Fluoreszenz von mindestens $10 \%$ notwendig war. Wurde also in Schritt 2 weder eine zuvor festgelegte minimale Fluoreszenz, noch ein vorher bestimmter Faktor von Messwert eins zu Messwert zwei überschritten, so wurde die Messung an dieser Position auf der Platte nach dem zweiten Messwert von Schritt 2 abgebrochen. In Schritt 3 wurde die Kinetik des Ausschaltens gemessen, indem gleichzeitig mit grünem und blauem Licht bestrahlt wurde.

Als Schrittweite für das Raster wurden je nach Größe und Dichte der Kolonien 1 bis 2 Millimeter gewählt. Die Belichtungsdauer der einzelnen Schritte wurde an die Eigenschaften des Ausgangsklons angepasst. Das Programm wurde so eingestellt, dass zumindest der Ausgangsklon einen kompletten Schaltzyklus durchläuft.

\section{IV.2.4 Auswertung einer Zufallsmutagenese}

Die Auswertung der Daten von gemessenen Kolonien wurde am Computer durch eine graphische Darstellung der Messwerte ermöglicht. Zunächst wurde ausgewählt, welcher der Belichtungsschritte betrachtet wird. Weiterhin musste für diesen Belichtungsschritt ausgewählt werden, welche der gemessenen Daten dargestellt werden sollen. So kann z.B. die Restfluoreszenz durch das Verhältnis vom ersten $\left(\mathrm{n}_{\text {Start }}=\right.$ Fluo $\left.{ }^{\max }\right)$ zum letzten Messwert $\left(\mathrm{n}_{\text {Ende }}\right.$ $=$ Fluo $^{\text {min }}$ ) beim Einschalten dargestellt werden. Diese berechneten Werte können sowohl graphisch, als auch in einem Histogramm dargestellt werden (Abbildung 12). Das Histogramm dient dazu, Werte, die sich stark vom Durchschnitt unterscheiden, sofort identifizieren zu können. Jede von dem Mikroskop angesteuerte Position auf der Agarplatte kann durch Selektion mit einem Fadenkreuz in der graphischen Darstellung ausgewählt werden, um die Daten dieses Punktes genauer darzustellen. 


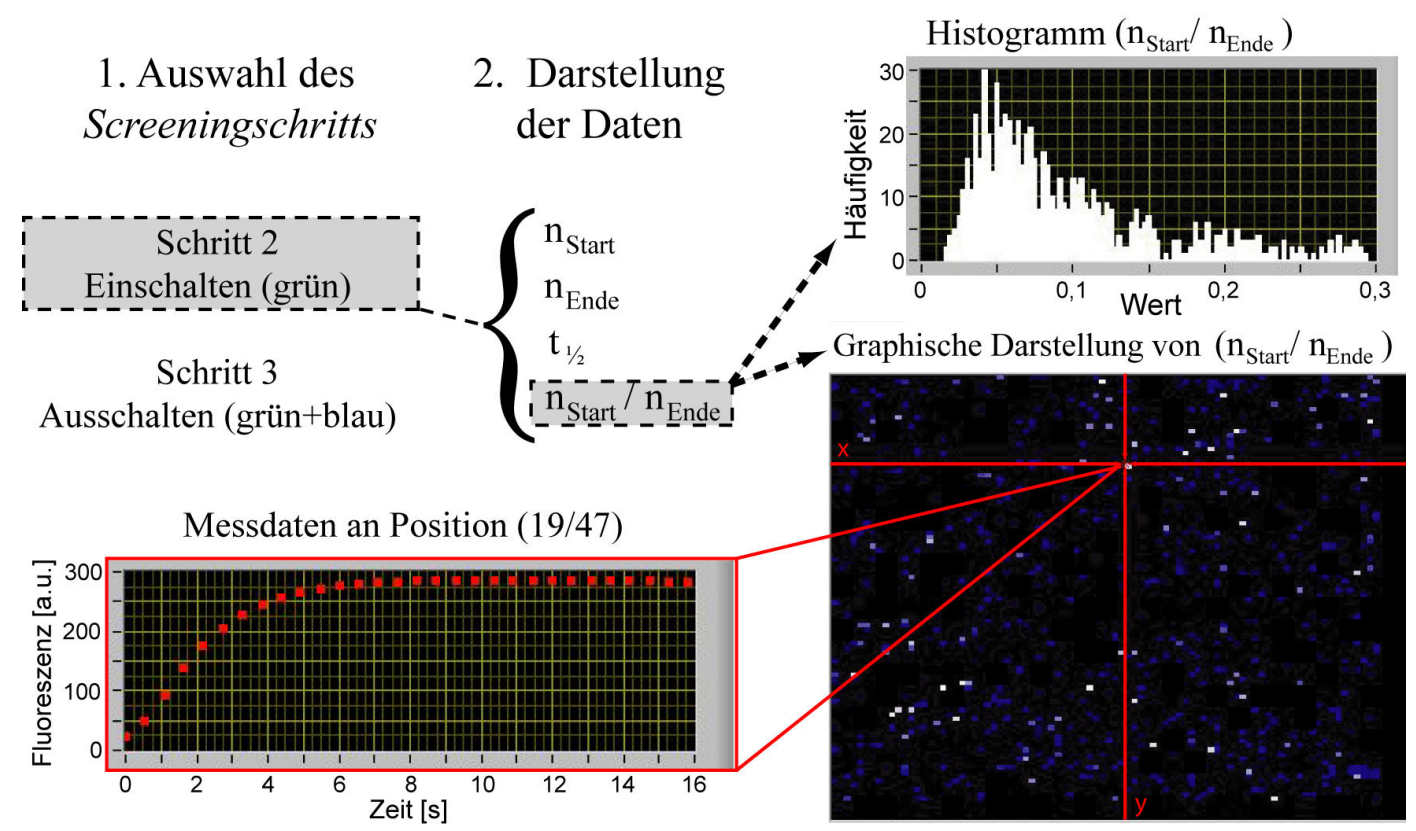

Abbildung 12: Auswertung eines Screenings. Bei der Auswertung wurden die Schritte Einschalten (Schritt 2) und Ausschalten (Schritt 3) separat behandelt. Nach der Wahl des Screeningschritts konnten verschiedene Werte gewählt werden, die dann graphisch dargestellt wurden. Zur Auswahl stehen der erste und der letzte Wert einer Messung ( $\mathrm{n}_{\text {Start }}$ und $\mathrm{n}_{\text {Ende }}$ ), die je nach Schaltmodus die maximale Helligkeit angeben. Der Wert $t_{1 / 2}$ gibt die Halbwertszeit des Schaltens an. Der Wert $\left(\mathrm{n}_{\text {Start }} / \mathrm{n}\right.$ Ende) ist ein Maß für die Restfluoreszenz. In dem Histogramm werden alle auf der Platte vorhandenen Werte entsprechend ihrer Häufigkeit dargestellt. In der graphischen Darstellung entspricht jeder Punkt der Berechnung von der Restfluoreszenz ( $\mathrm{n}_{\text {Start }} / \mathrm{n}_{\text {Ende }}$ ) an dem jeweiligen Ort auf der Agarplatte. Bei steigendem Wert für die Restfluoreszenz wird die Farbe des Punktes heller, diejenigen Klone mit sehr geringer Restfluoreszenz sind in der graphischen Darstellung also sehr dunkel und in dem Histogramm nahe bei Null zu finden. Mit einem Fadenkreuz kann ein Punkt ausgewählt werden, für den die Messdaten des ausgewählten Schrittes angezeigt werden. Die in diesem Beispiel ausgewählten Optionen sind grau hinterlegt.

Kolonien, die verbesserte Eigenschaften, oder interessante Veränderungen aufwiesen, wurden auf eine neue Agarplatte umgestrichen und nach erneutem Anwachsen nochmals auf ihre Eigenschaften überprüft. Bei Bestätigung dieser wurde eine Minipräparation der PlasmidDNS durchgeführt, welche anschließend sequenziert und analysiert wurde. Die auf diese Weise identifizierten verbesserten Mutanten wurden in neuen Mutageneserunden als Ausgangsklone eingesetzt. 


\section{IV.2.5 Ergebnisse der asFP595 Mutagenese}

Aufgrund der Strukturen und dem hypothetischen Schaltmechanismus wurden für die gezielte Mutagenese Aminosäuren ausgesucht, die einen Einfluss auf das Chromophor oder die Isomerisierung haben könnten. Insgesamt wurden 15 Positionen ausgewählt (Abbildung 13 a,b), die je nach ihrer Lage und ihrem Einfluss auf das Chromophor mehr oder weniger intensiv mutagenisiert und analysiert wurden. Für diese 15 Positionen wurden mutagene Primer erstellt ( $\rightarrow$ IX.1.2) welche einen zufälligen Austausch gegen jede Aminosäure ermöglichen.

Eine Sequenzanalyse wurde bei allen Kolonien durchgeführt, die erhöhte Helligkeit, schnelleres Einschalten, oder geringere Restfluoreszenz zeigten. An Positionen, die potentiell für die Fluoreszenzeigenschaften des Chromophors wichtig waren, wurden zusätzlich 12-16 Klone ausgewählt und analysiert. Von diesen 12-16 Klonen wurden jeweils sechs bis acht zufällig ausgewählt, die asFP595 exprimierten und eine deutliche Färbung aufwiesen, bzw. keine Färbung aufwiesen (Chromophor wird nicht gebildet).

Insgesamt sind bei einer Mutagenese von 15 Aminosäuren 285 unterschiedliche Einzelmutationen möglich. Bei der Sequenzanalyse wurden 69 dieser Mutationen isoliert, von denen 30 eine Verbesserung in mindestens einer der drei Eigenschaften Helligkeit, Schaltgeschwindigkeit oder Restfluoreszenz aufwiesen ( $\rightarrow$ IX.2.4.1).
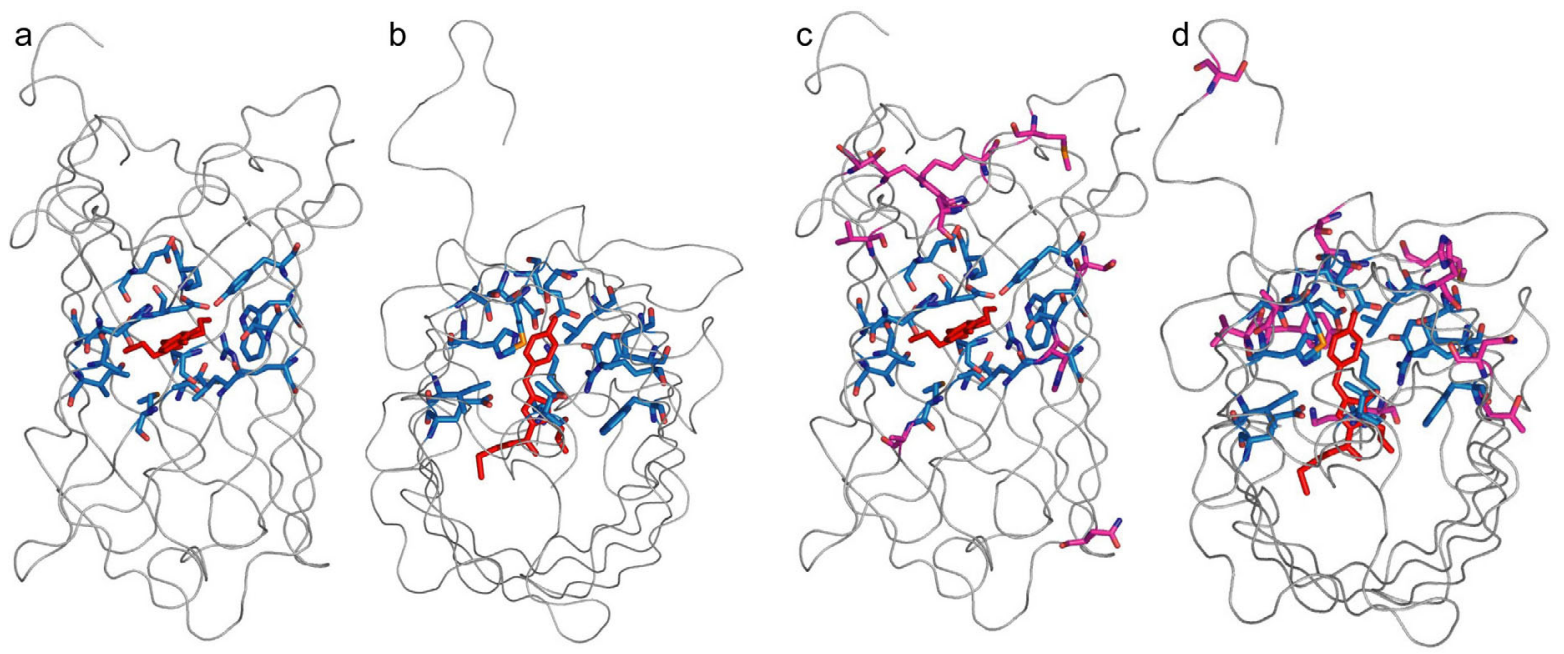

Abbildung 13: Übersicht mutagenisierter Aminosäuren bei der Evolution des Proteins asFP595. Positionen, die mit gerichteter Mutagenese adressiert wurden $(a, b)$, sind in blau dargestellt. Die Positionen der Mutanten, die bei der Zufallsmutagenese gefunden wurden, sind pink markiert (c,d). Die Strukturen in a,b und c,d sind jeweils einmal in der Seitenansicht und in der Aufsicht dargestellt.

Um Positionen einzuschließen, die sich nicht in der Nähe des Chromophors befinden, aber dennoch einen Effekt auf die Eigenschaften des Chromophors haben, wurden Zufalls- 
mutagenesen auf der gesamten kodierenden DNS von asFP595 und dessen Derivaten durchgeführt. Insgesamt wurden bei einer Zufallsmutagenese etwa 8000 bis 20000 Kolonien (potentielle Mutanten) vermessen. Dabei wurden auch solche Mutationen entdeckt, die bereits durch die gerichtete Mutagenese bekannt waren. Mit der Einschränkung, dass nur Mutationen berücksichtigt werden, die durch einen einzelnen Basenaustausch möglich sind, wurden tatsächlich über $90 \%$ der Mutationen wiedergefunden, die aufgrund ihrer verbesserten Eigenschaften beim Screening auffällig sein sollten. Die analysierte Anzahl scheint also ausreichend zu sein, wie auch die Berechnung der möglichen Variationen des Proteins zeigt. Da ein Codon aus 3 BP besteht und jede Base durch 3 andere ersetzt werden kann, ergeben sich 9 Möglichkeiten pro Codon, also etwa 2000 verschiedene Einfachmutationen. Da der genetische Code jedoch degeneriert ist, resultiert der Basenaustausch in einem Codon auf Proteinebene nicht direkt in einem anderen Protein. Im Durchschnitt können durch einen einzelnen Basenaustausch nicht 9, sondern nur 6,1 unterschiedliche Variationen eines Proteins entstehen. Dies bedeutet für asFP595, dass bei einer Mutation im Gen etwa 1400 Varianten entstehen können. Die Berechnung und die Erfahrung zeigen, dass eine Analyse von 10000 bis 20000 Kolonien eine ausreichend hohe Abdeckung der Mutagenese liefert.

Mit Hilfe der Zufallsmutagenese wurden zusätzlich zu den 39 Mutationen bei der gerichteten Mutagenese 11 weitere ausfindig gemacht, die einen positiven Effekt auf eine der zu verbessernden Eigenschaften hatten. Das Ausmaß der Effekte war jedoch oft gering, da diese Mutationen nur indirekt auf das Chromophor wirken. Dies zeigt sich daran, dass die Mutationen meist neben Aminosäuren liegen, die einen starken Einfluss auf das Chromophor haben (Abbildung $13 \mathrm{c}, \mathrm{d}$ ).

Neben den Mutanten mit verbesserten Schalteigenschaften bzw. verbesserter Helligkeit wurden auch 7 Varianten von asFP595 identifiziert, die die Fähigkeit des Schaltens verloren haben. Insgesamt wurden 50 Einzelmutationen identifiziert, die gegenüber dem Wildtyp verbesserte Eigenschaften aufwiesen.

\section{IV.2.6 Analyse der Einzelmutationen}

Die Helligkeit ( $\rightarrow$ VI.5.5.1) war die am stärksten und auch die am häufigsten verbesserte Eigenschaft von asFP595. Dies resultiert wahrscheinlich daraus, dass die Helligkeit auch gleichzeitig die komplexeste der drei Eigenschaften ist. Sie setzt sich aus der Faltungsgeschwindigkeit, der Expressionsstärke in der Kolonie, der Quantenausbeute und dem Absorptionskoeffizienten zusammen. 
Die besten Einzelmutationen bezüglich der Helligkeit waren in absteigender Reihenfolge L174M > A143S > H197R > A143G > M160L, wobei die Mutation L174M im Vergleich zum Wildtyp die 39fache Helligkeit aufweist (Abbildung 14). Der Austausch M160L führt immer noch zu einer 14-mal helleren Variante des Proteins ( $\rightarrow$ IX.2.4.1 und Abbildung 14). Bei der Einschaltgeschwindigkeit $\left(\mathrm{t}_{1 / 2}{ }^{\text {on }}\right)$ wurden ebenfalls starke Verbesserungen erzielt. Die Mutanten L174F, L174Q, M160V, S158T und H197R zeigten Kinetiken, die bis zu 20-mal schneller waren als die des unveränderten asFP595. Die Klone mit der geringsten Restfluoreszenz tragen die Mutationen L174M, A143G, N125D und H175D, wobei abermals L174M den größten Effekt zeigt. Mit nur 0,33 \% Restfluoreszenz im ausgeschalteten Zustand hat L174M gegenüber dem Wildtyp einen um den Faktor zehn verbesserten dynamischen Bereich des Fluoreszenzsignals (300: 1). Insgesamt konnten für jede der drei Eigenschaften Mutationen entdeckt werden, die diese deutlich verbessern. 

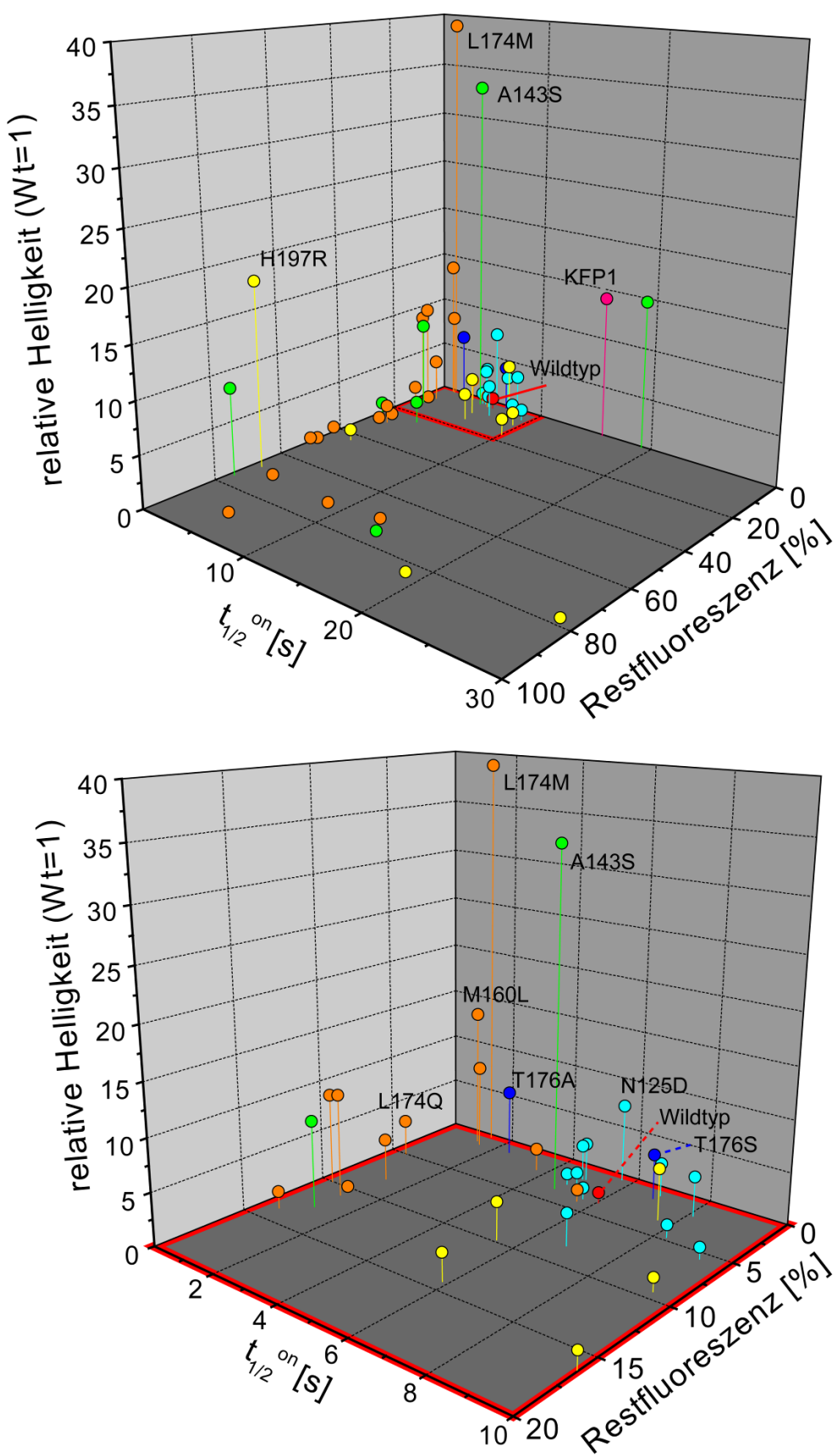

Abbildung 14: Eigenschaften der Einzelmutanten von asFP595. Aufgetragen sind die drei Eigenschaften Helligkeit, Restfluoreszenz und Schaltzeit $t_{1} / 2$. Übersicht (oben) und der rote Kasten vergrößert (unten). Einige Mutanten mit stark verbesserten Eigenschaften sind durch zusätzliche Beschriftung hervorgehoben. Die Helligkeit ist normiert auf den Wildtyp, welcher in Rot dargestellt ist. Die unterschiedlichen Farben der Mutanten stehen jeweils für eines der Cluster ( $\rightarrow$ V.2.5). Grün $=$ Stabilitätscluster; orange $=$ sterischer Cluster; gelb $=$ Histidin Cluster; blau $=$ trans-Cluster; türkis $=$ Peripheriecluster.

Bei der Betrachtung verschiedener Mutationen an derselben Position wurde deutlich, dass Variationen an einer Position häufig zu ähnlichen Effekten führen. Dies wird zum Beispiel bei den Mutationen M160L und M160A deutlich, die beide sowohl die Helligkeit als auch die 
Schaltgeschwindigkeit deutlich verbessern. Ähnliche Effekte bei den Variationen an einer Position konnten jedoch auch zwischen benachbarten Aminosäuren festgestellt werden. So ist der Einfluss auf die Helligkeit und die Schaltgeschwindigkeit nicht nur bei Mutationen an Position 160 ein häufig vorkommender Effekt, sondern auch bei solchen der direkt benachbarten Position 174. Es scheint so zu sein, dass gesamte Bereiche von Aminosäuren einen ähnlichen Einfluss auf das Chromophor haben. Aus dieser Beobachtung ergab sich eine Einteilung der Aminosäuren in Cluster, welche in der Diskussion ausführlicher behandelt wird $(\rightarrow$ V.2.5).

\section{IV.2.7 Kombination einzelner Mutationen}

Bei der Kombination von Mutanten mit verbesserten Eigenschaften zeigte sich, dass sich die Eigenschaften zweier Mutationen eher kombinieren lassen, wenn sie unterschiedlich auf das Chromophor wirken, sprich sich in unterschiedlichen Clustern befinden. Zum Beispiel ist die Kombination der Verbesserungen von L174M (sterischer Cluster) und A143S (Stabilitätscluster) möglich, obwohl beide Mutationen die Helligkeit stark erhöhen. Die Mutante asFP595 A143S, L174M ist im Vergleich zu asFP595 150-mal heller. Aufgrund der hohen Restfluoreszenz von $11 \%$ ist sie jedoch nicht als RSFP geeignet. Aus diesem Grund wurde die Kombination der Mutationen A143G und L174M bevorzugt, welche zwar nur eine 80-fache Erhöhung der Helligkeit bewirkt, jedoch eine Restfluoreszenz von nur 0,36 \% zeigt. Darüber hinaus hat die Kombinationsmutante asFP595 A143G, L174M eine um den Faktor 3 schnellere Einschaltgeschwindigkeit $\mathrm{t}_{1 / 2}$. . Leider zeigten zusätzliche Mutationen aus dem Histidin- und dem Trans-Cluster, die als Einzelmutationen die Helligkeit und Restfluoreszenz verbesserten, keinen positiven Effekt in Kombination mit der Variante asFP595 A143S, L174M ( $\rightarrow$ IX.2.4.2). Die spektralen Eigenschaften der Einzelmutationen im His-Cluster ließen sich mit den Eigenschaften der Doppelmutanten kombinieren; die positive Wirkung auf die Helligkeit und die Restfluoreszenz jedoch nicht ( $\rightarrow$ IX.2.4.2). Die Verbesserungen dieser zwei Eigenschaften der Einzelmutationen im His- und Trans-Cluster scheinen dieselbe Wirkungsweise zu haben, wie die Mutationen des sterischen Clusters. Dies lässt sich anhand der Doppelmutanten L174M, T176S und L174M, E195T erkennen, bei deren Kombination keine zusätzliche Verbesserung der Helligkeit oder Restfluoreszenz zu erkennen war. Allerdings ließen sich Effekte bezüglich der Einschaltgeschwindigkeit kombinieren.

Auch mit intensiver Error-Prone Mutagenese, so wie gerichteter Mutagenese an Positionen um das Chromophor auf der Doppelmutante asFP595 A143G, L174M konnten in Bezug auf 
die drei Eigenschaften Helligkeit, Einschaltgeschwindigkeit und Restfluoreszenz keine besseren Mutanten identifiziert werden (Abbildung 15).
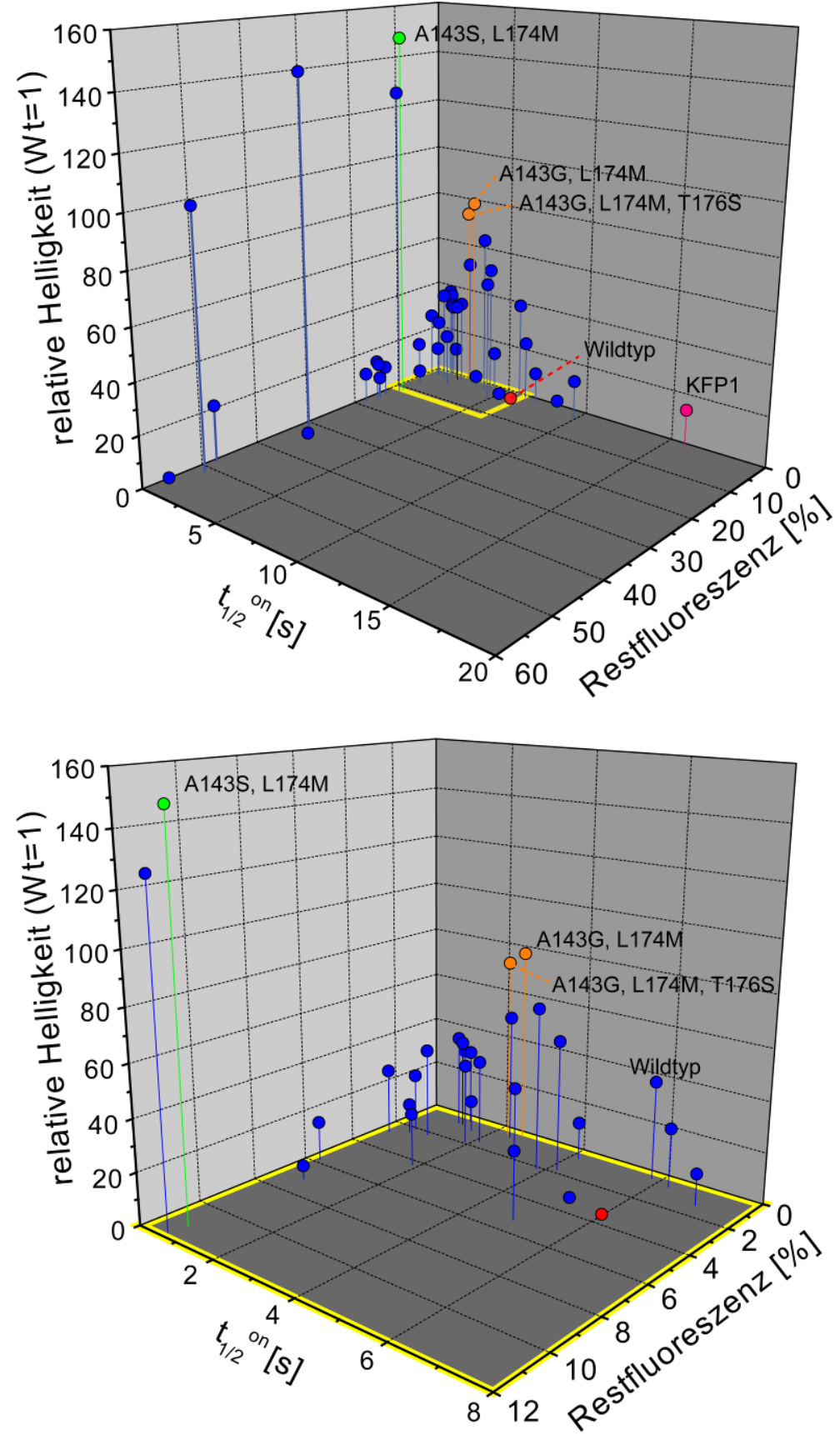

Abbildung 15: Eigenschaften der Kombinationsmutanten von asFP595. Aufgetragen sind die drei Eigenschaften Helligkeit, Restfluoreszenz und Einschaltzeit $t_{1 / 2}$ on der asFP595 Varianten mit mehr als einer Mutation. Übersicht (oben) und der gelbe Kasten vergrößert (unten). Die Helligkeit ist normiert auf den Wildtyp. Die hellste Mutante asFP595 A143S, L174M ist grün, die beiden nahezu gleichwertigen, besten Mutanten asFP595 A143G, L174M, sowie asFP595 A143G, L174M, T176S sind orange hervorgehoben. Eine bereits veröffentlichte Mutation, die Variante KFP1 (asFP595A143G) ist in Pink markiert. Der Wildtyp ist in Rot, alle anderen Mehrfachmutanten in Blau dargestellt. 
Das Protein asFP595 A143G, L174M ist in allen drei Eigenschaften, die beim Screening berücksichtigt wurden, verbessert. Die Schaltgeschwindigkeit wurde etwa um den Faktor drei verbessert, während die Helligkeit um den Faktor 80 erhöht werden konnte. Die Restfluoreszenz konnte, obwohl asFP595 bereits einen guten dynamischen Bereich zeigt, nochmals um den Faktor 10 von 3,6 \% auf 0,36 \% reduziert werden. Das Protein ist in seiner Helligkeit mit mRFP1 und eqFP611 Vergleichbar, allerdings oligomerisiert das Protein noch immer zu Tetrameren und ist daher für die Verwendung als Fusionsprotein nicht gut geeignet. Im Folgenden sollte die Variante asFP595-A143G, L174M für die Erforschung von Proteinen in lebenden Zellen durch Mutagenese zum Monomer nutzbar gemacht werden.

\section{IV.2.8 Monomerisierung von asFP595}

Zunächst wurde das asFP595 Tetramer (die Variante asFP595-A143G, L174M) durch Austausch hydrophober Aminosäuren zwischen den beiden Untereinheiten A und C zu einem Dimer mutagenisiert. Dazu war der Austausch zweier Aminosäuren ausreichend (E91S und L122H). Da diese jedoch wichtig für die korrekte Faltung des Proteins waren, musste durch anschließende Zufallsmutagenese die Faltung der Mutanten wieder verbessert werden. Auf diese Weise wurde ein Dimer mit sechs Mutationen erstellt (asFP595: T13A, V73A, E91S, R139G, A143G, H169Y, L122H).

Bei der Mutagenese vom Dimer zum Monomer wurden ebenfalls hauptsächlich hydrophobe Aminosäuren mutiert. Da zwischen den Untereinheiten A und B jedoch mehr hydrophobe Kontakte bestanden, waren auch mehr Mutationen notwendig, um ein Protein zu erzeugen welches als Monomer vorliegt. Dabei wurde die korrekte Faltung allerdings noch stärker in Mitleidenschaft gezogen als bei der Mutagenese zum Dimer. Letztendlich wurde ein Monomer durch den Austausch von insgesamt 14 Aminosäuren und einer Deletion ab Position 222 entwickelt (T13A, T68A, V73A, E91S, L122H, R139G, A143S, I146N, E149V, L159H, H169Y, E195V, K207I, Q213L, C222Stop). Dieses Monomer zeigt jedoch auch nach dem Einschalten mit 488 nm nur ein sehr geringes Fluoreszenzsignal. Zusätzlich ist die Faltung sehr langsam und unvollständig. Dieses Problem konnte jedoch auch mit intensiver Mutagenese, sowohl zufälliger als auch gerichteter, nicht behoben werden.

$\mathrm{Zu}$ diesem Zeitpunkt wurde jedoch das reversibel schaltbare, monomere und sehr helle fluoreszierende Protein Dronpa entdeckt (Ando et al. 2004). Dieses Protein wurde parallel zu der Monomerisierung von asFP595 untersucht. 


\section{IV.3. Der Dronpa Schaltmechanismus}

Dronpa liegt als Monomer vor und weist eine gute Helligkeit auf, im Gegensatz zu asFP595 ist es daher bereits für einige Anwendungen in der Zellbiologie geeignet (Kurokawa et al. 2005; Aramaki et al. 2006; Fujioka et al. 2006). Das Schalten selbst unterscheidet sich jedoch von demjenigen in asFP595. Aus diesem Grund wurde der Schaltmechanismus in Dronpa untersucht, um die Eigenschaften des Proteins anschließend wie bei asFP595 zu optimieren.

\section{IV.3.1 Das RSFP Dronpa}

Der Schaltprozess von Dronpa ist genau umgekehrt zu dem von asFP595. Während asFP595 nach einem positiven Modus geschaltet wird, funktioniert Dronpa nach einem negativen Modus. Dies bedeutet, dass asFP595 mit der Wellenlänge eingeschaltet wird, mit der die Fluoreszenz ausgelesen wird. Im Gegensatz dazu ist bei Dronpa die Wellenlänge mit der die Fluoreszenz angeregt wird diejenige, die das Ausschalten induziert (Abbildung 16). Dronpa muss als grün fluoreszierendes Protein mit blau-grünem Licht $(488 \mathrm{~nm})$ angeregt (bzw. ausgeschaltet) werden, während es mit UV-Licht (405 nm) wieder eingeschaltet werden kann. Aufgrund des ähnlichen, wenn auch genau umgekehrten Schaltverhalten von asFP595 und Dronpa, liegt die Hypothese nahe, dass auch im Falle von Dronpa eine cis-trans-Isomerie bei dem Schaltvorgang beteiligt ist. Da es von dem Protein Dronpa jedoch noch keine Struktur gab, konnte über den molekularen Schaltmechanismen nur spekuliert werden. Um Dronpa für die Strukturbestimmung aufzureinigen, wurde die kodierende Sequenz von Dronpa in den Vektor pQE31 eingebaut und in dem E.coli-Stamm BL21 exprimiert, aufgereinigt und für die Kristallisierung eingesetzt. 


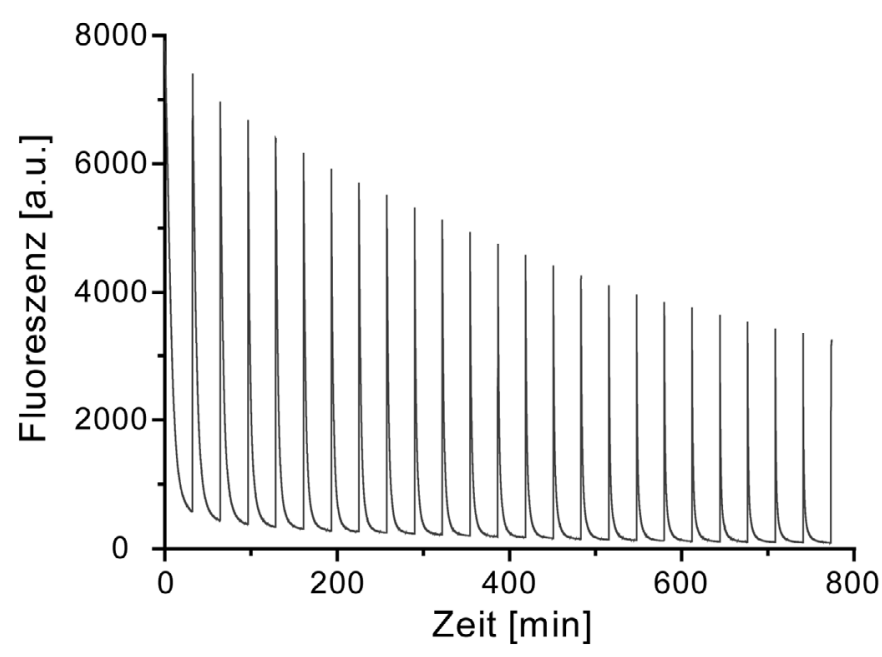

Abbildung 16: Reversibles Schalten von Dronpa. Dargestellt sind Schaltkurven, die auf einer Dronpa exprimierenden E.coli-Kolonie aufgenommen wurden. Die Zellen wurden abwechselnd für $28 \mathrm{~s}$ mit der Wellenlänge $488 \pm 5 \mathrm{~nm}\left(0,2 \mathrm{~W} \cdot \mathrm{cm}^{-2}\right)$ und für $2 \mathrm{~s}$ mir der Wellenlänge $405 \pm 5 \mathrm{~nm}(0,1$ $\mathrm{W} \cdot \mathrm{cm}^{-2}$ ) bestrahlt.

\section{IV.3.2 Struktur von Dronpa im Grundzustand}

Die Kristallisierung von Dronpa war unter den Bedingungen 22\% PEG 3350, 0,14 M $\mathrm{Mg}\left(\mathrm{NO}_{3}\right)_{2}$ möglich. Die Kristalle (Abbildung 19 SeiteX) zeigten einen orthorhombischen Aufbau und ergaben eine Struktur mit der Auflösung von 1,8 $\AA$ (Messung: PXII Beamline, swiss light source). Das Protein wurde in seinem fluoreszierenden Grundzustand kristallisiert, weshalb die Kristalle eine starke Fluoreszenz zeigten. Diese Fluoreszenz konnte auch durch Bestrahlung mit $405 \mathrm{~nm}$ nicht weiter gesteigert werden. Die Kristallstruktur im Grundzustand wird daher als Dronpa ${ }^{\text {on }}$ (PDB ID: 2IOV) bezeichnet, und stellt den fluoreszierenden Zustand des RSFP Dronpa dar (Abbildung 17a).

Die Grundstruktur entspricht der aller GFP-ähnlichen fluoreszierenden Proteine. Bei Dronpa besteht das Chromophor aus den drei Aminosäuren Cys62, Tyr63 und Gly64. Der Chromophor nimmt eine cis-Konformation ein und ist leicht in sich verdreht. Die Ebenen des Imidazol- und Tyrosylringes stehen aufgrund der Verkippung $(\alpha)$ und Verdrehung $(\beta)$ um die beiden Bindungen der Methinbrücke im Winkel von ca. $15^{\circ}$ zueinander (Abbildung 17b). Das Chromophor ist in der Proteinmatrix durch ein Netz aus 10 Wasserstoffbrücken befestigt $(\rightarrow$ IX.2.1). Der potentiell bewegliche para-Hydroxyphenylring interagiert dabei über die $\mathrm{OH}$ Gruppe mit der Aminosäure Ser142, sowie indirekt über ein Wassermolekül mit Glu140. 

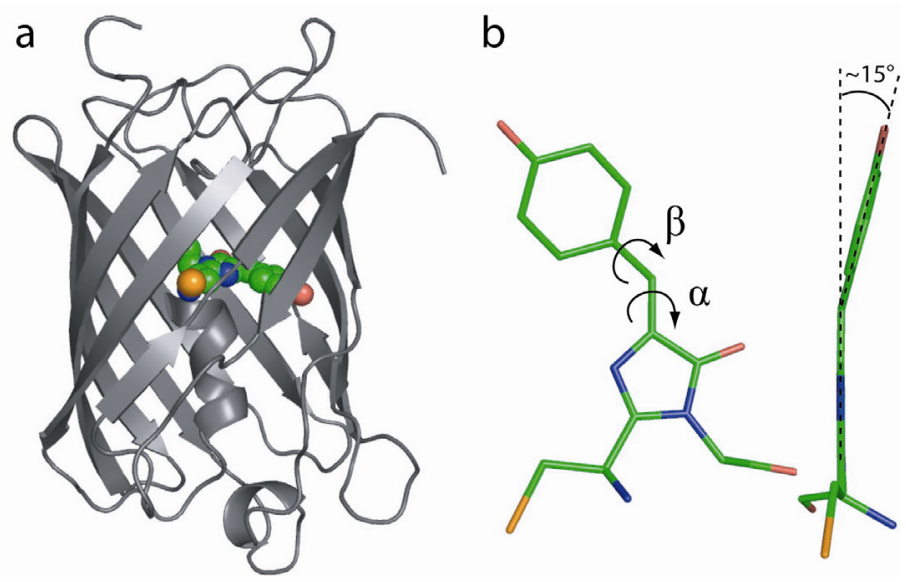

Abbildung 17: Struktur von Dronpa im fluoreszierenden Zustand. Übersicht (a) und Detailansicht (b) des Chromophors. Das Chromophor hat sowohl eine leichte Verkippung um den Winkel $\alpha$ von $\sim 12^{\circ}$ als auch eine Verdrehung um den Winkel $\beta$ von $\sim 16^{\circ}$. Dies führt zu einem Winkel zwischen den Ebenen von $15^{\circ}$.

\section{IV.3.3 Struktur von Dronpa im nicht fluoreszierenden Zustand}

Die spektroskopischen Eigenschaften und die Struktur von Dronpa im fluoreszierenden Zustand deuten auf einen ähnlichen Schaltmechanismus wie im Falle von asFP595 hin.

Um die Hypothese für den Mechanismus zu überprüfen, musste daher auch eine Strukturanalyse von Dronpa im geschalteten Zustand durchgeführt werden. Die Kristalle wurden im Reservoir des jeweiligen Kristallansatzes geschaltet, anschließend in Öl überführt und eingefroren. Ein Problem bei der Ermittlung der Kristallstruktur von Dronpa im nicht fluoreszierenden Zustand, stellte die hohe Effektivität des Einschaltens von Dronpa mit UVLicht dar. Nach dem Ausschalten musste darauf geachtet werden, dass der Kristall möglichst schnell und ohne weitere Bestrahlung mit Licht einer Wellenlänge unter $480 \mathrm{~nm}$ in das Öl Perfluoropolyether transferiert und in flüssigem Stickstoff eingefroren wurde. Dieser Transfer wurde innerhalb von etwa $15 \mathrm{~s}$ durchgeführt. In dieser Zeit fällt der Kristall zu weniger als $2 \%$ in den fluoreszierenden Grundzustand zurück.

Die sargförmigen Kristalle ließen sich mit Licht der Wellenlängen $488 \mathrm{~nm}$ und $405 \mathrm{~nm}$ reversibel zwischen dem fluoreszierenden und dem nicht fluoreszierenden Zustand hin und her schalten. Dabei betrug das Bleichen nur etwa $2 \%$ pro Zyklus (Abbildung 18). 
a
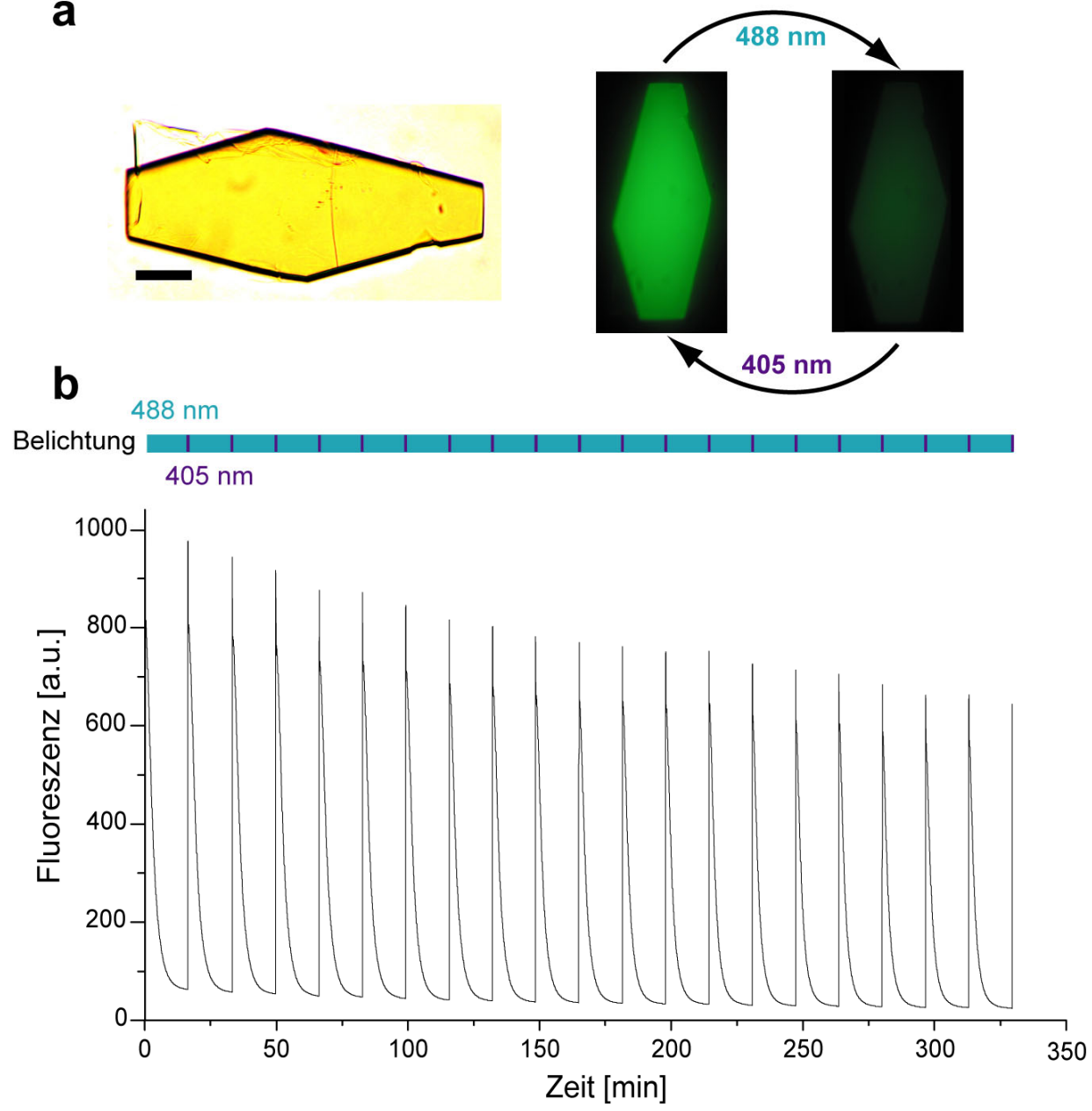

Abbildung 18: Reversibles Schalten eines Dronpa Kristalls. Der Kristall wurde einmal im Hellfeld, sowie im fluoreszierenden und nicht fluoreszierenden Zustand aufgenommen (a). Größenstandard: $50 \mu \mathrm{m}$. Der Kristall wurde im Reservoir des entsprechenden Kristallisierungsansatzes geschaltet. Ausgeschaltet wurde mit $488 \mathrm{~nm}$, das Einschalten war durch gleichzeitige Belichtung mit $488 \mathrm{~nm}$ und $405 \mathrm{~nm}$ möglich. Der Graph zeigt das reversible Schalten eines Kristalls (b). Der Balken über dem Graph zeigt die Sequenz der Belichtung an, wobei dauerhaft mit $488 \mathrm{~nm}$ belichtet wurde. Jeweils nach 16,5 Minuten wurde für 2,2 Sekunden zusätzlich mit $405 \mathrm{~nm}$ belichtet, um den Kristall wieder einzuschalten. Der Graph zeigt die Änderung des Fluoreszenzsignals im Kristall in Abhängigkeit von der Zeit.

Die Kristalle mussten für 16,5 min mit $488 \pm 5 \mathrm{~nm}\left(0,3 \mathrm{~W} \cdot \mathrm{cm}^{-2}\right)$ bestrahlt werden, um sie auf eine Restfluoreszenz von $5 \%$ auszuschalten, während das Einschalten mit $405 \pm 5 \mathrm{~nm}$ $\left(0,2 \mathrm{~W} \cdot \mathrm{cm}^{-2}\right)$ nur $2,2 \mathrm{~s}$ in Anspruch nimmt. Ein einmalig auf $5 \%$ Restfluoreszenz ausgeschalter Kristall, wurde für die Bestimmung der Struktur von Dronpa ${ }^{\text {off }}$ wie oben beschrieben in Öl überführt und eingefroren. Die Streudaten wurden in der Schweiz (PXII beamline der Swiss Light Source; Villigen, Schweiz) bei $100 \mathrm{~K}$, mit einem MarResearch CCD Detektor aufgenommen und mit dem HKL Software Paket analysiert. Die Lösung der 
Struktur erfolgte wie bei asFP595 und der Dronpa ${ }^{\text {on }}$ Struktur in Zusammenarbeit mit der Gruppe von Dr. Markus Wahl.

\section{IV.3.4 Vergleich der Strukturen Dronpa ${ }^{\text {off }}$ und Dronpa $^{\text {on }}$}

Ein $\mathrm{C}_{\alpha}$ Abgleich der Strukturen Dronpa ${ }^{\text {off }}$ und Dronpa ${ }^{\text {on }}$ wies keine deutlichen Änderungen der B-Fassstruktur auf. Das Chromophor und zwei weitere Aminosäuren (R66, H193) in der direkten Umgebung nehmen jedoch unterschiedliche Konformationen ein. Zusätzlich sind zwei weitere Aminosäuren (S142, V157) in der Struktur Dronpa ${ }^{\text {off }}$ durch eine Bewegung vom Chromophor weg etwas nach außen versetzt (Abbildung 19).

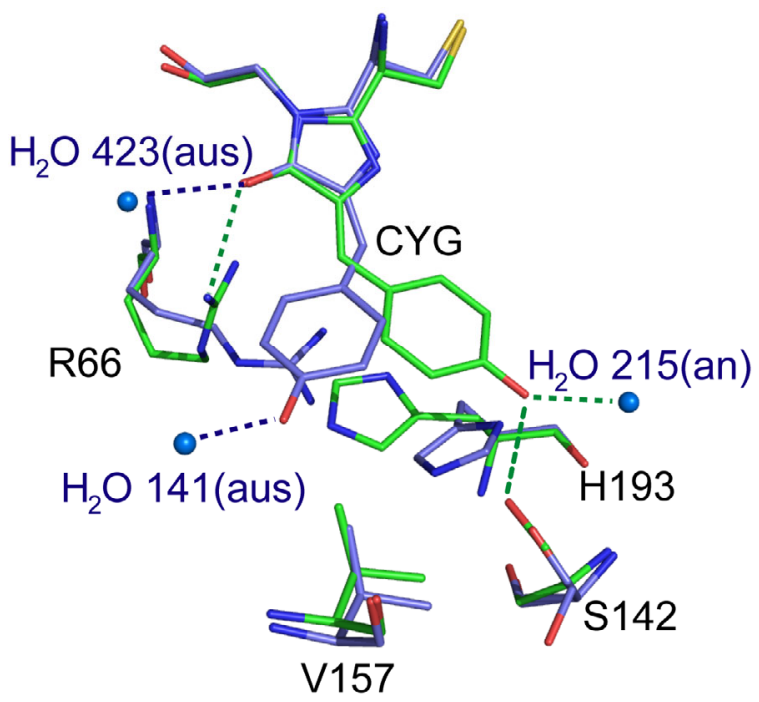

Abbildung 19: Unterschiede in der Chromophorumgebung von Dronpa im fluoreszierenden und nicht fluoreszierenden Zustand. Dargestellt ist ein $\mathrm{C}_{\alpha}$ Abgleich von Dronpa ${ }^{\text {off }}$ und Dronpa ${ }^{\text {on }}$. Die Kohlenstoffatome von Dronpa ${ }^{\text {off }}$ sind in Blau dargestellt, die von Dronpa ${ }^{\text {on }}$ in Grün. Die Linien zeigen Wasserstoffbrücken des Chromophors, die im An- und Auszustand unterschiedlich sind. Das Chromophor und vier weitere Aminosäuren verändern durch das Schalten merklich ihre Position, weiterhin ist das Chromophor im fluoreszierenden cis-Zustand (grün) besonders an der terminalen OH-Gruppe besser stabilisiert.

Die Konformationsänderung des Chromophors ist fast ausschließlich auf eine ausladende Bewegung der para-Hydroxyphenylgruppe beschränkt. Während der Imidazolring nur eine leichte Drehung um $5^{\circ}$ beschreibt, bewegt sich die terminale Hydroxylgruppe um 5,8 $\AA$. Das Arginin 66 nimmt in der ausgeschalteten Struktur eine ausgestreckte Konformation unter dem Chromophor ein, diese Position wurde zuvor von Histidin 193 belegt. Das Arginin ersetzt somit die stabilisierende $\pi$-Stapelwirkung zwischen dem Histidin 193 und dem Chromophor durch eine Kation- $\pi$-Stapelung. Das Histidin bewegt sich mit einer $116^{\circ}$ Drehung um die $C_{\alpha}-$ 
$\mathrm{C}_{\beta}$ Bindung unter dem Chromophor weg, in Richtung der frei gewordenen cisChromophortasche. Die beiden Aminosäuren Serin 142 und Valin 157 bewegen sich um 0,5 bzw. $1 \AA$ nach außen. Auf diese Weise wird Platz für die Aminosäure H193 und den Chromophor geschaffen. Das B-Fass wird durch das Ausweichen der beiden Aminosäuren leicht aufgeweitet.

\section{IV.3.5 Unterschiede in der Stabilisierung und der elektrostatischen Umgebung des Chromophors}

Die Konformationsänderungen des Chromophors und seiner Umgebung resultieren in einem nicht fluoreszierenden Chromophor, dessen terminale Hydroxylgruppe im protonierten Zustand vorliegt.

Die Quantenausbeute wird durch ein stabilisiertes Chromophor begünstigt (Remington 2006). Während das cis-Chromophor 10 Wasserstoffbrücken zu seiner Umgebung ausbildet, wird das trans-Chromophor nur durch 8 Wasserstoffbrücken befestigt ( $\rightarrow$ IX.2.1). Die geringere Stabilität im trans-Zustand zeigt sich in der Planarität des Chromophors. Im Mittel über die vier Dronpa-Moleküle in der Einheitszelle, schneiden sich die beiden Normalen der Ebenen des Imidazol- und des para-Hydroxyphenylringes im fluoreszierenden cis-Zustand nur mit einem Winkel von etwa $15^{\circ}$. Im Gegensatz dazu stehen Ebenen der Chromophorringe im nicht fluoreszierenden trans-Zustand im Winkel von etwa $30^{\circ}$ zueinander. Das konjugierte $\pi$ Elektronensystem kann also nicht die bevorzugte planare Konformation einnehmen und befindet sich daher in einem energetisch höheren Zustand. Dies hat einen starken Einfluss auf die Stabilität des Chromophors und somit auf die Fähigkeit zu fluoreszieren (Remington 2006).

Ein weiterer essentieller Unterschied ist der Protonierungszustand der Hydroxylgruppe des Chromophors ( $\rightarrow$ IX.2.2). Dieser Unterschied wird durch eine Änderung der elektrostatischen Umgebung dieser Gruppe hervorgerufen. Eine Berechnung der Ladungsverteilung mit dem Programm ABPS zeigt deutliche Unterschiede in der cis- und der trans-Chromophortasche (Abbildung 20). Die Protonierung der Hydroxylgruppe im nicht fluoreszierenden Zustand zeigt sich ebenfalls durch das Fehlen der Wasserstoffbrücke zu Serin 142 ( $\rightarrow$ IX.2.1) in der Struktur von Dronpa ${ }^{\text {off }}$ (trans-Konformation). 


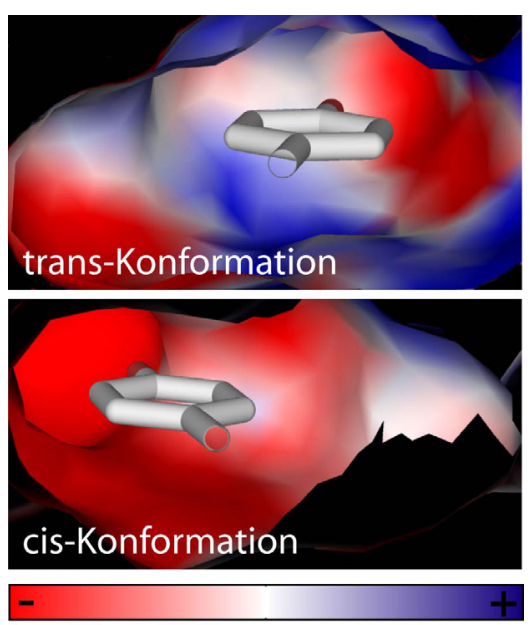

Abbildung 20: Ladungsverteilung in der Umgebung des Chromophors in der cis- und transKonformation. Die Ladungen wurden mit dem Programm ABPS anhand der Strukturen von Dronpa ${ }^{\text {on }}$ (cis-Konformation) und Dronpa ${ }^{\text {off }}$ (trans-Konformation) berechnet. Dargestellt ist die Tyrosylgruppe des Chromophors und dessen Umgebung. Zur Berechnung der Ladung wurde das Chromophor aus der Struktur entfernt.

Ebenso wie bei asFP595 wird das Schalten von Dronpa durch eine cis-trans-Isomerie des Chromophors ermöglicht. Der Mechanismus des Schaltens zwischen dem fluoreszierenden und nicht fluoreszierenden Zustand, dem eine cis-trans-Isomerie zu Grunde liegt, scheint für alle RSFPs zu gelten. Im Rahmen dieser Arbeit wurde der grundlegende Mechanismus für die zwei ersten Vertreter dieser neuen Spezies fluoreszierender Proteine (asFP595 und Dronpa) aufgeklärt. Das Ziel war jedoch nicht allein das Verständnis des Mechanismus, sondern auch die Verbesserung und Anwendung der RSFPs. Die Verbesserung konnte bei asFP595 bereits erfolgreich gezeigt werden, jedoch ist asFP595 aufgrund seiner Oligomerisierung zu einem Tetramer wenig geeignet für Anwendungen in lebenden Zellen. Im nachfolgenden Kapitel wird die Verbesserung und die Anwendung von Varianten des Proteins Dronpa beschrieben. 


\section{IV.4 Entwicklung und Anwendung neuer RSFPs}

\section{IV.4.1 Erstellen von rsFastLime}

Bei Dronpa und asFP595 nehmen die Chromophore im fluoreszierenden Zustand eine cisPosition ein. Eine einfache Drehung des Dronpa-Chromophors in eine hypothetische nicht fluoreszierende trans-Position (entsprechend asFP595) resultiert in einer Kollision des Chromophors mit der Aminosäure Valin 157. Ein Austausch von Valin 157 gegen eine kleinere Aminosäure würde vermutlich einen leichteren Zugang des nicht fluoreszierenden Zustands ermöglichen. Um dies zu testen wurde die Variante Dronpa-V157G erstellt. Diese Variante zeigt ein deutlich schnelleres Schaltverhalten, was anhand des Modells durch den energetisch günstigeren trans-Zustand erklärbar ist. Die Halbwertszeit, die für das Ausschalten benötigt wird ( $\mathrm{t}_{1} / 2$ off $)$, ist um den Faktor 50 reduziert. Während Dronpa nach $263 \mathrm{~s}$ um die Hälfte des dynamischen Bereichs geschaltet wurde, benötigt die Variante DronpaV157G nur $5 \mathrm{~s}$. Diese schnellere Isomerisierung resultiert wahrscheinlich daraus, dass die Energiebarriere für die Konformationsänderung reduziert ist. Die Energiebarriere kann durch die natürliche Rückfallrate in den Grundzustand $t_{1 / 2}{ }^{\text {relax }}$ bestimmt werden, welche bei Dronpa V157G ebenfalls etwa um den Faktor 100 schneller ist (Tabelle 1). Die Zeit, die für das Schalten in den fluoreszierenden Zustand benötigt wird, ist dagegen nahezu unverändert und um Größenordnungen schneller als das Ausschalten ( $\mathrm{t}_{1 / 2}{ }^{\text {on }}$-Dronpa: $0,10 \mathrm{~s} ; \mathrm{t}_{1 / 2}{ }^{\text {on }}$-DronpaV157G: 0,11 s).

\begin{tabular}{lccccccc}
\hline $\begin{array}{c}\text { Fluoreszierendes } \\
\text { Protein }\end{array}$ & $\begin{array}{c}\text { Absorptions- } \\
\text { maximum } \\
{[\mathrm{nm}]}\end{array}$ & $\begin{array}{c}\text { Emissions- } \\
\text { maximum } \\
{[\mathrm{nm}]}\end{array}$ & $\begin{array}{c}\text { Extinktions- } \\
\text { koeffizient } \\
{\left[\mathrm{M}^{-1} \cdot \mathrm{cm}^{-1}\right]^{*}}\end{array}$ & $\begin{array}{c}\text { Quanten- } \\
\text { Ausbeute } \\
\left(\Phi_{\mathrm{FL}}\right)^{*}\end{array}$ & $\begin{array}{c}\text { Halbwertszeit } \\
\text { ausschalten } \\
\mathrm{t}_{1 / 2} \text { off }[\mathrm{s}]\end{array}$ & $\begin{array}{c}\text { Halbwertszeit } \\
\text { einschalten } \\
\mathrm{t}_{1 / 2}{ }^{\text {on }}[\mathrm{s}]\end{array}$ & $\begin{array}{c}\text { Natürliche } \\
\text { Rückfallrate } \\
\mathrm{t}_{1 / 2} \text { relax }\left[\mathrm{min}^{2}\right.\end{array}$ \\
\hline Dronpa & 503 & 522 & 125000 & 0,68 & 263.00 & 0,10 & 840 \\
Dronpa-M159T & 489 & 515 & 82000 & 0,18 & 0,23 & 0,05 & 0,5 \\
$\begin{array}{l}\text { Dronpa-V157G } \\
\text { (rsFastLime) }\end{array}$ & 496 & 518 & 51000 & 0,60 & 5,00 & 0,11 & 8 \\
\hline
\end{tabular}

Tabelle 1: Eigenschaften von Dronpa und den Varianten Dronpa-V157G (rsFastLime) und Dronpa-M159T. *Die Werte wurden im Vergleich zu EGFP ermittelt.

Eine weitere Mutante Dronpa-M159T adressiert ebenfalls eine Position, die bei einer cistrans-Konformationsänderung sterisch hindert. Die Mutation zeigt einen noch stärkeren Einfluss auf die beiden Eigenschaften $t_{1 / 2}$ off und $t_{1 / 2}{ }^{\text {relax }}$ (Tabelle1). Allerdings scheint sich die höhere Schaltgeschwindigkeit der Mutanten negativ auf die Quantenausbeute $\left(\Phi_{\mathrm{FL}}\right)$ auszuwirken. Während Dronpa-V157G eine Quantenausbeute von 0,60 hat, ist diese bei 
Dronpa-M159T sogar auf 0,18 reduziert. Neben der Helligkeit ist jedoch auch das Photobleichen ein essentieller Aspekt für die Anwendung fluoreszierender Proteine. Diesbezüglich wurde zum Vergleich der drei RSFPs Dronpa, Dronpa-V157G und DronpaM159T das Bleichen in Abhängigkeit der Schaltzyklen gemessen. Dabei zeigte sich, dass das maximale Fluoreszenzsignal bei Dronpa nach $\sim 20$ Zyklen, bei Dronpa-V157G erst nach $\sim 75$ Zyklen auf die Hälfte des maximalen Wertes gefallen ist. Bei der Variante Dronpa-M159T war sogar nach 650 Zyklen kaum Bleichen zu detektieren. Aufgrund seiner geringen Helligkeit ist Dronpa-M159T jedoch wahrscheinlich dennoch für die meisten Anwendungen ungeeignet. Das Protein Dronpa-V157G zeigt gegenüber Dronpa eine um den Faktor 50 erhöhte Schaltgeschwindigkeit, hat nur etwa ein Viertel der Restfluoreszenz und ist nach wie vor ein monomeres, helles fluoreszierendes Protein mit einer Quantenausbeute von 0,60. Die Dronpa-Variante bekam aufgrund ihres schnellen Schaltens den Namen rsFastLime. Im folgenden Absatz werden zwei Beispiele dieser Anwendbarkeit beschrieben.

\section{IV.4.2 rsFastLime ermöglicht die Umsetzung neuer Mikroskopietechniken}

Das Ausschalten von rsFastLime in den nicht fluoreszierenden Zustand ermöglicht es, die aktive Fluorophorkonzentration nahezu um den Faktor $100 \mathrm{zu}$ senken. Diese Eigenschaft wurde in einer FCS (fluorescence correlation spectroscopy) Studie genutzt, da hier eine geringe Dichte an Fluorophoren zwingend erforderlich ist (Eggeling et al. 2007).

Eine weitere Anwendung für reversibles Schalten von RSFPs wurde mit der Nutzung von rsFastLime für die hochauflösende Mikroskopie in einem EinzelmolekülLokalisationsverfahren ( $\rightarrow$ III.1.4) gezeigt. Dabei wird ausgenutzt, dass die Detektion von einzelnen fluoreszierenden Molekülen eine Berechnung des Ursprungs der Fluoreszenz zulässt. Dies ist möglich, da die Photonen eines einzelnen Moleküls auf einem Detektor eine Gaussverteilung ergeben. Durch die Berechnung des Mittelpunktes dieser Gaussverteilung ergibt sich der Ort des Moleküls (Betzig et al. 2006; Dedecker et al. 2006; Rust et al. 2006; Egner et al. 2007). Beide Methoden bedienen sich der Reduzierung fluoreszierender Chromophore durch das Ausschalten. 


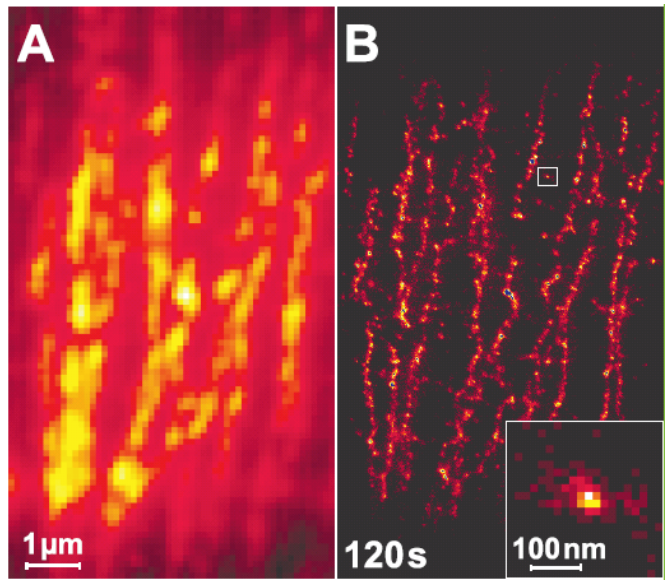

Abbildung 21: Hochauflösende Mikroskopie durch Einzelmolekülspektroskopie. Links (a) ist ein rekonstruiertes Weitfeldbild einer PtK2-Zelle zu sehen, in der $\alpha$-Tubulin über Antikörper mit rsFastLime markiert ist. Rechts (b) ist derselbe Ausschnitt nach dem EinzelmolekülLokalisationsverfahren dargestellt. Ausschnitt unten rechts: Vergrößerte Darstellung des markierten Bereichs in (b).

\section{IV.4.3 Padron und bsDronpa zwei RSFPs mit einzigartigen Eigenschaften}

Obwohl rsFastLime in einigen Eigenschaften gegenüber Dronpa verbessert wurde, sind die zwei Proteine als einzige verfügbare monomere RSFPs in ihren Eigenschaften sehr ähnlich. Da rsFastLime über eine ausreichend hohe Quantenausbeute $(0,60)$, sowie einen guten dynamischen Bereich (1:66) verfügt, wurde es als Ausgangsklon für die weitere Entwicklung von RSFPs mit grundlegend unterschiedlichen Eigenschaften ausgewählt.

Bei einem Vergleich der Kristallstrukturen Dronpa ${ }^{\text {off }}$ und Dronpa $^{\text {on }}$ ergaben sich mehrere für die Eigenschaften des Chromophors und des Schaltens potentiell wichtige Positionen (66, 159, 157, 173 und 193). Diese Aminosäuren wurden mittels gerichteter Mutagenese durch Austausch gegen alle zwanzig Aminosäuren variiert. Bei dieser Mutagenese traten Varianten mit stark veränderten Eigenschaften auf, wobei die Mutation Met159Tyr sogar eine Umkehr des Schaltmodus bewirkte. Die Variante Dronpa-V157G, M159Y ist im Gegensatz zu den anderen Dronpa Varianten positiv schaltbar. Dies bedeutet, dass das gemessene Fluoreszenzsignal durch Belichtung mit $488 \mathrm{~nm}$ stärker wird, anstatt wie bei Dronpa abzunehmen. Durch Bestrahlung mit 405 nm wird die emittierte Fluoreszenz wieder weniger. Diese Mutation allein erzeugt zwar eine Umkehr des Schaltmodus, jedoch ist das Schalten nur auf einen sehr kleinen dynamischen Bereich begrenzt. Die Fluoreszenz lässt sich mit $405 \mathrm{~nm}$ nur auf einen Wert, der 50\% des maximalen Fluoreszenzsignals entspricht, ausschalten. Durch anschließende zufällige und gerichtete Mutagenese, konnte diese Mutante jedoch in 
sechs Evolutionsrunden zu einem sehr guten, positiv schaltbaren RSFP verbessert werden (Tabelle 2). Die Dronpa Variante wurde aufgrund des gegenüber Dronpa umgekehrten Schaltens Padron genannt $($ Padron = Dronpa: T59M, V60A, N94I, P141L, G155S, V157G, M159Y, F190S).

Padron hat eine Quantenausbeute von 0,64 $\left(\lambda_{\mathrm{Em}}=522 \mathrm{~nm}\right)$ und einen Extinktionskoeffizienten bei $503 \mathrm{~nm}$ von $43000 \mathrm{M}^{-1} \cdot \mathrm{cm}^{-1}$. Das Protein zeigt mit einer Restfluoreszenz von nur $0,7 \%$ einen sehr guten dynamischen Bereich von 1:150 und ist, obwohl es fast so schnell schaltet wie rsFastLime ( $\mathrm{t}_{1 / 2}$ on Padron $=5,6 \mathrm{~s} ; \mathrm{t}_{1} / 2$ off $r$ rsFastLime $\left.=2,6 \mathrm{~s}\right)$ nahezu bistabil $\left(\mathrm{t}_{1 / 2}{ }^{\text {relax }}=150 \mathrm{~min}\right)$. Das Protein liegt bei $37^{\circ} \mathrm{C}$ als komplettes Monomer vor, bei $4{ }^{\circ} \mathrm{C}$ dagegen ist Padron $\mathrm{zu} \sim 15 \%$ dimerisiert ( $\rightarrow$ IX.2.5). Die Dimerisierung konnte jedoch durch gezielten Austausch hydrophober Aminosäuren an der Außenseite des ß-Fasses unterbunden werden. Daraus ergab sich die Mutante Padron* (Padron* = Dronpa T59M, V60A, N94H, I100S, P141R, G155S, V157G, M159Y, F190S, K222N), die auch bei $4{ }^{\circ} \mathrm{C}$ vollständig als Monomer vorliegt. Padron* hat allerdings im Vergleich zu Padron, mit einer Restfluoreszenz von 2 statt $0,7 \%$ und einem Bleichen von 3 statt $2 \%$ pro Schaltzyklus, etwas schlechtere Eigenschaften. Deshalb ist Padron* speziell für Anwendungen bei niedrigen Temperaturen geeignet, für die meisten in vivo Anwendungen sollte jedoch Padron besser geeignet sein.

Eine weitere Mutante mit veränderten Eigenschaften wurde während der Evolution von Padron entdeckt. Eine Mutante mit einem Cystein an Position 159 zeigte ein besonders breites, asymmetrisches, blauverschobenes Absorptionsspektrum. Die Mutante zeigt bei Anregung mit $405 \mathrm{~nm}$ eine ähnlich starke Fluoreszenz, wie bei Anregung mit $488 \mathrm{~nm}$. Durch weitere Mutagenese dieser Variante wurde das Protein bsDronpa generiert (bsDronpa = Dronpa V60A, A69T, D112N, P141Q, G155S, V157G, M159C, F173C ), wobei bs für breites Spektrum steht. Mit einer Quantenausbeute von $\Phi_{\mathrm{FL}}=0,5$ und einem Extinktionskoeffizienten bei $460 \mathrm{~nm}$ von $45000 \mathrm{M}^{-1} \cdot \mathrm{cm}^{-1}$ ist das Protein ein helles, monomeres und reversibel schaltbares fluoreszierendes Protein. Die Restfluoreszenz im ausgeschalteten Zustand beträgt bei bsDronpa $6 \%$. Aufgrund des breiten, blauverschobenen Absorptionsspektrums von bsDronpa mit einem Maximum bei 460 nm, und einer Emission bei 504 nm, kann bsDronpa effektiv mit UV-Licht (405 nm) angeregt werden (Extinktionskoeffizient ${ }_{405}: 18500 \mathrm{M}^{-1} \cdot \mathrm{cm}^{-1}$ ). Dadurch ergibt sich ein Unterschied von etwa 100 Nanometern zwischen der Anregungs- und Emissionswellenlänge. 


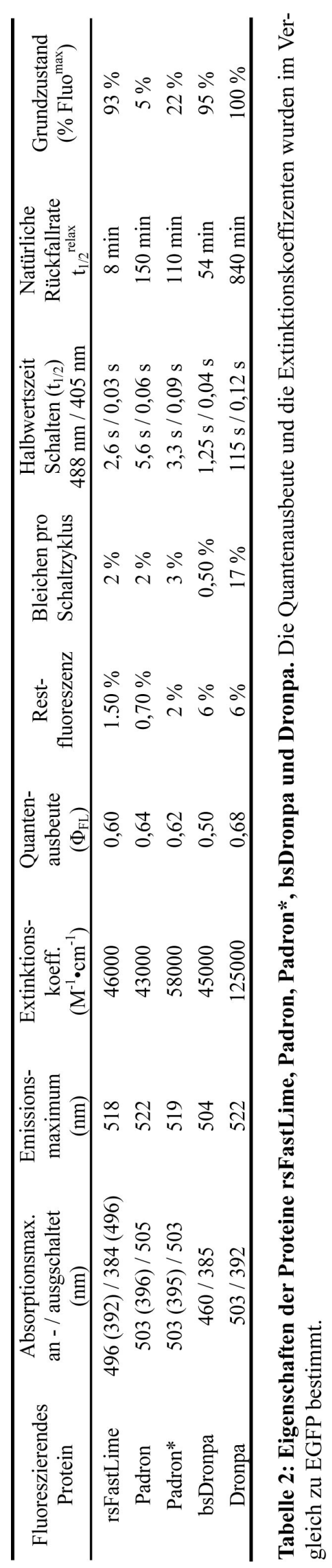




\section{IV.4.4 Monochromatische Dreifarben-Fluoreszenzmikroskopie}

Die Unterschiede der grün fluoreszierenden RSFPs bsDronpa, rsFastLime und Padron ermöglichen trotz gleicher Emissionswellenlänge ein separates Auslesen der einzelnen Proteine. Weil rsFastLime und Padron entgegengesetzt schalten, kann ihre Fluoreszenz durch eine bestimmte Belichtungsreihenfolge zu unterschiedlichen Zeitpunkten ausgelesen werden. Da bsDronpa genauso schaltet wie rsFastLime, kann es nicht wie Padron von rsFastLime getrennt aufgenommen werden. Im Gegensatz zu rsFastLime kann bsDronpa jedoch effektiv mit UV-Licht angeregt werden. Das Fluoreszenzsignal aller drei Proteine kann daher mit nur einem einzigen Detektionsfenster (498 - 520 nm) und zwei Anregungswellenlängen (405 nm und $496 \mathrm{~nm}$ ) separat aufgenommen werden (Abbildung 22).

Um dies in einem Experiment nachzuweisen, wurden drei E.coli-Kulturen, die jeweils eines der drei Proteine exprimierten, in gleichem Verhältnis gemischt. Um die Fluoreszenz der unterschiedlichen E.coli-Zellen einzeln aufnehmen zu können, waren fünf Belichtungsschritte notwendig (Abbildung 22a). Die Zellen wurden zunächst mit $405 \mathrm{~nm}$ bestrahlt $\left(100 \mathrm{~kW} \cdot \mathrm{cm}^{-2}\right)$, um bsDronpa und rsFastLime vollständig in den fluoreszierenden bzw. Padron in den nicht fluoreszierenden Zustand zu bringen (1). Als erstes der Proteine wurde dann bsDronpa durch Anregung mit $405 \mathrm{~nm}\left(70 \mathrm{~kW} \cdot \mathrm{cm}^{-2}\right)$ ausgelesen (2), gefolgt von rsFastLime, welches mit 496 $\mathrm{nm}$ angeregt wurde (3). Bei diesem Schritt ist die Intensität der Bestrahlung entscheidend, da Padron mit $496 \mathrm{~nm}$ angeschaltet und rsFastLime ausgeschaltet wird. Es muss mit relativ geringer Intensität angeregt werden $\left(5 \mathrm{~kW} \cdot \mathrm{cm}^{-2}\right)$, so dass die Proteine möglichst geringfügig geschaltet werden, rsFastLime aber trotzdem ein ausreichendes Fluoreszenzsignal liefert. Bei der in diesem Experiment verwendeten Intensität wurde Padron zu 0,3 \% aktiviert und rsFastLime zu 1,3\% inaktiviert. Im nächsten Schritt wurde nun mit hoher $496 \mathrm{~nm}$ Leistung bestrahlt $\left(100 \mathrm{~kW} \cdot \mathrm{cm}^{-2}\right)$, um Padron in den fluoreszierenden und rsFastLime, wie auch bsDronpa, in den nicht fluoreszierenden Zustand $\mathrm{zu}$ bringen (4). Zuletzt wurde die Fluoreszenz von Padron ausgelesen, indem mit moderater $496 \mathrm{~nm}$ Intensität $\left(15 \mathrm{~kW} \cdot \mathrm{cm}^{-2}\right)$ ein Bild aufgenommen wurde (5) (Abbildung 22 b-f). 


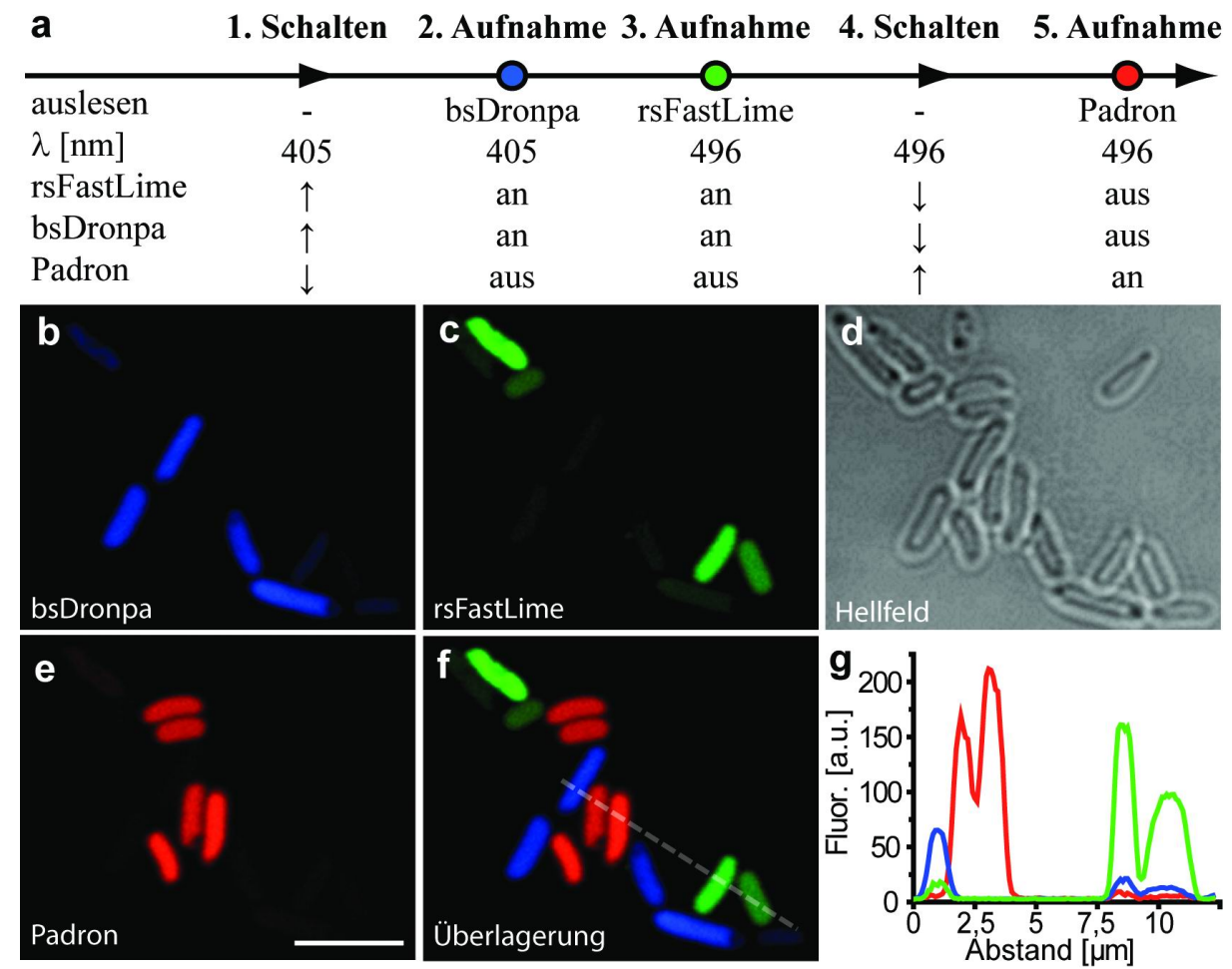

Abbildung 22: Monochromatische Dreifarben-Mikroskopie einer gemischten E.coli-Kultur mit Zellen, die rsFastLime, bsDronpa oder Padron exprimieren. Die Belichtungsreihenfolge besteht aus fünf Schritten, wobei zweimal geschaltet werden muss. Das Schalten der Proteine in den Schritten 1. und 4. in dem Schema ist mit Pfeilen dargestellt ( $\uparrow=$ anschalten; $\downarrow=$ ausschalten). Zunächst werden bsDronpa und rsFastLime an- und Padron ausgeschaltet (1). Dann wird bsDronpa mit $405 \mathrm{~nm}$ ausgelesen (2), gefolgt von rsFastLime, welches mit $496 \mathrm{~nm}$ ausgelesen wird (3). Als nächstes wird dann Padron eingeschaltet und gleichzeitig rsFastLime und bsDronpa ausgeschaltet (4). Als letztes Protein wird Padron mit Belichtung von 496 nm ausgelesen (5). Die Bilder b-e zeigen die einzelnen Aufnahmen, so wie ein Hellfeld Bild der E.coli-Zellen. In $\mathrm{f}$ ist eine Überlagerung der drei Kanäle in $\mathrm{b}, \mathrm{c}$ und e dargestellt. $\mathrm{g}$ zeigt ein Intensitätsprofil entlang der gestrichelten Linie in $\mathrm{f}$.

\section{IV.4.5 Crosstalk bei monochromatischer Dreifarben-Fluoreszenzmikroskopie}

Die Überlagerung der drei separat aufgenommenen Kanäle (Abbildung 22f) zeigt, dass eine Trennung der drei gemischten E.coli-Kulturen problemlos möglich ist. Aufgrund des entgegengesetzten Schaltens ist die Fluoreszenz von Padron in den Kanälen von rsFastLime und bsDronpa mit weniger als $0,5 \%$ sehr gering ( $\rightarrow$ IX.2.6). Dementsprechend ist das Signal von bsDronpa und rsFastLime, das beim Auslesen von Padron sichtbar ist, mit $5 \%$ und $3 \%$ ebenfalls relativ gering. Der Crosstalk ist nur zwischen bsDronpa und rsFastLime ein Problem, da diese Proteine gleichzeitig angeschaltet sind, und allein durch die Anregung getrennt werden. Während rsFastLime noch zu etwa $10 \%$ in dem bsDronpa Kanal zu 
erkennen ist, zeigt sich bsDronpa noch mit ca. $25 \%$ des eigentlichen bsDronpa Signals, wenn rsFastLime ausgelesen wird. (Abbildung 22g).

\section{IV.4.6 Lineares Entmischen und optimierte Detektionsfenster reduzieren den}

\section{Crosstalk auf ein Minimum}

Der Crosstalk der Fluoreszenz in die anderen Kanäle lässt sich entweder durch lineares Entmischen (linear unmixing), oder durch unterschiedliche Detektionsfenster reduzieren. Zur Bestimmung des Crosstalks für das lineare Entmischen wurden die Daten aus der Abbildung 22 ( $\rightarrow$ IX.2.6) verwendet. Für das Entmischen wurde die Leica LAS-AF simulator software (Version 1.7.0 build 1240; Leica Microsystems, Wetzlar, Deutschland) verwendet. Das resultierende Bild zeigt, dass der Crosstalk nach dem linearen Entmischen in allen Kanälen auf nahezu Null reduziert ist (Abbildung 23).
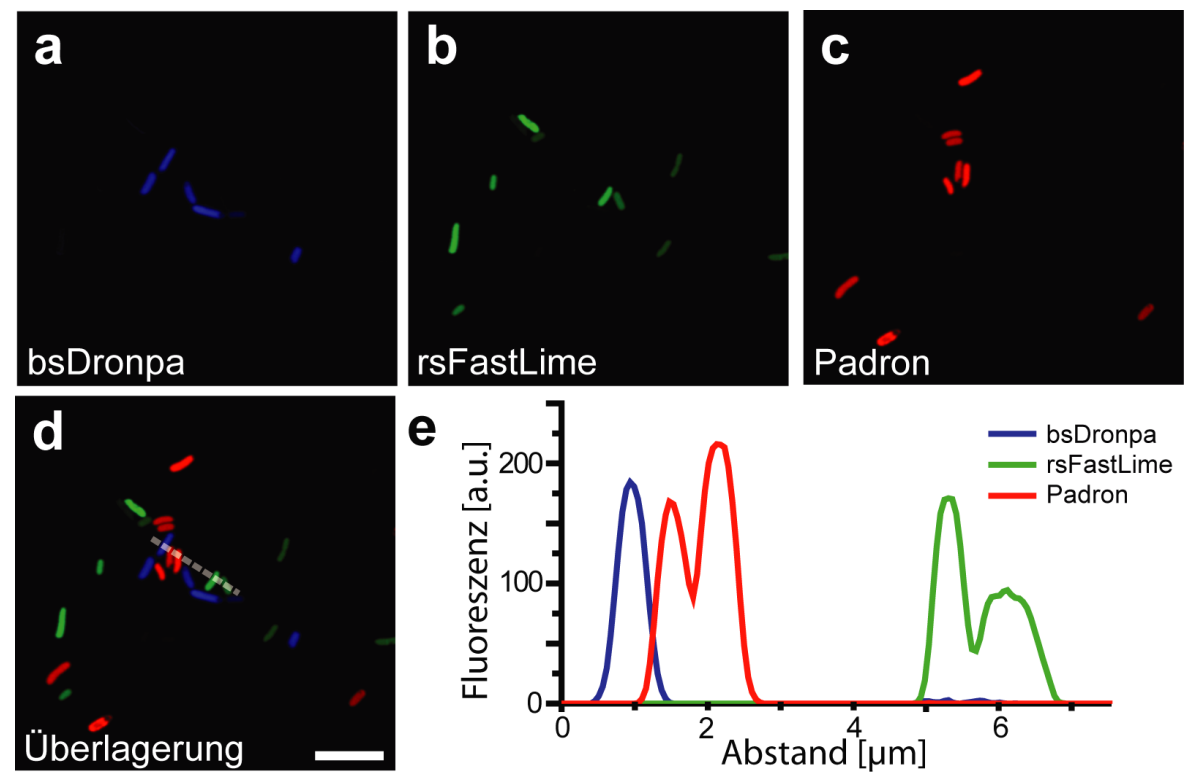

Abbildung 23: Darstellung der Daten aus Abbildung 22 nach linearem Entmischen. Die Daten wurden auf ihren Crosstalk analysiert, indem das Signal in den anderen beiden Kanälen über mindestens 100 Pixel für jedes Protein gemittelt wurde. Für die Berechnung der Bilder wurde die Leica LAS-AF simulator software benutzt. Die Bilder (a-c) zeigen die berechneten Intensitäten der einzelnen Kanäle, (d) zeigt eine Überlagerung und (e) zeigt das Intensitätsprofil entlang der in (d) markierten Linie. Größenstandard: $5 \mu \mathrm{m}$

Eine Möglichkeit, den Crosstalk direkt bei der Messung zu reduzieren, ist die Detektion der Fluoreszenz in unterschiedlichen Spektralbereichen. Aufgrund des um $20 \mathrm{~nm}$ blauverschobenen Emissionsspektrums von bsDronpa gegenüber rsFastLime, kann der Crosstalk zwischen diesen beiden Kanälen deutlich reduizert werden. Bei der Aufnahme von Padron und rsFastLime wurde das Fluoreszenzlicht zwischen $510 \mathrm{~nm}$ und $550 \mathrm{~nm}$ detektiert, bei 
bsDronpa zwischen $480 \mathrm{~nm}$ und $500 \mathrm{~nm}$. Abgesehen davon ist keine weitere Änderung der Belichtungsreihenfolge notwendig, um den Crosstalk auf minimale Werte zu reduzieren (Abbildung 24).
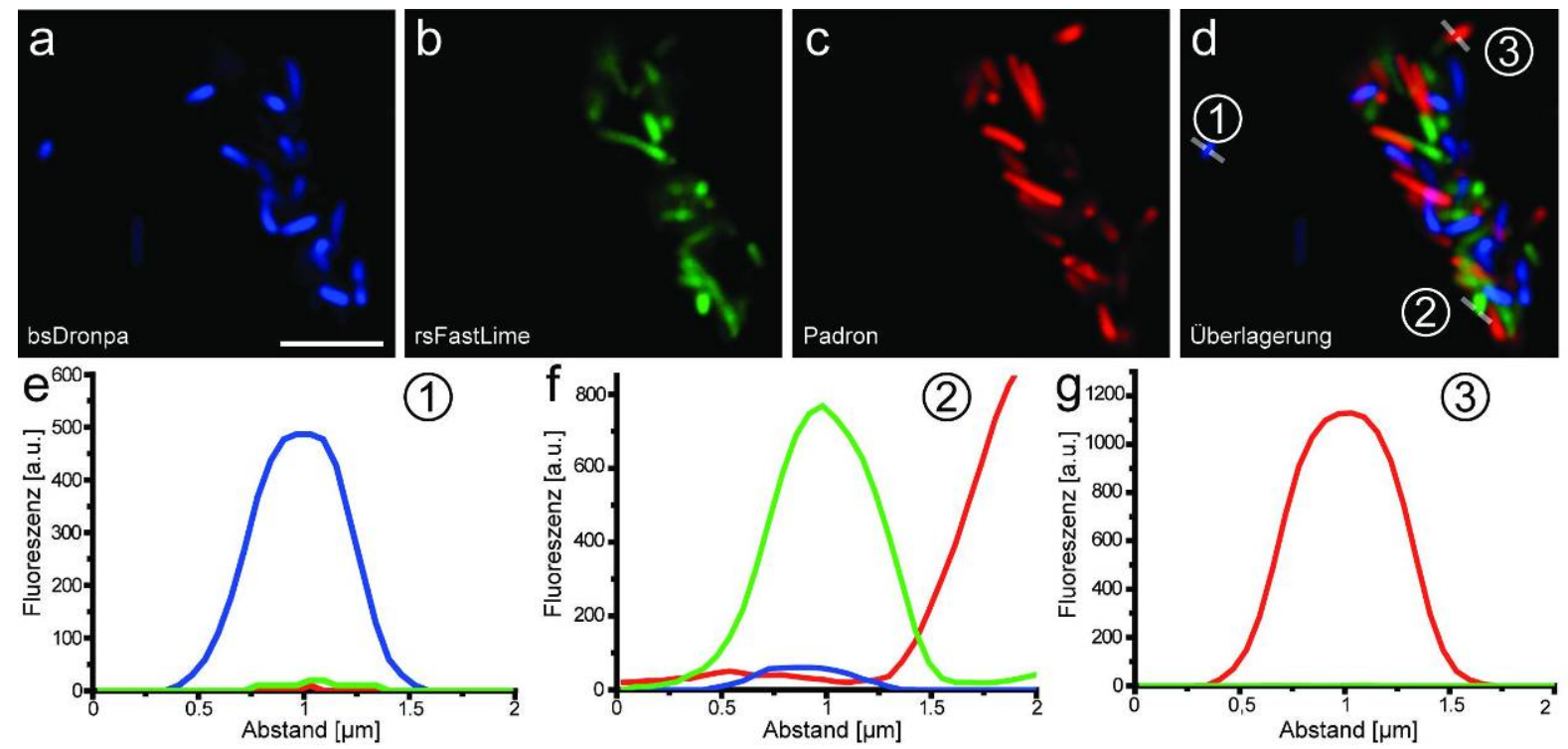

Abbildung 24: Reduktion des Crosstalks durch unterschiedliche Detektionsfenster bei der monochromatischen Dreifarben-Mikroskopie. Aufnahme einer gemischten E.coli-Kultur mit Zellen, die jeweils eines der Proteine rsFastLime, bsDronpa oder Padron exprimieren. Das Belichtungsprogramm entspricht dem in Abbildung 22, wobei das Detektionsfenster für bsDronpa von 480-500 nm und für Padron und rsFastLime von 500-520 nm gewählt wurde. Die Bilder (a-c) zeigen die Intensitäten der einzelnen Kanäle, (d) zeigt eine Überlagerung und (e-g) zeigen Intensitätsprofile entlang der in (d) markierten Linien. Größenstandard: $5 \mu \mathrm{m}$

Dieses Experiment in E.coli-Zellen zeigt, dass drei grün fluoreszierende RSFPs auch ohne nachträgliche Berechnung separat aufgenommen werden können.

Bei dieser Methode, der monochromatischen Mehrfarben-Fluoreszenzmikroskopie, zeigen rsFastLime und Padron besonders wenig Crosstalk, da sie gegensätzlich Schalten und beide einen großen dynamischen Bereich zwischen dem fluoreszierenden und nicht fluoreszierenden Zustand aufweisen.

\section{IV.4.7 Konfokale 3D Zeitraffer Aufnahmen mit monochromatischer}

\section{Zweifarben-Mikroskopie in lebenden Hefezellen}

Die beiden Proteine rsFastLime und Padron wurden verwendet, um in lebenden Hefezellen das Aktin bindende Protein Abp1 sowie die Mitochondrien aufzunehmen. ABP1 wurde durch homologe Rekombination in dem Hefestamm BY4741 mit Padron markiert. Das endogene ABP1 wurde dabei so verändert, dass ein Fusionsprotein aus Abp1 und C-terminal 
angeknüpftem Padron exprimiert wird ( $\rightarrow$ IX.1.2). Abp1 ist unter dem Zellcortex an Punkten lokalisiert, an denen Aktin vorhanden ist (Mulholland et al. 1994). Die Mitochondrien wurden mittels eines Plasmids markiert, welches für das Protein rsFastLime kodiert. Der Transport in die mitochondriale Matrix geschieht dabei über ein 69 Aminosäuren langes N-terminales Signalpeptid, das auf dem Plasmid in 5'-Richtung vor rsFastLime kodiert ist.

Es wurden konfokale dreidimensionale Bilder von Hefezellen aufgenommen, die rsFastLime und Padron exprimieren. Die Belichtungssequenz entspricht im Prinzip derjenigen, die auch für die E.coli-Zellen verwendet wurde (Abbildung 22a).

Zuerst werden die Proteine durch Bestrahlung mit $405 \mathrm{~nm}$ (1) vollständig in den fluoreszierenden (rsFastLime) bzw. nicht fluoreszierenden (Padron) Zustand geschaltet. Anschließend wird rsFastLime ausgelesen, indem Licht der Wellenlängen 488 und 405 nm zusammen eingestrahlt werden (2). Die zusätzliche Bestrahlung mit $405 \mathrm{~nm}$ verhindert, dass Padron und rsFastLime geschaltet werden. Im nächsten Schritt wird die Probe intensiv mit der Wellenlänge $488 \mathrm{~nm}$ bestrahlt $\left(100 \mathrm{~kW} \cdot \mathrm{cm}^{-2}\right)$, um Padron in den fluoreszierenden und rsFastLime, in den nicht fluoreszierenden Zustand zu schalten (3). In dem letzten Schritt kann schließlich Padron durch Anregung mit $488 \mathrm{~nm}$ ausgelesen werden.

Die aus den Aufnahmen gewonnenen Daten ermöglichen eine 3D-Rekonstruktion der Verteilungen von rsFastLime in den Mitochondrien und Abp1-Padron. Die Proteine wurden auch in diesem Fall einzig über sequenzielle Anregung unterschieden (Detektion 498-520), wobei der Crosstalk minimal war (Abbildung 25b-d). Trotz des Unterschiedes in der Expressionsstärke innerhalb der Abp1-Punkte, sowie zwischen Abp1-Padron und mitorsFastLime konnten die Proteine gut separat abgebildet werden. 


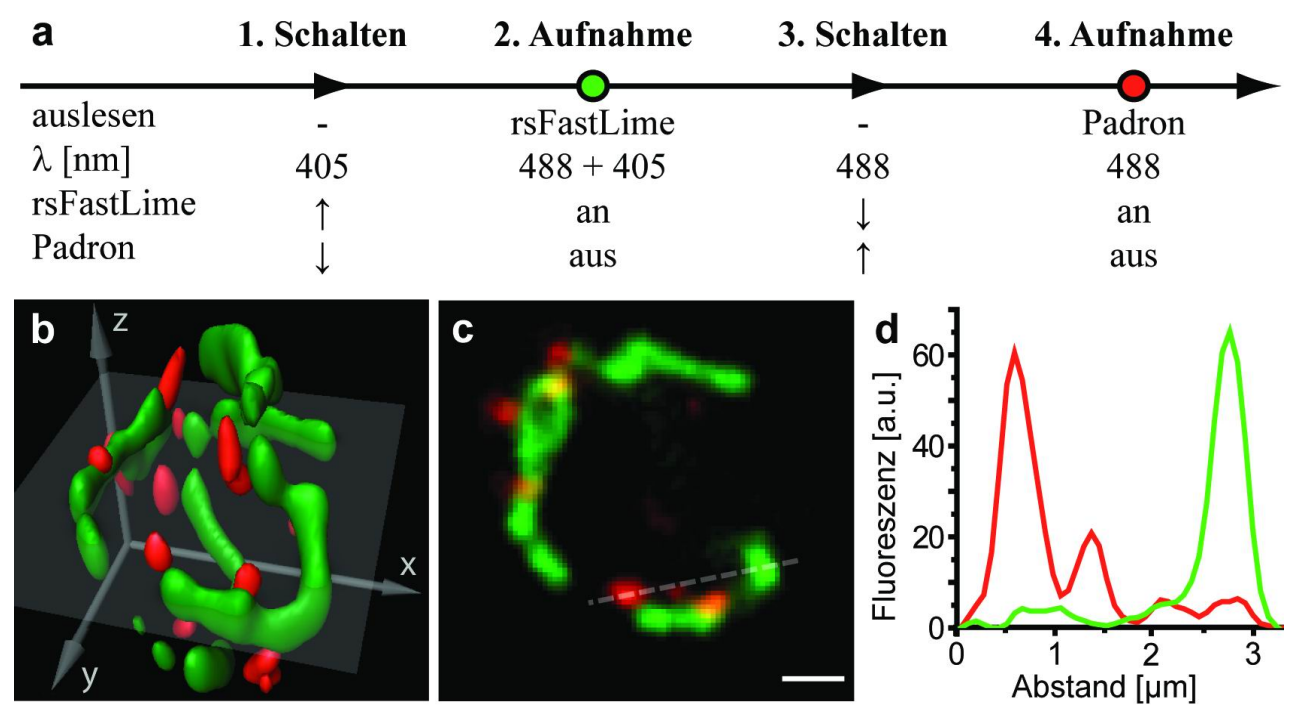

Abbildung 25: 3D-Aufnahme von rsFastLime und Padron in lebenden Hefezellen. In (a) ist die Abfolge der einzelnen Belichtungen abgebildet, die notwendig ist, um die zwei Proteine getrennt aufnehmen zu können. Die Pfeile symbolisieren in den Schritten 1 und 3 das Schalten $(\uparrow=$ anschalten; $\downarrow=$ ausschalten). Weiterhin ist eine 3D-Rekonstruktion einer Hefezelle (b), sowie eine Ebene (grau markiert in b) aus dieser 3D-Rekonstruktion (c) und ein Intensitätsprofil entlang der gestrichelten Linie in c (d) dargestellt. Die Mitochondrien und die einzelnen Abp1-Punkte können mit sehr geringem Crosstalk separat abgebildet werden. Größenstandard: $1 \mu \mathrm{m}$.

Anhand der Bilder lässt sich erkennen, dass sich Abp1 während der Teilung in Aggregaten (rote Punkte) um die Knospungsnarbe in der Mutterzelle und in der Peripherie der Tochterzelle sammelt (Abbildung 26a-i). Die Mitochondrien sind häufig nahe an den Abp1 Punkten, sind jedoch scheinbar nie kolokalisiert.

Insgesamt wurden neun Bilderstapel im Abstand von jeweils 20 Minuten über einen Zeitraum von 160 Minuten aufgenommen (Abbildung 26). Dabei konnte kein Nachlassen des Fluoreszenzsignals aufgrund von Photobleichen detektiert werden ( $\rightarrow$ IX.2.3). Dies ist jedoch der neuen Synthese von Proteinen während des Wachstums der Zellen zuzuschreiben. In einem separaten Experiment, in dem fünfundzwanzig Bilderstapel direkt hintereinander aufgenommen wurden, betrug das Bleichen $2 \%$ bei Padron und 3,5 \% bei rsFastLime. 

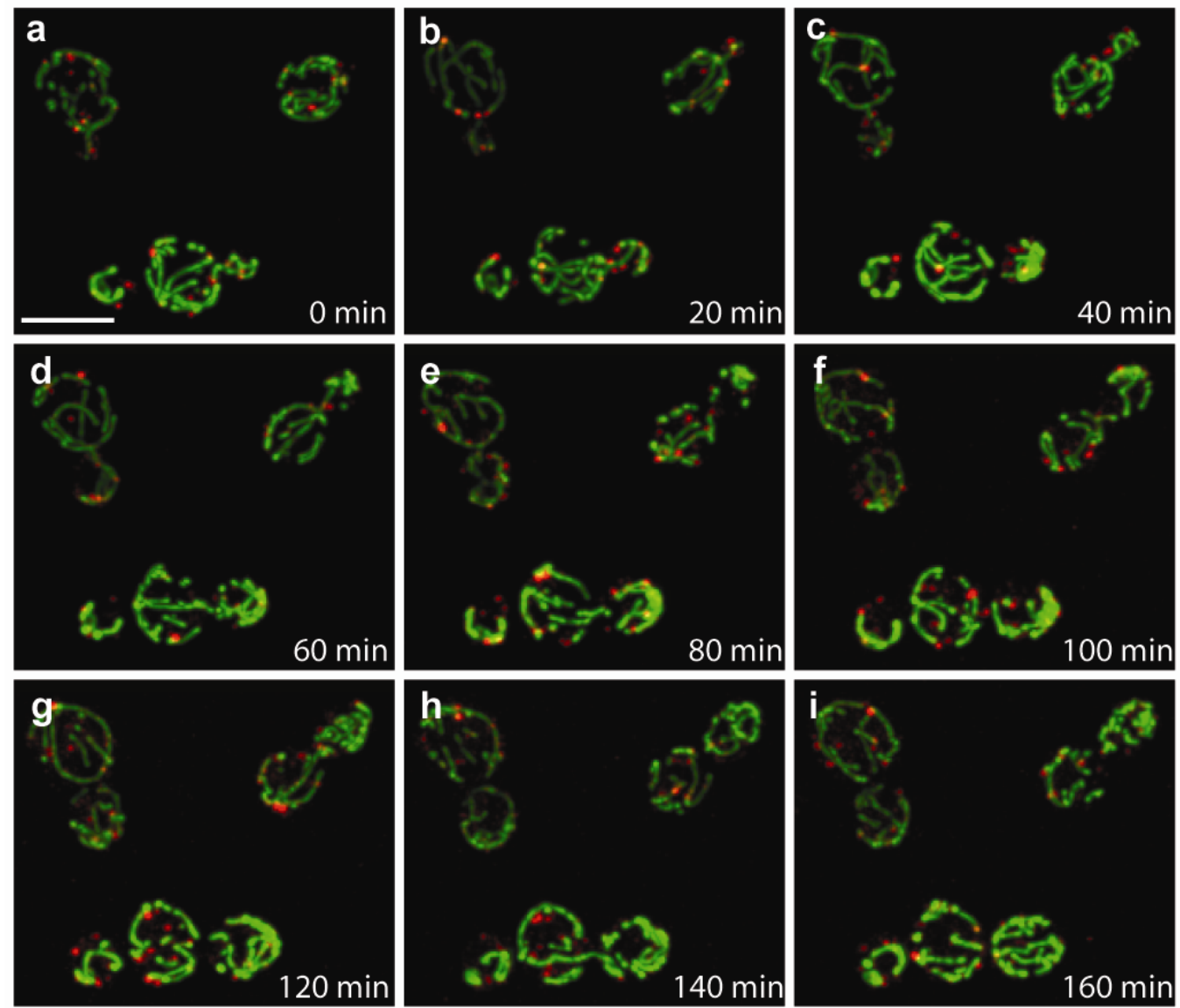

Abbildung 26: Zeitrafferaufnahme von wachsenden Hefezellen mit Abp1-Padron und mitorsFastLime. Die Abbildung zeigt Zellen, die in einer Durchflusskammer mit Agarose immobilisiert wurden. Die Zellen wurden dabei ständig mit frischem Medium versorgt und im Abstand von 20 Minuten mit der in Abbildung 25 verwendeten Belichtungsreihenfolge aufgenommen. Dargestellt sind Projektionen der einzelnen z-Schnitte einer Aufnahme. Größenstandard: $5 \mu \mathrm{m}$.

Die beiden Proteine rsFastLime und Padron sind gut als Paar für monochromatische Mehrfarben-Mikroskopie geeignet, da sie sich fast ohne Crosstalk aufnehmen lassen und beide relativ geringes Bleichen zeigen und ähnliche Kinetik beim Ein- und Ausschalten haben.

\section{IV.4.8 Aberrationsfreie monochromatische Mehrfarben Fluoreszenzmikroskopie}

Ein Vorteil der monochromatischen Mehrfarben Fluoreszenzmikroskopie ist, dass Aufgrund der exakt gleichen Aufnahmebedingungen keine Aberrationen auftreten (Abbildung 27). Um dies zu zeigen, wurden Padron, rsFastLime und EqFP611 an Kugeln mit 50 nm Durchmesser gebunden. Die Position dieser markierten Kugeln wurde an der Oberfläche eines Deckglases mit einem konfokalen Mikroskop bestimmt. Das Protein eqFP611 wurde mit der Laserlinie bei $561 \mathrm{~nm}$ angeregt, die Fluoreszenz wurde bei 570 bis $700 \mathrm{~nm}$ detektiert. Die beiden 
Proteine Padron und rsFastLime wurden durch das antagonistische Schalten unterschieden, wie im Abschnitt 4.5 beschrieben (Details siehe Methoden XY, SeiteX).

Bei der Aufnahme der Kugeln an der Oberfläche des Deckglases wurde ein scheinbarer Versatz in z-Richtung von $150 \mathrm{~nm}$ zwischen eqFP611 und den zwei anderen Proteinen festgestellt. Zwischen Padron und rsFastLime konnte keine Aberration gemessen werden.
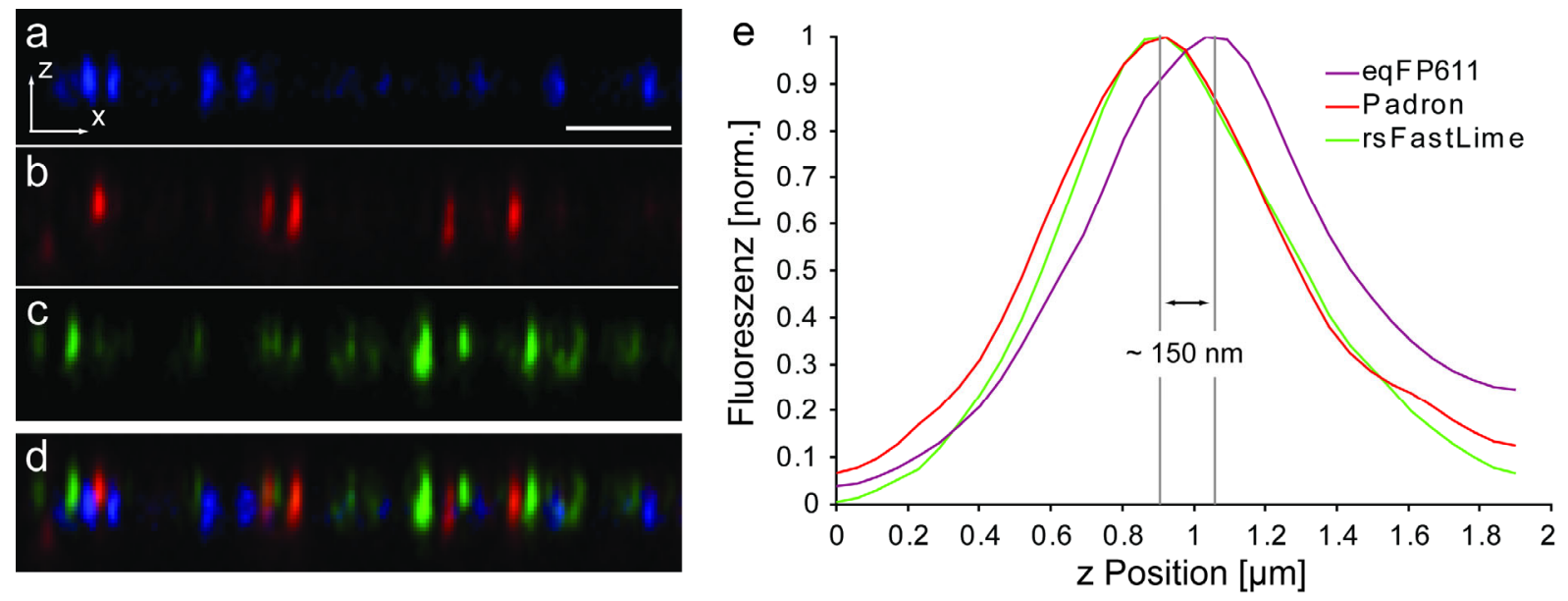

Abbildung 27: Aberrationen bei der Aufnahme von Padron, rsFastLime und eqFP611. Ein Gemisch von Kugeln an die jeweils eines der drei Proteine über Biotin gekoppelt ist, wurde auf ein Deckglas gegeben und aufgenommen. Die Trennung von rsFastLime und Padron geschieht dabei über reversibles Schalten, während eqFP611 über die Wellenlänge der Fluoreszenz getrennt wird. Die Fluoreszenzsignale der drei Proteine konnten gut getrennt voneinander aufgenommen werden (a-d), Größenstandard: $2 \mu \mathrm{m}$. Ein Vergleich der z-Position zeigt, dass die eqFP611-Kugeln scheinbar um $150 \mathrm{~nm}$ versetzt sind, während Padron und rsFastLime exakt auf gleicher Höhe erscheinen (e).

\section{IV.4.9 Zwei Farben Hochauflösung mit bsDronpa und Dronpa}

Das Protein bsDronpa hat gegenüber Dronpa eine Blauverschiebung der Emission von nur $18 \mathrm{~nm}$, dies ist zu wenig, um die Fluoreszenz mit konventioneller Mikroskopie in zwei Kanäle zu trennen. Bei den Einzelmolekül-Lokalisationsverfahren (Betzig et al. 2006; Dedecker et al. 2006; Rust et al. 2006; Egner et al. 2007), werden viele Photonen eines einzelnen Moleküls detektiert, um anschließend den Ort dieses Moleküls genauer zu bestimmen. Dazu wird der Mittelpunkt der Photonenverteilung auf dem Detektor ermittelt. Je mehr Photonen von einem einzelnen Molekül abgegeben werden, desto genauer kann der Ort des Moleküls bestimmt werden. Nach dem gleichen Prinzip erhält man Information über das Fluoreszenzspektrum des Moleküls, weshalb bei der Einzelmolekülspektroskopie auch zwei fluoreszierende Proteine mit sehr geringem Unterschied im Emissionsspektrum getrennt werden können 
(Bossi et al. 2008). Ein Bild entwickelt sich je nach Markierungsdichte der Probe durch die Überlagerung von zehntausenden von Bildern, in denen jeweils die Position der einzelnen Moleküle berechnet wurde.

Für diese Experiment wurden Dronpa und bsDronpa mit einem Membrananker in dem E.coliStamm SURE exprimiert, so dass sie an der Bakterienmembran lokalisieren ( $\rightarrow$ IX.1.1.2). Die beiden Kulturen wurden einzeln, sowie gemischt aufgenommen (Abbildung 28). Da die Methode nach dem Prinzip der exakten Ortsbestimmung durch Einzelmoleküldetektion jedoch nur in zweidimensionalen Proben angewendet werden kann, wurden die E.coli-Zellen in gefrorenem Zustand in Sektionen von 200-400 nm geschnitten.
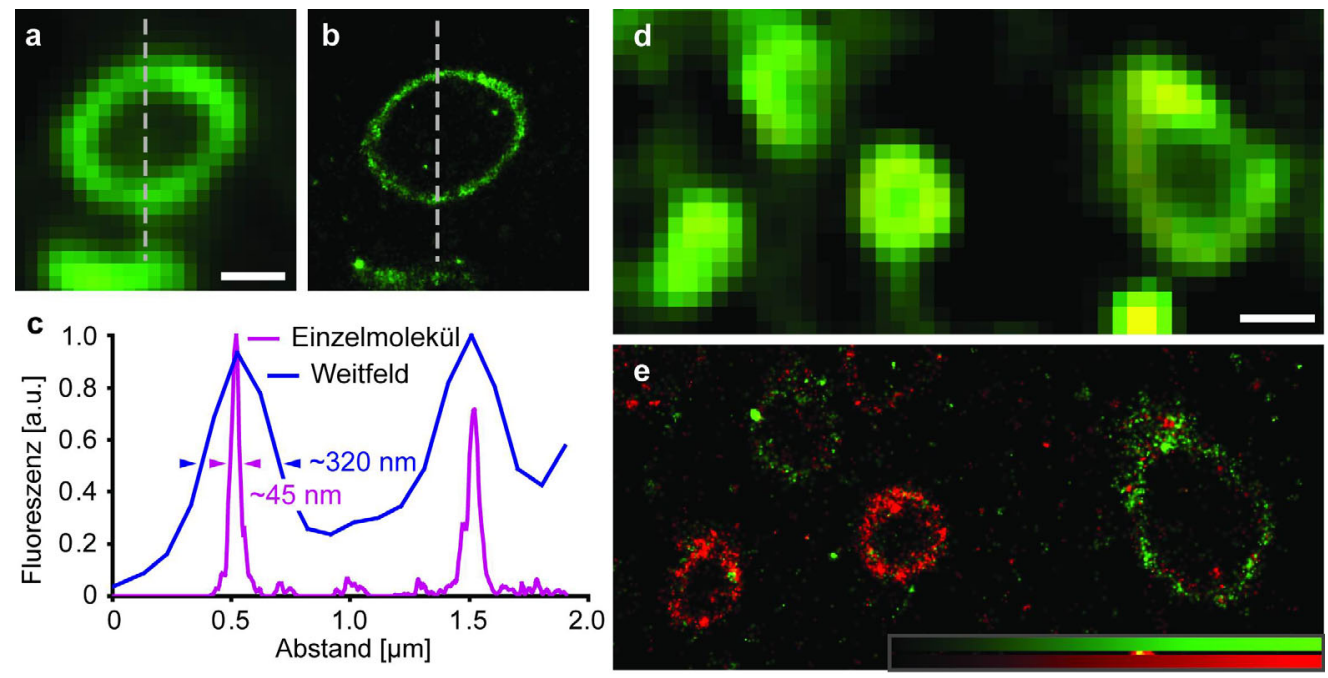

Abbildung 28: Spektrale Trennung von bsDronpa und Dronpa durch Einzelmolekülspektroskopie. Die Bilder zeigen Fluoreszenzaufnahmen von E.coli-Zellen, deren Membran mit bsDronpa oder Dronpa markiert sind. Die Zellen wurden vor den Aufnahmen in gefrorenem Zustand in dünne Scheiben von 200-400 nm geschnitten. Für bsDronpa zeigt die Analyse nach dem EinzelmolekülLokalisationsverfahren in xy-Richtung gegenüber dem rekonstruierten Weitfeldbild eine siebenfach verbesserte Auflösung (a-c). In einer Probe die bsDronpa und Dronpa exprimierende E.coli Zellen beinhaltet, können die beiden Proteine nach einer Analyse der Einzelmoleküle getrennt dargestellt werden $(\mathrm{d}, \mathrm{e})$. Dies wird durch eine Trennung der Emission erreicht, wobei die Fluoreszenz bei $520 \mathrm{~nm}$ (z520 DCXR) getrennt wurde. Bei jedem einzelnen Bild wurden die fluoreszierenden Moleküle aufgrund der Verteilung auf die zwei Detektionskanäle einer der beiden Spezies zugeordnet.

Der Vergleich des rekonstruierten Weitfeldbildes mit der Analyse der Einzelmolekülbilder von bsDronpa, zeigt eine siebenfach erhöhte Auflösung in xy-Richtung (Abbildung 28a-c). Bei dem selben Vergleich einer gemischten E.coli-Probe ist neben der Auflösungserhöhung weiterhin zu erkennen, dass eine Trennung von Zellen die entweder bsDronpa oder Dronpa exprimieren möglich ist (Abbildung 28d,e). Die Trennung wird durch einen Filter im Detektionsstrahlengang ermöglicht, der die Emission bei $520 \mathrm{~nm}$ in zwei Kanäle auftrennt. 
Durch eine Analyse der Photonenverteilung in den beiden Kanälen für jedes einzelne Molekül, kann zugeordnet werden, um welches der fluoreszierenden Proteine es sich handelt. Die Proteine bsDronpa und Padron erweitern durch ihre einzigartigen Eigenschaften bezüglich des Schaltmodus und des breiten Absorptionsspektrums die Auswahl der RSFPs. Die Verschiebung des Spektrums von bsDronpa reicht jedoch nur in dem Einzelmolekülspektroskopie für eine Unterscheidung gegenüber Dronpa, rsFastLime und Padron. Aus diesem Grund sind weitere RSFPs mit deutlich verschiedener Fluoreszenz notwendig. Daher wurden aus dem rot fluoreszierenden monomeren Protein rsCherry weitere RSFPs entwickelt.

\section{IV.4.10 Die RSFPs rsCherry und rsCherryRev}

Um RSFPs in anderen Farben zu generieren, wurde mCherry als Ausgangspunkt für die Mutagenese ausgewählt. Eine Betrachtung der Struktur (PDB ID:2H5Q) (Shu et al. 2006) unter der Annahme, dass ein potentiell nicht fluoreszierender Zustand ebenfalls ein transChromophor benötigt, zeigte, dass in mCherry das Isoleucin 161 ein hypothetisches transChromophor sterisch blockiert. Durch Mutagenese dieser Position wurde die Variante Ile161Ser identifiziert, welche in den Grundzügen bereits reversibles Schalten zeigt. Mit dieser Variante als Ansatzpunkt wurde durch gerichtete- sowie zufällige Mutagenese, die Vatiante rsCherry entwickelt (mCherry E144V-I161S-V177F-K178W).

Bei diesem Screening wurde außerdem die Variante E163M identifiziert, die ähnlich wie die Mutation M159Y im Fall von Dronpa eine Umkehr des Schaltens hervorruft. Die Verbesserung dieser Mutante durch weitere Mutagenese führte zu dem Protein rsCherryRev (mCherry E144V, S146C, I161S, Q163M, V177F). Bei rsCherry und rsCherryRev wird die Fluoreszenz mit $550 \mathrm{~nm}$ angeregt. Bei rsCherry bewirkt Bestrahlung mit $550 \mathrm{~nm}$ das Einschalten, bei rsCherryRev das Ausschalten. Entsprechend umgekehrt wird mit der Wellenlänge von ca. $450 \mathrm{~nm}$ rsCherry aus, und rsCherryRev wieder angeschaltet (Tabelle 3).

\begin{tabular}{|c|c|c|c|c|c|c|c|}
\hline $\begin{array}{l}\text { Fluoreszie- } \\
\text { rendes } \\
\text { Protein } \\
\end{array}$ & $\begin{array}{l}\text { Abs. / Emm. } \\
\text { Maximum } \\
{[\mathrm{nm}]}\end{array}$ & $\begin{array}{c}\text { relative } \\
\text { Helligkeit } \\
\text { (Kolonie) } \\
\end{array}$ & $\begin{array}{c}\text { Einzel- } \\
\text { molekül } \\
\text { Helligkeit }\end{array}$ & $\begin{array}{c}\text { Halbwertszeit } \\
\text { ausschalten } \\
\mathrm{t}_{1 / 2}{ }^{\text {off }}[\mathrm{s}]\end{array}$ & $\begin{array}{l}\text { Halbwertszeit } \\
\text { einschalten } \\
\mathrm{t}_{1 / 2}{ }^{\text {on }}[\mathrm{s}]\end{array}$ & $\begin{array}{c}\text { Relaxations- } \\
\text { kinetik } \\
\text { relax }[\mathrm{min}] \\
\mathrm{t}_{1 / 2}\end{array}$ & $\begin{array}{c}\text { Rest- } \\
\text { fluoreszenz } \\
{[\%]} \\
\end{array}$ \\
\hline mCherry & $586 / 611$ & 1 & 1 & n.a. & n.a. & n.a. & n.a. \\
\hline rsCherry & $572 / 610$ & $\sim 0,1$ & 0,77 & 3,0 & 0,05 & 40 & $15 \%$ \\
\hline rsCherryRev & $572 / 608$ & $\sim 0,1$ & 0,23 & 0,05 & 0,7 & 13 & $5 \%$ \\
\hline
\end{tabular}

Tabelle 3: Eigenschaften der Proteine mCherry, rsCherry und rsCherryRev.

Das Protein rsCherryRev schaltet somit nach dem negativen Modus, und ist daher wie auch rsFastLime und bsDronpa für hochauflösende Mikroskopie nach dem Einzelmolekül- 
Lokalisationsverfahren geeignet. Es konnten Bilder von rsCherryRev in lebenden PtK2 Zellen mit einer Auflösung von etwa $75 \mathrm{~nm}$ gemacht werden. Das Protein wird dabei zusammen mit einem Signalpeptid exprimiert, so dass es in das Endoplasmatische Retikulum (ER) transportiert wird (Abbildung 29).

Auf den Bildern kann die Struktur des ER genauer aufgelöst werden, z.B. gibt es Stellen, an denen zwei dicht nebeneinander liegende Stränge im Weitfeldbild nicht getrennt werden können.
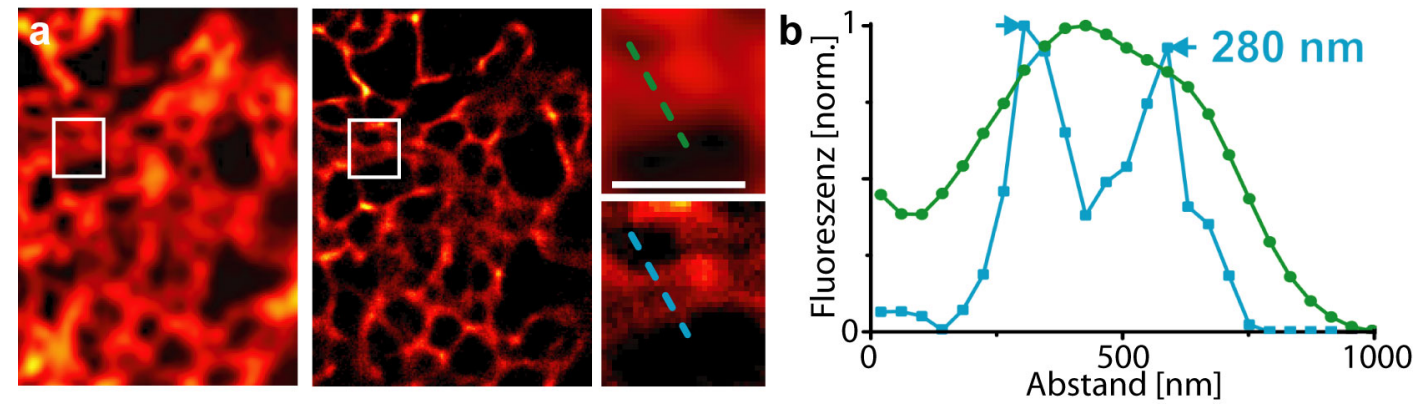

Abbildung 29: Aufnahme von rsCherryRev im ER lebender PtK2 Zellen nach dem Einzelmolekül-Lokalisationsverfahren. Die Aufnahme zeigt das ER einer PtK2 Zelle links das rekonstruierte weitfeld Bild, rechts das Einzelmolekül-Lokalisationsbild (a). Daneben befinden sich die in a markierten Bereiche vergrößert. Der Graph (b) zeigt die Intensitätsprofile entlang der gestrichelten Linien in a. Größenstandard: $1 \mu \mathrm{m}$.

Die Ergebnisse dieser Arbeit haben zu großen Teilen das Verständnis des Schaltmechanismus der RSFPs vorangetrieben. Durch das erlangte Wissen und die Entwicklung eines Verfahrens zur Verbesserung konnten neue RSFPs generiert werden, die sich in ihren Eigenschaften von den zwei bisher bekannten Vertretern dieser Klasse, Dronpa und asFP595, deutlich unterscheiden. Die im Rahmen dieser Arbeit neu generierten Proteine rsFastLime, Padron, bsDronpa, rsCherry und rsCherryRev sind für die Mikroskopie in lebenden Zellen und speziell für hochauflösende Mikroskopietechniken geeignet. 


\section{Diskussion}

Ziel dieser Doktorarbeit war die Aufklärung der molekularen Funktionsmechanismen reversibel schaltbarer Proteine. Mit Hilfe dieses Wissens sollten RSFPs zielgerichtet verändert und ihre Eigenschaften für verschiedene Anwendungen, speziell im Bereich hochauflösender Lichtmikroskopie, optimiert werden.

Die fluoreszierenden Proteine sind eine der größten Entdeckungen der Molekularbiologie in den letzten Jahrzehnten. Die Relevanz der fluoreszierenden Proteine wurde im Oktober 2008 unterstrichen, indem der Chemie-Nobelpreis für die „Entdeckung und Weiterentwicklung des grün fluoreszierenden Proteins" vergeben wurde. Der Preis wurde zu gleichen Teilen an den Entdecker von GFP Osamu Shimomura, sowie Martin Chalfie und Roger Tsien verliehen, die einen entscheidenden Anteil an dessen Entwicklung und Anwendung in der Forschung hatten. Innerhalb dieser ständig wachsenden Klasse fluoreszierender Proteine haben sich in den letzten Jahren die RSFPs als sehr interessant für die Verwirklichung und Entwicklung neuer Mikroskopietechniken erwiesen. Besonders im Bezug auf hochauflösende Lichtmikroskopie und das Verfolgen aktivierter Subpopulationen von Proteinen (protein tracking) wurde den RSFPs großes Potential zugeschrieben (Hell et al. 2004), welches innerhalb kurzer Zeit auch experimentell bestätigt werden konnte (Hofmann et al. 2005; Chudakov et al. 2006). Die Erforschung und Entwicklung von RSFPs, die im Rahmen dieser Doktorarbeit stattgefunden hat, führte zum Verständnis (Andresen et al. 2005; Andresen et al. 2007; Stiel et al. 2007), der Verbesserung und der Anwendung dieser Proteine (Stiel et al. 2007; Andresen et al. 2008; Stiel et al. 2008).

In dieser Arbeit wurden die grundlegenden molekularen Mechanismen von asFP595 und Dronpa anhand von Röntgenkristallstrukturanalysen aufgeklärt ( $\rightarrow$ IV.3.2 und IV.3.3). Weiterhin wurden aus beiden Proteinen neue RSFPs mit verbesserten Eigenschaften generiert $(\rightarrow$ IV.4.1 und IV.4.3). Abschließend wurden die verschiedenen Anwendungsmöglichkeiten dieser RSFPs, wie hochauflösende Lichtmikroskopie und monochromatische MehrfarbenMikroskopie demonstriert ( $\rightarrow$ IV.4.10 und IV.4.4). 


\section{V.1 Funktionsweise von RSFPs}

Im Rahmen dieser Doktorarbeit sollte der molekulare Mechanismus des Schaltens zwischen dem fluoreszierenden und dem nicht fluoreszierenden Zustand reversibel schaltbarer fluoreszierender Proteine aufgeklärt werden. Der grundlegende Mechanismus konnte zunächst an asFP595 und später an Dronpa mit Hilfe von Röntgenkristallographie identifiziert werden. Durch das Schalten ganzer Proteinkristalle und deren anschließende Analyse wurden die Strukturen des fluoreszierenden und des nicht fluoreszierenden Zustands bestimmt. Anhand dieser Strukturen wurde deutlich, dass dem Schaltmechanismus sowohl bei asFP595 als auch bei Dronpa eine cis-trans-Isomerisierung des Chromophors zugrunde liegt.

\section{V.1.1 Der molekulare Mechanismus von RSFPs}

Die Hypothese einer cis-trans-Isomerie als Funktionsweise des reversiblen Schaltens von asFP595 wurde bereits 2003 von dem Entdecker des Proteins Konstantin Lukyanov aufgestellt (Chudakov et al. 2003). Sie basiert einerseits darauf, dass bis auf eqFP611 alle fluoreszierenden GFP-ähnlichen Proteine ein Chromophor in der cis-Konformation ausweisen und postuliert, dass die GFP-ähnlichen nicht fluoreszierenden Proteine vermutlich ein Chromophor in der trans-Konformation haben. Andererseits konnte die Hypothese durch verschiedene Mutanten von asFP595 gestärkt werden, die ebenfalls darauf hindeuten, dass der fluoreszierende Zustand durch ein cis-Chromophor charakterisiert ist, während der nicht fluoreszierende Zustand ein trans-Chromophor aufweist (Chudakov et al. 2003).

Eine weitere Hypothese wurde anhand einer Struktur von KFP1 (PDB-ID: 1XMZ), einer asFP595-Variante dessen entscheidende Mutation A143G ist, im Dunkelzustand aufgestellt (Quillin et al. 2005). Dabei wurde eine Umlagerung des Histidins an Position 197 als der entscheidende Unterschied zwischen dem fluoreszierenden und dem nicht fluoreszierenden Zustand postuliert. Diese These wurde im Jahr 2006 von Henderson et al. durch Kristallstrukturdaten, die eine Bewegung eben dieses Histidins zeigen gestärkt (Henderson et al. 2006). Allerdings ist die beschriebene Bewegung des Histidins in der untersuchten Mutante von asFP595 nur möglich, weil die Mutation A143G in der Variante ausreichend Platz für eine Bewegung des Histidins schafft. Alle in dieser Arbeit bestimmten Strukturen von asFP595 zeigen jedoch deutlich eine cis-trans-Isomerie als einzige Änderung zwischen dem fluoreszierenden und dem nicht fluoreszierenden Zustand ( $\rightarrow$ IV.1 und IV.3). Die Isomerisierung des Histidins stellt also einen Spezialfall dar, denn das Schalten ist auch ohne eine Bewegung des Histidins möglich. 
Die Kristallstrukturanalysen im Rahmen dieser Arbeit an dem RSFP Dronpa deuten ebenfalls auf eine cis-trans-Isomerie des Chromophors hin. Das Chromophor ist, wie im Falle von asFP595, im fluoreszierenden Zustand in der cis-Konformation und im nicht fluoreszierenden Zustand in der trans-Konformation. Abgesehen von der Isomerisierung des Chromophors waren jedoch noch weitere strukturelle Veränderungen auffällig. Bei Dronpa wurden zusätzlich Umlagerungen der Aminosäuren H193 und R66 beobachtet. Diese sind jedoch höchstwahrscheinlich eine Folge der Isomerisierung des Chromophors, welche eine Kaskade von Aminosäureumlagerungen nach sich zieht.

Die Umlagerungen könnten folgendermaßen stattfinden: Das Chromophor selbst gerät durch Anregung mit $488 \mathrm{~nm}$ in Bewegung, so dass die Wasserstoffbrücke mit Ser142 bricht und die Isomerisierung von der cis- in die trans-Konformation stattfinden kann. Da in der transChromophortasche jedoch das Arg66 liegt, muss dieses durch eine Umlagerung unter das Chromophor ausweichen. Gleichzeitig weicht das Val157 um etwa 0,5 ̊̊ zurück, um Platz für die apikale Hydroxylgruppe zu schaffen. Die Umlagerung des Arg66 unter das Chromophor führt dazu, dass die in der cis-Konformation unter dem Chromophor liegende Aminosäure His193 in die frei gewordene cis-Chromophortasche klappen muss. Das zuvor über eine Wasserstoffbrücke gebundene Ser142 ist nun flexibel und weicht ebenfalls um etwa $0,5 \AA$ zurück, wodurch das Histidin mehr Platz in der ehemaligen cis-Chromophortasche findet.

Dieses Modell wird durch die Ergebnisse einer Computersimulation gestützt, in der das Schalten verschiedener Dronpa-Varianten untersucht wurde (Moors et al. 2008).

Im scheinbaren Gegensatz zu den Kristallstrukturen steht die Veröffentlichung einer NMRStrukturanalyse von Mizuno et al (Mizuno et al. 2008). Der Versuch die, Struktur von Dronpa im nicht fluoreszierenden Zustand zu messen, war nur teilweise erfolgreich, da für den gesamten Bereich um das Chromophor keine exakte Positionsbestimmung der Aminosäuren möglich war. Diese Ergebnisse wurden so gedeutet, dass das Chromophor und der gesamte umgebende Bereich im nicht fluoreszierenden Zustand flexibel ist. Diese Schlussfolgerung kann aus den gemessenen Daten gezogen werden, wahrscheinlicher ist jedoch eine andere Erklärung für die Flexibilität im nicht fluoreszierenden Zustand.

Die Daten für die NMR-Strukturanalyse wurden über mehrere Tage bei Raumtemperatur aufgenommen. In diesem Zeitraum wurde der Kristall ständig mit einem Laser der Wellenlänge 514,5 nm bestrahlt. Die Schlussfolgerung, dass das Chromophor im nicht fluoreszierenden Zustand flexibel ist, ist insofern richtig, dass die absorbierte Energie in diesem Zustand besser in Bewegungsenergie umgewandelt werden kann. Der Grund für das Scheitern der exakten Ortsbestimmung des Chromophors und der Aminosäuren in dessen 
Umgebung könnten durch die stetige Bestrahlung mit 514,5 nm erklärt werden. Denn auch wenn die Absorption von Dronpa im nicht fluoreszierenden Zustand bei 514,5 nm sehr gering ist, werden trotzdem Photonen vom Chromophor absorbiert. Die aufgenommene Energie wird, da keine Fluoreszenz auftritt, strahlungsfrei abgegeben. Dies führt wahrscheinlich zu der beobachteten ständigen Bewegung des Chromophors und den Aminosäuren in dessen Umgebung. Deshalb resultiert die starke Flexibilität des Chromophors und der Umgebung in der NMR-Analyse wahrscheinlich aus dem Versuchsaufbau und steht nicht im Widerspruch zu den Ergebnissen dieser Doktorarbeit.

Unabhängig von den Ergebnissen dieser Doktorarbeit, wurde die cis-trans-Isomerie bei einem weiteren reversibel schaltbaren fluoreszierenden Protein, mTFP0.7 als grundlegender Unterschied zwischen dem fluoreszierenden und nicht fluoreszierenden Zustand identifiziert (Henderson et al. 2007). Da bei allen bisher untersuchten RSFPs die cis-trans-Isomerie ausschlaggebend für das Schalten ist, liegt die Vermutung nahe, dass dies der grundlegende Mechanismus von RSFPs ist.

\section{V.1.2 Die cis-trans-Isomerie als genereller Mechanismus des Schaltens}

Eine theoretische Betrachtung der Änderungen, die für einen fluoreszierenden und einen nicht fluoreszierenden Zustand und das reversible Schalten mit Licht zwischen diesen Zuständen notwendig sind, unterstützt die Hypothese der cis-trans-Isomerie als generellen Schaltmechanismus der RSFPs.

Für eine lichtgetriebene Umwandlung zwischen zwei Zuständen sind mindestens zwei unterschiedliche Wellenlängen nötig, eine für jede Richtung des Schaltens. Um ein relativ vollständiges Schalten zu ermöglichen, sollten die zwei Wellenlängen außerdem möglichst wenig Einfluss auf das Schalten in die jeweils andere Richtung haben. Das bedeutet, dass Licht derjenigen Wellenlänge, mit der eingeschaltet wird, die Chromophore, die sich bereits im eingeschalteten Zustand befinden, nur in sehr geringem Maße wieder ausschalten. Daraus ergibt sich, dass die durch Bestrahlung mit einer einzigen Wellenlänge hervorgerufenen Isomerisierungen (cis-trans und trans-cis) in beide Richtungen unterschiedlich schnell ablaufen müssen.

Die Reaktionsgeschwindigkeit der Isomerisierung ( $\rightarrow$ V.1.4) ist von der Häufigkeit der Absorption und der Wahrscheinlichkeit der Isomerisierung abhängig. Unterschiedliche Wahrscheinlichkeiten für eine Isomerisierung ergeben sich aus verschieden starker Stabilisierung des Chromophors. Auf diese Weise wird bei dem positiv schaltbaren RSFP Padron nahezu vollständiges Schalten in die fluoreszierende cis-Konformation ermöglicht $(\rightarrow$ 
V.1.5), obwohl das Chromophor im eingeschalteten wie auch im ausgeschalteten Zustand hauptsächlich deprotoniert vorliegt $(63 \%$ in cis- gegenüber nahezu $100 \%$ in transKonformation). Durch die bessere Stabilisierung des Chromophors im angeregten Zustand der cis-Konformation ist die Wahrscheinlichkeit für eine Isomerisierung aus dem angeregten trans-Zustand wesentlich größer. Ein effektives Ausschalten kann allerdings auf andere Weise ermöglicht werden, wie im Folgenden erklärt wird.

Diese zweite Möglichkeit die Reaktionsgeschwindigkeit der Isomerisierung zu beeinflussen, ist durch eine unterschiedlich starke Absorption im ein- und ausgeschalteten Zustand gegeben, da die Absorption ebenfalls Einfluss auf die Reaktionsgeschwindigkeit hat. Die Absorptionseigenschaften des Chromophors bezüglich der zweiten Wellenlänge müssen daher deutlich unterschiedlich sein, damit ein Protein quantitativ zwischen einem fluoreszierenden und einem nicht fluoreszierenden Zustand geschaltet werden kann. Eine solche Änderung der Absorption kann, abgesehen von einer chemischen Modifikation des Chromophors, welche die Reversibilität des Prozesses sehr schwierig machen würde, jedoch nur durch eine Umgebungsänderung induziert werden.

Die Chromophorumgebung kann entweder durch eine Bewegung des Chromophors selbst, oder durch eine Umlagerung der umgebenden Aminosäuren verändert werden. Die Bewegung von Aminosäuren ist jedoch nur indirekt möglich, da die Energie, die zur Umlagerung führt vom Chromophor absorbiert wird. Dementsprechend wird bei strahlungsfreier Abgabe der Energie das Chromophor selbst in Bewegung geraten und nicht die umgebenden Aminosäuren. Obwohl eine Änderung der Umgebung also auch durch Umlagerungen von Aminosäuren in der Nähe des Chromophors möglich ist, ist es wesentlich wahrscheinlicher, dass das Chromophor selbst isomerisiert.

Durch eine Isomerisierung des chromophoren Hydroxyphenylrings von der cis- in die transKonformation kann die Hydroxylgruppe bis zu $6 \AA$ bewegt werden. Dies ermöglicht eine Interaktion der Hydroxylgruppe mit jeweils anderen Aminosäuren und damit deren unterschiedliche Protonierung. Die Protonierung der Hydroxylgruppe ist weiterhin die einzige bekannte reversible Modifikation des Chromophors, die eine ausreichend starke Verschiebung des Absorptionsspektrums zur Folge hat.

Die Hypothese der cis-trans-Isomerie wird weiterhin durch die Untersuchungen der Proteine asFP595 und Dronpa in dieser Arbeit, wie auch der Untersuchung von mTFP0.7 gestützt, da bei allen drei Proteinen eine cis-trans-Isomerie des Chromophors als grundlegender Mechanismus für das Schalten identifiziert wurde (Andresen et al. 2005; Andresen et al. 2007; Henderson et al. 2007). 


\section{V.1.3 Protonierungszustände}

Das Chromophor kann an der terminalen Hydroxylgruppe und am Imidazolring protoniert oder deprotoniert vorliegen. Dabei hat jedoch nur die Protonierung der Hydroxylgruppe einen starken Einfluss auf die Absorptionseigenschaften (Voityuk et al. 1997; Haupts et al. 1998; Elsliger et al. 1999).

Eine Isomerisierung des Hydroxyphenylrings verändert zwar die Position der Hydroxylgruppe, hat jedoch keinen direkten Einfluss auf dessen Protonierungszustand. Anders verhält es sich bei dem Stickstoff des Imidazolrings, da dieser in der cisKonformation durch eine sterische Hinderung mit dem meta-Wasserstoffmolekül am Hydroxyphenylring um etwa vier pK-Einheiten saurer ist als in der trans-Konformation (Schaefer et al. 2007). Obwohl eine Änderung der Protonierung am Imidazolring keine ausreichende Änderung im Absorptionsspektrum bewirkt (Haupts et al. 1998; Elsliger et al. 1999), wird die bei einer cis-trans-Isomerisierung höchstwahrscheinlich auftretende Protonierung eine Ladungsveränderung der gesamten Chromophortasche nach sich ziehen. Somit hat die Protonierung am Imidazolring auch Einfluss auf die terminale Hydroxylgruppe des Chromophors, die für die Absorptionseigenschaften entscheidend ist. Letztendlich ist aber doch wahrscheinlich die direkte Umgebung der Hydroxylgruppe ausschlaggebend für das Gleichgewicht zwischen der protonierten und der deprotonierten Form.

Wegen dieser Abhängigkeit der Protonierung von der Umgebung sind zwei unterschiedliche Modi des Schaltens von RSFPs möglich: das positive und negative Schalten (positiv: Anregung der Fluoreszenz schaltet gleichzeitig ein; negativ: Anregung der Fluoreszenz schaltet gleichzeitig aus; siehe $\rightarrow$ IV.3.1). Obwohl asFP595 wie auch Dronpa im cis-Zustand fluoreszieren, ist asFP595 ein positiv schaltbares RSFP, während Dronpa ein negativ schaltbares RSFP ist.

Bei beiden Proteinen wird eine Änderung der Protonierung beim Schalten beobachtet, die jedoch entgegengesetzt ausfällt. Bei asFP595 ist der trans-Zustand stärker deprotoniert als der cis-Zustand, während bei Dronpa der cis-Zustand stärker deprotoniert vorliegt (Habuchi et al. 2006; Schaefer et al. 2008). Dies kann auch anhand zweier positiv schaltbarer Mutanten beobachtet werden.

Die Variante asFP595-A143S zeigt im fluoreszierenden cis-Zustand eine stark erhöhte Helligkeit. Dies liegt daran, dass die Interaktion von Serin mit der Hydroxyphenylgruppe das Gleichgewicht des Chromophors in der cis-Konformation in Richtung der deprotonierten Form verlagert. Es liegen also mehr Moleküle in der fluoreszierenden, deprotonierten cisKonformation vor. Allerdings ist ebenfalls ein deutlicher Anteil des protonierten 
Chromophors vorhanden, der wesentlich größer sein muss, als im trans-Zustand. Ähnliches lässt sich bei Padron, einer positiv schaltbaren Variante von Dronpa beobachten. Im Vergleich zu Dronpa ist die Protonierung der beiden Zustände umgekehrt, also wie bei dem ebenfalls positiv schaltbaren asFP595. Auch hier enthält der cis-Zustand einen signifikanten Anteil des protonierten Chromophors, während der trans-Zustand deprotoniert vorliegt.

Eine Änderung der Protonierung allein ist also wahrscheinlich nicht ausreichend für ein gutes reversibel schaltbares fluoreszierendes Protein. Neben dieser Eigenschaft sollten ebenfalls die Wahrscheinlichkeiten der lichtinduzierten Isomerisierung nach Absorption eines Photons so geschaffen sein, dass man nahezu vollständig in jeden der beiden Zustände schalten kann. 


\section{V.1.4 Die Kinetik der Isomerisierung}

Wie im letzten Abschnitt bereits erwähnt wurde, ist die Protonierung entscheidend für das Schalten von RSFPs. Damit man ein solches Protein in einer Lösung quantitativ mit Licht von einem Zustand in einen anderen schalten kann, muss die lichtgetriebene Reaktion in eine Richtung wesentlich effektiver und somit schneller ablaufen als in die andere. Betrachtet man die Isomerisierung als vereinfachte chemische Reaktion, ergeben sich, bei Bestrahlung mit einer bestimmten Wellenlänge, Reaktionsgeschwindigkeiten für die cis-trans- und die transcis-Isomerisierung $\left(\mathrm{v}^{\text {iso }}\right)$. Ist $\mathrm{v}^{\text {iso }}$ für die Isomerisierung von der cis- in die trans-Konformation wesentlich größer als umgekehrt, so kann man das Chromophor mit dem Licht dieser Wellenlänge in die trans-Konformation bringen.

Vereinfacht betrachtet ergibt sich die Reaktionsgeschwindigkeit der Isomerisierung $\left(\mathrm{v}^{\text {iso }}\right)$ bei den RSFPs aus zwei Komponenten: (1) der Häufigkeit, mit der das Chromophor in dem jeweiligen Zustand Photonen der Wellenlänge, mit der geschaltet wird, absorbiert und (2) die Wahrscheinlichkeit der Isomerisierung im angeregten Zustand. Diese Wahrscheinlichkeit hängt von der Höhe der Energiebarriere ab, die zur Isomerisierung benötigt wird. Die benötigte Energie ist für jedes Molekül gleich und somit konstant; bei der Berechnung der Reaktionsgeschwindigkeit wird sie als k bezeichnet.

Die Häufigkeit der Absorption ergibt sich aus dem Absorptionskoeffizienten der Chromophore im jeweiligen Zustand (welcher direkt von der Konzentration absorbierender cis- bzw. trans-Chromophore abhängig ist) und der Anzahl verfügbarer Photonen, also der Lichtintensität. Daraus ergeben sich für die Isomerisierung zwischen den beiden Zuständen die folgenden Formeln für die Geschwindigkeiten der Reaktionen:

$$
\begin{aligned}
& \mathrm{v}_{\text {cis-trans }}^{\text {iso }}=\mathrm{k}_{\text {cis-trans }} \cdot \mathrm{Abs}^{\text {cis }} \cdot \mathrm{c}(\text { Photonen }) \\
& \mathrm{v}_{\text {trans-cis }}^{\text {iso }}=\mathrm{k}_{\text {trans-cis }} \cdot \mathrm{Abs}^{\text {trans }} \cdot \mathrm{c}(\text { Photonen })
\end{aligned}
$$

Formel 1: Die Reaktionsgeschwindigkeit $v^{\text {iso }}$ ist abhängig von der Absorption* in der jeweiligen Konformation (Abs), der Konzentration der Photonen, also der Lichtintensität und der Wahrscheinlichkeit der Isomerisierung nach Absorption eines Photons, welche durch k gegeben ist.

*das Produkt aus der Konzentration absorbierender Chromophore und deren Absorptionsquerschnitt

Die Konzentration der Photonen ist für beide Reaktionen gleich und konstant, weshalb sie nicht berücksichtigt werden muss. Die Konzentration der absorbierenden Chromophore dagegen ändert bei Verschiebung des Gleichgewichts, so dass sich ebenfalls die Reaktionsgeschwindigkeit ändert. Beim Schalten eines RSFP von der fluoreszierenden cis- in 
die nicht fluoreszierende trans-Konformation wird die Konzentration der Chromophore in der trans-Konformation größer. Daher stellt sich bei der Bestrahlung ein Gleichgewicht ein. Dieses Gleichgewicht sollte bei einem RSFP mit großem dynamischen Bereich dann eintreten, wenn nahezu alle Chromophore in der nicht fluoreszierenden trans-Konformation vorliegen.

Zusätzlich zu der Konzentration der absorbierenden Chromophore im jeweiligen Zustand ist jedoch auch die Wahrscheinlichkeit der Isomerisierung entscheidend für die Lage des Gleichgewichts bei Bestrahlung. So ist zum Beispiel bei dem positiv schaltbaren RSFP Padron die Absorption des deprotonierten Chromophors im fluoreszierenden cis- und im nicht fluoreszierenden trans-Zustand ähnlich hoch (Verhältnis: 0,63 zu 1). Allerdings wird die absorbierte Energie in der cis-Konformation eher in Form von Fluoreszenz abgegeben, dies bedeutet, dass das Chromophor in diesem Zustand wesentlich besser fixiert ist. Die Energiebarriere für die cis-trans-Isomerie ist also größer und daher die Wahrscheinlichkeit der Isomerisierung $\mathrm{k}_{\text {cis-trans }}$ geringer. Dieser Unterschied ermöglicht das nahezu vollständige Einschalten positiv schaltbarer RSFPs in die fluoreszierende cis-Konformation. Die Isomerisierung aus der stabileren cis-Konformation wird durch die Absorption der kürzeren Wellenlänge möglich, da die Energie in diesem Fall ausreichend für eine effektive Isomerisierung von der cis- in die trans-Konformation ist. Das Gleichgewicht zwischen der cis- und trans-Konformation wird bei Bestrahlung mit der kürzeren Wellenlänge fast vollständig auf die Seite des trans-Chromophors gedrückt, weil dieses nahezu vollständig deprotoniert vorliegt.

Das Gleichgewicht, das durch Bestrahlung mit Licht eingestellt wird, ist also einerseits von der Wahrscheinlichkeit der Isomerisierung und den Verhältnissen der Protonierung in der cisund trans-Konformation abhängig.

Mit dem in dieser Arbeit erlangten Wissen und Verständnis über die Zustände verschiedener RSFPs, sowie dessen Protonierungs- und Absorptionseigenschaften, kann ein Modell für das Schalten von RSFPs aufgestellt werden. 


\section{V.1.5 Ein Schema für das Schalten von RSFPs}

Alle bisher untersuchten RSFPs zeigen als fluoreszierenden Zustand die cis-Konformation des Chromophors. Das Prinzip des Schaltens, die cis-trans-Isomerie, scheint zwar bei allen RSFPs gleich zu sein, allerdings können zwei Arten des Schaltens von RSFPs unterschieden werden, ein positiver und ein negativer Schaltmodus.

Die positiv schaltbaren RSFPs werden mit der gleichen Wellenlänge eingeschaltet, mit der auch die Fluoreszenz angeregt wird. Die Bestrahlung mit dieser Wellenlänge resultiert also in einem Anstieg der Fluoreszenz bis zum Maximum ( $\rightarrow$ VI.5.1.1). Im Gegensatz dazu führt die Anregung bei den negativ schaltbaren RSFPs zu einem Ausschalten bis hin zum Minimum der Fluoreszenz ( $\rightarrow$ VI.5.1.2).

Es ist möglich, ein vereinfachtes Schema aufzustellen, das für alle derzeit bekannten positiv bzw. negativ schaltbaren RSFPs gültig ist. Die Betrachtung der Protonierung des Chromophors bezieht sich in dem Modell nur auf den Hydroxyphenylring, da dieser entscheidend für die Absorptionsspektren und somit für das Schalten ist.

$\mathrm{Zu}$ den positiv schaltbaren RSFPs gehören derzeit Padron, asFP595 und rsCherry. Zumindest für Padron und asFP595 ist bekannt, dass der nicht fluoreszierende trans-Chromophor nahezu vollständig deprotoniert vorliegt, während sich der cis-Chromophor in einem Gleichgewicht zwischen der protonierten und der deprotonierten Form befindet (Abbildung 1).

Durch Anregung des deprotonierten, nicht fluoreszierenden trans-Chromophors wird die Isomerisierung zum ebenfalls hauptsächlich deprotonierten, fluoreszierenden cis-Chromophor induziert. Aufgrund der größeren Stabilität des angeregten deprotonierten Chromophors im fluoreszierenden cis-Zustand, ist die Wahrscheinlichkeit einer Isomerisierung hier sehr gering. Die Energie wird in den meisten Fällen über Fluoreszenz abgegeben. Im trans-Zustand dagegen, ist der Chromophor flexibel und die Energie wird meist in Bewegungsenergie umgewandelt, so dass eine Isomerisierung des angeregten deprotonierten Chromophors wahrscheinlicher ist als in der cis-Konformation. Aus diesem Grund ist es möglich, dass die Absorptionen der längeren Wellenlänge im eingeschalteten und ausgeschalteten Zustand ähnlich sind.

Da sich das cis-Chromophor im Gleichgewicht zwischen der deprotonierten und der protonierten Form befindet, wird mit der kürzeren Wellenlänge der Chromophor in der cisKonformation angeregt. Dies kann einerseits zur Fluoreszenz nach ESPT führen ( $\rightarrow$ III.2.4). Die vom Chromophor aufgenommene Energie reicht aber andererseits ebenfalls für eine Isomerisierung in die nicht fluoreszierende trans-Konformation aus. Aufgrund des Protonierungsgleichgewichts in der trans-Konformation ist bei Bestrahlung mit der kürzeren 
Wellenlänge die Isomerisierung von cis nach trans wesentlich schneller als diejenige von trans nach cis (Abbildung 1). Weil das Chromophor in der trans-Konformation aufgrund seiner Umgebung nahezu ausschließlich deprotoniert vorliegt, wird es durch Bestrahlung mit der kürzeren Wellenlänge kaum angeregt.

Das cis-Chromophor kann durch Anregung der protonierten Form quantitativ in die nicht fluoreszierende trans-Konformation geschaltet werden, weil die protonierten Chromophore aus dem Gleichgewicht entfernt werden. Einmal in der trans-Konformation wird das Chromophor aufgrund der Umgebung deprotoniert und der Kreislauf kann von neuem gestartet werden.
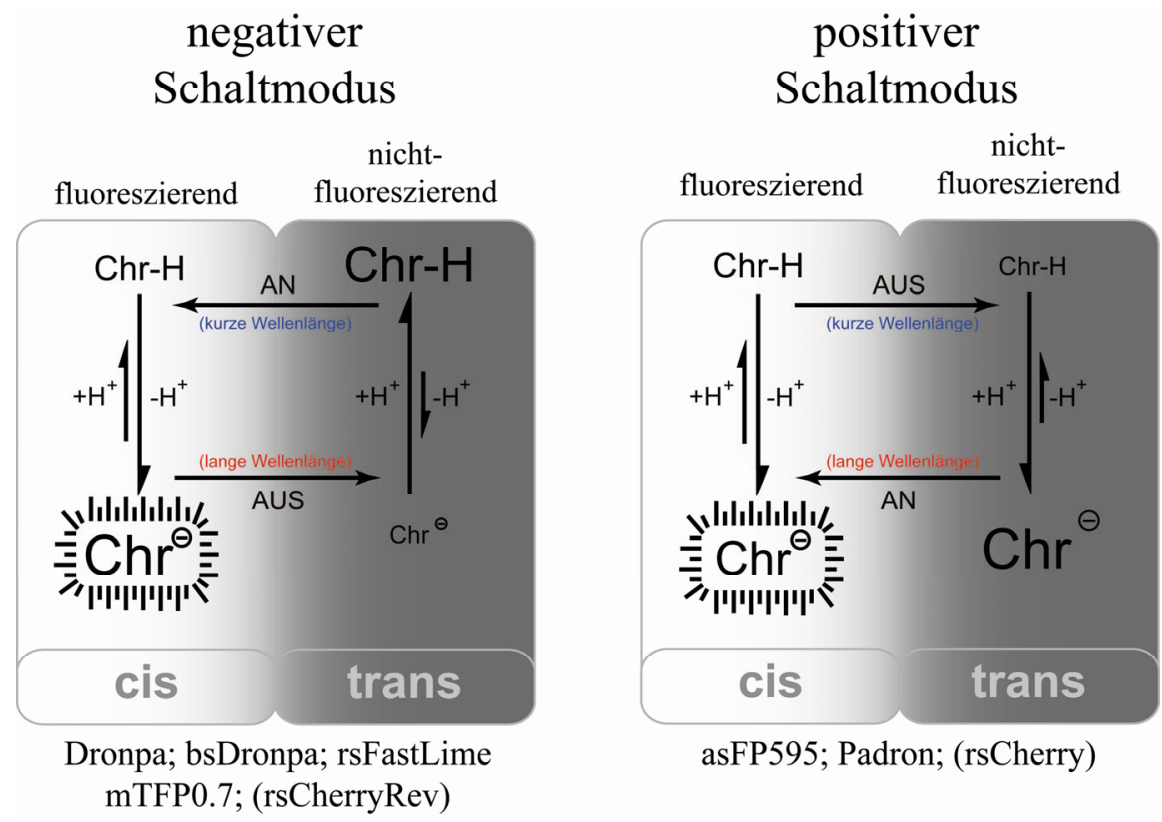

Abbildung 1: Schema des Schaltens positiv und negativ schaltender RSFPs. Das Chromophor wird als Chr abgekürzt, die Ladung, bzw. Protonierung des Chromophors bezieht sich in dem Schema nur auf die Hydroxylgruppe. Details siehe Text. Die Proteine rsCherryRev und rsCherry sind in Klammern gesetzt, da die Zustände der Protonierung noch nicht bekannt sind.

Als negativ schaltbare RSFPs sind derzeit Dronpa, rsFastLime, bsDronpa, rsCherryRev und mTFP0.7 bekannt. Bei allen drei Dronpa-Varianten und mTFP0.7 ist der nicht fluoreszierende trans-Chromophor nahezu vollständig protoniert (Henderson et al. 2007), während der fluoreszierende cis-Chromophor nahezu vollständig deprotoniert vorliegt (bei mTFP0.7 nicht bekannt) (Abbildung 1). Für die Proteine rsCherryRev und rsCherry sind die Zustände der Protonierung nicht bekannt, weil sie sehr kurze Halbwertszeiten haben. 
Eine Anregung mit der längeren Wellenlänge führt bei den negativ schaltbaren RSFPs zu Fluoreszenz und bei längerer Belichtungsdauer auch zum Ausschalten. Es wird beinahe ausschließlich das deprotonierte cis-Chromophor angeregt, welches meist fluoresziert, manchmal aber auch die Energie in Bewegung umsetzt, sodass eine Isomerisierung erfolgt.

Die Reaktionsgeschwindigkeit $v^{\text {iso }}{ }_{\text {cis-trans }}$ ist aufgrund der stark verschobenen Protonierung in den jeweiligen cis- und trans-Konformationen größer. Daher ist ein quantitatives Ausschalten der negativ schaltbaren RSFPs möglich.

Das trans-Chromophor der negativ schaltbaren RSFPs bevorzugt die protonierte Form, so dass eine Anregung mit der kürzeren Wellenlänge effektiv zur Isomerisierung in die cisKonformation führt. Die Isomerisierung von der cis- in die trans-Konformation durch Bestrahlung mit der kurzen Wellenlänge ist aufgrund des stabileren angeregten cis-Zustands und der geringeren Anzahl protonierter cis-Chromophore langsamer. In der cis-Konformation liegt das Chromophor aufgrund der Umgebung größtenteils deprotoniert vor und befindet sich somit wieder im fluoreszierenden Zustand.

Diese zwei Modelle für das Schalten sind stark vereinfacht. Es werden weder Umlagerungen anderer Aminosäuren, die Protonierung des Imidazolrings oder die Quantenausbeuten der „nicht fluoreszierenden“ Zustände berücksichtigt. Außerdem gibt es vermutlich noch weitere Zwischenzustände, die zwar wesentlich kurzlebiger sind, aber trotzdem einen Einfluss auf das Schaltverhalten haben können. Die Modelle erklären jedoch die Grundlagen des positiven und negativen Schaltens und scheinen für alle bisher untersuchten RSFPs gültig zu sein. Die Ergebnisse anderer Gruppen bezüglich des Mechanismus und der Protonierungszustände stimmen ebenfalls mit diesem Modell überein (Habuchi et al. 2005; Dedecker et al. 2006; Habuchi et al. 2006; Schuettrigkeit 2006; Fron et al. 2007; Moors et al. 2008).

Aus dem Modell lassen sich zudem die Eigenschaften ableiten, die ein FP unbedingt aufweisen muss, damit es reversibel schaltbar ist. Erstens muss ausreichend Platz in der Proteinmatrix vorhanden sein, dass das Chromophor eine cis- und eine trans-Konformation einnehmen kann. Zweitens muss das Chromophor in einem der beiden Zustände fluoreszieren und in dem anderen nicht. Drittens muss die Hydroxylgruppe des Chromophors unterschiedlich protoniert vorliegen, sodass die Anregung mit der kurzen, bzw. der langen Wellenlänge zu einer Isomerisierung führt, die das Gleichgewicht zwischen der cis- und transKonformation beinahe vollständig auf eine der beiden Seiten verschiebt. 


\section{V.2 Die Entwicklung von RSFPs}

Im Rahmen dieser Doktorarbeit wurden Dronpa und asFP595 als Basis für die Entwicklung neuer und verbesserter RSFPs verwendet. Weiterhin wurde das rot fluoreszierende, monomere Protein mCherry schaltbar gemacht. Die Entwicklung eines Test- und Auswahlverfahrens zur Verbesserung von RSFPs, war ein grundlegender Teil dieser Arbeit, der in Zusammenarbeit mit Kollegen aus der Arbeitsgruppe realisiert wurde.

Bei der Verbesserung reversibel schaltbarer FPs muss im Gegensatz zu der Verbesserung normaler FPs auf viele Eigenschaften gleichzeitig geachtet werden. Bei normalen fluoreszierenden Proteinen ist in der Regel ausreichend, die Helligkeit zu verbessern, während bei den RSFPs ebenfalls die Eigenschaften der Restfluoreszenz und der Schaltgeschwindigkeit berücksichtigt werden müssen.

Bei einem Test- und Auswahlverfahren zur Verbesserung von RSFPs muss aufgrund der zu testenden Eigenschaften jede Variante einmal vollständig geschaltet werden. Dazu ist es notwendig, die Varianten einzeln zu analysieren. Wie bereits im Ergebnisteil beschrieben, wurden daher ganze E.coli-Kolonien auf Agarplatten analysiert. Die Agarplatten wurden dabei mit einem computergesteuerten Mikroskop Punkt für Punkt abgerastert ( $\rightarrow$ IV.2.2). Mit den Messdaten konnten anschließend die Eigenschaften aller auf der Agarplatte gemessenen Kolonien untereinander verglichen werden.

\section{V.2.1 Einfluss des Test- und Auswahlverfahrens auf die gemessenen}

\section{Eigenschaften der RSFPs}

Die Helligkeit ist bei dem Test- und Auswahlverfahren die komplexeste Größe. Während die Schaltgeschwindigkeit und die Restfluoreszenz bei gleichbleibender Lichtintensität nur von den Proteinen selbst bestimmt werden, wird die Helligkeit auch noch von äußeren Umständen beeinflusst. Die Helligkeit ergibt sich aus der Quantenausbeute, dem Absorptionskoeffizienten, der Faltungseffizienz, der Koloniegröße, dem Expressionsgrad und der Lichtintensität. Bei der Analyse einer Mutagenese muss also möglichst ausgeschlossen werden, dass Unterschiede in der Helligkeit gemessen werden, weil die äußeren Faktoren Koloniegröße oder Lichtintensität variieren. Bezüglich der Koloniegröße kann die Schrittweite des Mikroskops angepasst werden, so dass nur geringe Schwankungen der maximalen Helligkeit verschieden großer Kolonien gemessen werden. Bei der Lichtintensität müssen jedoch mehrere Faktoren berücksichtigt werden. Dies ist umso wichtiger, da neben der Helligkeit auch die Schaltgeschwindigkeit stark von der Lichtintensität abhängig ist. Die 
Restfluoreszenz ist im Gegensatz dazu über einen relativ großen Bereich der für das Test- und Auswahlverfahren verwendeten Intensitäten stabil.

Die Abhängigkeit der getesteten Eigenschaften von der Lichtintensität stellt für die Auswahl verbesserter Proteine ein Problem dar, weil die verwendeten Quecksilberdampflampen über ihre gesamte Lebensdauer Schwankungen der Intensität von bis zu 50 \% aufweisen. Um dies auszugleichen wurden einerseits Kontrollen, wie die Analyse des Ursprungsklons einer Mutagenese, durchgeführt. Die Lampenschwankungen wurden weiterhin gering gehalten, indem die Intensität vor den Messungen bestimmt und mit einem regulierbaren Filter auf den gewünschten Wert eingestellt wurde. Mit diesen zwei Maßnahmen konnte der Einfluss der Lichtintensität auf die gemessenen Eigenschaften kompensiert werden.

\section{V.2.3 Die Restfluoreszenz in Abhängigkeit der Lichtintensität}

Bei der Optimierung von RSFPs wäre es von Vorteil mit stärker fokussierenden Objektiven $\mathrm{zu}$ arbeiten, da sich zeigte, dass bei hohen Intensitäten die Restfluoreszenz zunimmt. Diese Abhängigkeit des Schaltens von der Intensität zeigte sich auch immer wieder als Problem bei der Übertragung verbesserter Proteine in eine RESOLFT Anwendung. So wurde beobachtet, dass bei höheren Intensitäten die Restfluoreszenz generell stärker wurde. Dies könnte einerseits an zeitlich begrenzten Reaktionen beim Schalten zwischen den beiden Zuständen liegen, da das Schalten bei der Optimierung der Proteine im Bereich von Sekunden liegt, während für die mikroskopischen Anwendungen Schalten in weniger als einer Millisekunde notwendig ist.

Andererseits wird sich eine Sättigung der Anregung auf die Effektivität des lichtgetriebenen Schaltens auswirken, da die Absorptionskoeffizienten in cis- und trans-Konformation nicht mehr direkt die Anzahl absorbierter Photonen bestimmen. Bei annähernd gesättigter Anregung ist das Verhältnis der absorbierten Photonen nicht mehr gleich dem Verhältnis der Absorptionskoeffizienten, da Moleküle, die sich bereits im $\mathrm{S}_{1}$-Zustand befinden erst wieder angeregt werden können, wenn sie sich in $\mathrm{S}_{0}$ befinden. Das Verhältnis der absorbierten Photonen zwischen den beiden Zuständen gleicht sich somit bei hohen Intensitäten an (Condon 1964). Aus diesem Grund kann das Gleichgewicht der durch Licht getriebenen Isomerisierung zwischen dem fluoreszierenden und nicht fluoreszierenden Zustand nicht mehr ganz so weit auf eine Seite verschoben werden. Dies resultiert in einer stärkeren Restfluoreszenz bei hohen Intensitäten.

Es wäre also von Vorteil, direkt mit hohen Intensitäten nach verbesserten RSFPs zu suchen. Allerdings würden bei der Verwendung von Objektiven mit starker Fokussierung die 
Probleme bezüglich der Lichtintensität wesentlich stärker werden. Denn bei stärkerer Fokussierung wird auch die Ausdehnung des Fokus in z-Richtung wesentlich kleiner. Die Höhe der Kolonien und die Unebenheiten auf einer Agarplatte müssten in diesem Fall ausgeglichen werden, z.B. durch einen automatischen Fokus, der vor jeder Messung den Fokus an die Kolonie anpasst, oder indem man die Kolonien an eine lichtdurchlässige, ebene Platte anpresst und so alle Kolonien auf eine Ebene bringt. Eine Hochdurchsatzanalyse auf Agarplatten, bei der die Kolonien mit hohen Intensitäten geschaltet werden, ist also möglich.

\section{V.2.4 Mutagenese von asFP595}

Für die gerichtete Mutagenese von asFP595 mussten zunächst Aminosäuren ausgewählt werden, die einen Einfluss auf das Chromophor bzw. das Schaltverhalten haben könnten. Von den Aminosäuren A143 bzw. S158 war bereits bekannt, dass sie die Stabilität des fluoreszierenden bzw. des nicht fluoreszierenden Zustands zum Großteil bestimmen (Chudakov et al. 2003). Mit den Röntgenstrukturen beider Zustände ließen sich für das Schalten weitere mit hoher Wahrscheinlichkeit wichtige Aminosäuren bestimmen, wie z.B. M160 und L174, die sich beide zwischen dem cis- und dem trans-Chromophor befinden. Damit keine entscheidenden Mutationen übersehen werden, wurden letztendlich alle Aminosäuren in einem $6 \AA$ Radius um das Chromophor mutagenisiert und analysiert. Die aufgrund der Röntgenstrukturen als wichtig eingeschätzten Positionen wurden dabei intensiver behandelt, es wurden insgesamt mehr Mutanten analysiert und ebenfalls solche, die keinen, oder einen negativen Einfluss auf eine der Eigenschaften zeigten.

Beim Vergleich der Eigenschaften verschiedener Mutanten einer Aminosäureposition wurde deutlich, dass ein Austausch an dieser Position häufig zu ähnlichen Effekten führt. Zum Beispiel erhöhen die Mutationen M160L und M160A beide die Helligkeit und die Schaltgeschwindigkeit deutlich. Weiterhin zeigte sich, dass die Effekte von Mutationen auch in ganzen Bereichen um das Chromophor herum ähnlich waren. Zum Beispiel sind Helligkeit und Schaltgeschwindigkeit Effekte, die nicht nur bei Position 160 häufig vorkommen, sondern auch bei Mutanten an der direkt benachbarten Position 174. Diese Beobachtung wurde in Form eines Modells verarbeitet, welches verschiedene Aminosäurepositionen in funktionelle Gruppen zusammenfasst. 


\section{V.2.5 Die Hypothese funktional und örtlich begrenzter Clustern}

Die Positionen um das asFP595 Chromophor, konnten aufgrund der Mutantenstudie $(\rightarrow$ IV.2.6) bestimmten Clustern zugeordnet werden, die örtlich und funktional begrenzt zu sein scheinen (Stabilitätscluster, sterischer Cluster, Histidin-Cluster, trans-Cluster, und Peripheriecluster).

Die Positionen 143 und 158 liegen in den beiden Zuständen (cis und trans) direkt vor der terminalen Hydroxylgruppe des Chromophors und bilden den Stabilitätscluster (Abbildung 2a). Ein Austausch von Aminosäuren kann hier sowohl stabilisierend, im Fall von A143S, als auch destabilisierend, im Fall von S158V, auf das Chromophor von asFP595 wirken. Die Mutation A143S stabilisiert das cis-Chromophor und S158V destabilisiert das trans-Chromophor. Beide Mutanten resultieren in erhöhter Stabilität der fluoreszierenden cisKonformation, einer Verschiebung des Gleichgewichts im Grundzustand des Proteins, sowie einer erhöhten Helligkeit.

Einen ebenfalls sehr starken Einfluss auf das Chromophor hat der sterische Cluster, welcher aus den Aminosäuren T60, M160, L174 und I199 besteht (Abbildung 2b). Die Reste bilden einen Grossteil der Tasche des Chromophors, und haben daher einen starken Effekt auf das Quenchen eines angeregten Chromophors und damit auch auf die Helligkeit. Des Weiteren ist dieser Cluster essentiell für die Isomerisierung von cis nach trans, weshalb Variationen dieser Aminosäuren zusätzlich einen starken Einfluss auf die Schaltgeschwindigkeit haben.

Der Histidin Cluster besteht aus den Aminosäuren K67, E145, E195 und E215, die sich um das Histidin an Position 197 gruppieren (Abbildung 2c). H197 bildet eine $\pi$-Stapelwirkung mit dem Chromophor aus und hat daher einerseits einen starken Einfluss auf dessen Elektronensystem, andererseits stabilisiert es das Chromophor. Mutationen von H197 und dessen Umgebung haben einen großen Einfluss auf die Absorption und daher auf die Färbung der Mutanten.

Der trans-Cluster besteht aus den Aminosäuren W90, R92, T176 und Y178 und umfasst das Chromophor in der trans-Konformation (Abbildung 2d). Dieser Bereich scheint essentiell für die Faltung des Proteins zu sein, weshalb bei der Mutagenese nur zwei Mutanten gefunden wurden, die gefärbte E.coli-Kolonien ergaben, also ein korrekt gefaltetes Chromophor aufwiesen. Diese zwei Varianten haben allerdings beide einen Einfluss auf die Stabilität des nicht fluoreszierenden trans-Zustands.

Der Peripheriecluster wird durch alle Positionen gebildet, die bei der Zufallsmutagenese entdeckt wurden und nicht in der direkten Umgebung des Chromophors lagen. Bei den Vertretern dieses Clusters handelt es sich meist um Positionen, die sich direkt neben solchen 
Aminosäuren befinden, die einen großen Einfluss auf das Chromophor haben. So liegt z.B. H175 zwischen L174 und T176, oder T89 nahe bei Y178. Der Austausch von Aminosäuren dieses Clusters hat vermutlich nur indirekten Einfluss auf die Eigenschaften des Chromophors. Das erklärt die relativ weit entfernt gelegenen Mutationen, die scheinbar subtile Veränderungen in den Sekundärstrukturen hervorrufen, und somit Einfluss auf die Aminosäuren in der Nähe des Chromophors nehmen.

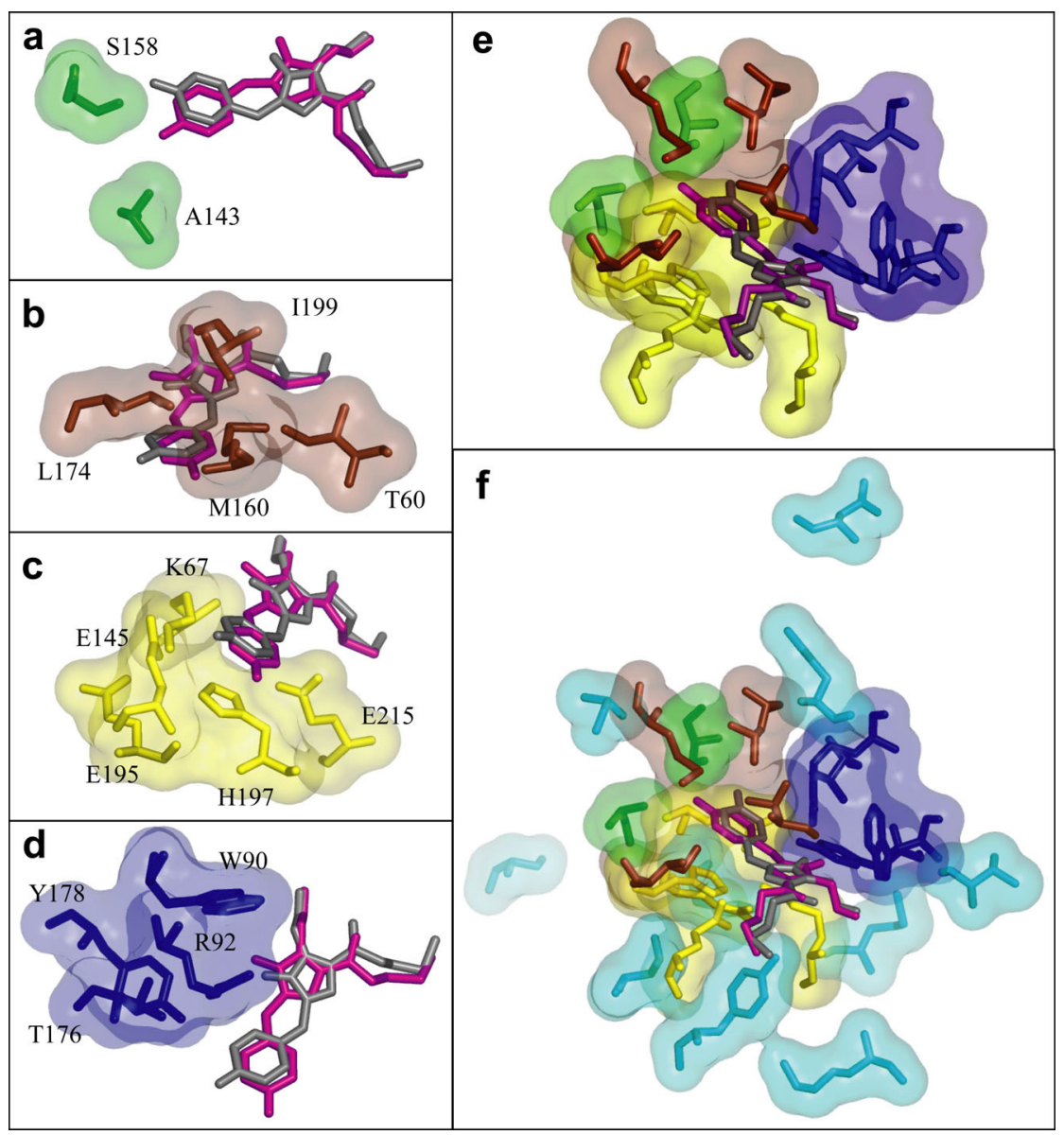

Abbildung 2: Cluster in der Umgebung des Chromophors. (a) Stabilitätscluster (grün); (b) sterischer Cluster (orange); (c) Histidin-Cluster (gelb); (d) Trans-Cluster (blau); (e) Übersicht der Cluster um das Chromophor; (f) die Positionen des Peripherie-Clusters in hellblau.

Die Einteilung in Cluster gruppiert Aminosäuren, die eine ähnliche Wirkung auf das Chromophor und das Schaltverhalten haben. Dies erwies sich bei der Kombination von Einzelmutationen als hilfreich.

So konnte die Variante L174M durch zusätzliche Mutationen an den Positionen desselben Clusters (60, 160 und 199) nicht verbessert werden, obwohl viele der Mutationen einzeln einen starken positiven Effekt auf die Helligkeit oder die Schaltgeschwindigkeit hatten. Im Gegensatz dazu führt die Kombination von L174M und A143S, zwei Einzelmutationen, dessen Positionen verschiedenen Clustern angehören, zu einer deutlich helleren Variante. Die 
Mutante L174M reduziert wahrscheinlich direkt die Fluoreszenzlöschung über Stöße und Rotationen, während A143S das cis-Chromophor durch eine Wasserstoffbrücke stabilisiert und die Fluoreszenzlöschung somit indirekt reduziert. Daher lassen sich die zwei Mutationen kombinieren, so dass eine ca. 150-fache Erhöhung der Helligkeit resultiert.

Die Cluster geben somit Hinweise darauf, ob die Vorteile verschiedener Einzelmutationen in Kombinationsmutanten miteinander verknüpft werden können.

\section{V.2.6 Entwicklung eines roten RSFP}

Insgesamt konnte das Protein asFP595 so weit verbessert werden, dass es mit einer ähnlichen Helligkeit wie mRFP1 und eqFP611 und einer Restfluoreszenz von 0,3\% ein sehr gutes RSFP ist. Allerdings bestand immer noch das Problem, dass asFP595 ein sehr stabiles Tetramer bildet.

Wie bereits in den Ergebnissen beschrieben wurde, konnte das Protein asFP595 durch insgesamt 15 Mutationen monomerisiert werden ( $\rightarrow$ IV.2.8). Allerdings wurden dabei die Proteinfaltung, die Fluoreszenz und das reversible Schalten so sehr verschlechtert, dass auch durch intensive Mutagenese kein gutes monomeres RSFP erzeugt werden konnte. Um ein monomeres rot fluoreszierendes RSFP zu erzeugen, wurde daher das helle, gut gefaltete rot fluoreszierende Protein mCherry als Ausgangsbasis für die Mutagenese gewählt. Aus diesem Protein konnten die beiden RSFPs rsCherry und rsCherryRev generiert werden ( $\rightarrow$ IV.4.10). Für die Entwicklung grün fluoreszierender RSFP war das Protein Dronpa die sinnvollste Basis, da es bereits ein monomeres RSFP mit einer guten Helligkeit und Faltungseffizienz ist.

\section{V.2.7 Dimerisierungstendenz neuer Dronpa Varianten}

Bei der Verbesserung von Dronpa konnten die Erfahrungen aus der asFP595 Mutantenstudie zum Teil übertragen werden. So wurden zunächst diejenigen Positionen ausgetauscht, die denjenigen mit dem größten Effekt bei asFP595 entsprachen. Daraus ergab sich direkt die Variante rsFastLime mit der Mutation V157G. Die Position 159 bei Dronpa entspricht der Position 160 bei asFP595 und führte zu dem Austausch M159Y, dem Grundstein der Varianten Padron und bsDronpa.

Einige für die Restfluoreszenz und die Proteinfaltung zuträgliche Mutationen bei der Entwicklung von Padron bewirkten jedoch leider eine schwache Dimerisierung. Obwohl dies in lebenden Zellen nicht stören sollte, da ein Dimer mit Säulenchromatographie bei $37^{\circ} \mathrm{C}$ nicht mehr nachweisbar ist ( $\rightarrow$ IX.2.5), wurde das Protein Padron* erstellt, welches auch bei niedrigen Temperaturen ein vollständiges Monomer ist $(\rightarrow$ IV.4.3). Dazu wurden die 
Positionen an der Außenseite des $\beta$-Fasses, die zur Dimerisierung führten, durch andere Aminosäuren ersetzt. Die Mutationen N94H, I100S und P141R waren diejenigen, die nur einen geringen negativen Einfluss auf die Restfluoreszenz, die Helligkeit und die Proteinfaltung hatten, trotzdem aber ausreichend waren, das Monomer wiederherzustellen. Mit anschließender Zufallsmutagenese wurden diese Eigenschaften wieder verbessert, was zu dem vollständig monomeren RSFP Padron* führte.

Die aus dem Protein Dronpa generierten Varianten ermöglichen verschiedene Anwendungen, unter anderem erlauben die beiden neuen RSFPs monochromatische Mehrfarben-Mikroskopie ohne Aberrationen, und hochauflösende Mikroskopie mit zwei Farben nach dem Einzelmolekül-Lokalisationsverfahren. 


\section{V.3 Anwendungen}

Die Eigenschaften der RSFPs sollten speziell für hochauflösende Lichtmikroskopietechniken modifiziert werden. Für beide derzeit bekannten Verfahren, die RESOLFT-Technik (reversible saturable optical fluorescence transitions) und die EinzelmolekülLokalisationsverfahren (PALM, STORM, PALMIRA), wurden Proteine entwickelt, die dessen Anwendung ermöglichen. Für das RESOLFT-Verfahren sind positiv schaltbare RSFPs besser geeignet, wie Padron, rsCherry und die asFP595 Varianten. Das EinzelmolekülLokalisationsverfahren dagegen benötigt man negativ schaltbare RSFPs. Für diese Anwendungen sind die Proteine rsFastLime, rsCherryRev und bsDronpa geeignet. Während die Anwendungen nach dem Einzelmolekül-Konzept bereits in vivo verwirklicht wurden, konnte das technisch anspruchsvollere RESOLFT-Verfahren mit RSFPs bisher nicht erfolgreich in Zellen benutzt werden.

Neben der essentiellen Bedeutung der RSFPs für hochauflösende Mikroskopietechniken, ermöglichen die Proteine auch Anwendungen in anderen Bereichen, wie der Bestimmung von Diffusionsgeschwindigkeiten (Chudakov et al. 2006), in der Fluoreszenz-KorrelationsSpektroskopie (FCS: fluorescence correlation spectroscopy) (Eggeling et al. 2007) oder die monochromatische Mehrfarben-Mikroskopie (Andresen et al. 2008).

\section{V.3.1 RSFPs in der RESOLFT-Mikroskopietechnik}

Mit asFP595 wurde bereits gezeigt, dass es für das RESOLFT-Verfahren prinzipiell geeignet ist (Hofmann et al. 2005). Allerdings ist die erzielte Auflösungserhöhung mit einem Faktor von 2,3 eher gering und nur an Strukturen, die in einen Objektträger geätzt wurden und mit aufgereinigtem Protein gefüllt waren, demonstriert worden.

Die während dieser Doktorarbeit entwickelten Varianten von asFP595 sollten aufgrund der stark reduzierten Restfluoreszenz, der erhöhten Helligkeit und des schnelleren Schaltens wesentlich besser für die Anwendung des RESOLFT Konzepts geeignet sein. Allerdings zeigte sich, dass die Verwendung hoher Lichtintensitäten die Restfluoreszenz beim Schalten deutlich erhöht ( $\rightarrow$ V.2.3). Hohe Intensitäten sind bei RESOLFT notwendig, da die Probe mit sehr kleinen Schrittweiten abgerastert wird, bei Verwendung geringer Intensitäten steigt die Zeit für die Aufnahme eines Pixels stark an, wodurch die Aufnahme eines gesamten Bildes oder sogar eines ganzen Bilderstapels erheblich länger dauert.

Die Verwendung hoher Intensitäten führt zusätzlich $\mathrm{zu}$ einem zweiten Problem, da das Bleichen mit erhöhter Intensität ebenfalls zunimmt. Das Bleichen stellt ein Problem dar, weil die RSFPs bei der Aufnahme eines RESOLFT-Bildes bis zu 100-mal geschaltet werden 
müssen. Dies kommt daher, dass das Einschalten und das Auslesen der Fluorophore mit derselben Wellenlänge induziert werden. Der ausgeschaltete Bereich wird also beim Auslesen wieder eingeschaltet, sodass der Hintergrund ansteigt, und die Fluoreszenz nur für kurze Dauer ausgelesen werden kann. Um ein ausreichend hohes Fluoreszenzsignal zu bekommen, muss an einer Position mehrmals geschaltet und ausgelesen werden. Die RSFPs müssen also sehr resistent gegen Photobleichen sein.

Obwohl mit Padron, rsCherry und asFP595-A143S, L174M mehrere Proteine vorhanden sind, die für RESOLFT geeignet scheinen, ist es bis jetzt mit keinem dieser Proteine gelungen Bilder von ähnlicher Qualität $\mathrm{zu}$ erzeugen, wie es mit dem EinzelmolekülLokalisationsverfahren unter Verwendung der negativ schaltbaren RSFPs möglich war.

Es gibt zwei Möglichkeiten, die eine Aufnahme von qualitativ hochwertigen hochauflösenden Bildern im RESOLFT-Modus ermöglichen könnten. Bei den bisherigen Anwendungen der RESOLFT-Technik wurde das Ausschalten durch Einstrahlung beider Wellenlängen gleichzeitig durchgeführt. Dies erlaubt ein permanentes Auslesen der Fluoreszenz, erhöht jedoch die Restfluoreszenz und das Bleichen in der Probe. Durch sequenzielles Ausschalten und Auslesen sollten sowohl die Restfluoreszenz, als auch das Bleichen deutlich reduziert werden können.

Die zweite Möglichkeit, gute Bilder im RESOLFT-Modus aufzunehmen, wäre die Intensität stark zu reduzieren. Da mit hoher Intensität das Bleichen und die Restfluoreszenz zunehmen, sollte auch die Reduktion der Intensität eine Möglichkeit darstellen, die Bilder im RESOLFTModus zu verbessern.

\section{V.3.2 Negativ schaltbare RSFPs in dem Einzelmolekül-Lokalisationsverfahren}

Die negativ schaltbaren Varianten von Dronpa sind für hochauflösende Mikroskopie nach dem Einzelmolekül-Prinzip geeignet. Es wurde sowohl für rsFastLime, als auch für bsDronpa und Dronpa selbst gezeigt, dass sie für die hochauflösende Mikroskopie benutzt werden können. Dronpa ist jedoch mit der relativ hohen Restfluoreszenz von $6 \%$ nicht so gut geeignet, wie die beiden neu erstellten Proteine rsFastLime und bsDronpa. Weiterhin ist durch die Entwicklung von bsDronpa, obwohl es nur um $18 \mathrm{~nm}$ in der Emissionswellenlänge gegenüber Dronpa verschoben ist, hochauflösende Mikroskopie mit zwei Farben möglich.

Die Entwicklung neuer Proteine für diese Art der Mikroskopie sollte in den nächsten Jahren die Qualität der hochauflösenden Bilder in der Einzelmolekülspektroskopie deutlich verbessern. Zwei Eigenschaften der RSFPs sind entscheidend für das Aufnehmen guter Bilder nach dem Einzelmolekül-Lokalisationsverfahren. Einerseits die Restfluoreszenz eines RSFP, 
und andererseits die Anzahl der Photonen, die ein eingeschaltetes Molekül aussendet, bevor es wieder in den nicht fluoreszierenden Zustand übergeht (Photonen pro aktiviertem Fluorophor).

Die Restfluoreszenz ist entscheidend, da sie die Markierungsdichte in der Probe bestimmt. Weil bei der Einzelmolekülspektroskopie, wie der Name schon sagt, Einzelmoleküle gemessen werden, ist eine sehr geringe aktive Fluorophorkonzentration notwendig. Bei Proben mit hoher Markierungsdichte muss diese deshalb reduziert werden. Eine solche Reduktion der aktiven Fluorophore ist mit RSFPs möglich, wie bereits 2007 gezeigt wurde (Eggeling et al. 2007). Falls das Ausschalten nicht ausreicht, muss zunächst geblichen werden. Dies reduziert die Anzahl der Moleküle, die in der Probe gemessen werden können, weshalb die Qualität der Bilder schlechter wird. Bis zu welcher Restfluoreszenz ein RSFP ausgeschaltet werden kann, bestimmt also die Anzahl der Moleküle, die in einer Probe mit dem Einzelmolekül-Lokalisationsverfahren gemessen werden können.

Die zweite wichtige Eigenschaft, die Anzahl der ausgesandten Photonen pro aktiviertem Fluorophor, bestimmt, wie genau einem Molekülen seine Position zugeordnet werden kann. Je mehr Photonen für die Bestimmung des Mittelpunkts der Gaussverteilung auf dem Detektor zur Verfügung stehen, desto genauer kann die Position des Moleküls bestimmt werden.

Während die Restfluoreszenz bereits bei der Auswahl verbesserter Klone berücksichtigt wurde, muss für die Anzahl der ausgesandten Photonen pro aktivem Fluorophor ein neues Test- und Auswahlverfahren generiert werden. Dieser Wert kann nur in der Einzelmolekülspektroskopie gemessen werden, daher ist er nicht einfach in einem Hochdurchsatzverfahren zu messen.

Werden nicht genügend Photonen aufgefangen, wird der Mittelpunkt der Gaussverteilung nicht bestimmt, da eine ungenaue Bestimmung die Auflösung verringern würde. Eine Verbesserung dieser zweiten Eigenschaft könnte die Qualität der Bilder deutlich erhöhen, da bei den derzeit verfügbaren RSFPs etwa nur 50-80\% der aktivierten Fluorophore zur Bestimmung der Position benutzt werden können.

Die RSFPs haben jedoch nicht nur im Bezug auf die hochauflösende Mikroskopie ein großes Potential, wie die Anwendung in anderen Bereichen der Mikroskopie zeigt.

\section{V.3.3 RSFPs als Katalysatoren für neue Techniken in der Mikroskopie}

Neben der bereits angesprochenen Relevanz der RSFPs für die hochauflösende Mikroskopie, ist das reversible Schalten auch für andere Anwendungen von großem Interesse. So ist die 
Nutzung für das Verfolgen aktivierter Subpopulationen markierter Proteine innerhalb einzelner Zellen (protein tracking) eine sehr naheliegende Anwendung (Chudakov et al. 2006; Henderson et al. 2006). Aufgrund der Kopplung von Schalten und Auslesen, sowie dem Zurückfallen der aktivierten RSFPs in ihren Grundzustand, ist eine Verfolgung über längere Zeit mit den derzeitigen RSFPs nur schwer möglich. Die Entwicklung von RSFP-Varianten, die in beiden Zuständen thermodynamisch stabil vorliegen, und nur mit hoher Intensität geschaltet, aber mit geringer Intensität ausgelesen werden können, werden solche Anwendungen erleichtern.

Selbst mit KFP1, welches relativ dunkel und ein Tetramer ist, war es bereits möglich, durch kurzfristige mehrmalige Messungen in einer Zelle die Diffusion markierter Proteine innerhalb kurzer Zeit sehr genau zu bestimmen (Chudakov et al. 2006). Durch das reversible Schalten kann die Diffusionsgeschwindigkeit mehrmals direkt hintereinander gemessen werden, so dass eine höhere Genauigkeit erreicht wird, als bei Messungen mit irreversibel schaltbaren FPs.

Die Möglichkeit von Mehrfachmessungen in einer Zelle erlaubt es ebenfalls, die Auswirkungen von Umgebungseffekten auf die Dynamik von Proteinen in derselben Zelle zu untersuchen. Während beim Vergleich der Dynamik in unterschiedlichen Zellen niemals exakt gleiche Bedingungen vorhanden sein können, sind Messungen in derselben Zelle genau miteinander vergleichbar.

Im Rahmen dieser Arbeit wurde weiterhin eine Methode entwickelt, mit der mehrere Proteine in einer Zelle aberrationsfrei detektiert werden können ( $\rightarrow$ IV.4.8). Diese monochromatische Mehrfarben-Mikroskopie, basiert auf dem antagonistischen Schalten eines negativ und eines positiv schaltbaren RSFP.

In dieser Arbeit wurde gezeigt, dass nahezu alle Eigenschaften der RSFPs modifiziert werden können. Die einzigartigen Eigenschaften von RSFPs wie die Schaltgeschwindigkeit, die Stabilität des fluoreszierenden und nicht fluoreszierenden Zustands und die Restfluoreszenz, sowie die generellen Eigenschaften fluoreszierender Proteine, wie Helligkeit und Absorptions- bzw. Emissionseigenschaften konnten Rahmen dieser Arbeit verändert und für bestimmte Anwendungen optimiert werden. Die große Anzahl verschiedener Eigenschaften zeigt, dass es notwendig ist FPs im Allgemeinen und die RSFPs im speziellen für ihre jeweilige Anwendung zu optimieren.

Diese Arbeit führte zum Verständnis des grundlegenden Mechanismus für das Schalten der reversibel schaltbaren fluoreszierenden Proteine und wird die Optimierung von RSFPs für zukünftige Anwendungen in der Mikroskopie vereinfachen. 


\section{V.4 Ausblick}

Die Ergebnisse dieser Arbeit haben gezeigt, dass reversibel schaltbare fluoreszierende Proteine verbessert und für bestimmte Anwendungen optimiert werden können. Dabei hat sich das in dieser Arbeit erlangte Verständnis des Mechanismus als sehr hilfreich erwiesen.

Obwohl der Mechanismus durch die Strukturanalysen grundlegend aufgeklärt ist, wäre eine detaillierte Analyse weiterer photophysikalischer Zustände der RSFPs von großem Interesse. Solche Zustände können bei Prozessen, die sehr schnelles Schalten benötigen, wie bei der hochauflösenden Mikroskopie nach dem RESOLFT-Verfahren, einen Einfluss auf das Schaltverhalten der Proteine haben. Die Entwicklung von RSFPs für die RESOLFT-Technik könnte durch eine Optimierung bei hohen Intensitäten verwirklicht werden.

Während die RSFPs in dieser Arbeit hauptsächlich für die Verwendung in der hochauflösenden Mikroskopie optimiert wurden, ist es ebenso notwendig, die Proteine für weitere Anwendungen wie das protein tracking zu verbessern. Im Gegensatz zum schnellen Schalten, das bei hochauflösenden Mikroskopietechniken notwendig ist, müssen die Proteine in diesem Fall möglichst langsam Schalten und sehr stabil in beiden Zuständen vorliegen. Weil das Auslesen möglichst wenig Schalten induzieren sollte, wäre auch hier eine Optimierung der Proteine bei hohen Intensitäten sinnvoll. Dabei müssten solche Proteine ausgewählt werden, die mit der Anregungswellenlänge trotz hoher Leistung möglichst langsam Schalten. Für das protein tracking wäre eine vollständige Entkopplung von Auslesen und Schalten die beste Lösung, dies ist jedoch nur mit einer dritten Absorptionswellenlänge möglich.

Weiterhin ist eine genaue Untersuchung des Einflusses der Protonierungen und der Stabilität der Chromophore von großem Interesse. Dies könnte dazu beitragen die Frage zu beantworten, weshalb ein Chromophor in einem Zustand fluoresziert und in dem anderen nicht. Die RSFPs stellen für diese Frage ein besonders gutes Modell dar, da in demselben Protein ein fluoreszierender und ein nicht fluoreszierender Zustand vorhanden sind.

Aufgrund der geringen Anzahl unterschiedlicher RSFPs, speziell im Bezug auf die Emissionswellenlänge, ist deren Anwendungen in der Mikroskopie limitiert. Daher sind weitere RSFPs mit einer Fluoreszenz in anderen Spektralbereichen notwendig. Generell wird es aufgrund der großen Diversität der Eigenschaften von RSFPs notwendig sein, die Proteine für ihre jeweilige Anwendung zu gestalten. Das Verständnis des Mechanismus, sowie die Entwicklung der RSFPs in dieser Arbeit sollten dabei von großem Nutzen sein. 


\section{Material und Methoden}

\section{VI.1 Hefegenetik}

\section{VI.1.1 Kreuzung zweier Hefestämme}

Um zwei Hefestämme miteinander zu kreuzen, müssen sie unterschiedliche Paarungstypen (mating Type) aufweisen. Ist dies der Fall, ist es ausreichend, die Stämme in räumlicher Nähe wachsen zu lassen. Zur Überprüfung der Fusion beider Stämme sollte man die Zellen anschließend auf einem Selektionsmedium wachsen lassen. Auf diesem Medium sollte keiner der beiden haploiden Stämme, sondern nur der diploide Stamm wachsen können.

Benötigtes Material:

- Agarplatte mit Selektivmedium für den diploiden Hefestamm

- YPD-Agarplatte

Protokoll:

Auf einer YPD-Platte werden die beiden Stämme mit einer Impföse in räumliche Nähe gebracht. Dazu wird der erste Stamm in der Mitte der Platte von links nach rechts ausgestrichen. Der zweite Stamm wird mit der Impföse von oben nach unten verteilt, wobei die Zellen an dem Kreuzungspunkt vermischt und dann nach unten ausgestrichen werden. Dadurch entsteht ein Kreuz, dessen eine Ader Zellen beider Stämme enthält. Die Platte wird bei $25{ }^{\circ} \mathrm{C}$ oder $30{ }^{\circ} \mathrm{C}$ für $2-3$ Tage inkubiert und dann auf das entsprechende Selektivmedium umgestempelt, auf dem nur noch die diploiden Zellen wachsen können.

\section{VI.1.2 Tropftest}

Beim Tropftest werden verschiedene Stämme in exakt gleicher Konzentration auf einer Agarplatte ausgetropft. Nach mehreren Tagen Inkubation kann man das Wachstum der verschiedenen Stämme vergleichen. Es können verschiedene Temperaturen und Nährmedien zum Vergleich von Stämmen benutzt werden. Dieser Test dient dazu, eventuelle Wachstumsdefekte zu erkennen.

Protokoll:

Es werden alle Hefestämme in die logarithmische Wachstumsphase gebracht und dann zu einer exakt gleichen $\mathrm{OD}_{600}$ (ca. 0,1) verdünnt. Jeder Stamm wird nun 3-4 mal 1:10 in sterilem 
$\mathrm{H}_{2} \mathrm{O}$ verdünnt. Aus jeder Verdünnungsstufe werden ca. 6-10 $\mu$ l vorsichtig auf eine Agarplatte getropft. Nach mehreren Tagen werden Bilder von den Platten aufgenommen und das Wachstum der verschiedenen Stämme bei unterschiedlichen Bedingungen verglichen.

\section{VI.1.3 Tetradenanalyse}

Hefestämme kommen in der Natur normalerweise nur in diploider Form vor. Wachsen zwei Hefen mit unterschiedlichem Paarungstyp in räumlicher Nähe, so werden die Kolonien aufeinander zuwachsen und die Zellen zu Zygoten verschmelzen. Damit diploide Hefezellen sporulieren, müssen sie mehrere Tage lang hungern, dies geschieht im Labor auf einem Stickstoff-Mangelmedium mit Acetat als einziger Kohlenstoffquelle.

Benötigtes Material:

- Zymolyase Stammlösung (10 mg/ml)

- 1 M Sorbitol

- Kaliumacetat-Agarplatten, YPD-Agarplatten

- YPD, YPGal

Protokoll:

1) Sporulation der Hefen: Ein diploider Hefestamm wird bei $30^{\circ} \mathrm{C}$ und $150 \mathrm{U} / \mathrm{min}$ in YPD Medium über Nacht angezogen und am nächsten Morgen in gleichem Volumen YPGal aufgenommen. In diesem Galaktosemedium wird die Kultur mindestens für 3 Stunden bei $30{ }^{\circ} \mathrm{C}$ und $150 \mathrm{U} / \mathrm{min}$ inkubiert. Anschließend wird auf einer Kaliumacetat-Platte ca. $1 \mathrm{ml}$ der Kultur ausgetropft (nicht verstreichen!). Dieser Tropfen wird nicht verteilt, da eine hohe Zelldichte notwendig ist. Den Tropfen eintrocknen lassen und anschließend für 2-5 Tage bei $30{ }^{\circ} \mathrm{C}$ inkubieren.

2) Tetraden ziehen: Es werden $20 \mu \mathrm{l}$ einer Zymolyaselösung $(0,5 \mathrm{mg} / \mathrm{ml}$ in $1 \mathrm{M}$ Sorbitol) hergestellt, in der steril einige Zellen von der Kaliumacetat-Agarplatte resuspendiert werden. Diese Suspension wird bei $30^{\circ} \mathrm{C}$ für ca. 5 min inkubiert, um die Ascus-Hülle anzudauen. Anschließend werden vorsichtig $500 \mu \mathrm{H}_{2} \mathrm{O}$ zugegeben. Von dieser Zellsuspension werden $15 \mu l$ auf die Seite einer YPD-Agarplatte gegeben. Durch Schrägstellen der Platte verläuft der Tropfen zu einer Linie am Rand der Platte. Falls man unter einem Mikroskop Tetraden findet, werden diese mit einem Mikromanipulator getrennt und einzeln in einem Raster in der Mitte der Platte ausgelegt. 
3) Analyse: Im Normalfall sind nach 3-5 Tagen die Tetraden zu Kolonien angewachsen (je nach Phänotyp). Für eine weitere Analyse (z.B. auf Resistenzen oder mating type) können die Zellen nun auf die entsprechenden Selektivplatten umgesetzt werden.

\section{VI.1.4 Präparation genomischer DNS aus S.cerevisiae}

Die Trennung von Proteinen und DNS wird durch eine Phenol-Chlorophorm-Extraktion erzielt. Dabei werden die Proteine denaturiert und sammeln sich zwischen der wässrigen und der organischen Phase, da sie sowohl aus hydrophilen als auch aus hydrophoben Aminosäuren bestehen. Der Zellaufschluss geschieht durch Vortexen mit Glaskugeln in der PhenolChloroform Lösung.

Benötigtes Material:

- Phenol-Chloroform (1:1)

- TE-Puffer (10 mM Tris-HCl pH 8, 1 mM EDTA)

- Lysepuffer: $100 \mathrm{mM} \mathrm{NaCl} ; 10 \mathrm{mM}$ Tris $\mathrm{HCl}$ pH 8; 1 mM EDTA; 1 \% SDS; $2 \%$ Triton X-100

- Ethanol $100 \%$

- RNSse A (10 mg/ml)

- $4 \mathrm{M}$ Ammoniumacetat $\left(\mathrm{NH}_{4} \mathrm{Ac}\right)$

- Glaskugeln (mit konzentrierter Salzsäure gewaschen)

Protokoll:

Eine $10 \mathrm{ml}$ Übernachtkultur wird in einem $50 \mathrm{ml}$ Falkon abzentrifugiert. Das Pellet wird in $0,5 \mathrm{ml} \mathrm{H} \mathrm{H}_{2} \mathrm{O}$ aufgenommen und in ein 1,5 $\mathrm{ml}$ Reaktionsgefäß überführt. Durch Zentrifugation für $2 \mathrm{~min}$ bei $800 \mathrm{~g}$ werden die Zellen nochmals pelletiert und dann in 0,2 ml Lysepuffer resuspendiert. Nach Zugabe von 0,2 $\mathrm{ml}$ Phenol-Chloroform und ca. 0,3 g Glaskugeln wird der Ansatz für 5-10 Minuten gevortext. Danach werden 0,2 ml TE-Puffer zugegeben und nochmals kurz gevortext. Die Phasentrennung geschieht durch fünfminütige Zentrifugation bei $14000 \mathrm{~g}$. Die wässrige Phase wird abgenommen und in ein neues 1,5 ml Reaktionsgefäß überführt. Es folgt eine Fällung der DNS durch Zugabe von $1 \mathrm{ml}$ Ethanol und anschließender Zentrifugation für $3 \mathrm{~min}$ bei $14000 \mathrm{~g}$. Der Überstand wird verworfen und das Pellet in $0,4 \mathrm{ml}$ TE Puffer mit $3 \mu \mathrm{l}$ der RNSse A aufgenommen. Durch Inkubation für 5 min bei $37{ }^{\circ} \mathrm{C}$ wird die mit der DNS aufgereinigte RNS verdaut. Die DNS wird ein zweites Mal gefällt, indem 10 $\mu \mathrm{l}$ der $4 \mathrm{M}$ Ammoniumacetat-Lösung und $1 \mathrm{ml}$ Ethanol zugegeben werden. Abschließend wird die DNS bei 14000 g pelettiert und dann getrocknet. Die DNS einer 10 ml Kultur wird in $\sim 50 \mu \mathrm{l} \mathrm{H}_{2} \mathrm{O}$ aufgenommen. 


\section{VI.1.5 Transformation von Plasmid DNS in S.cerevisiae}

Für die Aufnahme eines Plasmids müssen Hefezellen zunächst durch eine spezielle Vorbehandlung kompetent gemacht werden. Als Kompetenz bezeichnet man die Fähigkeit zur Aufnahme von frei in der Zellsuspension gelöster DNS. Hauptsächlich werden zwei Arten kompetenter Zellen für Transformationen benutzt, elektrisch- und chemisch-kompetente Zellen.

Nach der Transformation ist die Differenzierung zwischen den Zellen, die ein Plasmid aufgenommen haben und denen, die keines tragen, wichtig. Aus diesem Grund kodieren Plasmide in der Regel für ein Protein, welches als Selektionsmarker fungiert. In Laborstämmen hat man zu diesem Zweck Gene aus dem Syntheseweg verschiedener Aminosäuren ausgeschaltet. Durch das Fehlen des kodierten Proteins kann ein solcher Laborstamm nicht auf einem Nährboden ohne diese Aminosäure leben. Nach der Transformation werden die Zellen daher auf dem entsprechenden Aminosäuremangelmedium ausplattiert. Neben diesen Auxotrophiemarkern, können auch Proteine verwendet werden, die Resistenz gegen ein Antibiotikum vermitteln.

Benötigte Lösungen:

- $\mathrm{H}_{2} \mathrm{O}$ - eiskalt

- 1 M Sorbitol - eiskalt

- Agarplatten mit Selektivmedium

- Plasmid DNS

Protokoll:

1) Vorbereitung der Zellen: Eine $50 \mathrm{ml}$ Kultur des zu transformierenden Hefestammes wird bei $30^{\circ} \mathrm{C}$ und $180 \mathrm{U} / \mathrm{min}$ in YPD bis zu einer $\mathrm{OD}_{600}$ von $\sim 1,0$ angezogen. Die Zellen werden einmal mit $50 \mathrm{ml}$ und danach mit $25 \mathrm{ml}$ eiskaltem $\mathrm{H}_{2} \mathrm{O}$ gewaschen (vorsichtig resuspendieren - nicht vortexen). Wie mit Wasser wird dementsprechend noch zweimal mit $10 \mathrm{ml}$ bzw. $1 \mathrm{ml}$ eiskaltem 1 M Sorbitol gewaschen. Die Zentrifugation zwischen den Waschschritten wird mit $800 \mathrm{~g}$ durchgeführt. Für die Transformation werden die Zellen in $250 \mu 1 \mathrm{M}$ Sorbitol resuspendiert und bis zu ihrer Verwendung auf Eis gelegt.

2) Transformation: $40 \mu \mathrm{l}$ der kompetenten Zellen werden mit maximal $5 \mu$ l Plasmid-DNS (20$40 \mathrm{ng}$ ) in einer sterilen Küvette gemischt und für 5 min auf Eis inkubiert. Anschließend wird an die Küvette bei den Einstellungen $25 \mu \mathrm{F}, 1,5 \mathrm{kV}$ und $200 \Omega$ Gleichstrom angelegt. Nach erfolgter Entladung wird dem Transformationsansatz sofort $1 \mathrm{ml} 1 \mathrm{M}$ Sorbitol zugegeben. Anschließend kann man die Zellen je nach Resistenz auf entsprechenden Selektionsplatten ausstreichen (Becker et al. 1991). 


\section{VI.1.6 Verwendung von Auxotrophiemarkern in S.cerevisiae}

Um einen Auxotrophiemarker einsetzen zu können, verwendet man haploide Hefestämme, bei denen Enzyme in Synthesewegen wichtiger Stoffwechselprodukte, z.B. Aminosäuren oder Nukleosidtriphosphaten, ausgeschaltet wurden. Ein Auxotrophiemarker kodiert für dieses fehlende Enzym. Die Gene URA3 (kodiert die Orotidin-5'-Phosphat-Decarboxylase), LEU2 (kodiert die 3-Isopropylmalat-Dehydrogenase) und HIS3 (kodiert die Imidazolglycerinphosphat-Dehydrogenase) sind solche Marker und sind jeweils essentiell für die Synthese von Uracil, Leucin und Histidin.

\section{VI.1.7 Integration von DNS ins Genom von S.cerevisiae über homologe Rekombination}

Die Integration in das Genom von S.cerevisiae geschieht über homologe Rekombination. Das DNS Fragment muss linear sein und von Bereichen flankiert werden, die eine Homologie zu dem Bereich besitzen, in den die DNS eingebaut werden soll. Das lineare DNS-Fragment ist meist ein PCR-Produkt. Die Primer der entsprechenden PCR bestehen hierbei aus zwei funktionellen Bereichen. Das 5'-Ende (ca. 40 bp) des Primers ist für die Rekombination und das 3'-Ende (ca. 20 bp) für die Amplifikation notwendig. Zur Selektion der positiven Transformanten enthält das eingebrachte, lineare DNS-Fragment außerdem eine Resistenzkassette (Wach et al., 1994). Die hier verwendete Methode ist eine modifizierte Form der Elektrotransformation von Hefezellen (Guarente et al., 1991), bei der die Zellen vorher mit Lithiumacetat behandelt werden.

Benötigte Lösungen:

- Lithiumacetatlösung (100mM LiAc / 10 mM Tris-HCl pH 7.5 / 1mM EDTA)

- 1 M DTT-Lösung

- $\mathrm{H}_{2} \mathrm{O}$ - eiskalt

- 1 M Sorbitol - eiskalt

Protokoll:

Eine $50 \mathrm{ml} \mathrm{Kultur}$ des zu transformierenden Hefestammes wird bei $30{ }^{\circ} \mathrm{C}$ und $180 \mathrm{U} / \mathrm{min}$ in YPD bis zu einer $\mathrm{OD}_{600}$ von 1,0 bis 1,2 wachsen gelassen. Die Hefekultur wird in einem Falkon abzentrifugiert und in $9 \mathrm{ml}$ Lithium-Acetat-Lösung resuspendiert. Diese Zellsuspension wird bei $30^{\circ} \mathrm{C}$ und $180 \mathrm{U} / \mathrm{min}$ für 45 min inkubiert. Nach einer Zugabe von $210 \mu \mathrm{l}$ einer $1 \mathrm{M}$ DTT-Lösung wird nochmals für $15 \mathrm{~min}$ bei $30{ }^{\circ} \mathrm{C}$ und $180 \mathrm{U} / \mathrm{min}$ inkubiert. 
Anschließend werden $34 \mathrm{ml} \mathrm{H} \mathrm{H}_{2} \mathrm{O}$ zugegeben und abzentrifugiert. Die Zellen werden daraufhin einmal mit $50 \mathrm{ml}$ und danach mit $25 \mathrm{ml}$ eiskaltem $\mathrm{H}_{2} \mathrm{O}$ gewaschen. Anschließend folgt noch ein Waschschritt mit $20 \mathrm{ml}$ eiskaltem 1 M Sorbitol und die Aufnahme in $250 \mu 1$ Sorbitol. Die Zentrifugation zwischen den Waschschritten wird mit $800 \mathrm{~g}$ durchgeführt. Bis zu ihrer Verwendung werden die Zellen auf Eis gelagert.

Die Transformation erfolgt in einer sterilen Küvette mit $40 \mu$ der kompetenten Zellen und jeweils $5 \mu$ PCR-Produkt (2-4 $\mu$ g DNS). Die Zellen werden mit der DNS für 5 min auf Eis inkubiert.

Den Zellen wird bei den Einstellungen $25 \mu \mathrm{F}, 1,5 \mathrm{kV}$ und $200 \Omega$ ein Elektroschock verabreicht. Der Transformationsansatz wird sofort mit $1 \mathrm{ml} 1 \mathrm{M}$ Sorbitol in $3 \mathrm{ml}$ YPD überführt und für $2 \mathrm{~h}$ bei $30^{\circ} \mathrm{C}$ und $180 \mathrm{U} / \mathrm{min}$ inkubiert. In diesen zwei Stunden soll den Zellen Zeit gegeben werden, das für die Resistenz nötige Protein zu bilden. Der Transformationsansatz wird anschließend auf mehrere G418-Platten verteilt.

\section{VI.1.8 Deletion einer KanMX4-Kassette aus dem Genom von S. cerevisiae mit der Cre-Rekombinase}

Die KanMX4-Kassette wird häufig als Marker benutzt, wenn man bei Hefen auf genomischer Ebene eine Mutation erstellen will. Die Kassette kodiert für ein Protein, welches Resistenz gegen G418 vermittelt und wird von zwei Erkennungsstellen (loxP) für die Cre-Rekombinase flankiert. Durch Expression dieser Rekombinase kann die KanMX4-Kassette nachträglich ausgeschnitten werden (Sauer 1987). Der Vorteil der Deletion ist, dass man die Resistenz gegen G418 nochmals bei dem gleichen Stamm verwenden kann. Des Weiteren wird der Eingriff in die Region der Insertion geringer, da sich unter anderem auch ein Promotor auf der ca. 1,5 kb großen KanMX4-Kassette befindet. Die Cre-Rekombinase steht unter einem Galaktose-Promotor und ist auf dem Plasmid pSH47 kodiert, welches als Selektionsmarker das URA3 Gen trägt.

\section{Protokoll:}

In den G418 resistenten Hefestamm wird das Plasmid pSH47 mittels Transformation eingebracht und auf SC-Ura Platten ausgestrichen. Nach 2-3 Tagen werden von zwei der angewachsenen Kolonien Übernachtkulturen erstellt. Anschließend wird in diesen Kulturen die Expression der Cre-Rekombinase induziert, indem die Zellen für mindestens 3 Stunden bei $37^{\circ} \mathrm{C}$ in YPGal geschüttelt werden. Nach der Induktion werden Verdünnungen ausplattiert, so dass Einzelkolonien auf den Platten wachsen. Diese Einzelkolonien werden 
daraufhin auf ihre Resistenz gegenüber G418 geprüft, indem sie umgestempelt werden. Kolonien die auf YPD, aber nicht auf G418 anwachsen, haben durch die kurzfristige Expression der Cre-Rekombinase ihre KanMX4-Kassette verloren. Anschließend muss das Plasmid wieder entfernt werden. Dies geschieht durch Zugabe von 5'-FoA.

\section{VI.1.9 Selektion auf Verlust von URA3 Plasmiden mit 5'Fluoroorotic acid}

Die Methode selektiert auf den Verlust eines Plasmids, welches Zellen dazu befähigt Uracil zu synthetisieren. Diese Selektion wird möglich, indem man zu einem Uracil-Mangelmedium (aber nicht gänzlich ohne Uracil) 5'-Fluoroorotic acid (5'-FoA) zugibt. Diese Substanz wird in dem Syntheseweg von Uracil verwendet und zu einem toxischen Produkt verarbeitet. Somit produzieren die Zellen, die zur Uracilsynthese aufgrund des Plasmids befähigt sind, eine toxische Substanz. In dieser Doktorarbeit wurde ein abgewandeltes Protokoll nach Boeke benutzt (Boeke et al. 1987).

Benötigtes Material:

- SC-Ura-Medium

- sterile Uracil-Stammlösung $(2 \mathrm{~g} / \mathrm{l})$

- 5'-FoA (Feststoff)

Protokoll:

1) Herstellung des Mediums: Zu einem SC-Ura-Medium wird im Verhältnis 200:1 die UracilStammlösung gegeben, sodass eine Konzentration von $10 \mathrm{mg} / 1$ Uracil eingestellt wird. Das Medium wird mit einem Rührkern autoklaviert. Wenn das Medium auf ca. $50{ }^{\circ} \mathrm{C}$ abgekühlt ist wird 1 g 5'-FoA pro Liter Medium zugegeben und gelöst. Anschließend wird das Medium bei $4{ }^{\circ} \mathrm{C}$ kalt gestellt, da 5'-FoA hitzeempfindlich ist.

2) Induktion des Plasmidverlusts: Zur Induktion des Plasmidverlusts wird eine Kultur mit Uracil-Plasmid in ca. $5 \mathrm{ml}$ FoA-Medium angeimpft. Die Zellen mit dem URA3-Plasmid synthetisieren Uracil, da leichter Uracilmangel vorhanden ist. Dabei wird 5'-FoA verwendet und ein toxisches Produkt entsteht. Die Zellen ohne Plasmid sind nicht in der Lage Uracil zu synthetisieren und überleben deshalb.

3) Selektion auf Plasmidverlust: Es folgt die Selektion auf Verlust des Uracil Plasmids. Von der stationären Kultur in 5'-FoA-haltigem Medium wird eine Verdünnungsreihe erstellt und auf YPD-Platten ausgestrichen. Die Verdünnung, bei der eine günstige Koloniendichte vorhanden ist, wird auf eine SC-Ura Platte umgestempelt. Diejenigen Klone, die auf der SCUra Platte keine Kolonien bilden, haben das Plasmid verloren. 


\section{VI.2 Allgemeine Molekularbiologische Arbeitsmethoden}

\section{VI.2.1 Ethanolfällung von Nukleinsäuren}

Die Ethanolfällung ist eine Methode zur Aufreinigung und Konzentrierung von Nukleinsäuren. Sie beruht auf der Tatsache, dass DNS und RNS in der Gegenwart monovalenter Kationen gelöst in Ethanol einen unlöslichen Niederschlag bilden, der durch Zentrifugation isoliert werden kann.

Benötigtes Material:

- Ethanol $96 \%$

$-5 \mathrm{M} \mathrm{NH}_{4} \mathrm{Cl}$

- $70 \%$ Ethanol

\section{Protokoll:}

Zunächst bestimmt man das Volumen der Probe, um dann das 2,5 -fache Volumen eiskalten Ethanols sowie 1/10 des Probenvolumens $5 \mathrm{M} \mathrm{NH}_{4} \mathrm{Cl}$ hinzuzugeben. Der Ansatz wird für 30 Minuten bei $-20^{\circ} \mathrm{C}$ (oder auf Eis) inkubiert und dann für $10 \mathrm{~min}$ bei $14000 \mathrm{~g}$ und $4{ }^{\circ} \mathrm{C}$ abzentrifugiert. Nach Abnehmen des Überstandes wird das DNS-Pellet mit $500 \mu 1$ einer 70 \% Ethanollösung gewaschen, um Salze, insbesondere das Ammoniumchlorid, zu entfernen. Nach erneuter Zentrifugation wird das Pellet getrocknet und kann anschließend in $\mathrm{H}_{2} \mathrm{O}$ aufgenommen werden. Um die DNS besonders salzfrei zu bekommen, kann der Waschschritt mit $70 \%$ Ethanol mehrfach wiederholt werden.

\section{VI.2.2 Transformation elektrokompetenter E.coli Zellen}

Bei der Elektrotransformation in E.coli werden Plasmide in die Zellen eingebracht. Ein elektrischer Impuls und entsprechende Vorbehandlung der Zellen ermöglicht die Aufnahme der DNS.

Benötigtes Material:

- kaltes, steriles, zweifach destilliertes $\mathrm{H}_{2} \mathrm{O}$

- kaltes, steriles $10 \%$ Glycerin

- beschriftete $1,5 \mathrm{ml}$ Reaktionsgefäße auf $-20^{\circ} \mathrm{C}$ vorgekühlt

Protokoll:

1) Herstellung kompetenter Zellen: Für die Präparation elektrokompetenter E.coli Zellen müssen sich die Bakterien in der logarithmischen Wachstumsphase befinden. Eine $500 \mathrm{ml}$ 
E.coli Kultur wird bei einer $\mathrm{OD}_{600}$ von 0,6 bis 1,0 für 15-30 min auf Eis inkubiert. Es folgt ein Zentrifugationsschritt bei $4{ }^{\circ} \mathrm{C}$ für $15 \mathrm{~min}$ und $1400 \mathrm{~g}$. Die Zellen werden in $500 \mathrm{ml}$ kaltem sterilen zweifach destilliertem $\mathrm{H}_{2} \mathrm{O}$ resuspendiert und erneut abzentrifugiert. Anschließend wird der Waschschritt mit 1/2 Volumen $\mathrm{H}_{2} \mathrm{O}$ und dann noch mit 1/50 Volumen $10 \%$ Glycerin wiederholt. Aufgenommen werden die Zellen in $1 \mathrm{ml} 10 \%$ Glycerin. Es werden nun $40 \mu \mathrm{l}$ Aliquots in vorgekühlte $1,5 \mathrm{ml}$ Reaktionsgefäße portioniert und in flüssigem Stickstoff schockgefroren. Die Aliquots werden bei $-80{ }^{\circ} \mathrm{C}$ gelagert.

2) Transformation: Ein $40 \mu \mathrm{l}$ Aliquot wird auf Eis aufgetaut und dann mit ca. 10-20 ng Plasmid (oder $5 \mu \mathrm{l}$ Ligationsansatz bzw. PCR Produkt) für $5 \mathrm{~min}$ in einer sterilen Elektroporationsküvette auf Eis inkubiert. Nach einem Elektroschock mit den Einstellungen $25 \mu \mathrm{F}, 2,5 \mathrm{kV}$ und $200 \Omega$ werden die Zellen für eine Stunde in $1 \mathrm{ml}$ LB-Medium bei $37^{\circ} \mathrm{C}$ inkubiert. Anschließend kann der Transformationsansatz auf Selektivplatten ausgestrichen werden.

\section{VI.2.3 Verwendung von Resistenzmarkern in E.coli}

Das Prinzip der Selektionsmarker beruht darauf, dass bestimmte Gene Resistenzen gegen cytotoxische Stoffe, meist Antibiotika, vermitteln. Bei erfolgreicher Transformation des Plasmids kann auf Medien mit entsprechendem Antibiotikum auf Zellen selektiert werden, die das Plasmid tragen.

Ampicillinresistenz:

Ampicillin ist ein $\beta$-Lactam-Antibiotikum aus Penicillium notatum. Die Ampicillinresistenz wird durch das $a m p^{r}$-Gen oder auch bla-Gen vermittelt, welches eine $\beta$-Lactamase kodiert. Diese spaltet und inaktiviert $\beta$-Lactam-Antibiotika, die Enzyme der Zellwandsynthese inaktiviert oder inhibiert. Die Zellen sind bei einer derart gehemmten Zellwandsynthese nicht mehr in der Lage zu wachsen.

Kanamycinresistenz:

Kanamycin gehört ebenso wie das Neomycinhomolog G418 zu den Aminoglycosiden. Diese verhindern die Formation des prokaryotischen Initiationskomplexes sowie die Bindung von tRNS an das 70S-Ribosom. Diese Antibiotika wirken auch auf eukaryotische Zellen toxisch, da hier die mitochondriale Proteinbiosynthese inhibiert wird. Das NPTIII-Gen oder auch $K A N-G e n$ aus Enterococcus faecalis kodiert für eine Amino-glycosid-3'-Phosphotransferase. 
Die Phosphorylierung führt dazu, dass die Antibiotika nicht mehr an das Ribosom binden können.

\section{VI.2.4 Isolation von Plasmiden aus E.coli}

Die Bakterien werden bei der Plasmidpräparation mittels alkalischer Lyse geöffnet. Die für die Plasmidisolation essentielle Trennung von genomischer und Plasmid DNS geschieht physikalisch. Es wird hierbei ausgenutzt, dass die genomische DNS an Membranen der Zelle geknüpft ist, während die Plasmide frei im Cytoplasma vorliegen. Durch Zentrifugation nach nicht allzu stringenter Lyse der Zellen wird die genomische DNS mit den Proteinen pelletiert, während die Plasmide in Lösung bleiben.

Benötigtes Material:

- Qiagen Mini- oder Midi-Präp Kit (Qiagen, Hilden, Deutschland)

Protokoll:

Nach Anleitung des Herstellers

\section{VI.2.5 Gelelektrophorese von DNS}

Die Gelelektrophorese mit Agarose als Trägermaterial ist eine Methode zur Auftrennung von doppelsträngigen Nukleinsäuren unterschiedlicher Länge. Sie beruht auf der Tatsache, dass DNS aufgrund der Phosphatgruppen des Zucker-Phosphat-Rückgrates gleichmäßig negativ geladen ist und daher in einem elektrischen Feld in Richtung der Anode wandert. Größere DNS-Fragmente bewegen sich dabei langsamer, während kleine Fragmente schneller durch das Agarosegitter kommen.

Die Flussgeschwindigkeit hängt nicht allein von der Fragmentgröße, sondern auch von der Agarosekonzentration, der angelegten Spannung und der Ionenkonzentration im Laufpuffer ab. Für eine Größenauftrennung linearer doppelsträngiger DNS-Fragmente von 500-6000 Basenpaaren Länge eignet sich ein 1\%-iges Agarosegel bei Verwendung des StandardLaufpuffers 1xTAE (Lottspeich et al. 1998).

Um ein Absenken der DNS-Lösung in die Geltaschen zu gewährleisten, wird die Probe mit Ladepuffer versetzt. Die DNS wird sichtbar gemacht durch Färbung mit Ethidiumbromid, welches zwischen den Purin- und Pyrimidinbasen interkaliert und unter UV-Licht bei einer Wellenlänge von $590 \mathrm{~nm}$ emittiert (Lottspeich et al. 1998). 
Benötigte Lösungen:

- 6x DNS Ladepuffer (Sucrosefarbmarker)

- DNS Längenstandard (Gene Ruler 1kb DNS-Ladder, Fermentas, Burlington, Kanada)

- $1 \%$ (v/v) Ethidiumbromidlösung (Applychem, Gatersleben, Deutschland)

- Agarose in TAE gelöst (normalerweise 1\%)

- Laufpuffer (1xTAE)

- 50x TAE: 2M Tris, 1M Essigsäure, 50 mM EDTA, pH 8,0

Protokoll:

Die 1\%ige Agarose gelöst in TAE-Puffer wird aufgekocht und in eine Gelelektrophoresekammer gegossen. Die zu untersuchenden DNS-Fragmente werden durch Zugabe von $1 \mu$ Ladepuffer je $5 \mu$ Probenvolumen beschwert. Ist das Gel ausgehärtet, wird die Kammer mit TAE-Puffer gefüllt, bis das Gel komplett bedeckt ist. Anschließend werden die Proben und als Größenstandard eine DNS-Leiter aufgetragen. In TAE-Puffer wird Gleichstrom angelegt und die DNS aufgetrennt. Anschließend wird das Gel in einem Ethidium Bromid - Bad (20 $\mu$ l einer $1 \%$ Lösung auf etwa 0,5 Liter) für ca. 5 min gefärbt und unter UV-Licht fotografiert.

\section{VI.2.6 Aufreinigung von DNS-Fragmenten aus Agarosegelen}

Die DNS wird zunächst über Agarose-Gelelektrophorese getrennt und kann anschließend mit einem Skalpell ausgeschnitten werden. Auf diese Weise kann man DNS verschiedener Größen in einer Lösung trennen.

Benötigtes Material:

- Qiagen Gel-Extraction-Kit

- Isopropanol

- $\mathrm{H}_{2} \mathrm{O}$

Protokoll:

Nach Anleitung des Herstellers 


\section{VI.2.7 Konzentrationsbestimmung einer DNS- bzw. RNS-Lösung}

Die Konzentrationsbestimmung einer DNS-Lösung beruht auf der Absorption von DNS bei $260 \mathrm{~nm}$, die proportional zur Konzentration einer DNS-Lösung ist.

\section{Protokoll:}

Von der DNS-Lösung wird eine Verdünnung hergestellt, der Verdünnungsfaktor ist dabei von der Konzentration der Lösung abhängig. Zunächst wird als Referenz für 100 \% Transmission der Puffer in derselben UV-durchlässigen Küvette bestimmt, die später für die Messung der Probe verwendet wird. Die Messung der Absorption erfolgt bei $260 \mathrm{~nm}$. Die Extinktion sollte zwischen 0,1 und 1,0 liegen, wenn nicht sollte eine neue Verdünnung hergestellt werden. Eine optische Dichte von 1,0 der Lösung bei $260 \mathrm{~nm}$ entspricht bei doppelsträngiger DNS einer Konzentration von $50 \mu \mathrm{g} / \mathrm{ml}$, bei einzelsträngiger DNS und RNS 35-40 $\mu \mathrm{g} / \mathrm{ml}$ und bei kurzen Oligonukleotiden ca. $25 \mu \mathrm{g} / \mathrm{ml}$.

Die Reinheit der Lösung wird durch das Verhältnis von OD bei $260 \mathrm{~nm}$ zu OD bei $280 \mathrm{~nm}$ bestimmt. Dieses Verhältnis ist bei einer reinen DNS-Lösung ungefähr 2. Ein Wert unter 2 ergibt sich aus der Verunreinigung von DNS mit Proteinen.

\section{VI.2.8 Restriktion von DNS-Fragmenten}

Organismen haben im Laufe der Evolution als Schutz vor fremder DNS Restriktionsendonukleasen entwickelt, welche DNS sequenzspezifisch schneiden können. Es gibt drei verschiedene Typen solcher Endonukleasen, wobei vor allem der Typ II in der Molekularbiologie eine Verwendung findet.

Die Restriktionsendonukleasen des Typs II schneiden DNS ausschließlich innerhalb oder in der Nähe einer kurzen palindromischen Nukleotidsequenz. Dabei können je nach Endonuklease glatte- (blunt) oder überhängende- (sticky) Enden entstehen.

Es ist möglich, mehrere Enzyme in einem Reaktionsansatz zu verwenden. Dabei müssen jedoch die Reaktionstemperatur und die Reaktionsbedingungen (Puffer) beider Enzyme kompatibel sein. Diese können sehr verschieden sein, da die Enzyme in der Regel aus unterschiedlichen Organismen stammen.

Benötigtes Material:

- Restriktionsenzyme

- Reaktionspuffer (10x) je nach Enzym

- 10x BSA $(1 \mathrm{mg} / \mathrm{ml})$ 


\section{Protokoll:}

Zuerst wird das Volumen des Restriktionsansatzes bestimmt, das so gering wie möglich gehalten werden sollte. Dabei muss jedoch beachtet werden, dass die Menge zugegebener Restriktionsenzyme nicht 1/10 des gesamten Ansatzvolumens überschreitet (mögliche StarAktivität durch Glycerin). Der Puffer in dem die Reaktion stattfindet, richtet sich nach dem oder den Restriktionsenzymen, es wird 1/10 des Gesamtvolumens eingesetzt, sodass man eine 1x konzentrierte Pufferlösung bekommt. Ebenso wird standardmäßig BSA in einfacher Konzentration $(0,1 \mathrm{mg} / \mathrm{ml})$ zugegeben. Anschließend wird die DNS-Lösung zugegeben und mit Wasser aufgefüllt. Zuletzt werden zwischen 0,5 und $1 \mu 1$ der Restriktionsenzyme zugegeben, das genaue Volumen sollte dabei auf die Menge der zu verdauenden DNS angepasst werden sollte. Der Ansatz wird je nach Restriktionsenzym bei entsprechender Temperatur für 2 bis 16 Stunden inkubiert. Ein analytischer Verdau wurde für 1-2 Stunden inkubiert, falls die DNS weiter verarbeitet werden sollte wurde die DNS über Nacht verdaut. Nach der Reaktion wurden die Restriktionsenzyme inaktiviert, falls dies möglich war, dies ist meist durch eine Inkubation von ca. 15 Minuten bei $65{ }^{\circ} \mathrm{C}$ möglich. Ist keine Inaktivierung möglich und die DNS sollte weiter verwendet werden, kann sie über eine Ethanolfällung oder durch Aufreinigung mit dem Qiagen PCR-Purification Kit von den Restriktionsenzymen getrennt werden.

\section{VI.2.9 Dephosphorylierung von DNS}

Die Dephosphorilierung wird benutzt, um DNS-Fragmente an der Religation zu hindern. Dies ist möglich, da die DNS-Ligase ein Phosphat am 5'Ende der DNS benötigt, um zwei Stränge zu verknüpfen.

Benötigtes Material:

- Alkalische Phosphatase, CIP (Calf Intestine Phosphatase, NEB, Ipswich, MA)

Protokoll:

Die Reaktion wurde mittels Zugabe von $1 \mu$ l Alkalischer Phosphatase zu einem Restriktionsansatz und Inkubation für $1 \mathrm{~h}$ bei $37^{\circ} \mathrm{C}$ durchgeführt.

\section{VI.2.10 Ligation von DNS-Enden}

DNS-Ligasen können benachbarte 3'-Hydroxyl- und 5'-Phosphatgruppen unter Verbrauch von ATP verknüpfen (Lehman 1974). Die T4-DNS-Ligase kann sowohl überhängende als auch stumpfe DNS-Enden miteinander verbinden. Die Sequenzen der zu verknüpfenden 
Einzelstrang-Überhänge müssen dabei komplementär zueinander sein. Die Ligation glatter DNS-Enden ist zwar möglich, hat aber im Vergleich zu der Ligation überhängender DNSEnden eine stark eingeschränkte Effektivität.

Benötigte Lösungen:

- T4-Ligase-Puffer (10x)

- BSA (10x)

- T4-DNS-Ligase

\section{Protokoll:}

Bei der Ligation eines kurzen DNS-Fragments (Insert) in einen geschnittenen Vektor wird das Insert in dreifachem Überschuss eingesetzt. In den Reaktionsansatz werden der T4Ligasepuffer, sowie BSA in einfacher Konzentration zugegeben (1/10 des Gesamtvolumens). Weiterhin ist $1 \mu \mathrm{l}$ der T4-DNS-Ligase dem Ansatz hinzuzugeben. Die Inkubation erfolgt für 1-3 Stunden bei $37{ }^{\circ} \mathrm{C}$ oder bei RT über Nacht. Ligationen wurden in einem Volumen von 10 oder $20 \mu 1$ durchgeführt. Die Mengenverhältnisse der zu verknüpfenden Fragmente wurden anhand der Färbung in Agarosegelen abgeschätzt.

\section{VI.2.11 In vitro Amplifikation von DNS mittels PCR}

Die PCR (polymerase chain reaktion) ist eine Methode zur Vervielfältigung doppelsträngiger DNS (Saiki et al. 1985; Mullis et al. 1986). Für die Reaktion sind eine Matrize (die zu vervielfältigende DNS), Primer (kurze einzelsträngige Oligonukleotide), desoxyNukleotidtriphosphate (die vier Basen Adenin, Guanin, Cytosin und Thymin), sowie eine DNS-Polymerase und ein Puffer notwendig.

DNS-Polymerasen vervielfältigen DNS, indem sie an einzelsträngige DNS den komplementären Strang synthetisieren. Dazu muss die doppelsträngige DNS in zwei einzelne Stränge getrennt werden, dies geschieht in der Zelle durch spezielle Enzyme. Bei der PCR jedoch wird dieses Aufschmelzen durch Erhitzen der Probe auf etwa $95{ }^{\circ} \mathrm{C}$ erzielt, daher muss die DNS-Polymerase aus einem thermophilen Organismus stammen (z.B. die Taq Polymerase aus dem Organismus Thermus aquaticus). Die Primer sind notwendig, da die DNS-Polymerase einen kurzen doppelsträngigen Bereich benötigt, um die Synthese der DNS zu starten (in Zellen gibt es spezielle Enzyme, die kurze doppelsträngige Bereiche erstellen). Sie werden durch Absenken der Temperatur auf etwa $50-60^{\circ} \mathrm{C}$ an die aufgeschmolzene DNS angelagert. Die eigentliche Synthese findet bei etwa $70^{\circ} \mathrm{C}$ statt, da hier die Polymerase am besten arbeitet. 
Eine PCR besteht aus drei essentiellen Phasen: 1) Aufschmelzen der DNS, 2) Anlagerung der Primer und 3) Synthese der DNS. Eine Amplifikation wird durch die Wiederholung eines solchen Zyklus erreicht. Um eine exponentielle Vervielfältigung zu erzielen, müssen die Primer auf unterschiedlichen Strängen binden, sodass die Synthese jeweils in die entgegengesetzte Richtung startet. Ist die Synthese von ausreichender Länge, wird ein DNSFragment erstellt, an das der zweite Primer im nächsten Zyklus binden kann. Auf diese Weise wird die Anzahl der Matrizen mit jedem Zyklus verdoppelt.

In dieser Arbeit wurden zwei verschiedene Polymerasen verwendet, die Taq- und die PfuDNS-Polymerase. Die Taq-Polymerase synthetisiert etwa 1000 Basen pro Minute und produziert wegen ihrer fehlenden 3'-Exonukleaseaktivität relativ viele Fehler, statistisch einen alle 9000 Basenpaare (Tindall et al. 1988).

Polymerasen wie die Pfu besitzen eine 3'Exonukleaseaktivität, dies bedeutet, dass die Polymerase die eingebauten Basen bei einem Fehleinbau ausschneidet und erneut synthetisiert. Für die hier verwendete Pfu-DNS-Polymerase ergibt sich eine Fehlerrate von 1:1300000 und eine Synthesegeschwindigkeit von etwa 500 bp pro Minute.

Benötigtes Material:

- $10 \mu \mathrm{M}$ Primer (forward und reverse)

- 10x PCR Puffer

- dNTP's (ATP, TTP, CTP, GTP je 2 mM)

- DNS-Matrize (ca. 10-20 ng)

- DNS-Polymerase (Taq oder Pfu)

- (DMSO)

Protokoll:

Das Volumen einer Standard PCR beträgt $50 \mu \mathrm{l}$. Von jedem Primer werden 1,5 $\mu 1 \mathrm{zu}$ der Reaktion gegeben, so dass sie in einer Konzentration von $0,3 \mu \mathrm{M}$ vorliegen. Weiterhin werden $5 \mu \mathrm{l}$ des 10x PCR Puffers und $5 \mu \mathrm{dNTP}$ 's (0,2 mM) zugegeben. Die Matrize wird nur in sehr geringen Mengen benötigt, da theoretisch ein einziges Molekül für eine PCR ausreichend ist (bei Plasmiden ca. $50 \mathrm{ng}$ ). Der Ansatz wird auf $50 \mu \mathrm{lmit} \mathrm{H}_{2} \mathrm{O}$ aufgefüllt und die Polymerase zugegeben. DMSO ist ein Detergenz, das man verwenden kann, um Sekundärstrukturen der DNS zu lösen. Im Falle eine PCR-Verfielfältignung funktioniert nicht, kann DMSO in einer Konzentration von 1-5 \% zugesetzt werden. 
PCR-Programm:

1) Aufkochen $\quad 95{ }^{\circ} \mathrm{C} \quad 5 \mathrm{~min}$

2) Aufkochen $\quad 95{ }^{\circ} \mathrm{C} \quad 45 \mathrm{sec}$

3) Annealing $\quad 50-65^{\circ} \mathrm{C} \quad 30-60 \mathrm{sec}$

4) Elongation $\quad 72^{\circ} \mathrm{C} \quad \mathrm{X} /$ Synthesegeschwindigkeit der Polymerase

5) terminale Elongation $72{ }^{\circ} \mathrm{C} \quad 10 \mathrm{~min}$

Die Elongationszeit ist von der Größe des zu vervielfältigenden Bereichs (X) und der verwendeten Polymerase abhängig. Die Pfu-DNS-Polymerase synthetisiert ca. 500 bp pro min, die Taq-Polymerase etwa 1000 bp pro min. Durch wiederholen der Schritte 2 bis 4 (ein Zyklus) wird die Matrize vervielfältigt. Die Zyklenzahl wurde in den meisten Fällen auf 30-35 eingestellt, da die Effektivität der Vervielfältigung mit steigender Zyklenzahl anfangs zwar zunimmt (anfangs können weniger Matrizen als Polymerasen vorhanden sein) später dann aber stark nachlässt. Dies geschieht aufgrund mangelnder Rohstoffe, oder angesammelter Abfallprodukte wie Nukleotidmonophosphaten.

\section{VI.2.12 Zufallsmutagenese}

Bei der Zufallsmutagenese (Error Prone PCR) nutzt man den Fehleinbau von Basen bei der Synthese neuer DNS aus. Die natürliche Fehlerrate der Taq-Polymerase liegt bei 1:9000, kann jedoch durch die Zugabe von Mangan-Ionen $\left(\mathrm{Mn}^{2+}\right)$ stark erhöht werden (Leung et al. 1989). $\mathrm{Mn}^{2+}$-Ionen werden wie $\mathrm{Mg}^{2+}$-Ionen in das aktive Zentrum der Polymerase eingebaut. Aufgrund der unterschiedlichen Größe und Elektronegativität der Mangan-Ionen arbeitet die Polymerase jedoch nicht mehr so exakt wie mit Magnesium-Ionen. Da die Taq-DNSPolymerase keine 3'Exonukleaseaktivität (= proof-reading) besitzt führt dies zum vermehrten Einbauvon falschen Nucloetiden beim Replizieren der DNS. Über die Menge der $\mathrm{Mn}^{2+}$-Ionen lässt sich die Anzahl der Fehler beeinflussen.

Benötigte Lösungen:

- $10 \mu \mathrm{M}$ Primer (forward und reverse)

- 10x EP-PCR-Puffer (100 mM Tris, $500 \mathrm{mM} \mathrm{KCl,} 25 \mathrm{mM} \mathrm{MgCl}$ )

- 10x EP-dNTPs (2 mM: dATP, dGTP und 10 mM: dCTP, dTTP)

- $10 \mathrm{mM} \mathrm{MnCl}_{2}$

- Plasmid (Matrize)

- Taq Polymerase

Protokoll:

Ein Ansatz für eine Error-Prone-PCR wird auf $100 \mu 1$ ausgelegt. Es werden $10 \mu 1$ von jedem Primer, sowie 0,5 bis $1 \mu \mathrm{g}$ von dem Plasmid eingesetzt. Von dem EP-PCR-Puffer sowie den EP-dNTP's werden jeweils $10 \mu \mathrm{lu}$ dem Ansatz gegeben. Die Menge $\mathrm{MnCl}_{2}$ bestimmt die 
Anzahl der Fehler. Es sollten zwischen 1 und $3 \mu$ zugegeben werden (bei 1,5 $\mu 1$ entstehen nach 30 Zyklen etwa 1-2 Fehler bei der Synthese von 1000 bp). Zuletzt werden $2 \mu 1$ der TaqDNS-Polymerase zugegeben und auf $100 \mu 1$ mit $\mathrm{H}_{2} \mathrm{O}$ aufgefüllt. Die $100 \mu 1$ werden auf 8-10 PCR-Gefäße aufgeteilt, damit Fehler die in den ersten Synthesezyklen auftreten nicht im gesamten Ansatz dominant werden können.

PCR-Programm:
1) $95^{\circ} \mathrm{C}$
$5 \min$
2) $95^{\circ} \mathrm{C}$
$45 \mathrm{sec}$
3) $50-65^{\circ} \mathrm{C}$
$30-60 \mathrm{sec}$
4) $72^{\circ} \mathrm{C}$
1 min für 1000 Basenpaare
5) $72^{\circ} \mathrm{C}$
$10 \mathrm{~min}$

Die Schritte (2) bis (4) werden etwa 30x wiederholt. Nach der PCR werden die Produkte aus den einzelnen Gefäßen wieder vereint.

\section{VI.2.13 Ortsgerichtete Mutagenese}

Bei der örtlich gerichteten Mutagenese (site directed) werden die Fehler über die Primer eingebracht. Die Primer sollten etwa 40 bp lang sein und bis auf einen kurzen Bereich in der Mitte exakt an die Matrize binden. Der Fehler in der Mitte dieser Primer enthält die einzuführende Mutation. Bei der QuickChange Methode wird der gesamte Vektor repliziert, daher müssen die Primer komplementär sein.

Bei der Vervielfältigung entstehen zwei neue DNS Stränge, die komplementär zueinander sind und die gewünschte Mutation tragen. Das Template wird anschließend mit einem DpnIVerdau über Nacht abgebaut. Dies ist möglich, da in vitro synthetisierte DNS nicht methyliert und deshalb nicht von DpnI geschnitten wird. Es resultieren nahezu vollständige Plasmide, die zwei nicht verknüpfte Enden an den Stellen haben, wo die Synthese der DNS auf das 5, Ende des Primers getroffen ist. Die DNS wird in E.coli transformiert, wo die Lücken von DNS-Reparaturenzymen geschlossen werden.

Benötigtes Material:

- $10 \mu \mathrm{M}$ Primer (forward und reverse)

- 10x PCR Puffer

- dNTP's (ATP, TTP, CTP, GTP je 2 mM)

- DNS-Matrize (ca. 50-100 ng)

- DNS-Polymerase (Pfu)

- Restriktionsenzym DpnI 
Protokoll:

Als Template werden etwa 50-100 ng Plasmid-DNS benötigt (2 $\mu 1$ einer 1:100 Verdünnung einer DNS Minipräparation). Die PCR sollte mit $1 \mu 1$ der Pfu-Polymerase durchgeführt werden, um ungewollte Fehler beim Replizieren des Plasmids zu vermeiden. Das PCRProgramm wird wie bei der normalen PCR auf die Länge der Reaktion angeglichen. Ebenso werden die dNTP's, der Puffer und die Primer wie bei einer normalen PCR eingesetzt $(\rightarrow$ VI.2.11).

\section{VI.2.14 Multiple ortsgerichtete Mutagenese}

Diese PCR Methode basiert auf der normalen site directed QuickChange ${ }^{\mathrm{TM}}$ Mutagenese. Die multiple site directed PCR besteht allerdings aus zwei getrennten Reaktionen, wobei zunächst nur ein Strang des neuen Plasmids und nach einem DpnI-Verdau dessen Gegenstrang synthetisiert wird.

Es wurden bis $\mathrm{zu}$ drei mutagene Primer (entsprechend der site directed Mutagenese) eingesetzt, die alle dieselbe Orientierung haben und am 5'Ende phosphoryliert sein müssen. Auf diese Weise wird nur ein Strang synthetisiert, wobei die Synthese der DNS immer nur auf kleinen Teilstücken abläuft, die durch den jeweils nächsten Primer begrenzt sind. An den Matrizenstrang wird somit ein Tochterstrang synthetisiert, der Lücken aufweist. Diese können jedoch durch Zugabe der Taq-DNS-Ligase geschlossen werden, da die Primer an ihrem 5'Ende phosphoryliert sind. Anschließend wird für eine Stunde bei $37^{\circ} \mathrm{C}$ mit DpnI verdaut, um das ursprüngliche Plasmid als Matrize zu zerstören. Abschließend wird der Gegenstrang synthetisiert, indem ein entsprechender Primer zugegeben wird, der auf der neu synthetisierten DNS bindet.

(Alternativ kann man auch die bei dem DpnI-Verdau entstandenen DNS Fragmente des Gegenstranges als Primer für die nachfolgende Reaktion benutzen und auf die Zugabe eines Primers verzichten. Allerdings befinden sich auf diesen Fragmenten auch die nicht mutierten Bereiche der DNS.)

Benötigtes Material:

- Matrize

- Primer $(10 \mu \mathrm{M})$

- dNTP's (ATP, TTP, CTP, GTP je 2 mM)

- 10 x Polymerase-Puffer

- 10 x Taq-Ligase-Puffer

- Pfu-DNS-Polymerase

- Taq-DNS-Ligase 


\section{Protokoll:}

Für einen $50 \mu \mathrm{l}$ Ansatz benötigt man etwa 50 ng Plasmid als Matrize, 15 pmol Primer $(1,5 \mu 1)$ und $5 \mu 1$ der dNTP's. Der Puffer des Reaktionsansatzes besteht aus 0,5x Pfu-DNS-Polymerase und 0,5x Taq-DNS-Ligase Puffer (jeweils 2,5 $\mu \mathrm{l}$ ). Zuletzt werden 2,5 Einheiten Pfu-DNSPolymerase und 20 Units der Taq-DNS-Ligase zugegeben (jeweils $1 \mu 1$ ) und auf $50 \mu 1$ aufgefüllt. Die Vervielfältigung ist linear, da sich die Anzahl der Matrizen nicht verändert.

\section{PCR-Programm:}
1) $65^{\circ} \mathrm{C}$
$5 \min$
2) $95^{\circ} \mathrm{C}$
$2 \min$
3) $95^{\circ} \mathrm{C}$
$45 \mathrm{sec}$
4) $55^{\circ} \mathrm{C}$
$30 \mathrm{sec}$
5) $65^{\circ} \mathrm{C}$
2 min für je 1000 Basenpaare
6) $75^{\circ} \mathrm{C}$
$7 \mathrm{~min}$

Die Schritte (3) bis (5) werden 25x wiederholt.

Anschließend wird $1 \mu 1$ DpnI, sowie 1,5 $\mu$ l eines Primers, der auf der bereits synthetisierten DNS bindet, zugegeben. Danach kann sofort das nächste PCR-Programm zur Synthese des zweiten Stranges gestartet werden.

PCR-Programm:
1) $37^{\circ} \mathrm{C}$
$1 \mathrm{~h}$
2) $95^{\circ} \mathrm{C}$
$5 \mathrm{~min}$
3) $95^{\circ} \mathrm{C}$
$45 \mathrm{sec}$
4) $55^{\circ} \mathrm{C}$
$30 \mathrm{sec}$
5) $70^{\circ} \mathrm{C}$
2 min für je 1000 Basenpaare

Die Schritte (3) bis (5) werden 8x wiederholt

Die PCR kann nach einer Dialyse in E.coli transformiert werden. Bei einer Analyse auf einem Agarosegel ist selten ein PCR-Produkt zu sehen, da es keine exponentielle Vervielfältigung gibt. 


\section{VI.3 Proteinaufreinigung:}

Die Aufreinigung eines Proteins aus E.coli Zellen basiert meist auf Affinitätschromatographie. Im Rahmen dieser Arbeit wurde die Affinität von sechs aufeinander folgenden Histidinen zu Nickel ausgenutzt, um die fluoreszierenden Proteine von dem Rest der Proteine in E.coli zu trennen.

Es wurden zwei unterschiedliche Methoden der Proteinaufreinigung angewendet. Für Anwendungen, bei denen die Proteine sehr sauber benötigt werden, wie z.B. Kristallisierung und Bestimmung der Quantenausbeute, wurden die Proteine in großem Maßstab aus einer 6 Liter E.coli Kultur aufgereinigt. Dazu wurde das Zelllysat zunächst über eine Nickel-NTASäule und anschließend über eine Gelfiltrationssäule aufgereinigt. Für einfache Analysen wie der Messung von Spektren oder pH-Sensitivität der Proteine, wurden die Proteine in geringerem Maßstab aufgereinigt. Für die kleinere Aufreinigung war es ausreichend Kolonien von ein bis zwei Agaroseplatten zu ernten und mit dem Ni-NTA Spin Kit (Qiagen, Hilden, Deutschland) aufzureinigen.

Benötigte Lösungen:

- Lysepuffer - $\mathrm{pH} 8.0$

(10 mM Imidazol; $50 \mathrm{mM} \mathrm{NaH}{ }_{2} \mathrm{PO}_{4} ; 300 \mathrm{mM} \mathrm{NaCl}$ )

- Waschpuffer 1 - $\mathrm{pH} 8.0$ (20 mM Imidazol; $50 \mathrm{mM} \mathrm{NaH}{ }_{2} \mathrm{PO}_{4} ; 300 \mathrm{mM} \mathrm{NaCl}$ )

- Waschupffer2 - $\mathrm{pH} 8.0$ (30 mM Imidazol; $50 \mathrm{mM} \mathrm{NaH}{ }_{2} \mathrm{PO}_{4} ; 300 \mathrm{mM} \mathrm{NaCl}$ )

- Waschupffer3 - $\mathrm{pH} 8.0$ (50 mM Imidazol; $50 \mathrm{mM} \mathrm{NaH}{ }_{2} \mathrm{PO}_{4} ; 300 \mathrm{mM} \mathrm{NaCl}$ )

- Elutionspuffer - pH 8.0 (250 mM Imidazol; $50 \mathrm{mM} \mathrm{NaH} \mathrm{PO}_{4} ; 300 \mathrm{mM} \mathrm{NaCl}$ )

- Elutionspuffer 2 - pH8.0 (1000 mM Imidazol; $50 \mathrm{mM} \mathrm{NaH}{ }_{2} \mathrm{PO}_{4} ; 300 \mathrm{mM} \mathrm{NaCl}$ )

- Standard-Protein-Puffer $(100 \mathrm{mM}$ Tris $\mathrm{pH} 7,5 ; 150 \mathrm{mM} \mathrm{NaCl})$

- IPTG-Lösung

- Lysozymlösung: $1 \mathrm{M}$ Stammlösung $50 \mathrm{mg} / \mathrm{ml}$ (Sigma-Aldrich-Chemicals, Steinheim, Deutschland)

- Proteinaseinhibitoren:

1 Tablette in $1 \mathrm{ml}$ gelöst (Complete, EDTA-free, RocheDiagnostics, Mannheim, Deutschland)

\section{VI.3.1 Proteinaufreinigung aus einer 6 Liter Kultur}

Für eine Proteinaufreinigung aus einer sechs Liter E.coli Kultur wurde zunächst das Plasmid in einen E.coli Stamm transformiert. Für asFP595-Varianten wurde der E.coli Stamm HMS und für die Dronpa-Varianten der Stamm SURE verwendet. Die übrigen Proteine wurden in BL21-Codon Plus RIL Zellen exprimiert. Von einer gut gefärbten Kolonie (Expression des fluoreszierenden Proteins) wurde eine Vorkultur in $400 \mathrm{ml}$ LB-Medium mit entsprechendem Antibiotikum (meist Ampicillin) angeimpft und über Nacht bei $30^{\circ} \mathrm{C}$ und $150 \mathrm{U} / \mathrm{min}$ angezogen. Diese Vorkultur wurde anschließend auf mehrere Kolben mit insgesamt sechs Litern LB-Medium mit entsprechendem Antibiotikum verteilt, welche bei $25{ }^{\circ} \mathrm{C}$ und $150 \mathrm{U} / \mathrm{min}$ inkubiert wurden. Zu den Zellen wurde bei einer $\mathrm{OD}_{600}$ von etwa 0,6 IPTG in der 
Endkonzentration $1 \mathrm{mM}$ zugegeben (1:1000 verdünnen). Danach wurden die Kulturen für mindestens 8 Stunden wachsen gelassen und anschließend geerntet. Dazu wurden die Zellen in einer Sorvall-Zentrifuge mit einem SLA-1500 Rotor bei $5000 \mathrm{U} / \mathrm{min}$ für $30 \mathrm{~min}$ abzentrifugiert.

Die Pellets wurden gewogen, mit jeweils $2 \mathrm{ml}$ Lysepuffer pro Gramm Pellet resuspendiert und in $50 \mathrm{ml}$ Falkon-Röhrchen überführt. Nach Zugabe von $50 \mu 1$ Lysozymlösung pro Milliliter wurde die Zellsuspension für 30 min auf Eis inkubiert und hin und wieder gemischt. Dabei bricht die Zellwand auf und die Suspension bekommt eine zähflüssige Konsistenz. Um einen Abbau der Proteine durch zelleigene Proteinasen zu verhindern, wird nach den $30 \mathrm{~min}$ auf Eis Proteinaseinhibitor hinzugegeben (Stammlösung 1:50 verdünnen).

Der eigentliche Zellaufschluss wird durch Ultraschall erreicht. Die Suspension wird auf Eis in einem Branson-Sonifier (Branson, Danbury, CT) sonifiziert (Level 5, 60 \% Pulse, 30x, auf Eis). Bei erfolgtem Aufschluss sollte die Probe wieder flüssiger werden. Durch Zentrifugation bei $4{ }^{\circ} \mathrm{C}$ mit $10000 \mathrm{U} / \mathrm{min}$ in einem SS34-Rotor wurden die Zelltrümmer und unlöslichen Proteine von den löslichen Proteinen getrennt.

Die eigentliche Aufreinigung erfolgte über eine Nickel-NTA-Säule (Vantage-VL16 x 250; Millipore, Billerica, MS), welche mit einer Flussgeschwindigkeit von $1 \mathrm{ml} / \mathrm{min}$ betrieben wurde. Die Ni-NTA-Säule wurde mit 2-3 Säulenvolumen Lysepuffer equilibriert, bevor das Proteingesamtextrakt aufgetragen wurde. Die beladene Säule wurde daraufhin mit jeweils 2 Säulenvolumen Lysepuffer, sowie den verschiedenen Waschpuffern 1, 2 und 3 gewaschen. Die dabei aufgefangenen Fraktionen wurden nicht aufgehoben, da bei diesen Waschschritten hauptsächlich unspezifisch gebundenes Protein eluiert wird. Das angereicherte mit 6xHis markierte Protein an der Ni-NTA-Agarose wurde anschließend mit dem Elutionspuffer gelöst und in $2 \mathrm{ml}$ Fraktionen aufgefangen. Die Fraktionen mit der größten Proteinmenge (stärkste Absorption bei $280 \mathrm{~nm}$ im Chromatogramm) wurden vereinigt und durch Zentrifugation in $50 \mathrm{ml}$ Konzentratoren mit einem Ausschlussvolumen von $10 \mathrm{kDa}$ (Vivaspin 10.000 MWCOPES, Vivascience) konzentriert, bis nur noch etwa $2 \mathrm{ml}$ Proteinlösung vorhanden waren.

Die Gelfiltration wurde auf einer Gelfiltrationssäule (HiLoad26/60 Superdex 200; Pharmacia, Upsala, Schweden) mit einer Flussgeschwindigkeit von $0,2 \mathrm{ml} / \mathrm{min}$ durchgeführt. Die Säule wurde zunächst mit Standard-Protein-Puffer $(100 \mathrm{mM}$ Tris $\mathrm{pH} 7,5,150 \mathrm{mM} \mathrm{NaCl})$ equilibriert. Danach wurde das Protein über die Säule gegeben und in $2 \mathrm{ml}$ Fraktionen aufgefangen. Wie nach der Affinitätschromatographie wurden auch hier die Fraktionen mit der größten Proteinmenge vereinigt und aufkonzentriert. Die Konzentration des Proteins wurde mittels Bradford Assay bestimmt $(\rightarrow$ VI.3.3). Sofern das Protein nicht sofort 
verwendet wurde, wurde es in Aliquots von 50 bis $500 \mu 1$ in flüssigem Stickstoff eingefroren und bei $-80{ }^{\circ} \mathrm{C}$ gelagert.

Zur Kontrolle der Aufreinigung wurde eine SDS-Gelelektrophorese ( $\rightarrow$ VI.3.4) durchgeführt, auf der das Gesamtzellextrakt mit dem aufgereinigten Protein verglichen wurde.

\section{VI.3.2 Parallelisierte Proteinaufreinigung in kleinerem Maßstab}

Für die Aufreinigung von $\sim 100-200 \mu \mathrm{g}$ Protein vieler verschiedener Proteine gleichzeitig, wurde das Ni-NTA Spin Kit (Qiagen,Hilden, Deutschland) verwendet. Bei dieser Methode sind weitaus weniger Zellen notwendig als bei einer großen Präparation, daher ist es möglich, die Zellen von einer Agarplatte zu gewinnen. Der Vorteil liegt hier darin, dass einzelne E.coliKolonien räumlich getrennt anwachsen. Somit können einzelne E.coli Zellen, die das Protein nicht mehr herstellen und dadurch einen Wachstumsvorteil besitzen, die anderen Zellen nicht überwachsen.

Die Kolonien werden von zwei Agarplatten 2-3 Tage nach deren Transformation geerntet und in $2 \mathrm{ml}$ Reaktionsgefäßen mit 1,8 ml Lysepuffer resuspendiert. Nachdem die Proben jeweils mit $50 \mu 1$ Lysozymlösung gemischt und für 3 Stunden auf Eis inkubiert wurden, folgt die Zugabe von $100 \mu 1$ Proteaseinhibitorlösung. Der Zellaufschluss wird aufgrund des kleinen Volumens und der Vielzahl an Proben durch 4-5maliges Einfrieren in flüssigem Stickstoff erreicht. Zwischen den Einfrierzyklen können die Zellen in einem Wasserbad oder bei RT aufgetaut werden.

Die Trennung des Gesamtproteinextrakts von den Zelltrümmern erfolgt durch Zentrifugation bei $14000 \mathrm{~g}$ bei $4{ }^{\circ} \mathrm{C}$ für 3 Stunden. Anschließend werden die Proteine durch Zentrifugation bei $1000 \mathrm{~g}$ an die Ni-NTA Säulen gebunden. Alle Zentrifugationsschritte mit den Säulen wurden bei $1000 \mathrm{~g}$ durchgeführt. Die Säulen wurden zweimal mit $500 \mu 1$ Waschpuffer3 (50 mM Imidazol) gewaschen, danach wurde das Protein in ebenfalls zwei Schritten mit $200 \mu 1$ Elutionspuffer (250mM Imidazol), sowie Elutionspuffer2 (1000 mM Imidazol) eluiert.

Die Proteine wurden über NAP5 Säulen umgepuffert und in dem Standard-Protein-Puffer (100 mM Tris pH 7,5 mit $150 \mathrm{mM} \mathrm{NaCl)} \mathrm{aufgenommen.}$

\section{VI.3.3 Bestimmung von Proteinkonzentrationen}

a) Bradford Assay: Proteinkonzentrationen wurden standardmäßig über eine BradfordAnalyse bestimmt. Dabei wird ausgenutzt, dass der in der Bradford-Lösung enthaltene Farbstoff Coomassie bei Bindung an Proteine (Peptidbindungen) die Absorption ändert (die gebundene Form absorbiert maximal bei $595 \mathrm{~nm}$ ). 
Benötigtes Material:

- Bradford-Lösung

Protokoll:

Nach Angabe des Herstellers

b) Absorption bei $280 \mathrm{~nm}$ : Eine etwas genauere Methode als der Bradford Assay ist die Bestimmung der Konzentration über die Absorption bei $280 \mathrm{~nm}$ (Gill et al. 1989). Diese wird bestimmt durch die Absorption der Tryptophane, Tyrosine und Disulfidbrücken in einem Protein und kann somit nur verwendet werden, sofern die Aminosäuresequenz eines Proteins bekannt ist. Weiterhin sollte das Protein entfaltet vorliegen, um eine unterschiedliche Protonierung der Aminosäuren im Protein auszuschließen. Deshalb werden die Messungen in Denaturierungspuffer (6 M Guanidinhydrochlorid, 0,02 M Phosphat, $\mathrm{pH}$ 6,5) durchgeführt. Die Absorption bei $280 \mathrm{~nm}$ wurde mit der folgenden Formel berechnet:

$$
\mathrm{c}[\mathrm{mol} / \mathrm{l}]=\mathrm{Abs}_{280} /\left(5690 \mathrm{n}^{\mathrm{Trp}}+1280 \mathrm{n}^{\mathrm{Tyr}}+120 \mathrm{n}^{\mathrm{SS}}\right) \cdot \mathrm{d}
$$

Formel 1: $\mathrm{n}^{\text {Trp }}, \mathrm{n}^{\text {Tyr }}$ und $\mathrm{n}^{\mathrm{SS}}$ entsprechen der Anzahl der Tyrosine, Tryptophane und Disulfidbrücken im Protein. Die Werte 5690, 1280 und 120 sind die jeweiligen Löschungskoeffizienten bei $280 \mathrm{~nm}$. Weiterhin wird die Schichtdicke der Küvette bei der Absorptionsmessung mit $\mathrm{d}$ in $\mathrm{cm}$ berücksichtigt.

\section{Benötigtes Material:}

- DNS Lösung

- Denaturierungspuffer (6 M Guanidinhydrochlorid; 0,02 M Phosphat, pH 6,5)

Protokoll:

Die DNS-Lösung wurde in Denaturierungspuffer verdünnt und das Spektrum bzw. die Absorption bei $280 \mathrm{~nm}$ gemessen. Sofern die Aminosäuresequenz bekannt ist, kann mit der oben angegebenen Fromel die exakte Proteinmenge bestimmt werden.

\section{VI.3.4 SDS-Gelelektrophorese}

Die Trennung in der SDS-Polyacrylamidgelelektrophorese (SDS-PAGE (Laemmli 1970)) erfolgt durch die Bewegung eines Proteins im elektrischen Feld, dabei ist seine Bewegungsgeschwindigkeit direkt abhängig von seiner Größe. Die Ladung eines Proteins 
wird durch das negativ geladene SDS ausgeglichen, welches an Proteine bindet. Die Ladung eines Proteins ist dadurch fast ausschließlich durch seine Größe gegeben.

Benötigtes Material:

- 1,5 M Tris $\mathrm{HCl} \mathrm{pH} 8,8$

- 1,5 M Tris $\mathrm{HCl} \mathrm{pH} 6,8$

$-10 \% \operatorname{SDS}(\mathrm{w} / \mathrm{v})$

- Acrylamid: Bisacrylamid-Lösung (30:1)

- APS

- TEMED

- Protein-Probenpuffer (2\% (w/v) SDS, $2 \%$ (v/v) ß-Mercaptoethanol, $20 \%(\mathrm{v} / \mathrm{v})$ Glycerin, 0,02\% (w/v) Bromphenolblau, 0,1 M Tris $\mathrm{HCl} \mathrm{pH} 6,8$ )

- Laemmli-Puffer (25 mM Tris, $192 \mathrm{mM}$ Glyzerin, 0,1 \% (w/v) SDS; pH 8,3)

- Coomassie-Färbelösung (10 \% (v/v) Essigsäure; 25 \% (v/v) Isopropanol; 0,1 \% (w/v) Coomassie Blau R-250)

- Entfärbelösung (10 \% (v/v) Essigsäure)

\section{Protokoll:}

Die Acrylamid-Konzentration des Trenngels wurde in den meisten Fällen auf 12,5 \% (w/v) eingestellt $\left(6,3 \mathrm{ml} \mathrm{H} \mathrm{H}_{2} \mathrm{O}, 5 \mathrm{ml}\right.$ 1,5 M Tris/ $\mathrm{HCl} ; \mathrm{pH} 8,8,8,3 \mathrm{ml} 30 \%$, Acrylamid: Bisacrylamid-Lösung (30:1), $200 \mu \mathrm{l} 10 \%$ (w/v) SDS, $200 \mu 110 \%$ (w/v) APS, $20 \mu 1$ TEMED). Für das Sammelgel wurde eine Acrylamid-Konzentration von $5 \%$ benutzt $(5,6 \mathrm{ml}$ Wasser, 2,5 ml 0,5 M Tris / HCl; pH 6,8, 1,7 ml $30 \%$ (w/v) Acrylamid: Bisacrylamid-Lösung (30:1), $100 \mu 110 \%$ (w/v) SDS, $100 \mu 110 \%$ (w/v) APS, $10 \mu 1$ TEMED). Die Proteinextrakte wurden in Protein-Probenpuffer aufgenommen, und bis zur vollständigen Solubilisierung für zehn Minuten auf $95{ }^{\circ} \mathrm{C}$ erhitzt und nach 5 min Zentrifugation bei $15000 \mathrm{~g}$ auf das Gel aufgetragen. Die Auftrennung der Proteine wurde bei 10 - $20 \mathrm{~mA}$ pro Gel durchgeführt. Als Elektrophoresepuffer wurde Laemmli-Puffer verwendet. Zur Abschätzung der Größe der aufgetrennten Proteine wurde ein Proteinmarker als Größenreferenz mit auf das Gel aufgetragen (PageRuler Prestained Protein Ladder, MBI Fermentas, Burlington, Kanada). Anschließend wurden die Proteine mit einer Coomassie-Färbung sichtbar gemacht. Das Gel wurde für 15-30 min in einer Coomassie-Färbelösung gefärbt. Danach wurde der überschüssige Farbstoff durch Waschen in der Entfärbelösung aus der Gelmatrix entfernt.

\section{VI.3.5 Lösung von Kristallstrukturen}

Die Kristallstrukturen wurden unter Verwendung der Programme MOLREP (Vagin et al. 2001), COOT (Emsley et al. 2004), Arp/wArp (Morris et al. 2003) und Refmac5 (Murshudov et al. 1997) gelöst. Die Messung der Kristalle und die Erstellung der Strukturen fand in 
Zusammenarbeit mit Dr. Gert Weber, Dr. Simon Trowitzsch und Prof. Dr. Markus Wahl statt (Arbeitsgruppe Röntgenkristallographie, Max-Planck-Institut für biophysikalische Chemie, Göttingen, Deutschland).

\section{VI.4 Mikroskopie}

Die Aufnahmen der Fluoreszenzbilder wurden mit konfokaler Laser-Raster-Mikroskopie (Leica SP5) oder Standard-Weitfeld (widefield) Mikroskopie (Leica DM6000) gemacht. Ein Weitfeld Mikroskop beleuchtet einen relativ großen Bereich einer Probe und reflektiert dieses Bild meist auf eine CCD Kamera, dabei wird die Auflösung des Systems durch die Detektion bestimmt. Im Gegensatz dazu rastert ein Laser-Raster-Mikroskop die Probe mit einem beugungslimitierten Fokus ab und detektiert an jedem Punkt die Anzahl der Photonen. Anschließend kann das Bild wieder zusammengesetzt werden. Ein konfokales Mikroskop ist durch eine Lochblende vor dem Detektor ausgezeichnet, die durch ihre Position und Größe das Signal aus den Ebenen über und unterhalb der Fokusebene wegschneidet. Dadurch wird besonders in Richtung des Strahlengangs (z-Richtung) eine bessere Auflösung erreicht.

\section{VI.4.1 Fixierung von Zellen auf einem Objektträger mit Poly-L Lysin}

Es wurde eine gebrauchsfertige $1 \%$ Poly-L Lysin-Lösung verwendet, die auf einen Objektträger gegeben wurde. Nach 5 min wurde die Lösung abgesaugt und der Rest an der Luft getrocknet. Die zu fixierenden Zellen wurden abzentrifugiert und zweimal mit Wasser gewaschen. Anschließend wurden die Zellen in hoher Konzentration auf den Objektträger gegeben und für ca. 15 min inkubiert. Danach wurde der Objektträger mehrmals mit $\mathrm{H}_{2} \mathrm{O}$ gespült. Bei Verwendung lebender Zellen sollte darauf geachtet werden, dass die Zellen anschließend nicht austrocknen.

\section{VI.4.2 Präparation lebender Zellen für die Mikroksopie}

E.coli oder S.cerevisiae Zellen wurden entweder direkt von einer Agarplatte abgenommen und in PBS gelöst, oder zunächst in entsprechendem Wachstumsmedium abzentrifugiert und danach in PBS aufgenommen. Etwa $10 \mu 1$ dieser Zellsuspension wurden auf einen Objektträger gegeben und mit einem Deckglas abgedeckt. Um eine Diffusion der Zellen unter dem Deckglas zu verhindern, wurden die Zellen entweder fest angedrückt, oder in $40{ }^{\circ} \mathrm{C}$ warmem PBS mit $1 \%$ bei niedriger Temperatur schmelzender Agarose resuspendiert. 
Für Langzeitaufnahmen wurden die Zellen immer mit Agarose immobilisiert, weiterhin musste jedoch sichergestellt werden, dass die Zellen ausreichend mit Nährstoffen versorgt werden, um weiter wachsen zu können. Daher wurden die Zellen nicht auf einen normalen Objektträger, sondern auf dem Deckglas in einer Durchflusskammer platziert. Die Kammer wird mit zwei Deckgläsern oben und unten verschlossen, welche mit Zweikomponentenkleber (Picodent twinisil speed; Wüpperfürt, Deutschland) versiegelt werden. Durch Einlässe an den Seiten dieser Zellkammer können die Zellen konstant mit neuem Medium versorgt werden. Es sollte bei dieser Methode Medium mit möglichst geringer Autofluoreszenz verwendet werden (z.B. SC-Medium), da normales Vollmedium (YPD) starke Eigenfluoreszenz aufweist.

\section{VI.4.3 Mikroskopie an einem konfokalen Mikroskop}

Die konfokalen Fluoreszenzaufnahmen wurden mit dem Mikroskop Leica SP5 (Leica Microsystems, Wetzlar, Deutschland) aufgenommen. Der Durchmesser der Lochblende betrug 1 Airy $(1,22 \cdot \lambda / \mathrm{nm})$, bzw. 1,15 Airy bei lichtschwachen Proben. Es wurde ein im UVBereich korrigiertes 1.4 NA Öl-Immersionsobjektiv (63× HCX PL APO) benutzt. Die Aufnahmen wurden standardmäßig bei $22{ }^{\circ} \mathrm{C}$ (Raumtemperatur) gemacht, für LangzeitExperimente mit lebenden Zellen wurde eine Durchflusskammer benutzt und die Temperatur wurde auf $25{ }^{\circ} \mathrm{C}$ erhöht.

Sofern nicht anders angegeben, wurden die Proben in der Ebene (x,y) mit Schrittgrößen zwischen 50 und $75 \mathrm{~nm}$ und in Z-Richtung mit 150-200 nm abgerastert (500 nm in z-Richtung für 3D Zeitraffer Fluoreszenzaufnahmen an lebenden Hefezellen). Um das Signal-zu-RauschVerhältnis zu verbessern wurde entweder jede Linie, oder jedes Bild zweimal direkt hintereinander aufgenommen (line average oder frame average) und die Fluoreszenzwerte gemittelt.

\section{VI.4.4 Separates Auslesen der Fluoreszenz von rsFastLime und Padron in} lebenden Zellen mit einem konfokalen Laser-Raster-Mikroskop

Die Unterscheidung von rsFastLime und Padron konnte durch das gegensätzliche Schalten der beiden Proteine realisiert werden. Eine Abfolge von vier Beleuchtungsschritten war ausreichend, um rsFastLime und Padron einzeln auszulesen ( $\rightarrow$ IV.4.7). Um ein Bleichen aufgrund vieler Schaltzyklen zu verhindern, wurde zwischen den Beleuchtungs-schritten nicht nach jedem einzelnen Bild, sondern nach einem kompletten Stack gewechselt. Es wurde also jeweils ein kompletter Stack für einen Beleuchtungsschritt aufgenommen. Die Geschwindigkeit des Scanners betrug hier $1000 \mathrm{~Hz}$. 
Zunächst wurde die Probe mit UV-Licht (405 $\mathrm{nm} \mathrm{mit} \sim 170 \mathrm{~W} \cdot \mathrm{cm}^{-2}$ ) bestrahlt (Schritt-1), um Padron aus- und rsFastLime anzuschalten. Durch nachfolgende Bestrahlung mit blauem Licht (488 $\mathrm{nm}$ mit $\sim 700 \mathrm{~W} \cdot \mathrm{cm}^{-2}$ ) und UV-Licht $\left(405 \mathrm{~nm} \mathrm{mit} \sim 170 \mathrm{~W} \cdot \mathrm{cm}^{-2}\right)$, konnte die Fluoreszenz von rsFastLime ausgelesen werden (Schritt-2), das Signal von Padron war dabei vernachlässigbar bis nicht detektierbar. Durch anschließende Bestrahlung mit blauem Licht (488 $\mathrm{nm}$ mit $\sim 120 \mathrm{~W} \cdot \mathrm{cm}^{-2}$ ) wurde diesmal Padron an- und rsFastLime ausgeschaltet (Schritt3). Nun konnte durch Bestrahlung mit blauem Licht $\left(488 \mathrm{~nm}\right.$ mit $\left.\sim 900 \mathrm{~W} \cdot \mathrm{cm}^{-2}\right)$ die Fluoreszenz von Padron detektiert werden, ohne einen deutlichen Hintergrund der ausgeschalteten rsFastLime Proteine. Für die nächste Aufnahme der beiden Proteine wurde der Zyklus bei dem ersten Schritt neu gestartet.

VI.4.5 Separates Auslesen der Fluoreszenz von rsFastLime, Padron und bsDronpa mit einem konfokalen Laser-Raster-Mikroskop

Die Fluoreszenzsignale von Padron, rsFastLime und bsDronpa können durch Anregung zu unterschiedlichen Zeitpunkten oder mit unterschiedlichen Wellenlängen separat aufgenommen werden. Ein fünfstufiger Schaltzyklus ist dazu notwendig, wobei jede Stufe der Aufnahme eines Bildes entspricht, die jedoch mit unterschiedlichen Wellenlängen, sowie Intensitäten, aufgenommen werden ( $\rightarrow$ IV.4.4).

Mit Bestrahlung der Wellenlänge $405 \mathrm{~nm}\left(\sim 1000 \mathrm{~W} \cdot \mathrm{cm}^{-2}\right)$ wurden zu Beginn des Zyklus Padron aus-, sowie rsFastLime und bsDronpa angeschaltet. Als zweiter Schritt wurde die Fluoreszenz des im fluoreszierenden Zustand befindlichen bsDronpa detektiert, indem mit $405 \mathrm{~nm}\left(\sim 700 \mathrm{~W} \cdot \mathrm{cm}^{-2}\right)$ angeregt wurde. Als zweites Protein wurde dann direkt rsFastLime, das sich zu diesem Zeitpunkt ebenfalls im fluoreszierenden Zustand befindet, durch Bestrahlung mit möglichst geringer Intensität bei $496 \mathrm{~nm}\left(\sim 50 \mathrm{~W} \cdot \mathrm{cm}^{-2}\right)$ ausgelesen. Als vierter Schritt wurde nun Padron angeschaltet und rsFastLime und bsDronpa ausgeschaltet. Dies konnte durch starke Belichtung der Probe mit $496 \mathrm{~nm}\left(\sim 1000 \mathrm{~W} \cdot \mathrm{cm}^{-2}\right)$ realisiert werden. In diesem Schritt der Belichtungssequenz befindet sich einzig Padron im fluoreszierenden Zustand und kann durch Anregung bei $496 \mathrm{~nm}\left(\sim 150 \mathrm{~W} \cdot \mathrm{cm}^{-2}\right)$ detektiert werden. Anschließend kann für weitere Aufnahmen die Sequenz von neuem gestartet werden.

\section{VI.4.6 Zwei Farben hochauflösende Mikroskopie nach dem Einzelmolekül-} Lokalisationsverfahren mit negativ schaltbaren RSFPs

Die Bilder wurden mit einem Weitfeldmikroskop durch ein 100x Ö1-Objektiv (PL APO 100x 0.7-1.4, Leica Microsystems) aufgenommen. Die Aufnahmedauer und Belichtung der Probe 
wurden dabei so eingestellt, dass möglichst nur Fluoreszenz von einzelnen Molekülen aufgenommen wurde. Um dies $\mathrm{zu}$ ermöglichen, wurde das jeweilige Protein (bsDronpa, rsFastLime oder Dronpa) mit einem Argon-Ionen-Laser (Innova 70C, Coherent) bei $476 \mathrm{~nm}$ nahezu vollständig ausgeschaltet. Die Fluoreszenz wurde mit einem dichroitischen Spiegel bei $520 \mathrm{~nm}$ getrennt (z520DCXR, AHF Analysentechnik) und mit einer EM-CCD Kamera (IXON-Plus DU-860, Andor Technology) detektiert.

Die einzelnen Aufnahmen wurden nachträglich am Computer ausgewertet. Dabei wurden Bilder von einer Software (Bossi et al. 2008) selektiert, auf denen anhand der Gaussverteilung und der Anzahl der Photonen einzelne Moleküle identifiziert werden konnten. Der Grenzwert bezüglich der minimalen Anzahl Photonen wurde auf 160 eingestellt (in beiden Kanälen zusammen). Dieser Grenzwert ist notwendig, um eine ausreichend genaue Bestimmung der Position des Moleküls zu gewährleisten. Die Position jedes identifizierten Moleküls wurde in dem jeweiligen Bild markiert. Durch die statistische Erfassung der Moleküle in der Probe bei ausreichend langer Aufnahme und Addition aller Einzelbilder ergibt sich die Verteilung der Fluorophore in der Probe. Das resultierende Bild hat eine erhöhte Auflösung, da für jeden Fluorophor die Position anhand der Gaussverteilung exakter bestimmt wurde, als es bei normaler Weitfeld-Mikroskopie möglich wäre.

\section{VI.4.7 Messung der Abberation an einem konfokalen Mikroskop}

Um die Abberation zu bestimmen, wurden Kugeln mit verschiedenen FPs markiert und an der Oberfläche eines Deckglases bei entsprechender Anregungs- und Detektionswellenlänge aufgenommen. Die RSFPs rsFastLime und Padron wurden bei diesem Experiment mit denselben Wellenlängen angeregt und detektiert.

Es wurden Neutravidin markierte Kugeln mit einem Durchmesser von $40 \mathrm{~nm}$ verwendet (FluoSpheres, Invitrogen, Paisley, Schottland), die nach Protokoll biotinyliert wurden (FluoReporter Biotin-XX Protein Labelling Kit, Invitrogen, Karlsruhe, Deutschland). Die verwendeten Proteine (rsFastLime, Padron und eqFP611) wurden mit Streptavidin markiert und anschließend an die biotinylierten Kugeln gekoppelt.

Die mit den Proteinen markierten Kugeln wurden im gleichen Verhältnis gemischt. Etwa $10 \mu 1$ dieses Gemisches wurden für die Aufnahmen unter einem Deckglas auf einen Objekträger gegeben. Aufgrund elektrostatischer Wechselwirkungen binden die markierten Kugeln an die Oberfläche des Deckglases. Die Messung wurde mit dem konfokalen Leica SP5 Laser-Raster-Mikroskop (Leica, Bensheim, Deutschland) durch ein 63× Öl-Objektiv 
(HCX PL APO CS NA 1.4) aufgenommen. Das Protein eqFP611 wurde mit der Laserlinie bei $561 \mathrm{~nm}$ mit $12 \mathrm{~kW} \cdot \mathrm{cm}^{-2}$ angeregt, detektiert wurde bei 570 bis $700 \mathrm{~nm}$.

Padron und rsFastLime wurden unterschieden, indem Padron zunächst mit der Laserlinie bei $476 \mathrm{~nm}\left(50 \mathrm{~kW} \cdot \mathrm{cm}^{-2}\right)$ vollständig ein- und rsFastLime ausgeschaltet wurde (Schritt1). Anschließend wurde dieser Schritt wiederholt, um die Fluoreszenz von Padron aufzunehmen (Schritt2). Danach wurden beide Proteine durch Bestrahlung mit $405 \mathrm{~nm}$ geschaltet $\left(14 \mathrm{~kW} \cdot \mathrm{cm}^{-2}\right)$, um Padron aus- und rsFastLime einzuschalten (Schritt3). Als letzter Schritt (4) wurde die Fluoreszenz von rsFastLime aufgenommen, indem die Probe gleichzeitig mit 476 $\left(26 \mathrm{~kW} \cdot \mathrm{cm}^{-2}\right)$ und $405 \mathrm{~nm}\left(22 \mathrm{~kW} \cdot \mathrm{cm}^{-2}\right)$ bestrahlt wurde. Die Fluoreszenz von Padron und rsFastLime wurde in dem Bereich zwischen 485 und $550 \mathrm{~nm}$ detektiert. Mit dem Mikroskop wurden X-z Schnitte aufgenommen, um später die Abberation, welche in z-Richtung auftritt, $\mathrm{zu}$ bestimmen.

\section{VI.4.8 Bildverarbeitung}

Für die Auswertung und Darstellung der mikroskopischen Daten wurde das Programm „ImSpector“ (Schoenle 2006) verwendet. Bilder mit Aufnahmen aus verschiedenen Ebenen wurden, sofern nicht anders erwähnt, als Projektionen der maximalen Helligkeiten entlang der optischen Achse abgebildet. Die Nachbearbeitung der Bilder beschränkte sich in den meisten Fällen auf das Anpassen des Kontrasts (der Farbtabelle) im Programm ImSpector. Alternativ wurde eine Entfaltung mit dem Programm Amira (Visage Imaging, Carlsbad, USA) durchgeführt.

Für die Nachbearbeitung der monochromatischen Mehrfarben-Aufnahmen wurde ein linear unmixing Programm der Leica SP-Sofware (Leica LAS-AF simulator software, Version1.7.0 build 1240; Leica Microsystems, Wetzlar, Deutschland) verwendet.

\section{VI.4.9 Messung der Lichtstärke}

Die Intensität des eingestrahlten Lichts beeinflusst die Helligkeit, Schaltgeschwindigkeit und sogar die Ausschalteffizienz von reversibel schaltbaren fluoreszierenden Proteinen. Um Eigenschaften verschiedener Mutanten eines Proteins vergleichen zu können, mussten diese bei der gleichen Lichtintensität gemessen werden. Dies ist entweder möglich durch einen direkten Vergleich am selben Tag oder durch eine Definition der Lichtintensitäten.

Um die Intensität des Lichts zu messen, wurde ein Photometer (LabMaster Ultima - Coherent Deutschland $\mathrm{GmbH}$ ) benutzt, welches mittels eines Halbleiters die Photonen in elektrisches Signal umwandelt. 
Gemessen wurde direkt am Objektiv, sofern das Objektiv nicht hochauflösend war (63x oder 100x). An dem Photometer muss die Wellenlänge des Lichts eingestellt werden, da Photonen unterschiedlicher Wellenlänge auch unterschiedliche Energie besitzen. Um einen allgemein vergleichbaren Wert zu bekommen, muss man die Intensität noch auf die Fokusgröße $(\rightarrow$ VI.4.10) des verwendeten Objektivs umrechnen, dazu wird die Intensität (in Watt) geteilt durch die Fokusgröße (in $\mathrm{cm}^{2}$ ). Daraus ergibt sich ein Wert, der auch mit denen anderer Mikroskope vergleichbar ist und die Einheit $\mathrm{W} / \mathrm{cm}^{2}$ trägt.

Bei hochnumerischen Objektiven, wie sie bei dem Laser-Raster-Mikroskop benutzt werden, konnte mit dem Detektor nicht direkt das Licht nach dem Objektiv gemessen werden. Daher wurde das Objektiv entfernt und mit einem Aufsatz, welcher der Rückapertur des verwendeten Objektives entspricht, die Lichtintensität bestimmt. Anschließend muss noch die Transmission des Objektivs berücksichtigt werden (diese liegt meist zwischen 75 und $85 \%$ im Sichtbaren Bereicht), um die Intensität zu bestimmen.

Bei der Intensitätsmessung eines Laser-Raster-Mikroskops ist weiterhin zu beachten, dass der Laser die Probe abrastert und somit nicht durchgängig beleuchtet, dies zeigt sich am Photometer durch einen stark schwankenden Wert. Um eine möglichst konstante Beleuchtung zu erreichen, werden zwei Modifikationen bezüglich der Aufnahmebedingungen durchgeführt. Erstens wird die Auflösung (Pixel pro Linie) möglichst hoch gestellt, weil der Laser bei der Messung einer Linie durchgängig angeschaltet bleibt. Zweitens wird die Geschwindigkeit beim Abrastern möglichst niedrig eingestellt ( $1 \mathrm{~Hz}=$ Pixel pro Sekunde). Auf diese Weise kommt es zu einer nahezu konstanten Bestrahlung der Probe. Dies sollte sich durch einen relativ konstanten Wert am Photometer zeigen. Anschließend muss ebenfalls wie bei den niedrig numerischen Objektiven die Fokusgröße berücksichtigt werden.

\section{VI.4.10 Bestimmung der Fokusgröße}

Bei Luftobjektiven mit bis zu 40-facher Vergrößerung kann einfach ein Millimeterpapier benutzt werden, um den Durchmesser des Fokus zu bestimmen. Der Durchmesser sollte hierbei für jede Wellenlänge einzeln bestimmt werden, des Weiteren sollte ein Abschwächer benutzt werden, um den ausgeleuchteten Bereich besser sehen zu können.

Bei dem Laser-Raster-Mikroskop wurde die Fokusgröße bestimmt, indem eine fluoreszierende Kugel mit $50 \mathrm{~nm}$ Durchmesser aufgenommen wurde. Als Größe des Fokus wurde die volle Breite des Querschnitts bei 50 \% der maximalen Intensität benutzt. 


\section{VI.5 Bestimmung der Eigenschaften von RSFPs}

\section{VI.5.1 Schalten von RSFPs auf ganzen E.coli-Kolonien}

Ein Großteil der Charakterisierung, sowie nahezu das komplette Screening wurde auf ganzen E.coli-Kolonien durchgeführt. Das Schalten der Proteine zwischen dem fluoreszierenden- und dem nicht fluoreszierenden Zustand wird durch Bestrahlung mit Licht ermöglicht. Dabei ist eine der Wellenlängen immer diejenige, die auch die Fluoreszenz induziert, da sie der Absorption des Chromophors im fluoreszierenden, deprotonierten Zustand entspricht. Die zweite Wellenlänge wird durch die Absorption in dem protonierten (meist nicht fluoreszierenden) Zustand definiert. Welche dieser Wellenlängen das Anschalten und welche das Ausschalten bewirkt, also die Richtung der Isomerisierung bestimmt, ist von mehreren Faktoren abhängig. Eine komplexe Zusammensetzung der Kinetiken aus Protonierungsgleichgewichten, den Energiebarrieren und der freien Enthalpie in den Grundzuständen bestimmen den Effekt der beiden Wellenlängen.

Da die Schaltkinetiken durch die Bestrahlung mit Licht induziert werden, liegt es nahe, dass die Intensität einen großen Einfluss auf die Messergebnisse hat. Daher muss bei vergleichenden Messungen darauf geachtet werden, dass die gleichen Intensitäten verwendet werden $(\rightarrow$ VI.4.9).

\section{VI.5.1.1 Maximale Fluoreszenz}

Die maximale Fluoreszenz (Fluo ${ }^{\text {max }}$ ) wurde bei den RSFPs als der Wert bestimmt, bei dem auf einer E.coli Kolonie die maximale Fluoreszenz gemessen wurde (nur mit der Wellenlänge, die die Fluoreszenz induziert). Die Kolonie wurde dazu in den Focus gebracht und mit der entsprechenden Wellenlänge komplett angeschaltet, bis kein Anstieg der Fluoreszenz mehr gemessen wurde.

\section{VI.5.1.2 Minimale Fluoreszenz}

Als minimale Fluoreszenz $\left(\right.$ Fluo $^{\mathrm{min}}$ ) wurde das Fluoreszenzsignal bestimmt, das eine Kolonie bei Anregung der Fluoreszenz abstrahlt, obwohl die Kolonie vorher mit der entsprechenden Wellenlänge so weit wie möglich ausgeschaltet wurde.

Beim Ausschalten war es notwendig, das Anregungslicht ebenfalls einzustrahlen, um die Kinetik des Ausschaltens zu bestimmen. Aus diesem Wert ergibt sich ein weiterer Wert, die minimale Fluoreszenz beim Ausschalten (Fluo ${ }_{\text {off }}^{\text {off }}$. 


\section{VI.5.1.3 Restfluoreszenz}

Als Restfluoreszenz ( $\mathrm{rfl}=$ residual fluorescence) wurde der Prozentsatz der minimalen von der maximalen Fluoreszenz bestimmt. Formel: $\mathrm{rfl}=\left(\right.$ Fluo $^{\min } /$ Fluo $\left.^{\max }\right) \cdot 100$

\section{VI.5.1.4 Grundzustand}

Der Grundzustand wird definiert durch das Fluoreszenzsignal bei Raumtemperatur und Raumlicht einer Kolonie, die zuvor noch nicht bestrahlt wurde. Die Höhe dieses Signals $\left(\right.$ Fluo $^{\mathrm{eq}}$ ) wurde in Relation gesetzt zu Fluo ${ }^{\mathrm{max}}$ und Fluo ${ }^{\mathrm{min}}$. Dabei wurde der Abstand der Fluoreszenz im Grundzustand zur minimalen Fluoreszenz $\left(\right.$ Fluo $^{\mathrm{eq}}-$ Fluo $^{\mathrm{min}}$ ) durch den dynamischen Bereich des Schaltens (Fluo ${ }^{\max }$ - Fluo ${ }^{\mathrm{min}}$ ) geteilt.

\section{VI.5.1.5 Schaltgeschwindigkeit}

Die Schaltgeschwindigkeit eines Proteins ist stark von der benutzten Intensität abhängig, daher ist ein Vergleich zwischen Proteinen nur bei gleicher Intensität möglich. Die Schaltgeschwindigkeit wurde bei einer bestimmten Lichtintensität als die Zeit definiert, nach der die Hälfte des dynamischen Bereichs geschaltet war (der Zeitpunkt bei dem 0,5 • (Fluo ${ }^{\max }$ Fluo $\left.^{\text {min }}\right)+$ Fluo $^{\text {min }}$ erreicht ist). Dazu wurde ein kompletter Schaltzyklus aufgenommen und Fluo $^{\text {max }}$, sowie Fluo ${ }^{\text {min }}$ bestimmt. Mit diesen Werten und den Daten des Schaltzyklus kann man die Halbwertszeiten $\left(t_{1 / 2}\right.$ on und $t_{1 / 2}$ off $)$ bestimmen.

\section{VI.5.1.6 Halbwertszeiten der natürlichen Rückfallrate in das thermodynamische Gleichgewicht}

Als Gleichgewicht wurde der zuvor bestimmte Grundzustand des Proteins angenommen. Das Protein wurde aus dem Gleichgewichtszustand entweder vollständig ein- oder ausgeschaltet. Anschließend wurde mit möglichst geringer Intensität und einer Dauer von $0,02 \mathrm{~s}$ die Fluoreszenz abgefragt. Die Abfrage wurde je nach Halbwertszeit der Zustände in verschiedenen Abständen wiederholt. Bei Proteinen, die sehr sensibel gegenüber dem Anregungslicht sind, wurde für die Bestimmung von jedem Zeitpunkt der Kinetik nochmals komplett geschaltet, um einen Effekt des Anregungslichtes auf die Kinetik auszuschließen. Die Halbwertszeit, die beim Zurückfallen aus dem am weitesten vom Gleichgewicht entfernten Zustand (vollständig angeschaltet oder vollständig ausgeschaltet) gemessen wurde, wurde als $t_{1 / 2}{ }^{\text {relax }}$ definiert. 


\section{VI.5.1.7 Bleichen pro Zyklus}

Zur Bestimmung des Bleichens wurde bei RSFPs die durchschnittliche Abnahme der maximalen Fluoreszenz (Fluo ${ }^{\max }$ ) nach einem kompletten Schaltzyklus bestimmt. Dazu wurden für jedes Protein 10 Schaltzyklen aufgenommen, deren einzelne Belichtungsdauern für jedes Protein individuell definiert wurden. Die einzelnen Teilschritte des Zyklus wurden so gewählt, dass sie direkt nach Erreichen der Werte Fluo ${ }^{\max }$ und Fluo ${ }^{\text {min }}$ enden. Dies ist notwendig, um unnötiges Bleichen durch zu lange Belichtung zu verhindern.

\section{VI.5.2 Messung der Absorptionsspektren}

Die Absorptionsspektren wurden an einem Photospektrometer (Varian Cary 4000 UV/VIS, Varian) mit aufgereinigtem Protein in einer 0,1 mm dicken Küvette und einem Volumen von etwa $70 \mu 1$ gemessen. Die aufgereinigten Proteine wurden mit dem Standardproteinpuffer (100 mM Tris $\mathrm{pH} 7,5 ; 150 \mathrm{mM} \mathrm{NaCl})$ verdünnt.

Für die Aufnahme der Spektren von RSFPs im fluoreszierenden und nicht fluoreszierenden Zustand wurden 2-4 $\mu$ l einer konzentrierten Proteinlösung unter einer 100W Hg-Lampe und einem 40x Objektiv so vollständig wie möglich ein- bzw. ausgeschaltet. Anschließend wurden die Proben mit Puffer verdünnt und so schnell wie möglich gemessen. Diese Methode funktioniert jedoch nur für solche Proteine, die in beiden Zuständen ausreichend stabil vorliegen. Für reversibel schaltbare fluoreszierende Proteine mit kurzer Lebensdauer des geschalteten Zustandes wurde eine 120W Hg-Lampe über eine Faser in das Spektrometer so eingekoppelt, dass die Probe in der Küvette vollständig beleuchtet wird. Damit konnte die Dauer zwischen Bestrahlung und Messung verringert werden, während jedoch die notwendige Bestrahlungsdauer stark erhöht wurde.

\section{VI.5.3 Messung der Fluoreszenzspektren}

Die Fluoreszenzspektren wurden mit $70 \mu 1$ verdünntem (Standardproteinpuffer, $100 \mathrm{mM}$ Tris $\mathrm{pH} 7,5 ; 150 \mathrm{mM} \mathrm{NaCl}$ ) aufgereinigtem Protein in einer $0,1 \mathrm{~mm}$ dicken Küvette mit einem Fluoreszenzspektrometer (Varian Cary Eclipse fluorescence spectrometer, Varian) gemessen. Für die Anregung wurde am Photometer die entsprechende Wellenlänge eingestellt und ein $10 \mathrm{~nm}$ breiter Anregungsschlitz gewählt. Zusätzlich wurde ein entsprechender Filter (z.B. 457 $\pm 2,5 \mathrm{~nm}$ für Dronpa) in den Strahlengang gebracht, da die Filter eine höhere Genauigkeit aufweisen als das Photometer.

Der Detektionsspalt wurde auf $5 \mathrm{~nm}$ Breite eingestellt. Die Signalstärke konnte mit Hilfe der Scandauer und der Spannung des internen Photomultipliers eingestellt werden. Die Werte 
mussten anschließend mit den Korrekturfaktoren für den $5 \mathrm{~nm}$ breiten Detektionsspalt multipliziert werden, um die Sensibilität des Photomultipliers in verschiedenen Bereichen des Spektrums zu korrigieren. Die Korrekturfaktoren wurden anhand eines bekannten Rhodaminfarbstoffes für dieses Photometer gemessen.

\section{VI.6 Optimierung der Eigenschaften von RSFPs}

Beim Suchen nach veränderten Eigenschaften von RSFPs ist das Suchen selbst der beschränkende Faktor. Durch eine Zufallsmutagenese ( $\rightarrow$ VI.2.12) auf dem ursprünglichen Gen des RSFPs können extrem viele Variationen dieses Gens in kurzer Zeit erstellt werden. Die auf diese Weise mutagenisierte DNS wird in einen Expressionsvektor eingebaut (hier pQE-30 bzw. pQE-31) und anschließend in E.coli transformiert. Man bekommt so eine Vielzahl einzelner E.coli Klone (je nach Effizienz der Mutagenese und der Transformation bis zu $10^{7}$ ), die unterschiedliche Varianten desselben Proteins produzieren können.

Würde man all diese Proteine isolieren oder auch nur in Flüssigkultur animpfen, wäre der Zeitaufwand enorm groß. Daher ist ein Screening auf ganzen E.coli-Kolonien eine Notwendigkeit für ein effektives Screening-System. Alternativ wäre es möglich, alle Klone zusammen in Flüssigkeit aufzunehmen und über ein FACS zu sortieren. Mit dieser Methode lassen sich jedoch nur FPs isolieren, die direkt eine höhere Helligkeit aufweisen. Bei RSFPs ist das Screening jedoch um einiges komplexer, da man die Proteine im Normalfall zunächst bestrahlen muss, um sie vergleichen zu können.

Dieses Beispiel zeigt, dass es für den Aufbau eines Screenings essentiell ist, welche Eigenschaften getestet und verbessert werden sollen. Bei den RSFPs waren diese Eigenschaften die maximale Fluoreszenz (Fluo ${ }^{\text {max }}$ ), die Restfluoreszenz (rfl), sowie die Schaltgeschwindigkeiten $\left(t_{1} / 2\right.$ on und $t_{1 / 2}$ off $)$.

Um alle diese Eigenschaften $\mathrm{zu}$ testen, ist es notwendig ein reversibel schaltbares fluoreszierendes Protein einem gesamten Schaltzyklus zu unterziehen. Ein Screening-Aufbau für RSFPs muss daher mindestens über zwei Wellenlängen verfügen, außerdem müssen je nach Variante des RSFPs die Abfolge und Dauer der Bestrahlung mit diesen zwei Wellenlängen frei wählbar sein.

Weiterhin ist es notwendig, dass diese Eigenschaften an ganzen E.coli-Kolonien getestet werden können. Dies bedeutet, dass ein Screening nach den essentiellen Eigenschaften von RSFPs nur mit Luftobjektiven möglich ist. 


\section{VI.6.1 Der Screeningaufbau}

Das Grundgerüst des Aufbaus bildet ein Standard Leica Mikroskop, dass mit zwei Quecksilberdampflampen (HBO 103W/2, Osram, Chemnitz, Deutschland) bestückt ist. Jeweils ein Shutter direkt hinter den Lampen, gefolgt von einem spezifischen Anregungsfilter, ermöglichen die Beleuchtung mit der richtigen Wellenlänge zur richtigen Zeit. Die Strahlengänge werden über einen dichroitischen Spiegel (Dronpa: 400 DCLP; asFP595: 495 DCXR) zusammengeführt und können wahlweise durch ein 20x (N PLAN L 20x NA 0.4, Leica, Deutschland) oder 40x (PLAN H 40x NA 0.6, Leica, Deutschland) Luftobjektiv auf die Probe fokussiert werden.

Die Probe wird auf einem in der $x-y$ Ebene beweglichen Objekttisch gelagert. Dieser Objekttisch kann über einen Computer angesteuert werden, um z.B. eine Agarplatte komplett abzurastern. Die für die Detektion notwendige Trennung der Fluoreszenz vom Anregungslicht, wird im Detektionsstrahlengang ebenfalls durch die dichroitischen Spiegel, sowie Langpassfilter bewerkstelligt (Dronpa: HQ525/50; asFP595: HQ600 LP). Die Fluoreszenz wird von einem Photomultiplier (Hamamatsu, Herrsching am Ammersee, Deutschland) detektiert und kann aufgrund der Geschwindigkeit des Shutters und der Regenerationsrate des PMT etwa alle 0,02 s aufgezeichnet werden.

Durch eine Verbindung der einzelnen Komponenten mit einem Computer und Vernetzung in das Programm Labview können die einzelnen Komponenten des Aufbaus angesteuert, sowie die Fluoreszenzsignale detektiert werden.

\section{VI.6.2 Das Screeningprogramm}

Das Screening musste mindestens einen gesamten Schaltzyklus umfassen, um nach den gewünschten Eigenschaften zu screenen. Ein solcher Zyklus besteht aus mindestens drei Teilschritten. Zunächst wird jede Kolonie für eine Sekunde mit der kürzeren Wellenlänge (Dronpa: $405 \pm 10 \mathrm{~nm}$; asFP595: $450 \pm 20 \mathrm{~nm}$ ) bestrahlt, um das Gleichgewicht der Proteine in eines der beiden Extrema zu zwingen (1). Als Zweites wird mit der längeren Anregungswellenlänge (Dronpa: $488 \pm 10 \mathrm{~nm}$; asFP595: $550 \pm 20 \mathrm{~nm}$ ) bestrahlt (2). Die Dauer dieser Bestrahlung sollte so gewählt werden, dass ein durchschnittlicher Klon vollständig ein- (asFP595 - positives Schalten) oder ausgeschaltet (Dronpa - negatives Schalten) wird. Als letzter Schritt werden beide Wellenlängen (Dronpa 488 \& 405; asFP595 450 \& 550) zusammen eingestrahlt, um die Entwicklung des Fluoreszenzsignals bei der Ausschaltkinetik aufzunehmen. Die Dauer der Beleuchtung sollte ebenfalls ausreichend für das Erreichen des Minimums (asFP595) bzw. des Maximums (Dronpa) sein (3). 
Ein solcher Zyklus dauert je nach Eigenschaften des Ausgangsproteins etwa 15-40 Sekunden, das Mikroskop rastert jedoch in $1 \mathrm{~mm}$ Schritten die Agarplatte ab. Eine Messung aller Punkte auf der Platte kommt daher nicht in Frage. Daher wird in das Screening-Programm ein Kriterium eingebaut, das über den Fortlauf der Messung an jeder Position entscheidet. Bei Schritt (2) gibt es zwei Kriterien, von denen eines erfüllt sein muss, damit die Messung fortgesetzt wird. Entweder muss das Fluoreszenzsignal ausreichend hoch sein, oder das Verhältnis zwischen dem ersten und zweiten Messwert muss einen zuvor festgelegten Grenzwert überschreiten. Trifft keine dieser beiden Kriterien zu, so wird die Messung an dieser Position der Agarplatte abgebrochen.

\section{VI.6.3 Die Auswertung eines Screenings}

Die Messwerte wurden für die Analyse der Eigenschaften graphisch dargestellt. Anschließend müssen anhand der Messwerte Klone ausgewählt werden, die in den entsprechenden Eigenschaften Verbesserungen aufweisen. Die hauptsächlichen Auswahlkriterien waren hier die maximale Fluoreszenz, die Restfluoreszenz, sowie die Schaltgeschwindigkeit. Außerdem wurde auf Besonderheiten Acht gegeben, dazu gehörten z.B. die Färbung der Klone oder außergewöhnliche Kinetiken bei der Analyse der Messwerte. 


\section{Abkürzungen}

\begin{tabular}{|c|c|}
\hline $5^{\prime}-\mathrm{FoA}$ & 5`-Fluoro-orotic-acid \\
\hline APBS & Adaptive Poisson-Boltzmann Solver \\
\hline As & Aminosäure(n) \\
\hline asFP595 & Anemonia sulcata fluoreszierendes Protein \\
\hline bla & ß-Laktamase-Gen \\
\hline bp & Basenpaar \\
\hline BSA & Rinderserumalbumin \\
\hline C-Terminus & Carboxy-Terminus \\
\hline CIP & calf intestine phosphatase \\
\hline DMSO & Dimethylsulfoxid \\
\hline DNS & Desoxyribonukleinsäure \\
\hline dNTPs & Desoxynukleosidtriphosphate \\
\hline DsRed & rot fluoreszierendes Protein aus Discosoma sp. \\
\hline DTT & Dithiothreitol \\
\hline EDTA & Ethylendiamintetraessigsäure \\
\hline EGFP & enhanced GFP \\
\hline eqFP611 & Entacmaea quadricolor fluoreszierendes Protein \\
\hline ER & endoplasmatisches Retikulum \\
\hline ESPT & excitet state proton transfer \\
\hline EYFP & gelb fluoreszierendes Protein \\
\hline FACS & fluorescence activated cell sorting \\
\hline FITC & Fluoreszeinisothiocyanat \\
\hline FP & Fluoreszierendesprotein \\
\hline FRET & Förster Resonanz Elektronen Transfer \\
\hline GFP & grün fluoreszierendes Protein \\
\hline HEPES & N-2-hydroxyethyl-piperazin-N-2-ethansulfonsäure \\
\hline HPLC & high performance liquid chromatography \\
\hline IPTG & Isopropyl- $\beta$-D-thiogalactopyranosid \\
\hline $\mathrm{kb}$ & Kilobasen \\
\hline $\mathrm{kDa}$ & Kilodalton \\
\hline KFP & kindling fluorescent protein \\
\hline LB & lysogeny broth \\
\hline mRFP & monomeres rot fluoreszierendes \\
\hline N-Terminus & Amino-Terminus \\
\hline NA & numerische Apertur \\
\hline NMR & nuclear magnetic resonance \\
\hline NTPs & Nukleosidtriphosphate \\
\hline OD & optische Dichte \\
\hline PAGE & Polyacrylamid-Gelelektrophorese \\
\hline paGFP & photo activable GFP \\
\hline PALM & photoactivated localization microscopy \\
\hline PALMIRA & photoactivated localization microscopy with independently running acquisition \\
\hline PBS & phosphatgepufferte Kochsalzlösung \\
\hline PCR & polymerase chain reaction \\
\hline PDB ID & protein database identifier \\
\hline PEG & Polyethylenglycol \\
\hline RESOLFT & REversible Saturable OpticaL Fluorescence Transitions \\
\hline RNS & Ribonukleinsäure \\
\hline RSFP & Reversibel Schaltbares Fluoreszierendes Protein \\
\hline RT & Raumtemperatur \\
\hline SDS & Natriumdodecylsulfat (Sodiumdodecylsulfate) \\
\hline STED & Stimulated Emission Depletion \\
\hline STORM & Stochastic Optical Reconstruction Microscopy \\
\hline TAE & Tris-Acetat Puffer \\
\hline $\mathrm{TE}$ & Tris-EDTA (-Puffer) \\
\hline TEMED & Tetramethylethylenediamine \\
\hline UV & Ultraviolett \\
\hline YPD & Yeast Peptone Dextrose \\
\hline zFP538 & Zoanthus sp. fluoreszierendes Protein \\
\hline
\end{tabular}




\section{Literaturverzeichnis}

Abbyad, P.; Childs, W.; Shi, X. und Boxer, S. G. (2007). "Dynamic Stokes shift in green fluorescent protein variants." Proc Natl Acad Sci U S A 104(51): 20189-20194.

Ai, H. W.; Shaner, N. C.; Cheng, Z.; Tsien, R. Y. und Campbell, R. E. (2007). "Exploration of new chromophore structures leads to the identification of improved blue fluorescent proteins." Biochemistry 46(20): 5904-5910.

Ando, R.; Hama, H.; Yamamoto-Hino, M.; Mizuno, H. und Miyawaki, A. (2002). "An optical marker based on the UV-induced green-to-red photoconversion of a fluorescent protein." Proc Natl Acad Sci U S A 99(20): 12651-12656.

Ando, R.; Mizuno, H. und Miyawaki, A. (2004). "Regulated fast nucleocytoplasmic shuttling observed by reversible protein highlighting." Science 306(5700): 1370-1373.

Andresen, M.; Stiel, A. C.; Fölling, J.; Wenzel, D.; Schönle, A.; Egner, A.; Eggeling, C.; Hell, S. W. und Jakobs, S. (2008). "Photoswitchable fluorescent proteins enable monochromatic multilabel imaging and dual color fluorescence nanoscopy." Nat Biotechnol 26(9): 1035-1040.

Andresen, M.; Stiel, A. C.; Trowitzsch, S.; Weber, G.; Eggeling, C.; Wahl, M. C.; Hell, S. W. und Jakobs, S. (2007). "Structural basis for reversible photoswitching in Dronpa." Proc Natl Acad Sci U S A 104(32): 13005-13009.

Andresen, M.; Wahl, M. C.; Stiel, A. C.; Gräter, F.; Schäfer, L. V.; Trowitzsch, S.; Weber, G.; Eggeling, C.; Grubmüller, H.; Hell, S. W. und Jakobs, S. (2005). "Structure and mechanism of the reversible photoswitch of a fluorescent protein." Proc Natl Acad Sci U S A 102(37): 13070-13074.

Aramaki, S. und Hatta, K. (2006). "Visualizing neurons one-by-one in vivo: optical dissection and reconstruction of neural networks with reversible fluorescent proteins." Dev Dyn 235(8): 2192-2199.

Baird, G. S.; Zacharias, D. A. und Tsien, R. Y. (2000). "Biochemistry, mutagenesis, and oligomerization of DsRed, a red fluorescent protein from coral." Proc Natl Acad Sci U S A 97(22): 11984-11989.

Barondeau, D. P.; Kassmann, C. J.; Tainer, J. A. und Getzoff, E. D. (2005). "Understanding GFP chromophore biosynthesis: controlling backbone cyclization and modifying posttranslational chemistry." Biochemistry 44(6): 1960-1970.

Barondeau, D. P.; Putnam, C. D.; Kassmann, C. J.; Tainer, J. A. und Getzoff, E. D. (2003). "Mechanism and energetics of green fluorescent protein chromophore synthesis revealed by trapped intermediate structures." Proc Natl Acad Sci U S A 100(21): 12111-12116.

Becker, D. M. und Guarente, L. (1991). "High-efficiency transformation of yeast by electroporation." Methods Enzymol 194: 182-187.

Betzig, E.; Patterson, G. H.; Sougrat, R.; Lindwasser, O. W.; Olenych, S.; Bonifacino, J. S.; Davidson, M. W.; Lippincott-Schwartz, J. und Hess, H. F. (2006). "Imaging intracellular fluorescent proteins at nanometer resolution." Science 313(5793): 16421645.

Bevis, B. J. und Glick, B. S. (2002). "Rapidly maturing variants of the Discosoma red fluorescent protein (DsRed)." Nat Biotechnol 20(1): 83-87.

Bock, H.; Geisler, C.; Wurm, C. A.; Jakobs, S.; Schönle, A.; Egner, A.; Hell , S. W. und Eggeling, C. (2007). "Two-color far-field fluorescence nanoscopy based on photoswitching emitters." Appl. Phys. B 88(161-165).

Boeke, J. D.; Trueheart, J.; Natsoulis, G. und Fink, G. R. (1987). "5-Fluoroorotic Acid as a Selective Agent in Yeast Molecular-Genetics." Methods in Enzymology 154: 164-175.

Bossi, M.; Fölling, J.; Belov, V. N.; Boyarskiy, V. P.; Medda, R.; Egner, A.; Eggeling, C.; Schönle, A. und Hell, S. W. (2008). "Multicolor Far-Field Fluorescence Nanoscopy 
through Isolated Detection of Distinct Molecular Species." Nano Letters 8(8): 2463 2468.

Brejc, K.; Sixma, T. K.; Kitts, P. A.; Kain, S. R.; Tsien, R. Y.; Ormo, M. und Remington, S. J. (1997). "Structural basis for dual excitation and photoisomerization of the Aequorea victoria green fluorescent protein." Proc Natl Acad Sci U S A 94(6): 2306-2311.

Brown, R. (1828). "A brief Account of Microscopical Observations made in the Months of June, July, and August, 1827, on the Particles contained in the Pollen of Plants; and on the general Existence of active Molecules in Organic and Inorganic Bodies." Philosophical Magazine 4: 161-173.

Bulina, M. E.; Chudakov, D. M.; Britanova, O. V.; Yanushevich, Y. G.; Staroverov, D. B.; Chepurnykh, T. V.; Merzlyak, E. M.; Shkrob, M. A.; Lukyanov, S. und Lukyanov, K. A. (2006). "A genetically encoded photosensitizer." Nat Biotechnol 24(1): 95-99.

Bulina, M. E.; Lukyanov, K. A.; Britanova, O. V.; Onichtchouk, D.; Lukyanov, S. und Chudakov, D. M. (2006). "Chromophore-assisted light inactivation (CALI) using the phototoxic fluorescent protein KillerRed." Nat Protoc 1(2): 947-953.

Campbell, R. E.; Tour, O.; Palmer, A. E.; Steinbach, P. A.; Baird, G. S.; Zacharias, D. A. und Tsien, R. Y. (2002). "A monomeric red fluorescent protein." Proc Natl Acad Sci U S A 99(12): 7877-7882.

Chalfie, M.; Tu, Y.; Euskirchen, G.; Ward, W. W. und Prasher, D. C. (1994). "Green fluorescent protein as a marker for gene expression." Science 263(5148): 802-805.

Chudakov, D. M.; Belousov, V. V.; Zaraisky, A. G.; Novoselov, V. V.; Staroverov, D. B.; Zorov, D. B.; Lukyanov, S. und Lukyanov, K. A. (2003). "Kindling fluorescent proteins for precise in vivo photolabeling." Nat Biotechnol 21(2): 191-194.

Chudakov, D. M.; Chepurnykh, T. V.; Belousov, V. V.; Lukyanov, S. und Lukyanov, K. A. (2006). "Fast and precise protein tracking using repeated reversible photoactivation." Traffic 7(10): 1304-1310.

Chudakov, D. M.; Feofanov, A. V.; Mudrik, N. N.; Lukyanov, S. und Lukyanov, K. A. (2003). "Chromophore environment provides clue to "kindling fluorescent protein" riddle." J Biol Chem 278(9): 7215-7219.

Cole, N. B.; Smith, C. L.; Sciaky, N.; Terasaki, M.; Edidin, M. und Lippincott-Schwartz, J. (1996). "Diffusional mobility of Golgi proteins in membranes of living cells." Science 273(5276): 797-801.

Condon, E. U. (1964). "Intensity-Dependent Absorption of Light." Proc Natl Acad Sci U S A 52(3): 635-637.

Dedecker, P.; Hotta, J.; Ando, R.; Miyawaki, A.; Engelborghs, Y. und Hofkens, J. (2006). "Fast and reversible photoswitching of the fluorescent protein dronpa as evidenced by fluorescence correlation spectroscopy." Biophys J. 91(5): L45-47.

Dickson, R. M.; Cubitt, A. B.; Tsien, R. Y. und Moerner, W. E. (1997). "On/off blinking and switching behaviour of single molecules of green fluorescent protein." Nature 388(6640): 355-358.

Eggeling, C.; Hilbert, M.; Bock, H.; Ringemann, C.; Hofmann, M.; Stiel, A. C.; Andresen, M.; Jakobs, S.; Egner, A.; Schonle, A. und Hell, S. W. (2007). "Reversible photoswitching enables single-molecule fluorescence fluctuation spectroscopy at high molecular concentration." Microsc Res Tech. 70(12): 1003-1009

Egner, A.; Geisler, C.; von Middendorff, C.; Bock, H.; Wenzel, D.; Medda, R.; Andresen, M.; Stiel, A. C.; Jakobs, S.; Eggeling, C.; Schonle, A. und Hell, S. W. (2007). "Fluorescence nanoscopy in whole cells by asnychronous localization of photoswitching emitters." Biophys J. 93(9): 3285-3290

Egner, A.; Geisler, C.; von Middendorff, C.; Bock, H.; Wenzel, D.; Medda, R.; Andresen, M.; Stiel, A. C.; Jakobs, S.; Eggeling, C.; Schonle, A. und Hell, S. W. (2007). 
"Fluorescence nanoscopy in whole cells by asynchronous localization of photoswitching emitters." Biophys J 93(9): 3285-3290.

Einstein, A. (1905). "Über die von der molekularkinetischen Theorie der Wärme geforderte Bewegung von in ruhenden Flüssigkeiten suspendierten Teilchen." Annalen der Physik 322(8): 549-560.

Elowitz, M. B.; Surette, M. G.; Wolf, P. E.; Stock, J. und Leibler, S. (1997). "Photoactivation turns green fluorescent protein red." Curr Biol 7(10): 809-812.

Elsliger, M. A.; Wachter, R. M.; Hanson, G. T.; Kallio, K. und Remington, S. J. (1999). "Structural and spectral response of green fluorescent protein variants to changes in pH." Biochemistry 38(17): 5296-5301.

Emsley, P. und Cowtan, K. (2004). "Coot: model-building tools for molecular graphics." Acta Crystallogr. Sect. D Biol. Crystallogr. 60: 2126-2132.

Fron, E.; Flors, C.; Schweitzer, G.; Habuchi, S.; Mizuno, H.; Ando, R.; Schryver, F. C.; Miyawaki, A. und Hofkens, J. (2007). "Ultrafast excited-state dynamics of the photoswitchable protein Dronpa." J Am Chem Soc 129(16): 4870-4871.

Fujioka, A.; Terai, K.; Itoh, R. E.; Aoki, K.; Nakamura, T.; Kuroda, S.; Nishida, E. und Matsuda, M. (2006). "Dynamics of the Ras/ERK MAPK cascade as monitored by fluorescent probes." J Biol Chem 281(13): 8917-8926.

Geisler, C.; Schönle, A.; von Middendorff, C.; Bock, H.; Eggeling, C.; Egner, A. und Hell , S. $W$. (2007). "Resolution of $\lambda / 10$ in fluorescence microscopy using fast single molecule photo-switching." Appl. Phys. A 88(2): 223-226.

Gill, S. C. und von Hippel, P. H. (1989). "Calculation of protein extinction coefficients from amino acid sequence data." Analytical Biochemistry 182(2): 319-326.

Gross, L. A.; Baird, G. S.; Hoffman, R. C.; Baldridge, K. K. und Tsien, R. Y. (2000). "The structure of the chromophore within DsRed, a red fluorescent protein from coral." Proc Natl Acad Sci U S A 97(22): 11990-11995.

Habuchi, S.; Ando, R.; Dedecker, P.; Verheijen, W.; Mizuno, H.; Miyawaki, A. und Hofkens, J. (2005). "Reversible single-molecule photoswitching in the GFP-like fluorescent protein Dronpa." Proc Natl Acad Sci U S A 102(27): 9511-9516.

Habuchi, S.; Dedecker, P.; Hotta, J.; Flors, C.; Ando, R.; Mizuno, H.; Miyawaki, A. und Hofkens, J. (2006). "Photo-induced protonation/deprotonation in the GFP-like fluorescent protein Dronpa: mechanism responsible for the reversible photoswitching." Photochem Photobiol Sci 5(6): 567-576.

Haupts, U.; Maiti, S.; Schwille, P. und Webb, W. W. (1998). "Dynamics of fluorescence fluctuations in green fluorescent protein observed by fluorescence correlation spectroscopy." Proceedings of the National Academy of Sciences of the United States of America 95(23): 13573-13578.

Hayashi, I.; Mizuno, H.; Tong, K. I.; Furuta, T.; Tanaka, F.; Yoshimura, M.; Miyawaki, A. und Ikura, M. (2007). "Crystallographic evidence for water-assisted photo-induced peptide cleavage in the stony coral fluorescent protein Kaede." J Mol Biol 372(4): 918-926.

Heim, R.; Cubitt, A. B. und Tsien, R. Y. (1995). "Improved green fluorescence." Nature 373(6516): 663-664.

Heim, R.; Prasher, D. C. und Tsien, R. Y. (1994). "Wavelength mutations and posttranslational autoxidation of green fluorescent protein." Proc Natl Acad Sci U S A 91(26): 12501-12504.

Heisenberg, W. (1930). The Physical Principles Of The Quantum Theory. Chicago, Chicago University Press.

Hell, S. W. (2003). "Toward fluorescence nanoscopy." Nat Biotechnol 21(11): 1347-1355.

Hell, S. W. (2007). "Far-field optical nanoscopy." Science 316(5828): 1153-1158. 
Hell, S. W.; Dyba, M. und Jakobs, S. (2004). "Concepts for nanoscale resolution in fluorescence microscopy." Curr Opin Neurobiol 14(5): 599-609.

Hell, S. W.; Jakobs, S. und Kastrup, L. (2003). "Imaging and writing at the nanoscale with focused visible light through saturable optical transitions." Applied Physics aMaterials Science \& Processing 77(7): 859-860.

Hell, S. W. und Wichmann, J. (1994). "Breaking the Diffraction Resolution Limit by Stimulated-Emission - Stimulated-Emission-Depletion Fluorescence Microscopy." Optics Letters 19(11): 780-782.

Henderson, J. N.; Ai, H. W.; Campbell, R. E. und Remington, S. J. (2007). "Structural basis for reversible photobleaching of a green fluorescent protein homologue." Proc Natl Acad Sci U S A 104(16): 6672-6677.

Henderson, J. N. und Remington, S. J. (2006). "The kindling fluorescent protein: a transient photoswitchable marker." Physiology (Bethesda) 21: 162-170.

Hofmann, M.; Eggeling, C.; Jakobs, S. und Hell, S. W. (2005). "Breaking the diffraction barrier in fluorescence microscopy at low light intensities by using reversibly photoswitchable proteins." Proc Natl Acad Sci U S A 102(49): 17565-17569.

Hooke, R. (1665). Micrographia.

Inouye, S. und Tsuji, F. I. (1994). "Aequorea green fluorescent protein. Expression of the gene and fluorescence characteristics of the recombinant protein." FEBS Lett 341(23): $277-280$.

Jablonski, A. (1933). "Efficiency of Anti-Stokes Fluorescence in Dyes." Nature: 839-840.

Jablonski, A. und Szymanowski, W. (1935). "Thermal Rotations of Fluorescence Molecules and Duration of Luminiscence." Nature 135: 582.

Jakobs, S.; Schauss, A. C. und Hell, S. W. (2003). "Photoconversion of matrix targeted GFP enables analysis of continuity and intermixing of the mitochondrial lumen." FEBS Lett 554(1-2): 194-200.

Klar, T. A.; Jakobs, S.; Dyba, M.; Egner, A. und Hell, S. W. (2000). "Fluorescence microscopy with diffraction resolution barrier broken by stimulated emission." Proc Natl Acad Sci U S A 97(15): 8206-8210.

Kurokawa, K. und Matsuda, M. (2005). "Localized RhoA activation as a requirement for the induction of membrane ruffling." Mol Biol Cell 16(9): 4294-4303.

Laemmli, U. K. (1970). "Cleavage of structural proteins during the assembly of the head of bacteriophage T4." Nature 227(5259): 680-685.

Lakowicz, J. R. (1999). Principles of fluorescence spectroscopy. New York, Kluwer Academic/Plenum.

Lehman, I. R. (1974). "DNA ligase: structure, mechanism, and function." Science 186(4166): 790-797.

Lippincott-Schwartz, J. und Patterson, G. H. (2003). "Development and use of fluorescent protein markers in living cells." Science 300(5616): 87-91.

Livet, J.; Weissman, T. A.; Kang, H.; Draft, R. W.; Lu, J.; Bennis, R. A.; Sanes, J. R. und Lichtman, J. W. (2007). "Transgenic strategies for combinatorial expression of fluorescent proteins in the nervous system." Nature 450(7166): 56-62.

Llopis, J.; McCaffery, J. M.; Miyawaki, A.; Farquhar, M. G. und Tsien, R. Y. (1998). "Measurement of cytosolic, mitochondrial, and Golgi $\mathrm{pH}$ in single living cells with green fluorescent proteins." Proc Natl Acad Sci U S A 95(12): 6803-6808.

Lottspeich, F. und Zorbas, H. (1998). Bioanalytik, Spektrum Akademischer Verlag.

Lukyanov, K. A.; Chudakov, D. M.; Lukyanov, S. und Verkhusha, V. V. (2005). "Innovation: Photoactivatable fluorescent proteins." Nat Rev Mol Cell Biol 6(11): 885-891.

Lukyanov, K. A.; Fradkov, A. F.; Gurskaya, N. G.; Matz, M. V.; Labas, Y. A.; Savitsky, A. P.; Markelov, M. L.; Zaraisky, A. G.; Zhao, X.; Fang, Y.; Tan, W. und Lukyanov, S. 
A. (2000). "Natural animal coloration can Be determined by a nonfluorescent green fluorescent protein homolog." J Biol Chem 275(34): 25879-25882.

Malo, G. D.; Wang, M.; Wu, D.; Stelling, A. L.; Tonge, P. J. und Wachter, R. M. (2008). "Crystal structure and Raman studies of dsFP483, a cyan fluorescent protein from Discosoma striata." J Mol Biol 378(4): 871-886.

Matz, M. V.; Fradkov, A. F.; Labas, Y. A.; Savitsky, A. P.; Zaraisky, A. G.; Markelov, M. L. und Lukyanov, S. A. (1999). "Fluorescent proteins from nonbioluminescent Anthozoa species." Nat Biotechnol 17(10): 969-973.

Matz, M. V.; Lukyanov, K. A. und Lukyanov, S. A. (2002). "Family of the green fluorescent protein: journey to the end of the rainbow." Bioessays 24(10): 953-959.

Merzlyak, E. M.; Goedhart, J.; Shcherbo, D.; Bulina, M. E.; Shcheglov, A. S.; Fradkov, A. F.; Gaintzeva, A.; Lukyanov, K. A.; Lukyanov, S.; Gadella, T. W. und Chudakov, D. M. (2007). "Bright monomeric red fluorescent protein with an extended fluorescence lifetime." Nat Methods 4(7): 555-557.

Mizuno, H.; Mal, T. K.; Walchli, M.; Kikuchi, A.; Fukano, T.; Ando, R.; Jeyakanthan, J.; Taka, J.; Shiro, Y.; Ikura, M. und Miyawaki, A. (2008). "Light-dependent regulation of structural flexibility in a photochromic fluorescent protein." Proc Natl Acad Sci U S A 105(27): 9227-9232.

Moerner, W. E. (2002). "A dozen years of single-molecule spectroscopy in physics, chemistry, and biophysics." Journal of Physical Chemistry B 106(5): 910-927.

Moerner, W. E. und Kador, L. (1989). "Optical detection and spectroscopy of single molecules in a solid." Phys Rev Lett 62(21): 2535-2538.

Moors, S. L. C.; Michielssens, S.; Flors, C.; Dedecker, P.; Hofkens, J. und Ceulemans, A. (2008). "How is cis-trans isomerization controlled in Dronpa mutants? A replica exchange molecular dynamics study." Journal of Chemical Theory and Computation 4(6): 1012-1020.

Morise, H.; Shimomura, O.; Johnson, F. H. und Winant, J. (1974). "Intermolecular energy transfer in the bioluminescent system of Aequorea." Biochemistry 13(12): 2656-2662.

Morris, R. J.; Perrakis, A. und Lamzin, V. S. (2003). "ARP/wARP and automatic interpretation of protein electron density maps." Methods Enzymol. 374: 229-244.

Mulholland, J.; Preuss, D.; Moon, A.; Wong, A.; Drubin, D. und Botstein, D. (1994). "Ultrastructure of the yeast actin cytoskeleton and its association with the plasma membrane." J Cell Biol 125(2): 381-391.

Mullis, K.; Faloona, F.; Scharf, S.; Saiki, R.; Horn, G. und Erlich, H. (1986). "Specific enzymatic amplification of DNA in vitro: the polymerase chain reaction." Cold Spring Harb Symp Quant Biol 51 Pt 1: 263-273.

Murshudov, G. N.; Vagin, A. A. und Dodson, E. J. (1997). "Refinement of macromolecular structures by the maximum-likelihood method." cta Crystallogr. Sect. D Biol. Crystallogr. 53: 240-255.

Niwa, H.; Inouye, S.; Hirano, T.; Matsuno, T.; Kojima, S.; Kubota, M.; Ohashi, M. und Tsuji, F. I. (1996). "Chemical nature of the light emitter of the Aequorea green fluorescent protein." Proc Natl Acad Sci U S A 93(24): 13617-13622.

Ormo, M.; Cubitt, A. B.; Kallio, K.; Gross, L. A.; Tsien, R. Y. und Remington, S. J. (1996). "Crystal structure of the Aequorea victoria green fluorescent protein." Science 273(5280): 1392-1395.

Palm, G. J.; Zdanov, A.; Gaitanaris, G. A.; Stauber, R.; Pavlakis, G. N. und Wlodawer, A. (1997). "The structural basis for spectral variations in green fluorescent protein." Nat Struct Biol 4(5): 361-365.

Patterson, G. H. und Lippincott-Schwartz, J. (2002). "A photoactivatable GFP for selective photolabeling of proteins and cells." Science 297(5588): 1873-1877. 
Peterman, E. J. G.; Brasselet, S. und Moerner, W. E. (1999). "The fluorescence dynamics of single molecules of green fluorescent protein." Journal of Physical Chemistry A 103(49): 10553-10560.

Petersen, J.; Wilmann, P. G.; Beddoe, T.; Oakley, A. J.; Devenish, R. J.; Prescott, M. und Rossjohn, J. (2003). "The 2.0-A crystal structure of eqFP611, a far red fluorescent protein from the sea anemone Entacmaea quadricolor." J Biol Chem 278(45): 4462644631.

Prasher, D. C.; Eckenrode, V. K.; Ward, W. W.; Prendergast, F. G. und Cormier, M. J. (1992). "Primary structure of the Aequorea victoria green-fluorescent protein." Gene 111(2): 229-233.

Quillin, M. L.; Anstrom, D. M.; Shu, X.; O'Leary, S.; Kallio, K.; Chudakov, D. M. und Remington, S. J. (2005). "Kindling fluorescent protein from Anemonia sulcata: darkstate structure at 1.38 A resolution." Biochemistry 44(15): 5774-5787.

Remington, S. J. (2006). "Fluorescent proteins: maturation, photochemistry and photophysics." Curr Opin Struct Biol 16(6): 714-721.

Rust, M. J.; Bates, M. und Zhuang, X. (2006). "Sub-diffraction-limit imaging by stochastic optical reconstruction microscopy (STORM)." Nat Methods 3(10): 793-795.

Saiki, R. K.; Scharf, S.; Faloona, F.; Mullis, K. B.; Horn, G. T.; Erlich, H. A. und Arnheim, N. (1985). "Enzymatic amplification of beta-globin genomic sequences and restriction site analysis for diagnosis of sickle cell anemia." Science 230(4732): 1350-1354.

Sauer, B. (1987). "Functional expression of the cre-lox site-specific recombination system in the yeast Saccharomyces cerevisiae." Mol Cell Biol 7(6): 2087-2096.

Schaefer, L. V.; Groenhof, G.; Boggio-Pasqua, M.; Robb, M. A. und Grubmuller, H. (2008).

"Chromophore protonation state controls photoswitching of the fluoroprotein asFP595." PLoS Comput Biol 4(3): e1000034.

Schaefer, L. V.; Groenhof, G.; Klingen, A. R.; Ullmann, G. M.; Boggio-Pasqua, M.; Robb, M. A. und Grubmuller, H. (2007). "Photoswitching of the fluorescent protein asFP595: mechanism, proton pathways, and absorption spectra." Angew Chem Int Ed Engl 46(4): 530-536.

Schoenle, A. (2006). Imspector Image Acquisition \& Analysis Software.

Schuettrigkeit, T., Till von Feilitzsch, Christian K. Kompa, Konstantin A. Lukyanov, Alexander P. Savitsky, Alexander A. Voityuk, Maria E. Michel-Beyerle (2006). "Femtosecond study of light-induced fluorescence increase of the dark chromoprotein asFP595." Chemical Physics 323(2-3): 149-160.

Schwentker, M. A.; Bock, H.; Hofmann, M.; Jakobs, S.; Bewersdorf, J.; Eggeling, C. und Hell, S. W. (2007). "Wide-field subdiffraction RESOLFT microscopy using fluorescent protein photoswitching." Microsc Res Tech 70(3): 269-280.

Shaner, N. C.; Lin, M. Z.; McKeown, M. R.; Steinbach, P. A.; Hazelwood, K. L.; Davidson, M. W. und Tsien, R. Y. (2008). "Improving the photostability of bright monomeric orange and red fluorescent proteins." Nat Methods 5(6): 545-551.

Shi, X.; Abbyad, P.; Shu, X.; Kallio, K.; Kanchanawong, P.; Childs, W.; Remington, S. J. und Boxer, S. G. (2007). "Ultrafast excited-state dynamics in the green fluorescent protein variant S65T/H148D. 2. Unusual photophysical properties." Biochemistry 46(43): 12014-12025.

Shimomura, O.; Johnson, F. H. und Saiga, Y. (1962). "Extraction, purification and properties of aequorin, a bioluminescent protein from the luminous hydromedusan, Aequorea." $\underline{\mathrm{J}}$ Cell Comp Physiol 59: 223-239.

Shu, X.; Shaner, N. C.; Yarbrough, C. A.; Tsien, R. Y. und Remington, S. J. (2006). "Novel chromophores and buried charges control color in mFruits." Biochemistry 45(32): 9639-9647. 
Sieber, J. J.; Willig, K. I.; Kutzner, C.; Gerding-Reimers, C.; Harke, B.; Donnert, G.; Rammner, B.; Eggeling, C.; Hell, S. W.; Grubmuller, H. und Lang, T. (2007). "Anatomy and dynamics of a supramolecular membrane protein cluster." Science 317(5841): 1072-1076.

Sniegowski, J. A.; Lappe, J. W.; Patel, H. N.; Huffman, H. A. und Wachter, R. M. (2005). "Base catalysis of chromophore formation in Arg96 and Glu222 variants of green fluorescent protein." J Biol Chem 280(28): 26248-26255.

Stiel, A. C.; Andresen, M.; Bock, H.; Hilbert, M.; Schilde, J.; Schonle, A.; Eggeling, C.; Egner, A.; Hell, S. W. und Jakobs, S. (2008). "Generation of Monomeric Reversibly Switchable Red Fluorescent Proteins for Far-Field Fluorescence Nanoscopy." Biophys J. 95(6): 2989-2997

Stiel, A. C.; Trowitzsch, S.; Weber, G.; Andresen, M.; Eggeling, C.; Hell, S. W.; Jakobs, S. und Wahl, M. C. (2007). "1.8 A bright-state structure of the reversibly switchable fluorescent protein Dronpa guides the generation of fast switching variants." Biochem J 402(1): 35-42.

Stoner-Ma, D.; Jaye, A. A.; Ronayne, K. L.; Nappa, J.; Meech, S. R. und Tonge, P. J. (2008). "An alternate proton acceptor for excited-state proton transfer in green fluorescent protein: rewiring GFP." J Am Chem Soc 130(4): 1227-1235.

Thastrup, O.; Tullin, S.; Kongsbak Poulsen, L. und Bjørn, S. (1995). Fluorescent proteins. US Patent.

Tindall, K. R. und Kunkel, T. A. (1988). "Fidelity of DNA synthesis by the Thermus aquaticus DNA polymerase." Biochemistry 27(16): 6008-6013.

Tsien, R. Y. (1998). "The green fluorescent protein." Annu Rev Biochem 67: 509-544.

Vagin, A. A. und Isupov, M. N. (2001). "Spherically averaged phased translation function and its application to the search for molecules and fragments in electron-density maps." Acta Crystallogr. Sect. D Biol. Crystallogr. 57: 1451-1456.

Voityuk, A. A.; MichelBeyerle, M. E. und Rosch, N. (1997). "Protonation effects on the chromophore of green fluorescent protein. Quantum chemical study of the absorption spectrum." Chemical Physics Letters 272(3-4): 162-167.

Voityuk, A. A.; Michel-Beyerle, M. E. und Rosch, N. (1998). "Structure and rotation barriers for ground and excited states of the isolated chromophore of the green fluorescent protein." Chemical Physics Letters 296(3-4): 269-276.

Wachter, R. M. (2007). "Chromogenic cross-link formation in green fluorescent protein." Acc Chem Res 40(2): 120-127.

Wachter, R. M.; Elsliger, M. A.; Kallio, K.; Hanson, G. T. und Remington, S. J. (1998). "Structural basis of spectral shifts in the yellow-emission variants of green fluorescent protein." Structure 6(10): 1267-1277.

Wachter, R. M.; King, B. A.; Heim, R.; Kallio, K.; Tsien, R. Y.; Boxer, S. G. und Remington, S. J. (1997). "Crystal structure and photodynamic behavior of the blue emission variant Y66H/Y145F of green fluorescent protein." Biochemistry 36(32): 9759-9765.

Wall, M. A.; Socolich, M. und Ranganathan, R. (2000). "The structural basis for red fluorescence in the tetrameric GFP homolog DsRed." Nat Struct Biol 7(12): 11331138.

Wang, L.; Jackson, W. C.; Steinbach, P. A. und Tsien, R. Y. (2004). "Evolution of new nonantibody proteins via iterative somatic hypermutation." Proc Natl Acad Sci U S A 101(48): 16745-16749.

Wang, S. und Hazelrigg, T. (1994). "Implications for bcd mRNA localization from spatial distribution of exu protein in Drosophila oogenesis." Nature 369(6479): 400-403.

Weber, W.; Helms, V.; McCammon, J. A. und Langhoff, P. W. (1999). "Shedding light on the dark and weakly fluorescent states of green fluorescent proteins." Proc Natl Acad Sci U S A 96(11): 6177-6182. 
Wood, T. I.; Barondeau, D. P.; Hitomi, C.; Kassmann, C. J.; Tainer, J. A. und Getzoff, E. D. (2005). "Defining the role of arginine 96 in green fluorescent protein fluorophore biosynthesis." Biochemistry 44(49): 16211-16220.

Wouters, F. S.; Bastiaens, P. I.; Wirtz, K. W. und Jovin, T. M. (1998). "FRET microscopy demonstrates molecular association of non-specific lipid transfer protein (nsL-TP) with fatty acid oxidation enzymes in peroxisomes." Embo J 17(24): 7179-7189.

Yang, F.; Moss, L. G. und Phillips, G. N., Jr. (1996). "The molecular structure of green fluorescent protein." Nat Biotechnol 14(10): 1246-1251.

Yarbrough, D.; Wachter, R. M.; Kallio, K.; Matz, M. V. und Remington, S. J. (2001). "Refined crystal structure of DsRed, a red fluorescent protein from coral, at 2.0-A resolution." Proc Natl Acad Sci U S A 98(2): 462-467. 


\section{Anhang}

\section{IX.1 Materialien}

IX.1.1 Verwendete Vektoren

\section{IX.1.1.1 Expressionsvektoren pQE30 und pQE31}

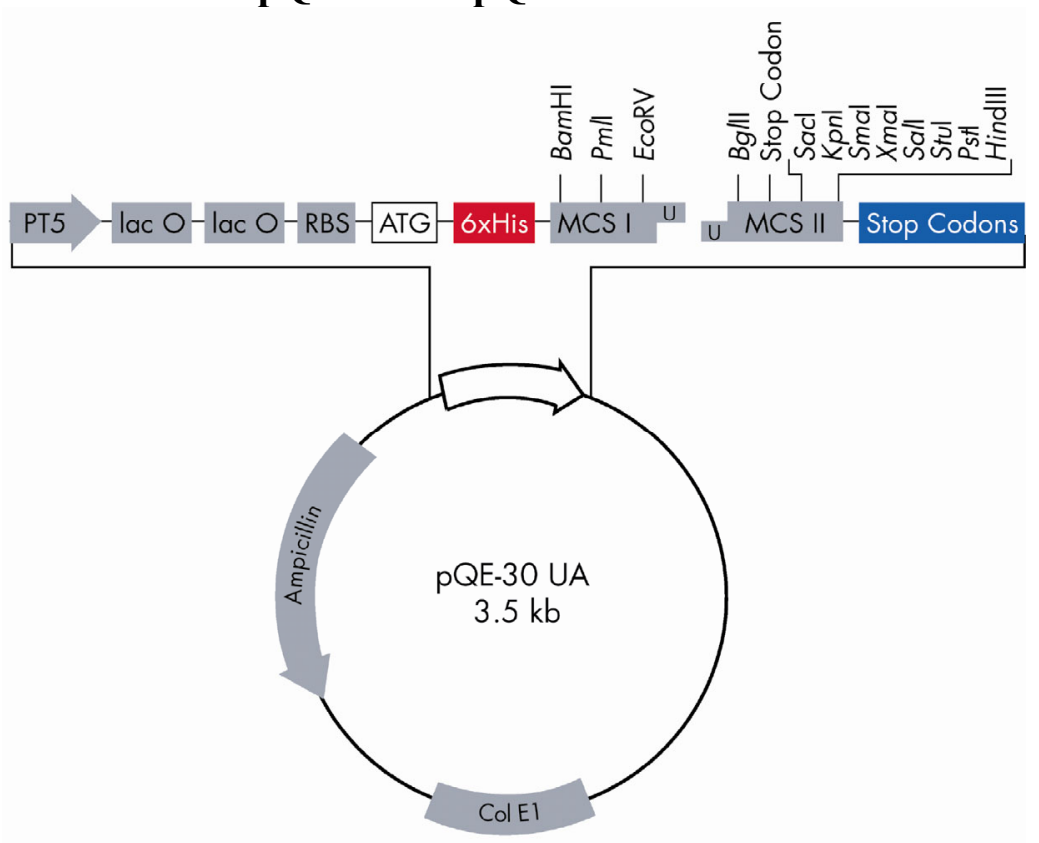

Abbildung 1: Schematische Darstellung des Vektors pQE30. Die Sequenz von pQE31 unterscheidet sich in der Sequenz von pQE30 in dem Leseraster. Zwischen der für die sechs Histidine kodierenden Sequenz (grau hinterlegt) und der Schnittstelle BamHI (blau hinterlegt) sind zusätzlich die Basen AC, welche das Leseraster in der MCS verschieben: Sequenz in pQE31: cacc atcaccatca ccatacggat cc.

\section{Klonierung in die Vektoren pQE30 und pQE31:}

Der Einbau von asFP595-Varianten in den Vektor pQE30 wurde über die zwei in der Sequenz markierten Schnittstellen BamHI und KpnI durchgeführt. Der Einbau von Dronpa-Varianten wurde über die Schnittstellen BamHI und HindIII durchgeführt. 
Sequenz von pQE-30:

1 ctcgagaaat cataaaaat ttatttgctt tgtgagcgga taacaattat aatagattca

61 attgtgagcg gataacaatt tcacacagaa

121 ggatcgcatc accatcacca tcacggatcc

181 gcagccaagc ttaattagct gagcttggac

241 aactccatct ggatttgttc agaacgctcg

301 atccaagcta gcttggcgag atttcagga

361 actggatata ccaccgttga tatatcccaa

421 cagtcagttg ctcalgtac ctatarcag

481 aagaccgtaa agaaaataa gcacaagttt

541 ctgatgaatg ctcatccgga atttcgtatg

601 gatagtgttc acccttgtta caccgttte

661 tggagtgaat accacgacga tttccggcag

721 tgttacggtg aaaacctggc ctatttccct

781 tcagccaatc cctgggtgag tttcaccagt

841 ttcttcgccc ccgttttcac catgggcaaa

901 ccgctggcga ttcaggttca tcatgccgtt

961 aatgaattac aacagtactg cgatgagtgg

1021 tattggtgcc cttaaacgce tggggtaatg

1081 aaaggctcag tcgaaagact gggcctttcg

1141 cctgagtagg acaatccgc cctctagagc

1201 aacctctgac acatgcagct cccggagacg

1261 agcagacaag cccgtcaggg cgcgtcagcg

1321 acccagtcac gtagcgatag cggagtgtat

1381 ttgtactgag agtgcaccat atgcggtgtg

1441 accgcatcag gcgctcttcc gcttcctcgc

1501 tgcggcgagc ggtatcagct cactcaaagg

1561 ataacgcagg aaagaacatg tgagcaaaag

1621 ccgcgttgct ggcgtttttc cataggctcc

1681 gctcaagtca gaggtggcga aacccgacag

1741 gaagctccct cgtgcgctct cctgttccga

1801 ttctccctc gggaagcgtg gcgcttect

1861 tgtaggtcgt tcgctccaag ctgggctgtg

1921 gcgccttatc cggtaactat cgtcttgagt

1981 tggcagcagc cactggtaac aggattagca

2041 tcttgaagtg gtggcctaac tacggctaca

2101 tgctgaagcc agttaccttc ggaaaaagag

2161 ccgctggtag cggtggttt tttgtttgca

2221 ctcaagaaga tccttgatc tttctacgg

2281 gttaagggat tttggtcatg agattatcaa

2341 aaaatgaag ttt aaatca atctaaagta

2401 aatgcttaat cagtgaggca cctatctcag

2461 cctgactccc cgtcgtgtag ataactacga

2521 ctgcaatgat accgcgagac ccacgctcac

2581 cagccggaag ggccgagcgc agaagtggtc

2641 ttaattgttg ccgggaagct agagtaagta

2701 ttgccattgc tacaggcatc gtggtgtcac

2761 ccggttccca acgatcaagg cgagttacat

2821 gctccttcgg tcctccgatc gttgtcagaa

2881 ttatggcagc actgcataat tctcttactg

2941 ctggtgagta ctcaaccaag tcattctgag

3001 gcccggcgtc atacgggat aataccgcgc

3061 ttggaaaacg ttcttcgggg cgaaaactct

3121 cgatgtaacc cactcgtgca cccaactgat

3181 ctgggtgagc aaaaacagga aggcaaatg

3241 aatgttgaat actcatactc ttccttttc

3301 gtctcatgag cggatacata tttgaatgta

3361 gcacatttcc ccgaaagtg ccacctgacg

3421 cctataaaa taggcgtatc acgaggccct tcattaaag aggagaaatt aactatgaga gcatgcgagc tcggtacccc gggtcgacct tcctgttgat agatccagta atgacctcag gttgccgccg ggcgttttt attggtgaga gctaaggaag ctaaaatgga gaaaaaatc tggcatcgta aagaacattt tgaggcattt accgttcagc tggatattac ggcctttta tatccggcet ttattcacat tcttgcccgc gcaatgaaag acggtgagct ggtgatatgg catgagcaaa ctgaaacgtt ttcatcgctc tttctacaca tatattcgca agatgtggcg aaagggttta ttgagaatat gtttttcgtc tttgatttaa acgtggccaa tatggacaac tattatacgc aaggcgacaa ggtgctgatg tgtgatggct tccatgtcgg cagaatgctt cagggcgggg cgtaatttt ttaaggcagt actctctagc ttgaggcatc aaataaacg ttttatctgt tgtttgtcgg tgaacgctct tgcctcgcge gtttcggtga tgacggtgaa gtcacagctt gtctgtaagc ggatgccggg ggtgttggcg ggtgtcgggg cgcagccatg actggcttaa ctatgcggca tcagagcaga aaataccgca cagatgcgta aggagaaaat tcactgactc gctgcgctcg gtcgttcggc cggtaatacg gttatccaca gaatcagggg gccagcaaaa ggccaggaac cgtaaaaagg gcccccctga cgagcatcac aaaatcgac gactataaag ataccaggcg tttccccctg ccctgccgct taccggatac ctgtccgcct atagctcacg ctgtaggtat ctcagttcgg tgcacgaacc ccccgttcag cccgaccget ccaacccggt aagacacgac ttatcgccac gagcgaggta tgtaggcggt gctacagagt ctagaaggac agtatttggt atctgcgctc ttggtagctc ttgatccggc aaacaaacca agcagcagat tacgcgcaga aaaaaggat ggtctgacgc tcagtggaac gaaaactcac aargatctt cacctagatc ctttaaat tatatgagta aacttggtct gacagttacc cgatctgtct atttcgttca tccatagttg tacgggaggg cttaccatct ggccccagtg cggctccaga tttatcagca ataaaccagc ctgcaacttt atccgcctcc atccagtcta gttcgccagt taatagtttg cgcaacgttg gctcgtcgtt tggtatggct tcattcagct gatcccccat gttgtgcaaa aagcggtta gtaagttggc cgcagtgtta tcactcatgg tcatgccatc cgtaagatgc ttttctgtga aatagtgtat gcggcgaccg agttgctctt cacatagcag aacttaaa gtgctcatca caaggatctt accgctgttg agatccagtt cttcagcatc ttttacttc accagcgtt ccgcaaaaa gggaataagg gcgacacgga aatattattg aagcatttat cagggttatt tttagaaaa taaacaaata ggggttccgc tctaagaaac cattattatc atgacattaa ttcgtcttca c 


\section{IX.1.1.2 Expressionsvektor M13-GFP}

\begin{tabular}{|c|c|}
\hline T7 promoter & $370-386$ \\
\hline $\mathrm{T} 7$ transcription start & 369 \\
\hline His $\cdot$ Tag coding sequence & $270-287$ \\
\hline $\mathrm{T} 7 \cdot \mathrm{Tag}$ coding sequence & $207-239$ \\
\hline Multiple cloning sites & \\
\hline$(B a m H \mathrm{I}-X h o \mathrm{I})$ & $158-203$ \\
\hline His $\cdot$ Tag coding sequence & $140-157$ \\
\hline T7 terminator & $26-72$ \\
\hline lacI coding sequence & $773-1852$ \\
\hline pBR322 origin & 3286 \\
\hline Kan coding sequence & $3995-4807$ \\
\hline f1 origin & $4903-5358$ \\
\hline \multicolumn{2}{|c|}{$\begin{array}{l}\text { The maps for pET-28b }(+) \text { and pET-28c }(+) \\
\text { are the same as pET-28a (+) (shown) with } \\
\text { the following exceptions: pET-28b (+) is a } \\
5368 \text { bp plasmid; subtract } 1 \mathrm{bp} \text { from each site } \\
\text { beyond BamH I at 198. pET-28c (+) is a } \\
5367 \mathrm{bp} \text { plasmid; subtract } 2 \mathrm{bp} \text { from each site } \\
\text { beyond BamH I at } 198 \text {. }\end{array}$} \\
\hline
\end{tabular}

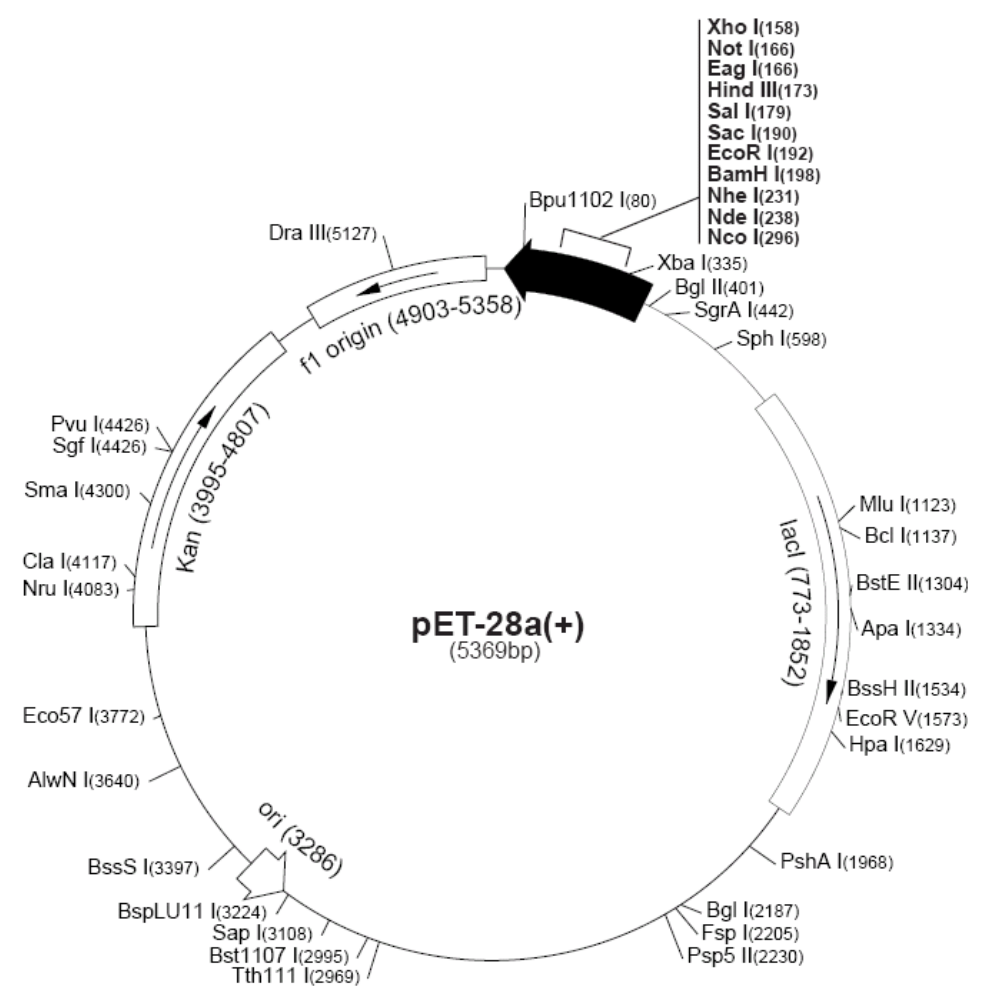

Abbildung 2: Vektorkarte von pET-28a(+). Der Ursprung des Vektors M13-GFP ist eine Variante des Vektors pET28(a+) (Waldo et al. 1999), in den die Sequenz für das M13 procoat Protein des Bakteriophagen M13 eingebracht wurde (Drew et al. 2001).

\section{Klonierung von M13-Dronpa-Varianten:}

Die Plasmide der M13-Dronpa-Varianten wurden erstellt, indem der Vektor M13-GFP (Drew et al. 2001) mit den Restriktionsenzymen EcoRI und XhoI geschnitten und die für eine Dronpa-Variante kodierende DNS-Sequenz eingefügt wurde. An die DNS-Sequenz wurden die entsprechenden Schnittstellen über eine PCR mit den Primern Dronpa-EcoRI-for und Dronpa-XhoI-rev angefügt (Tabelle 1).

Das resultierende Konstrukt hat auf der DNS-Ebene den folgenden Aufbau:

M13-Sequenz - BamHI - Verbindungssequenz - EcoRI - GFP - XhoI

M13-Sequenz - GGATCC GCTGGCTCCGCTGCTGGTTCTGGC GAATTC - RSFP - CTCGAG

_ $=$ Erkennungssequenz für Restriktionsenzyme

_ $=$ Verbindungssequenz 
IX.1.1.3 Hefe-Vektoren
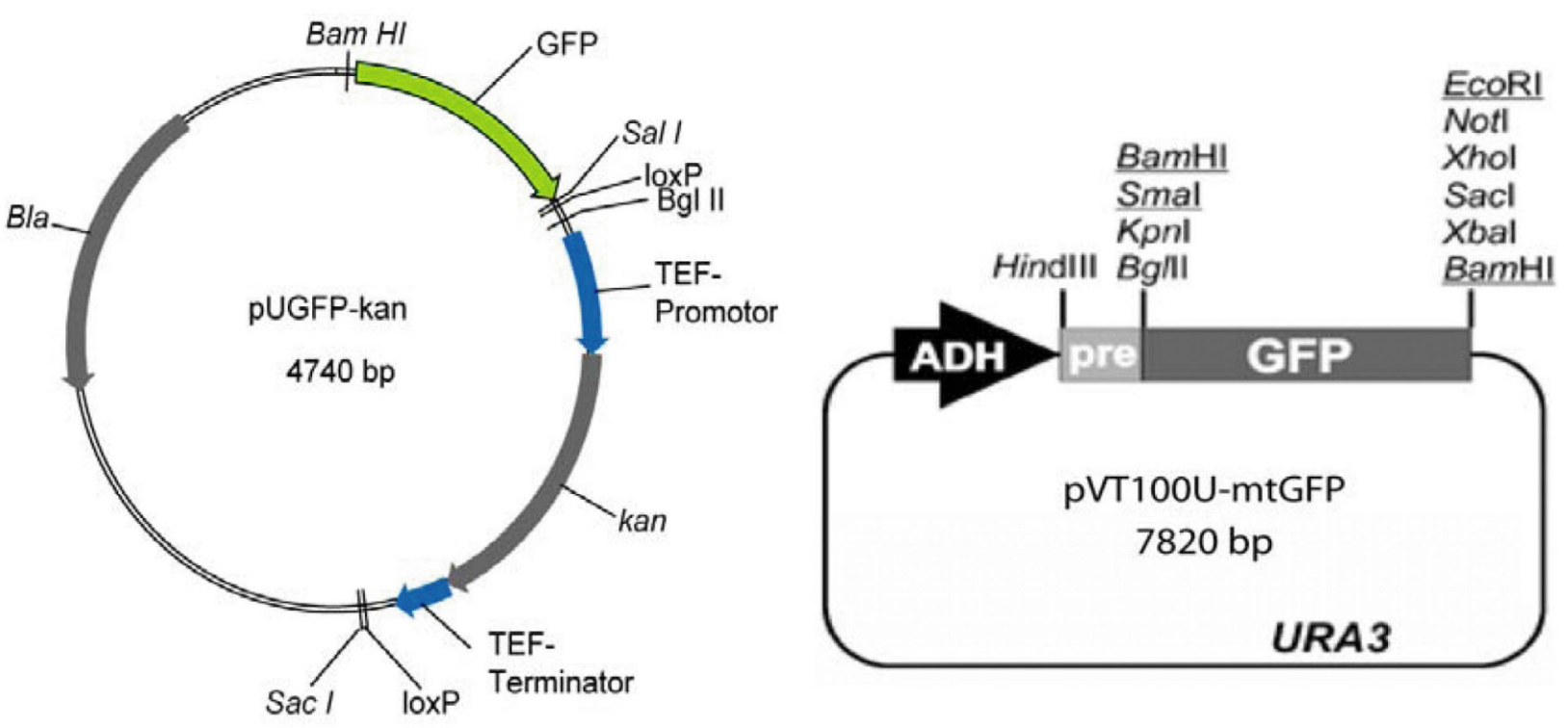

Abbildung 3: Die Vektoren pUGFP-kan und pVT100U-mtGFP wurden als Ursprung für die Expression der RSFPs in Hefen benutzt.

\section{Klonierung in den Vektor pUGFP-kan:}

Die DNS-Sequenzen der RSFPs wurden über die Schnittstellen BamHI und SalI in den Vektor pUGFP-kan eingebaut.

\section{Klonierung in den Vektor pVT100U-mtGFP:}

Die für die RSFPs kodierenden DNS-Sequenzen wurden in den Vektor pVT100U-mtGFP über die Schnittstellen KpnI und XhoI eingebaut. 
IX.1.2 Auswahl der verwendeten Oligonucleotide

\begin{tabular}{|c|c|}
\hline \multicolumn{2}{|r|}{ Zufällige ortsgerichtete Mutagenese von asFP595 } \\
\hline asCP-T60X-S & TTTGCCTTCCACATTTTGTCANNNAGTTGTATGTACGGTAGTAAG \\
\hline asCP-T60X-AS & CTTACTACCGTACATACAACTNNNTGACAAAATGTGGAAGGCAAA \\
\hline asCP-K67X-for & CGAGTTGTATGTACGGTAGTNNNACCTTCATCAAGTATGTGTC \\
\hline asCP-K67X-rev & GACACATACTTGATGAAGGTNNNACTACCGTACATACAACTCG \\
\hline asCP-R92X-S & CTGAAGGTTTTACTTGGGAANNNACCACAACCTACGAGGATGG \\
\hline asCP-R92X-AS & CCATCCTCGTAGGTTGTGGTNNNTTCCCAAGTAAAACCTTCAG \\
\hline asCP-A143X-S & AAGCAGGAAGATGGGAGCCANNNACCGAGATAGTTTATGAAGT \\
\hline asCP-A143X-AS & АCTTCATAAACTATCTCGGTNNNTGGCTCCCATCTTCCTGCTT \\
\hline asCP-E145X-S & TGGGAGCCAGCCACCNNNATAGTTTATGAAGTTGACG \\
\hline asCP-E145X-AS & CGTCAACTTCATAAACTATNNNGGTGGCTGGCTCCCA \\
\hline asCP-S158X-S & ACGGTGTCCTGCGTGGACAGNNNTTGATGGCCCTTAAGTGCCC \\
\hline asCP-S158X-AS & GGGCACTTAAGGGCCATCAANNNCTGTCCACGCAGGACACCGT \\
\hline asCP M160X-f & CCTGCGTGGACAGTCTTTGNNNGCCCTTAAGTGCCCTGGTG \\
\hline asCP M160X-r & CACCAGGGCACTTAAGGGCNNNCAAAGACTGTCCACGCAGG \\
\hline asCP L174X-f & TCGTCATCTGACTTGCCATNNNCATACTACTTACAGGTCCA \\
\hline asCP L174X-r & TGGACCTGTAAGTAGTATGNNNATGGCAAGTCAGATGACGA \\
\hline asCP-T176X-S & CTGACTTGCCATCTCCATNNNACTTACAGGTCCAAAAAACC \\
\hline asCP-T176X-AS & GGTTTTTTGGACCTGTAAGTNNNATGGAGATGGCAAGTCAG \\
\hline asCP-Y178X-S & ACTTGCCATCTCCATACTACTNNNAGGTCCAAAAAACCAGCTAGT \\
\hline asCP-Y178X-AS & ACTAGCTGGTTTTTTGGACCTNNNAGTAGTATGGAGATGGCAAGT \\
\hline asCP-E195X-S & TGCCAGGATTTCATTTTNNNGATCATCGCATCGAG \\
\hline asCP-E195X-AS & CTCGATGCGATGATCNNNAAAATGAAATCCTGGCA \\
\hline asCP-H197X-for & CCAGGATTTCATTTTGAAGATNNNCGCATCGAGATAATGGAGGAAG \\
\hline asCP-H197X-rev & CTTCCTCCATTATCTCGATGCGNNNATCTTCAAAATGAAATCCTGG \\
\hline asCP-I199X-S & GGATTTCATTTTGAAGATCATCGCNNNGAGATAATGGAGGAAGTTGAGA \\
\hline asCP-I199X-AS & TCTCAACTTCCTCCATTATCTCNNNGCGATGATCTTCAAAATGAAATCC \\
\hline asCP-E215X-S & GTGCTATAAACAGTACNNNGCAGCAGTGGGC \\
\hline asCP-E215X-AS & GCCCACTGCTGCNNNGTACTGTTTATAGCAC \\
\hline \multicolumn{2}{|r|}{ Zufallsmutagenese von asFP595 } \\
\hline asCP-mutpQE-f & CACCATCACCATCACGGATCC \\
\hline asCP-mutpQE-r & GCAGGGGTACCCCTTGGGAGCGGCTTGTATC \\
\hline \multicolumn{2}{|r|}{ Zufallsmutagenese von Dronpa } \\
\hline EP-pQE31-Dr-for & CACCATCACCATACGGATCCA \\
\hline EP-pQE31-Dr-rev & GCTAATTAAGCTTCGAATTCTTA \\
\hline \multicolumn{2}{|r|}{ Zur Sequenzierung verwendete Oligonukleotide } \\
\hline pQE-3x-Seq-5' & CGGATAACAATTTCACACAG \\
\hline pQE-3x-Seq-3' & CGAGCGTTCTGAACAAATCC \\
\hline T7 (MWG) & TAATACGACTCACTATAGGG \\
\hline M13 uni-21(MWG) & TGTAAAACGACGGCCAGT \\
\hline
\end{tabular}




\begin{tabular}{|l|l|}
\hline \multicolumn{2}{|c|}{ Klonierung von Säuger-Expressionsplasmiden } \\
\hline Dronpa-ER vorne & CTGCAGGTCGACATGAGTGTGATTAAACCAGA \\
\hline Dronpa-ER hinten & TTCTGCGGCCGCCTTGGCCTGCCTCGGCAGCTCAGAATGCGCTT \\
\hline \multicolumn{2}{|c|}{ Klonierung von Dronpa-Varianten in pVT100U-mtGFP } \\
\hline Dronpa-rev-XhoI & ACGCACTCGAGTTACTTGGCCTGCCTCGGCA \\
\hline Dronpa-for-KpnI & ACGCAGGTACCATGAGTGTGATTAAACCAGAC \\
\hline \multicolumn{2}{|c|}{ Klonierung von Dronpa-Vairanten in M13-GFP } \\
\hline Dronpa-EcoRI-for & GCGGAA TTCAGTGTGATTAAACCAGACATG \\
\hline Dronpa-XhoI-rev & AGCGCTCGAGTTACTTGGCCTGCCTCGGC \\
\hline \multicolumn{2}{|c|}{ Oligonukleotide für das Markieren von Abp1 in S.cerevisiae } \\
\hline Abp1-tag-for & $\begin{array}{l}\text { GCTCAAAAGGTCTCTTCCCCAGCAATTATGTGTCTTTGGGCAACGGATCCTCTGGATG } \\
\text { TTGTCCT }\end{array}$ \\
\hline Abp1-tag-rev & CAGTGTTGTTTTATGTTCGAGGTTTTGACAACGCCACTATAGGGAGACCGGCAG \\
\hline
\end{tabular}

Tabelle 1: Auswahl der verwendeten Oligonukleotide 


\section{IX.1.3 Auswahl generierter RSFPs}

Sequenz rsFastLime (PubMed GI:157805406)

1 atgagtgtga ttaaaccaga catgaagatc aagctgcgta tggaaggcgc tgtaaatgga

61 cacccgttcg cgattgaagg agttggcctt gggaagcctt tcgagggaaa acagagtatg

121 gaccttaaag tcaaagaagg cggacctctg cctttcgcct atgacatctt gacaactgtg

181 ttctgttacg gcaacagggt attcgccaaa tacccagaaa atatagtaga ctatttcaag

241 cagtcgtttc ctgagggcta ctcttgggaa cgaagcatga attacgaaga cgggggcatt

301 tgtaacgcga caaacgacat aaccctggat ggtgactgtt atatctatga aattcgattt

361 gatggtgtga actttcctgc caatggtcca gttatgcaga agaggactgt gaaatgggag

421 ccatccactg agaaattgta tgtgcgtgat ggagtgctga agggtgatgg taacatggct

481 ctgtcgcttg aaggaggtgg ccattaccga tgtgacttca aaactactta taaagctaag

541 aaggttgtcc agttgccaga ctatcacttt gtggaccacc acattgagat taaaagccac

601 gacaaagatt acagtaatgt taatctgcat gagcatgccg aagcgcattc tgagctgccg

661 aggcaggcca agtaa

Sequenz Padron:

1 atgagtgtga ttaaaccaga catgaagatc aagctgcgta tggaaggcgc tgtaaatgga

61 cacccgttcg cgattgaagg agttggcctt gggaagcctt tcgagggaaa acagagtatg

121 gaccttaaag tcaaagaagg cggacctctg cctttcgcct atgacatctt gacaatggcg

181 ttctgttacg gcaacagggt attcgccaaa tacccagaaa atatagtaga ctatttcaag

241 cagtcgtttc ctgagggcta ctcttgggaa cgaagcatga tttacgaaga cgggggcatt

301 tgtaacgcga caaacgacat aaccctggat ggtgactgtt atatctatga aattcgattt

361 gatggtgtga actttcctgc caatggtcca gttatgcaga agaggactgt gaaatgggag

421 ctatccactg agaaattgta tgtgcgtgat ggagtgctga agtctgatgg taactacgct

481 ctgtcgcttg aaggaggtgg ccattaccga tgtgacttca aaactactta taaagctaag

541 aaggttgtcc agttgccaga ctatcactct gtggaccacc acattgagat taaaagccac

601 gacaaagatt acagtaatgt taatctgcat gagcatgccg aagcgcattc tgagctgccg

661 aggcaggcca agtaa

Sequenz Padron*:

1 atgagtgtga ttaaaccaga catgaagatc aagctgcgta tggaaggcgc tgtaaatgga

61 caccogttcg cgattgaagg agttggcctt gggaagcctt tcgagggaaa acagagtatg

121 gaccttaaag tcaaagaagg cggacctctg cctttcgcct atgacatctt gacaatggcg

181 ttctgttacg gcaacagggt attcgccaaa tacccagaaa atatagtaga ctatttcaag

241 cagtcgtttc ctgagggcta ctcttgggag cgaagcatgc attacgaaga cgggggctca

301 tgtaacgcga caaacgacat aaccctggat ggtgactgtt atatctatga aattcgattt

361 gatggcgtga actttcctgc caatggtcca gttatgcaga agaggactgt gaaatgggag

421 cggtccactg agaaattgta tgtgcgtgat ggagtgctga agtctgatgg taactacgct

481 ctgtcgcttg aaggaggtgg ccattaccga tgtgacttca aaactactta taaagctaag

541 aaggttgtcc agttgccaga ctatcactct gtggaccacc acattgagat taaaagccac

601 gacaaagatt acagtaatgt taatctgcat gagcatgccg aagcgcattc tgagctgcc

661 aggcaggcca agtaa

Sequenz bsDronpa:

1 atgagtgtga ttaaaccaga catgaagatc aagctgcgta tggaaggcgc tgtaaatgga 61 cacccgttcg cgattgaagg agttggcctt gggaagcctt tcgagggaaa acagagtatg 121 gaccttaaag tcaaagaagg cggacctctg cctttcgcct atgacatctt gacaactgcg 181 ttctgttacg gcaacagggt attcaccaaa tacccagaaa atatagtaga ctatttcaag 241 cagtcgtttc ctgagggcta ctcttgggaa cgaagcatga attacgaaga cgggggcatt 301 tgtaacgcga caaacgacat aaccctggat ggtaactgtt atatctatga aattcgattt 361 gatggtgtga actttcctgc caatggtcca gttatgcaga agaggactgt gaaatgggag 
421 caatccactg agaaattgta tgtgcgtgat ggagtgctga agtctgatgg taactgcgct 481 ctgtcgcttg aaggtggtgg ccattaccga tgtgactgca aaactactta taaagctaag 541 aaggttgtcc agttgccaga ctatcacttt gtggaccacc acattgagat taaaagccac 601 gacaaagatt acagtaatgt taatctgcat gagcatgccg aagcgcattc tgagctgccg 661 aggcaggcca agtaa

Sequenz von asFP595 A143G-L174M:

1 atggcttcct ttttaaagaa gactatgccc tttaagacga ccattgaagg gacggttaat 61 ggccactact tcaagtgtac aggaaaagga gagggcaacc catttgaggg tacgcaggaa 121 atgaagatag aggtcatcga aggaggtcca ttgccatttg ccttccacat tttgtcaacg 181 agttgtatgt acggtagtaa gaccttcatc aagtatgtgt caggaattcc tgactacttc 241 aagcagtctt tccctgaagg ttttacttgg gaaagaacca caacctacga ggatggaggc 301 tttcttacag ctcatcagga cacaagccta gatggagatt gcctcgttta caaggtcaag 361 attcttggta ataattttcc tgctgatggc cccgtgatgc agaacaaagc aggaagatgg 421 gagccaggca ccgagatagt ttatgaagtt gacggtgtcc tgcgtggaca gtctttgatg 481 gcccttaagt gccctggtgg tcgtcatctg acttgccata tgcatactac ttacaggtcc 541 aaaaaccag ctagtgcctt gaagatgcca ggatttcatt ttgaagatca tcgcatcgag 601 ataatggagg aagttgagaa aggcaagtgc tataaacagt acgaagcagc agtgggcagg 661 tactgtgatg ctgctccatc caagcttgga cataactaa

Sequenz des asFP595-Monomers:

1 atggcttcct ttttaaagaa gactatgccc tttaaggcga ccattgaagg gacggttaat 61 ggccactact tcaagtgtac aggaaaagga gagggcaacc catttgaggg tacgcaggaa 121 atgaagatag aggtcatcga aggaggtcca ttgccatttg ccttccacat tctgtcaacg 181 agctgtatgt acggtagtaa ggccttcatc aagtatgcat caggaattcc tgactacttc 241 aagcagtctt tccctgaagg ttttacatgg tcaagaacca caacctacga ggatggaggc 301 tttcttacag cccaccagga cacaagccta gatggagatt gcctcgttta caaggtcaag 361 attcatggta ataattttcc tgctgatggc cccgtgatgc agaacaaagc aggaggttgg 421 gagccatgca ccgagaatgt ttatgtagtt gacggtgtcc tgcgtggaca gtctcatatg 481 gcccttaagt gccctggtgg tcgttatctg acttgccatc tccatactac ttacaggtcc 541 aaaaaccag ctagtgcctt gaagatgcca ggatttcatt ttgtagatca tcgcatcgag 601 ataatggagg aagttgagat aggcaagtgc tataaactgt acgaagcagc agtgggccgg 661 tactga 


\section{IX.2 Ergebnisse im Anhang}

IX.2.1 Darstellung der Interaktionen des Chromophors von Dronpa im ein- und ausgeschalteten Zustand
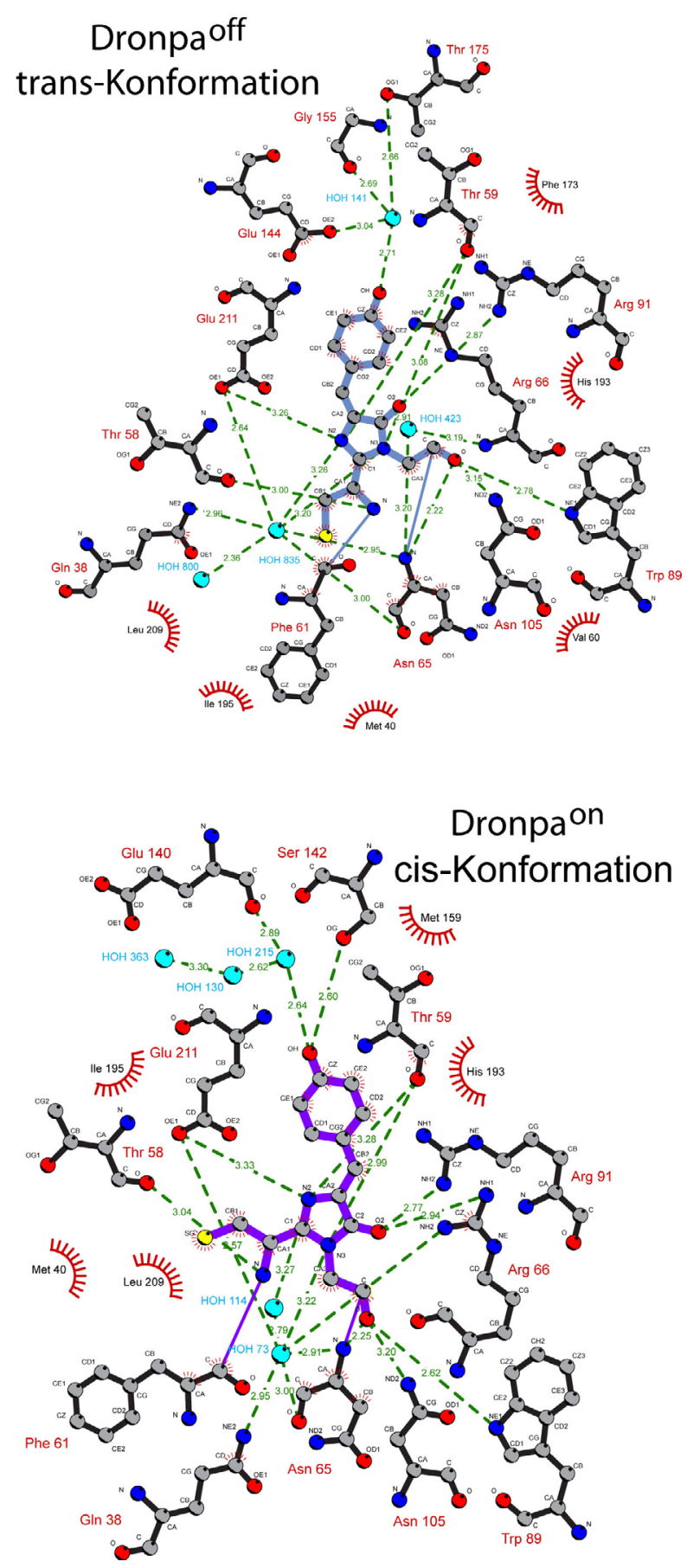

Abbildung 4: Ligplot der Strukturen Dronpa ${ }^{\text {on }}$ und Dronpa $^{\text {off }}$. Potentielle Wasserstoffbrücken sind als grüne gestrichelte Linien eingezeichnet. In der fluoreszierenden cis-Konformation der Struktur Dronpa $^{\text {on }}$ wird das Chromophor von zwei Wasserstoffbrückenbindungen mehr fixiert als in der nicht fluoreszierenden trans-Konformation von Dronpa ${ }^{\text {off }}$. Besonders die Stabilisierung des beweglichen Hydroxyphenylrings ist vermutlich für eine bessere Stabilisierung verantwortlich. 


\section{IX.2.2 Schalt- und $\mathrm{pH}-$ Spektren von Dronpa}

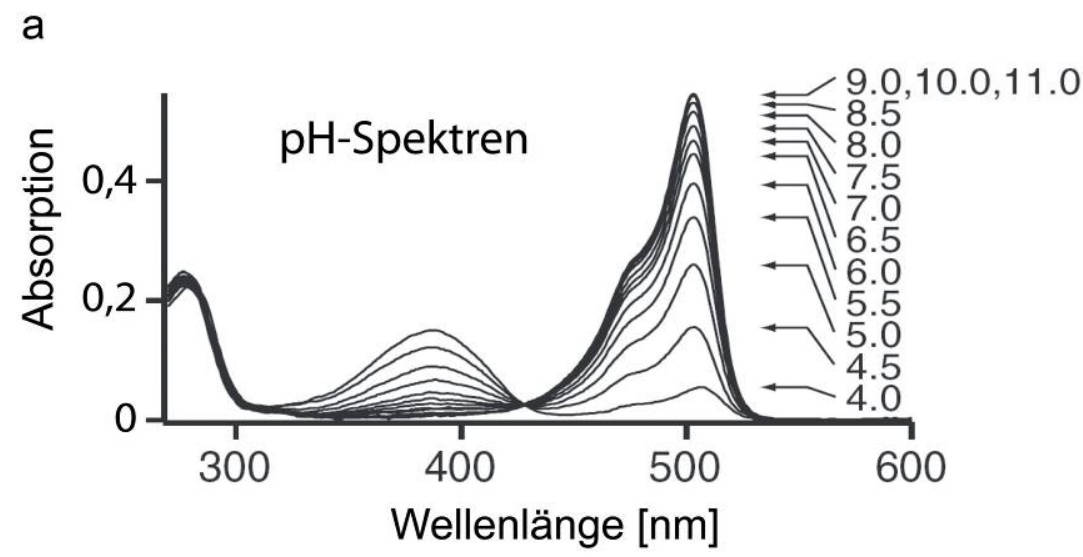

b

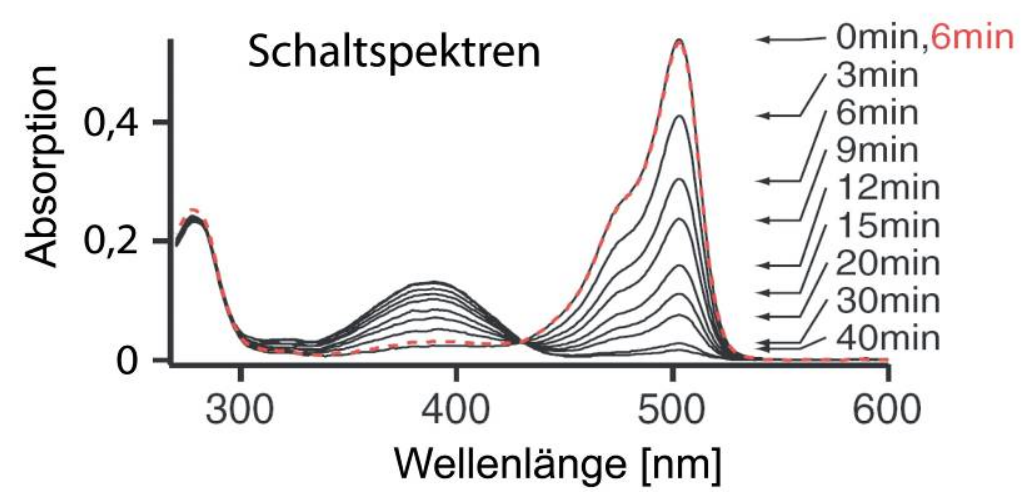

Abbildung 5: Spektren des Proteins Dronpa bei verschiedenen pH-Werten bzw. nach Belichtung mit $400 \mathrm{~nm}$ (in rot) oder $490 \mathrm{~nm}$ (schwarz) für die angegebene Zeit (Daten: Ando et al. Science 2004). Das durch die Belichtung hervorgerufene Schalten führt, wie auch die Änderung des pH-Werts, zu einer Änderung der Absorption, also zu einem verschobenen Protonierungsgleichgewicht. Da die Protonierung am Imidazolring keine Verschiebung des Spektrums um etwa $100 \mathrm{~nm}$ bewirkt, muss es sich um die Protonierung des Hydroxyphenylrings handeln, die hier beobachtet wird. 
IX.2.3 Bleichverhalten in der monochromatischen Mehrfarben-Mikroskopie in Hefezellen

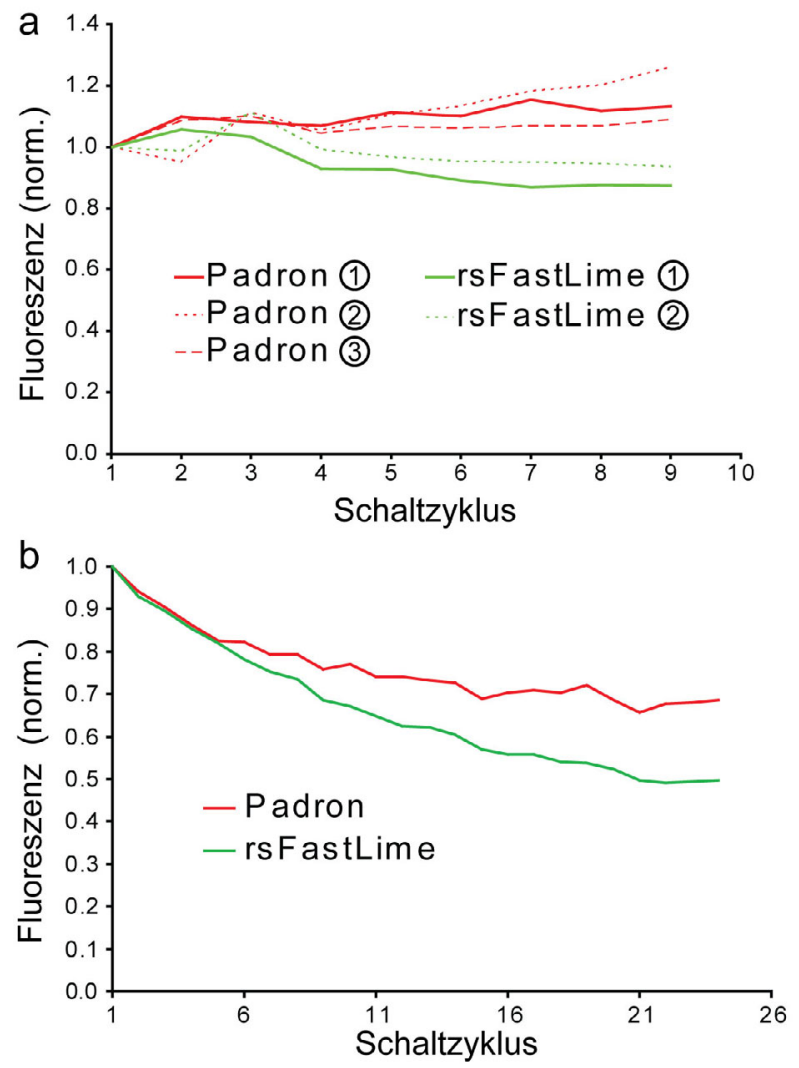

Abbildung 6: Abnahme des Fluoreszenzsignals (Bleichen) bei der monochromatischen Mehrfarben-Mikroskopie. Die auf der x-Achse dargestellte Fluoreszenz berechnet sich aus der Summe des detektierten Fluoreszenzsignals einer Gruppe von lebenden, wachsenden Hefezellen. Die Hintergrundfluoreszenz wurde vor der Berechnung des gesamten Fluoreszenzsignals abgezogen und direkt außerhalb der Zellen bestimmt. Jeder Schaltzyklus entspricht der Aufnahme eines Bilderstapels. In (a) ist das Bleichen von rsFastLime und Padron bei der Aufnahme eines Bilderstapels alle 20 Minuten aufgetragen. Bei Padron wurden drei Gruppen ausgewertet und bei rsFastLime nur zwei, da sich bei einer der Gruppen das Fluoreszenzsignal in der Sättigung befand. In (b) wurden die einzelnen Bilderstapel direkt aufeinanderfolgend aufgenommen.

Bei der Aufnahme eines Bilderstapels alle 20 Minuten ist kaum Bleichen erkennbar, während bei direkt aufeinanderfolgender Aufnahme die Proteine rsFastLime bzw. Padron ein Bleichen von etwa $3,5 \%$ bzw. $2 \%$ zeigen. Das Bleichen wird durch die Synthese neuer fluoreszierender Proteine in den 20 Minuten zwischen jedem Bild ausgeglichen. 
IX.2.4 Mutantenstudien von asFP595

IX.2.4.1 Eigenschaften der Einzelmutanten von asFP595

\begin{tabular}{|c|c|c|c|c|c|}
\hline Mutante & $\begin{array}{c}\text { Helligkeit } \\
(\text { asFP595=1) }\end{array}$ & $t_{1 / 2}$ off & $\begin{array}{c}\text { Restfluo- } \\
\text { reszenz [\%] }\end{array}$ & $\mathbf{t}_{1 / 2}^{\text {relax }}$ & $\begin{array}{c}\text { Grundzustand } \\
{[\%]} \\
\end{array}$ \\
\hline asFP595 & 1,00 & 6,04 & 3,64 & 6,73 & 1 \\
\hline KFP & 14,14 & 15,83 & 0,50 & n.d. & 1 \\
\hline \multicolumn{6}{|l|}{ Sterischer Cluster } \\
\hline T60S & 0,30 & 1,00 & 10,19 & 2,55 & 2 \\
\hline T60C & 0,47 & 1,50 & 26,16 & 4,67 & 6 \\
\hline T60N & 4,06 & 1,25 & 8,10 & 4,92 & 6 \\
\hline \multicolumn{6}{|c|}{ kein Schalten aber gefärbt: T60A, T60V } \\
\hline \multicolumn{6}{|c|}{ ungefaltet: T60P, T60E, T60K, T60R } \\
\hline M160A & 10,00 & 1,10 & 10,90 & n.d. & 33 \\
\hline M160V & 1,65 & 0,55 & 13,83 & 3,78 & 3 \\
\hline $\mathrm{M} 160 \mathrm{~L}$ & 13,86 & 1,29 & 1,25 & 4,89 & 1 \\
\hline M160Q & 8,31 & 1,49 & 1,52 & 9,87 & 2 \\
\hline \multicolumn{6}{|c|}{ ungefaltet: M160S, M160D } \\
\hline L174T & 0,64 & 0,27 & 43,09 & n.d. & 195 \\
\hline L174M & 38,92 & 1,39 & 0,33 & 7,41 & 1 \\
\hline L174F & 8,85 & 0,35 & 9,95 & 4,96 & 10 \\
\hline L174Q & 3,49 & 0,47 & 5,00 & 1,96 & 1 \\
\hline \multicolumn{6}{|c|}{ kein Schalten aber gefärbt: L174A, L174V, L174N } \\
\hline \multicolumn{6}{|c|}{ ungefaltet: L174A, L174V, L174T, L174N, L174H } \\
\hline I199A & 0,66 & 0,49 & 51,66 & 0,51 & 32 \\
\hline I199V & 2,14 & 3,69 & 2,34 & 6,14 & 0 \\
\hline I199S & 1,72 & 1,74 & 28,90 & 6,49 & 14 \\
\hline I199N & 1,14 & 5,59 & 4,11 & 6,50 & 2 \\
\hline $\mathrm{I} 199 \mathrm{H}$ & 0,44 & 0,52 & 49,38 & 0,52 & 14 \\
\hline \multicolumn{6}{|c|}{ ungefaltet: I199E, I199K } \\
\hline \multicolumn{6}{|c|}{ Stabilisierungscluster } \\
\hline A143G & 14,70 & 19,25 & 0,41 & n.d. & 1 \\
\hline A143S & 33,25 & 4,75 & 3,57 & n.d. & 77 \\
\hline A143C & 0,09 & 13,81 & 74,72 & 10,93 & 0 \\
\hline \multicolumn{6}{|l|}{ ungefaltet: A143D } \\
\hline S158A & 8,42 & 1,11 & 12,56 & 5,75 & 14 \\
\hline S158V & 8,49 & 0,39 & 75,49 & n.d. & 378 \\
\hline S158T & 1,57 & 0,84 & 27,46 & 3,09 & 27 \\
\hline S158C & 2,14 & 3,49 & 24,13 & n.d. & 59 \\
\hline \multicolumn{6}{|c|}{ ungefaltet: S158L, S158R } \\
\hline \multicolumn{6}{|l|}{ trans-Cluster } \\
\hline \multicolumn{6}{|c|}{ misfolded: R92I, R92P, R92T, R92Q, R92K } \\
\hline T176A & 6,47 & 2,46 & 1,41 & 4,20 & 5 \\
\hline T176S & 4,39 & 6,88 & 1,46 & 9,40 & 0 \\
\hline \multicolumn{6}{|c|}{ ungefaltet: T176L, T176Y, T176N, T176R } \\
\hline \multicolumn{6}{|c|}{ ungefaltet: Y178I, Y178S, Y178M, Y178K } \\
\hline \multicolumn{6}{|c|}{ Histidin-Cluster } \\
\hline E195A & 1,28 & 9,41 & 9,40 & n.d. & 3 \\
\hline E195V & 3,61 & 5,47 & 9,85 & n.d. & 1 \\
\hline
\end{tabular}




\begin{tabular}{|l|c|c|c|c|c|}
\hline E195L & 1,06 & 2,08 & 43,20 & n.d. & 11 \\
\hline E195I & 2,63 & 5,85 & 14,28 & n.d. & 2 \\
\hline E195T & 4,96 & 7,61 & 3,39 & n.d. & 0 \\
\hline E195F & 1,59 & 9,97 & 16,22 & n.d. & 15 \\
\hline H197R & 17,98 & 0,76 & 68,17 & n.d. & 30 \\
\hline kein Schalten aber gefärbt: H197A, H197T \\
\begin{tabular}{l} 
Peripheriecluster \\
\hline Y72H \\
\hline K81E
\end{tabular}$\quad 3,10$ & 6,82 & 8,35 & n.d. & 19 \\
\hline T89I & 3,84 & 8,13 & 2,04 & n.d. & 2 \\
\hline N125D & 1,11 & 5,62 & 3,68 & 7,26 & 0 \\
\hline A161S & 7,64 & 5,69 & 0,55 & 8,15 & 0 \\
\hline H175D & 3,44 & 4,93 & 1,78 & 8,40 & 1 \\
\hline M189V & 3,25 & 6,92 & 0,95 & 8,26 & 1 \\
\hline H193D & 1,37 & 5,08 & 2,74 & 5,55 & 0 \\
\hline V218A & 1,08 & 4,82 & 2,79 & 5,88 & 1 \\
\hline S227F & 3,69 & 5,00 & 1,65 & 6,01 & 1 \\
\hline S227Y & 1,08 & 9,36 & 5,56 & n.d. & 4 \\
\hline
\end{tabular}

Tabelle 2: Eigenschaften der Einfachmutanten des Proteins asFP595

IX.2.4.2 Eigenschaften der Mehrfachmutanten von asFP595

\begin{tabular}{|c|c|c|c|c|c|}
\hline Mutante & $\begin{array}{c}\text { Helligkeit } \\
(\mathbf{W t}=1)\end{array}$ & $t_{1 / 2}$ off & $\begin{array}{c}\text { Restfluo- } \\
\text { reszenz [\%] }\end{array}$ & $t_{1 / 2}^{\text {relax }}$ & $\begin{array}{c}\text { Grundzustand } \\
{[\%]}\end{array}$ \\
\hline $\mathrm{Wt}$ & 1,00 & 6,04 & 3,64 & 6,73 & 1 \\
\hline KFP & 14,14 & 15,83 & 0,50 & n.d. & 1 \\
\hline \multicolumn{6}{|l|}{ Doppelmutanten } \\
\hline M63A + L174M & 5,37 & 0,73 & 7,10 & n.d. & 84 \\
\hline M63Q + L174M & 16,37 & 0,58 & 16,72 & 1,89 & 86 \\
\hline \multicolumn{6}{|c|}{ kein Schalten aber gefärbt: M63A+L174I } \\
\hline \multicolumn{6}{|c|}{ ungefaltet: M63G+L174M, M63K+L174M } \\
\hline A143G + L174M & 78,47 & 2,62 & 0,36 & n.d. & 10 \\
\hline A143G + T60A & 5,35 & 7,88 & 1,60 & n.d. & n.d. \\
\hline A143S + L174M & 148,07 & 0,68 & 11,18 & n.d. & 68 \\
\hline A143S + T176S & 49,57 & 4,90 & 5,30 & n.d. & 100 \\
\hline A143S + T60A & 12,81 & 2,63 & 8,30 & n.d. & n.d. \\
\hline M160L + T68A & 12,64 & 1,57 & 1,00 & 6,09 & 1 \\
\hline M160L + T171I & 31,32 & 1,11 & 0,46 & 4,94 & 1 \\
\hline M160L + T176S & 12,12 & 0,64 & 2,42 & 8,66 & 3 \\
\hline M160L + L174M & 26,84 & 0,30 & 2,77 & 3,71 & 10 \\
\hline M160L + L174H & 0,37 & 0,10 & 55,79 & 0,62 & 51 \\
\hline M160L + L174Q & 15,73 & 0,28 & 5,82 & 2,06 & 4 \\
\hline M160Q + L174Q & 11,98 & 0,37 & 18,47 & 3,40 & 31 \\
\hline L174M + K81E & 8,66 & 0,53 & 15,94 & n.d. & 28 \\
\hline L174M + K118N & 30,80 & 1,22 & 0,43 & 7,96 & 2 \\
\hline L174M +S158A & 21,73 & 0,19 & 47,88 & n.d. & 79 \\
\hline L174M + T176A & 13,40 & 0,24 & 15,19 & 0,55 & 73 \\
\hline L174M + T176S & 36,37 & 1,21 & 0,81 & 8,53 & 5 \\
\hline L174M + E195S & 36,66 & 1,03 & 2,15 & 5,55 & 25 \\
\hline L174M + E195T & 32,84 & 1,89 & 1,87 & n.d. & 1 \\
\hline
\end{tabular}




\begin{tabular}{|l|c|c|c|c|c|}
\hline L174M + I199V & 23,71 & 0,63 & 2,13 & 5,60 & 1 \\
\hline L174M + A216T & 37,86 & 1,11 & 0,79 & 5,68 & 10 \\
\hline T176A + E195T & 23,34 & 6,26 & 0,67 & n.d. & 1 \\
\hline T176S + K81E & 12,26 & 7,07 & 1,31 & n.d. & 3 \\
\hline T176S + Q157H & 15,06 & 4,18 & 0,69 & n.d. & 5 \\
\hline T176S + E195T & 15,26 & 9,81 & 2,58 & n.d. & 0 \\
\hline T176S + I199V & 4,08 & 3,27 & 2,06 & 5,12 & 0 \\
\hline T176S + A217I & 39,01 & 5,81 & 0,53 & n.d. & 0 \\
\hline T176C + E195T & 21,17 & 1,85 & 4,30 & n.d. & 4 \\
\hline P34L + I46T & 3,35 & 8,52 & 1,62 & n.d. & 3 \\
\hline Dreifachmutanten & 1,19 & 5,19 & 3,26 & 6,28 & 1 \\
\hline T38A + M202T + S227P & 51,74 & 2,44 & 0,69 & n.d. & 12 \\
\hline A137S + A143G + L174M & 73,75 & 2,28 & 0,54 & n.d. & 11 \\
\hline A143G + L174M + T176S & 52,39 & 4,19 & 1,79 & n.d. & 2 \\
\hline A143G + L174M + E195T & 126,51 & 0,62 & 11,77 & n.d. & 92 \\
\hline A143S + L174M + T176S & 99,01 & 0,62 & 51,04 & 7,52 & 39 \\
\hline A143S + L174M + E195T & 11,70 & 0,38 & 14,18 & 4,46 & 48 \\
\hline L174M + T176A + E195T & \multicolumn{7}{|l|}{} \\
\hline Vierfachmutanten & 65,01 & 3,83 & 2,13 & n.d. & 1 \\
\hline $\begin{array}{l}\text { A143G + L174M + T176S + E195T } \\
\text { A143S + L174M + T176S + } \\
\text { E195T }\end{array} \quad 140,39$ & 0,93 & 32,37 & n.d. & 35 \\
\hline
\end{tabular}

Tabelle 3: Eigenschaften der Kombinations- und Mehrfachmutanten des Proteins asFP595. 
IX.2.5 Größenchromatographien der Dronpa-Varianten

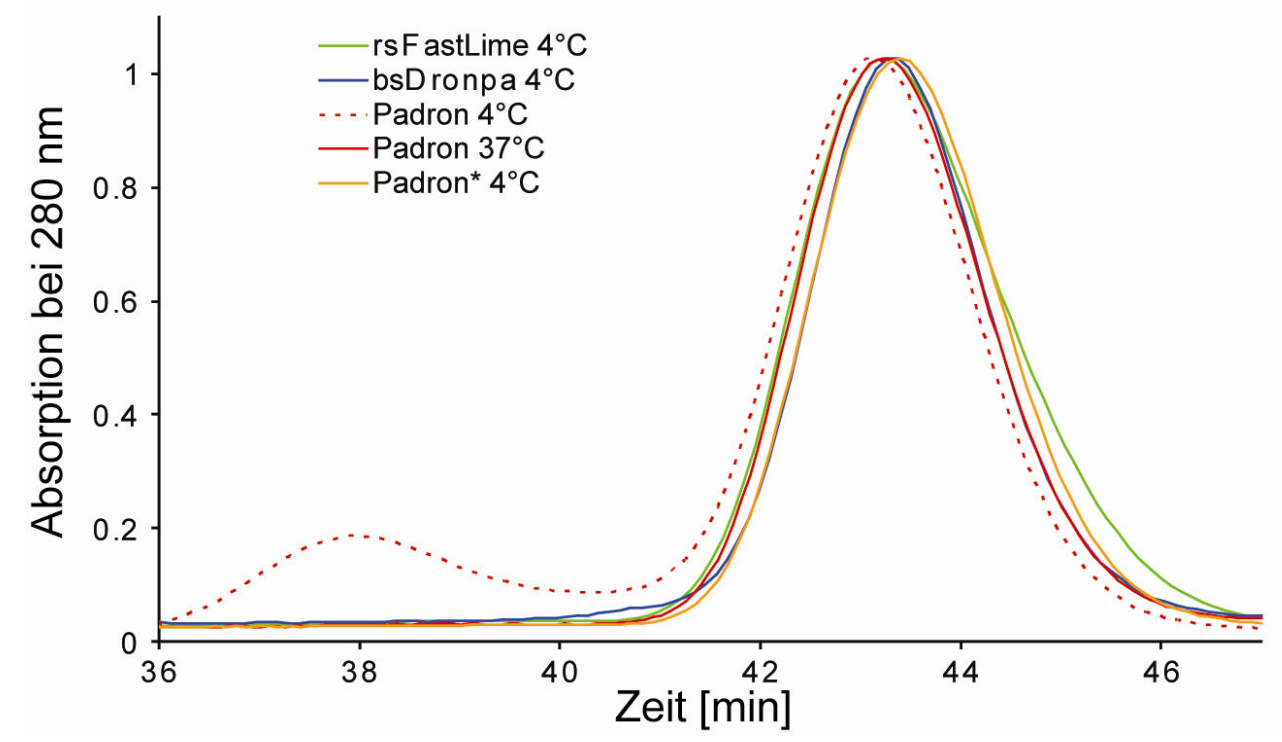

Abbildung 7: Überprüfung der Dimersierungstendenz verschiedener Dronpa-Varianten. Für die Größenauftrennung wurden die Proteine in $100 \mathrm{mM}$ Tris-HCl, $150 \mathrm{mM} \mathrm{NaCl}, \mathrm{pH}$ 7,5 mit einer SMART-System FPLC (GE Healthcare, Uppsala, Schweden) über eine Superdex 200 PC 3.2/30 Säule gegeben. Das Protein Padron liegt bei $4{ }^{\circ} \mathrm{C}$ zu etwa $15 \%$ als Dimer vor.

IX.2.6 Crosstalk bei der monochromatischen Mehrfarben-Mikroskopie

\begin{tabular}{lccc}
\hline & Kanal 1 & Kanal 2 & Kanal 3 \\
\hline bsDronpa & 100 & 25.55 & 5.37 \\
rsFastLime & 10.32 & 100 & 3.40 \\
Padron & 0.05 & 0.21 & 100 \\
\hline
\end{tabular}

Tabelle 4: Prozentualer Crosstalk der Fluoreszenz bei der monochromatischen Dreifarben Mikroskopie. Die Messungen wurden an einem Gemisch von E.coli-Zellen, die jeweils eines der drei Proteine bsDronpa, rsFastLime oder Padron exprimierten, durchgeführt. Für die Bestimmung des Crosstalks wurde das Fluoreszenzsignal mehrerer E.coli-Zellen einer Spezies in jedem der drei Kanäle gemittelt. Die Fluoreszenzsignale in den einzelnen Kanälen wurden verglichen und der höchste Wert auf $100 \%$ normiert. 


\section{Veröffentlichungen}

Andresen, M.; Wahl, M. C.; Stiel, A. C.; Gräter, F.; Schäfer, L. V.; Trowitzsch, S.; Weber, G.; Eggeling, C.; Grubmüller, H.; Hell, S. W. und Jakobs, S. (2005). "Structure and mechanism of the reversible photoswitch of a fluorescent protein." Proc Natl Acad Sci U S A 102(37): 13070-13074.

Stiel, A. C.; Trowitzsch, S.; Weber, G.; Andresen, M.; Eggeling, C.; Hell, S. W.; Jakobs, S. und Wahl, M. C. (2007). "1.8 A bright-state structure of the reversibly switchable fluorescent protein Dronpa guides the generation of fast switching variants." Biochem J. 402(1): 35-42.

Egner, A.; Geisler, C.; von Middendorff, C.; Bock, H.; Wenzel, D.; Medda, R.; Andresen, M.; Stiel, A. C.; Jakobs, S.; Eggeling, C.; Schönle, A. und Hell, S. W. (2007). "Fluorescence nanoscopy in whole cells by asnychronous localization of photoswitching emitters." Biophys J. 93(9): 3285-3290

Andresen, M.; Stiel, A. C.; Trowitzsch, S.; Weber, G.; Eggeling, C.; Wahl, M. C.; Hell, S. W. und Jakobs, S. (2007). "Structural basis for reversible photoswitching in Dronpa." Proc Natl Acad Sci U S A 104(32): 13005-13009.

Eggeling, C.; Hilbert, M.; Bock, H.; Ringemann, C.; Hofmann, M.; Stiel, A. C.; Andresen, M.; Jakobs, S.; Egner, A.; Schonle, A. und Hell, S. W. (2007). "Reversible photoswitching enables single-molecule fluorescence fluctuation spectroscopy at high molecular concentration." Microsc Res Tech 70(12): 1003-1009

Stiel, A. C.; Andresen, M.; Bock, H.; Hilbert, M.; Schilde, J.; Schönle, A.; Eggeling, C.; Egner, A.; Hell, S. W. und Jakobs, S. (2008). "Generation of Monomeric Reversibly Switchable Red Fluorescent Proteins for Far-Field Fluorescence Nanoscopy." Biophys J. 95(6): 2989-2997

Andresen, M.; Stiel, A. C.; Fölling, J.; Wenzel, D.; Schönle, A.; Egner, A.; Eggeling, C.; Hell, S. W. und Jakobs, S. (2008). "Photoswitchable fluorescent proteins enable monochromatic multilabel imaging and dual color fluorescence nanoscopy." Nat Biotechnol 26(9): 1035-1040. 


\section{Danksagung}

Zunächst danke ich Prof. Dr. Gerhard Braus für die Übernahme des Referats dieser Arbeit, sowie dessen Hilfsbereitschaft und seinem Interesse an meinem Thema. Ebenso möchte ich Prof. Dr. Ralf Ficner für die Übernahme des Koreferats und Nutzung der Anode (mit Umweg über Prof. Dr. Markus Wahl) danken.

Besonderer Dank gilt Prof. Dr. Stefan Hell, der es mir ermöglicht hat, diese Arbeit in seiner Abteilung anzufertigen. Sein Interesse an den RSFPs, hilfreiche Diskussionen und die zur Verfügung gestellte Infrastruktur der Abteilung NanoBiophotonik haben die Erforschung der in dieser Arbeit vorgestellten Ergebnisse ermöglicht.

Meinem Betreuer PD Dr. Stefan Jakobs möchte ich an dieser Stelle für die wissenschaftliche Anleitung großen Dank aussprechen. Die über vier Jahre währende Betreuung, sowie zahlreiche Diskussionen und Gespräche, haben entscheidend zur Entstehung dieser Arbeit beigetragen.

Herrn Prof. Dr. Markus Wahl, Dr. Gert Weber und Dr. Simon Trowitzsch danke ich für die hervorragende Zusammenarbeit bei der Lösung der Kristallstrukturen.

Als Nachfragewerk für alle Mikroskopiefragen und für die Entwicklung des „Klickerkastens“ möchte ich Dr. Christian Eggeling ein spezielles Dankeschön aussprechen. Weiterhin möchte ich mich bei zahlreichen anderen NanoBiophotonikern bedanken, für die Bereitschaft „dumme Fragen“ zu beantworten, zu diskutieren oder auch zu stellen.

Herzlich bedanken möchte ich mich bei André Stiel für vier Jahre sehr gute und oft sogar sehr effektive Zusammenarbeit auf kleinstem Raum. Seine „Stielblüten“ haben diese Zeit sowohl während, als auch außerhalb der Arbeit zu einer sehr angenehmen Zeit gemacht.

Weiterhin möchte ich mich bei Rita Schmitz-Salue, Maria Sermond und vor allem bei Sylvia Löbermann bedanken, die eine große Hilfe während der gesamten Arbeit waren. Für das Korrekturlesen danke ich Rebecca, Sylvia, Jessica, Tanja, André und Christian.

Der Abteilung NanoBiophotonik, im besonderen Tanja Brakeman, Christian Wurm, Stefan Stoldt und Jana Schmitz-Salue danke ich für die angenehme Atmosphäre bei der Arbeit. Meinen Freunden inner- und außerhalb Göttingens möchte ich ebenfalls für das Interesse an meiner Arbeit und die angenehme Freizeitgestaltung danken.

Bei Jessica bedanke ich mich sehr herzlich für die Unterstützung und die zusammen verbrachte Zeit bei, vor allem aber außerhalb der Arbeit.

Mein größter Dank gilt meiner Familie, die mich stets nach Kräften unterstützt hat. Sie haben auf diese Weise einen entscheidenden Anteil an dieser Arbeit. 


\section{Wissenschaftlicher Lebenslauf \\ von Martin Andresen \\ geboren am 02.04.1977 in Göttingen}

\section{Schulische Laufbahn}

1984-1988:

Besuch der Grundschule Dransfeld in Dransfeld

1988-1990:

Besuch der Haupt- und Realschule mit Orientierungsstufe in Dransfeld

1990-1997:

Besuch des Felix-Klein-Gymnasiums in Göttingen, Abschlussnote 2,8

\section{Studium}

09/1998-03/2004:

Studium der Biologie an der Georg-August-Universität Göttingen

10/2000:

Vordiplomsprüfung in den Fächern Genetik, Botanik, anorganische Chemie und physikalische Chemie

02/2003:

Diplomprüfungen in den Fächern Genetik, Immunologie und Chemie

05/2003-02/2004:

Diplomarbeit am MPI für biophysikalische Chemie in der Abteilung NanoBiophotonik. Thema: „Etablierung einer neuen Methode der Fluoreszenzmarkierung in Saccharomyces cerevisiae zur Untersuchung der Dynamik mitochondrialer Proteine“

03/2004:

Erlangung des Hochschulgrades Diplombiologe (mit Auszeichnung)

\section{Doktorarbeit}

seit 06/2004:

Doktorarbeit am MPI für biophysikalische Chemie in der Abteilung NanoBiophotonik. Thema der Arbeit: „Untersuchung, Entwicklung und Anwendung reversibel schaltbarer fluoreszierender Proteine“

Göttingen, den 4.12.2008 